EDUCACION

PÚBLICA

Y GRATUITA

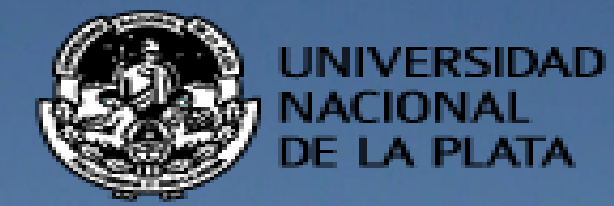

\title{
ESTUDIO PALEOBOTÁNICO, PALEOECOLÓGICO Y PALEOAMBIENTAL EN LA LOCALIDAD DE LAGUNA FLECHA NEGRA, MACIZO DEL DESEADO, JURÁSICO SUPERIOR, PROVINCIA DE SANTA CRUZ, ARGENTINA.
}

\section{Licenciada Ana Julia Sagasti}

Tesis para optar al título de Doctor en Ciencias Naturales

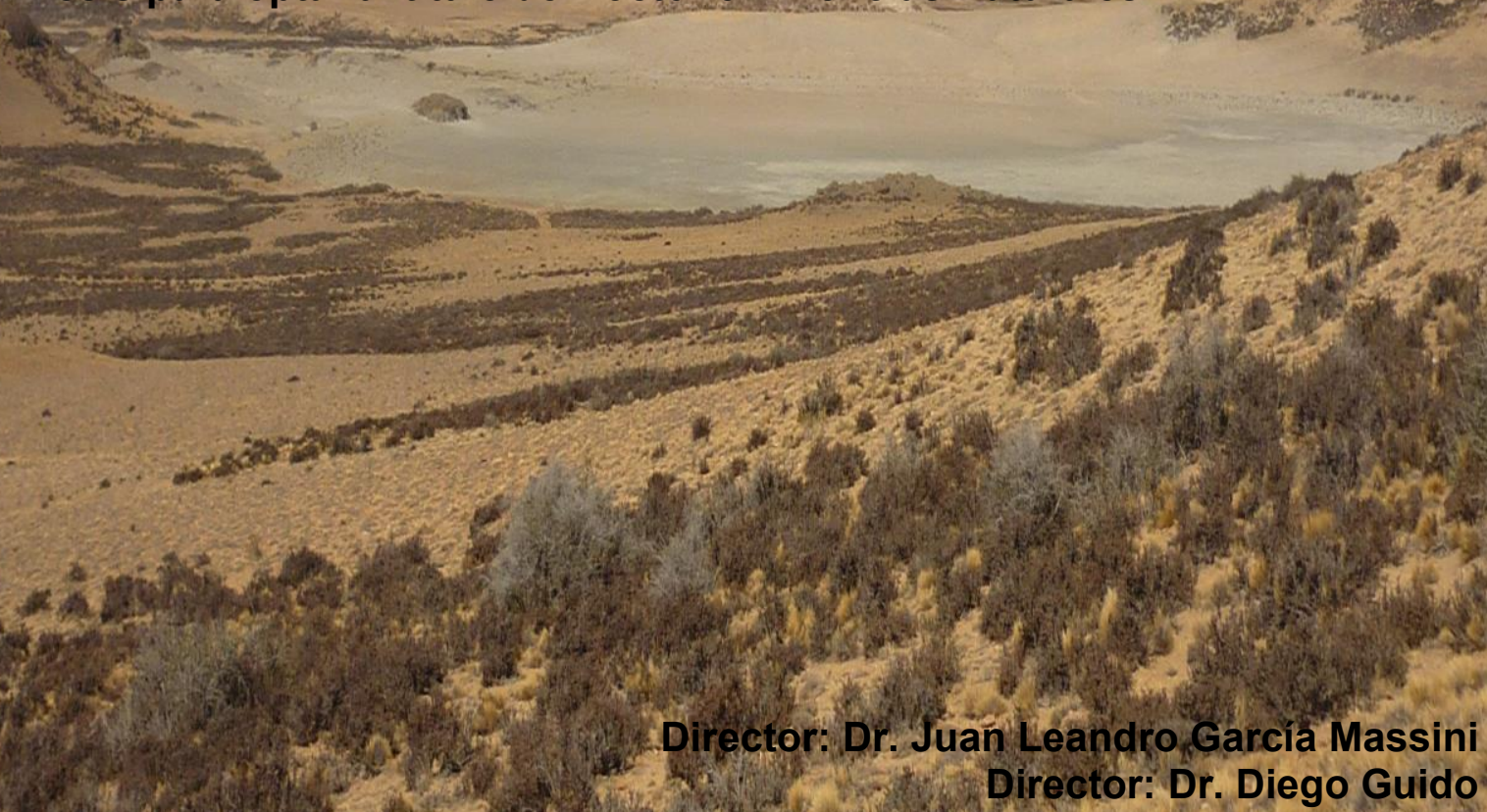

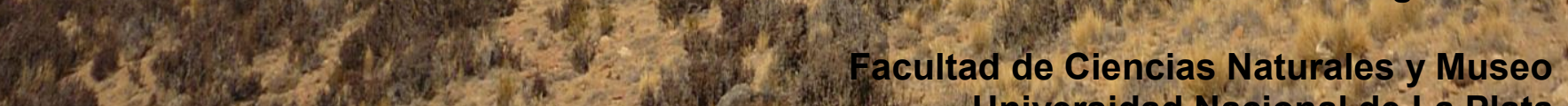



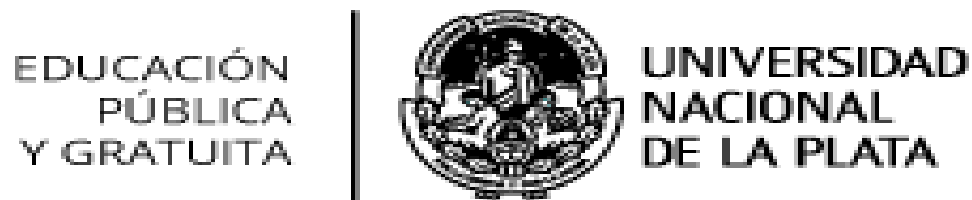

FACULTAD DE CIENCIAS NATURALES Y MUSEO

\section{ESTUDIO PALEOBOTÁNICO, PALEOECOLÓGICO Y PALEOAMBIENTAL EN LA LOCALIDAD DE LAGUNA FLECHA NEGRA, MACIZO DEL DESEADO, JURÁSICO SUPERIOR, PROVINCIA DE SANTA CRUZ, ARGENTINA.}

\section{TESIS DOCTORAL}

Lic. Ana Julia Sagasti

Dr. Juan. L. García Massini

Director
Dr. Diego M. Guido

Director

La Plata - Argentina 
Ana Julia Sagasti - Estudio paleobotánico, paleoecológico y paleoambiental...

“...No se veía un árbol, y apenas algún cuadrúpedo o ave; únicamente el guanaco aparecía en la cima de algún cerro, velando como fiel centinela por su rebaño. Todo era silencio y desolación. Sin embargo, al pasar por regiones tan yermas y solitarias, sin ningún objeto brillante que llame la atención, se apodera del ánimo un sentimiento mal definido, pero de íntimo gozo espiritual.

El espectador se pregunta por cuántas edades ha permanecido así aquella soledad, y por cuántas más perdurará en este estado."

Charles Darwin. Diario del viaje de un Naturalista.

"Adueñarnos del mundo de las ideas, para que las nuestras, sean las ideas del mundo."

Antonio Gramsci. 
Ana Julia Sagasti - Estudio paleobotánico, paleoecológico y paleoambiental...

\section{DEDICATORIA}

A mi compañero, Gastón.

Al final del viaje, estamos tú y yo, intactos. 


\section{AGRADECIMIENTOS}

Quiero expresar mi agradecimiento a todos aquellos que contribuyeron al desarrollo de esta Tesis. A Alba Zamuner, que guió mis primeros pasos en la Paleobotánica. A mis directores, Juan García Massini, Diego Guido, Eduardo Morel y Alan Channing, que aportaron discusiones y perspectiva a mi formación.

A la Universidad Nacional de La Plata, por la educación Pública, Gratuita y de Calidad. A las autoridades de la Facultad de Ciencias Naturales y Museo, y CONICET, que me permitieron realizar este Doctorado.

A Héctor Barbero y Guadalupe Godoy, que me enseñaron que el pensamiento crítico no es sólo teoría, sino práctica cotidiana.

A la Dra. Josefina Bodnar, colega y amiga, que me enseñó a enseñar Paleobotánica.

Al Dr. Ignacio Escapa y el equipo de Paleobotánica del Museo Paleontológico Egidio Feruglio, Andrés Elgorriaga, Ana Andruchov Colombo, Cristina Nunes y Luis Miguel Sander, que me abrieron sus puertas y contribuyeron al desarrollo de mis estudios.

A mis colegas de la División Paleobotánica, Eliana P. Coturel, Daniel Ganuza, Patricio Knigth y Adolfo Zúñiga, que me acompañaron en este camino.

A mis Padres, Viviana y Carlos, que me enseñaron a ser independiente, sin dejar jamás de acompañarme.

A mis amigos y amigas, por el apoyo incondicional. A Gregoria Cochero, Santiago Hernandez del Pino y Celeste Scattolini, por las discusiones sobre metodología y la terapia de grupo. A Caroline Gommendy, Sebastián Zurita, Ezequiel Bechi, Anabela Vague, Walter Defrik, Raúl Carriga, Julia Martino, Nahuel Martinez e Isabel Oeyen, gracias por los vinos y las risas, materia prima de la vida adulta. 


\section{ÍNDICE}

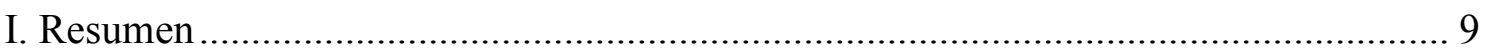

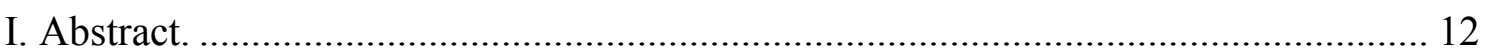

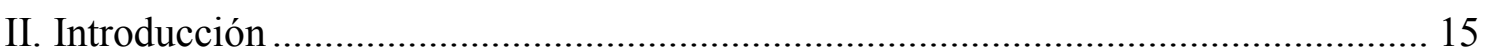

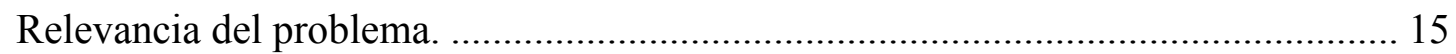

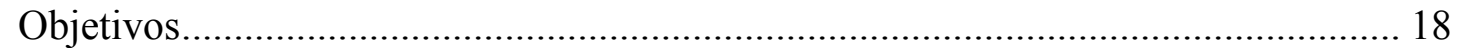

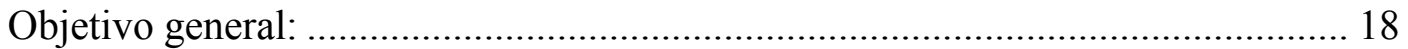

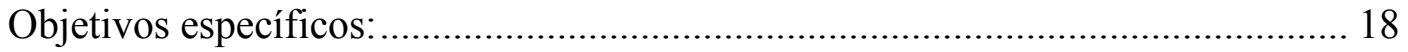

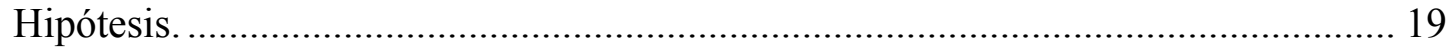

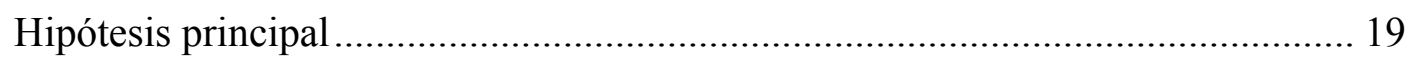

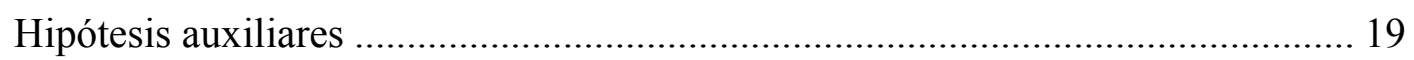

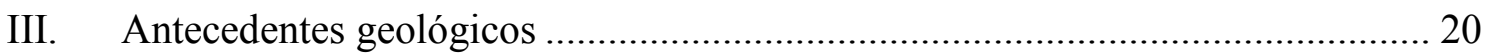

Provincia Geológica Macizo del Deseado.............................................................. 20

Historia geológica del Grupo Bahía Laura............................................................. 22

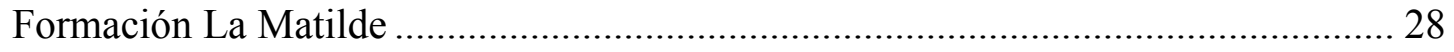

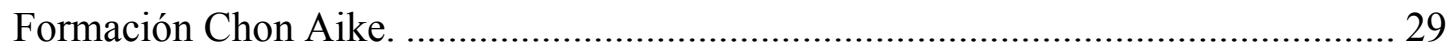

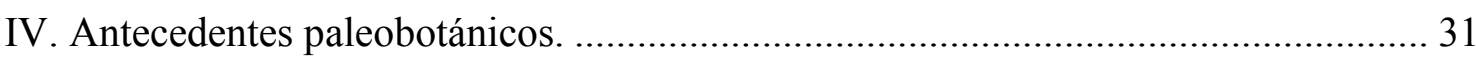

Reseña del estudio de las megafloras jurásicas en la Argentina................................ 31

Floras estudiadas en ambientes con influencia geotérmica del Macizo del Deseado. 50

Estudios previos de la Flora Fósil de la Formación Chon Aike................................. 51

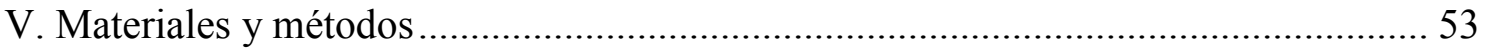

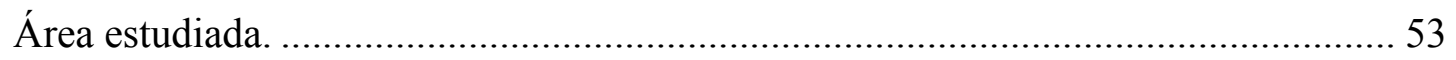

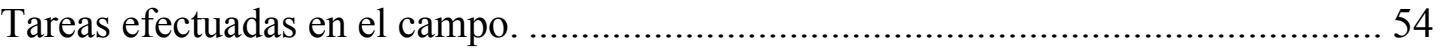

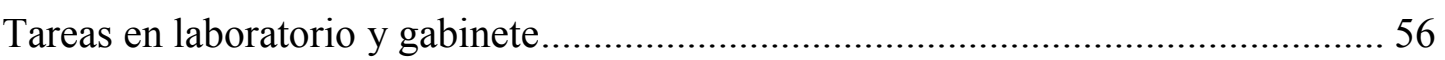

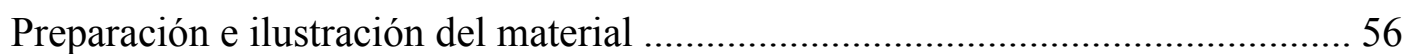

Análisis y determinación del material ............................................................... 57

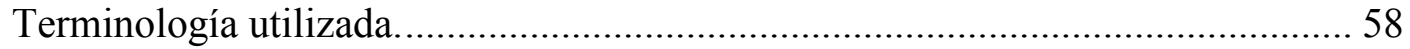

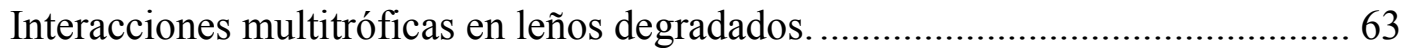

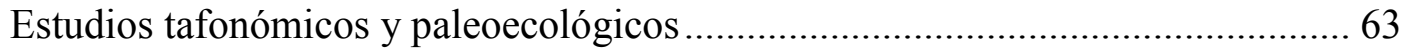

Reconstrucción ecológica de las paleocomunidades.......................................... 63

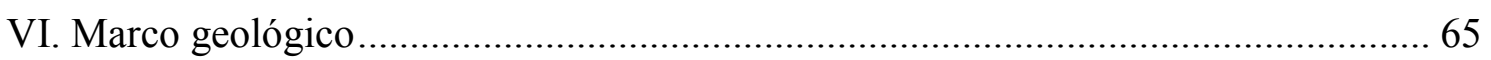

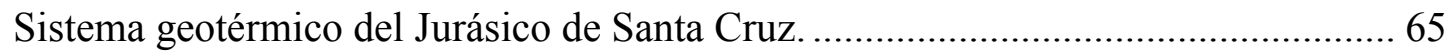

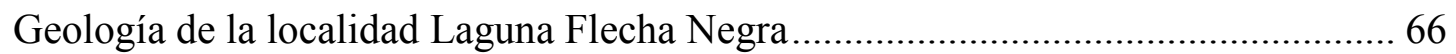

Sucesión volcaniclástica de base a techo (Figura 6.2).............................................67 67 
Ana Julia Sagasti - Estudio paleobotánico, paleoecológico y paleoambiental...

Análisis de facies de la localidad Laguna Flecha Negra (Tabla 6.1). ....................... 72

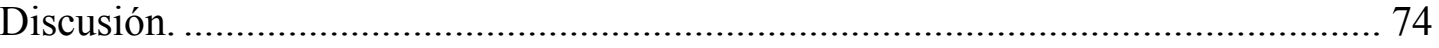

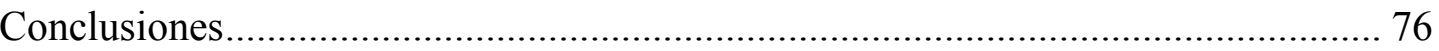

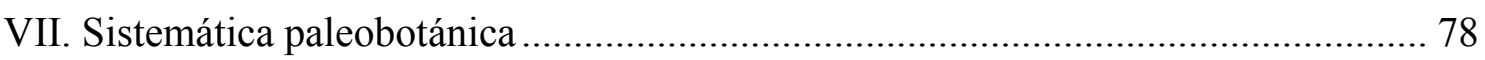

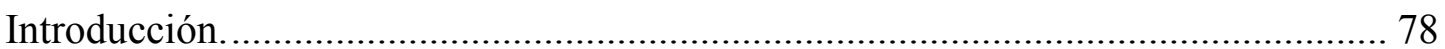

Clase Polypodiopsida Cronquist, Takhtajan y Zimmerman 1966 ............................. 80

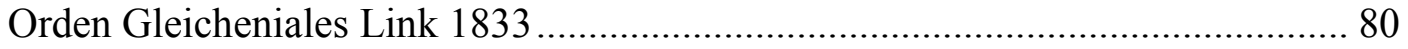

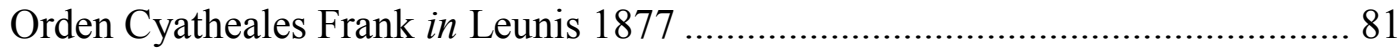

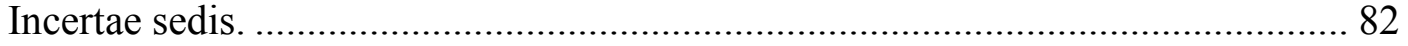

Clase Cycadeoideopsida (=Bennettitopsida) Scott, 1923 ....................................... 85

Orden Cycadeoideales sensu Stewart y Rothwell, 1993 ..................................... 85

Clase Coniferopsida Gifford y Foster 1989 .......................................................... 93

Orden CONIFERALES sensu Stewart y Rothwell 1993 ..................................... 93

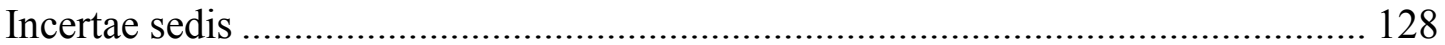

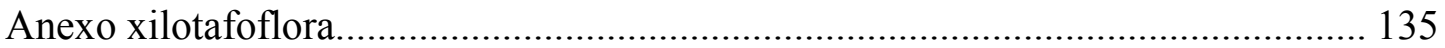

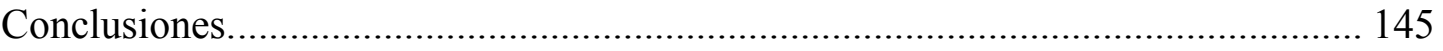

VIII. Interacciones multitróficas en leños degradados. ............................................. 149

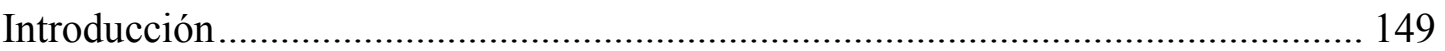

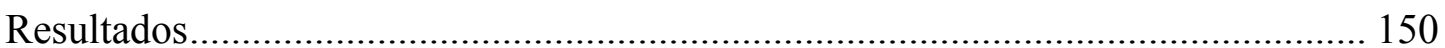

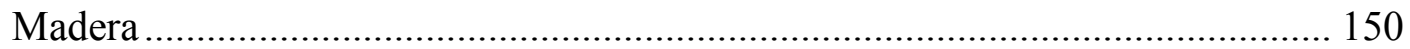

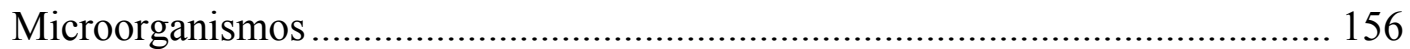

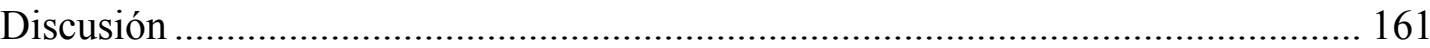

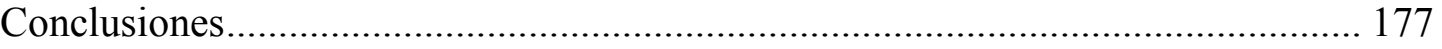

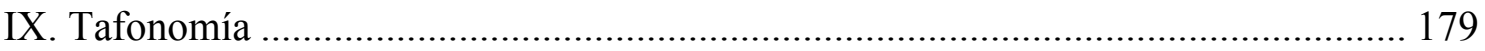

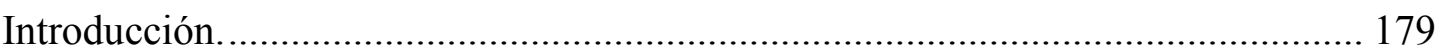

Tipos de fosilización.................................................................................... 181

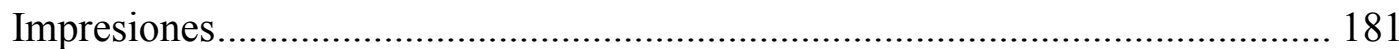

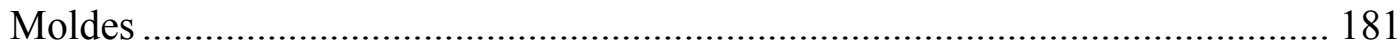

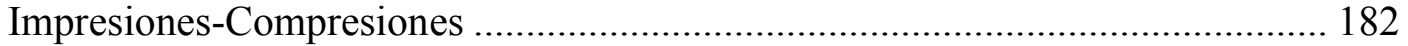

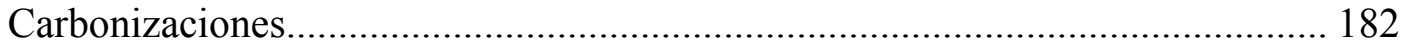

Permineralizaciones individuales .................................................................... 182

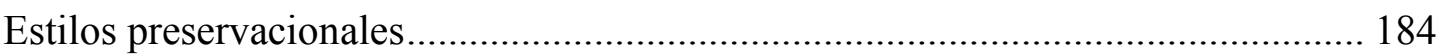

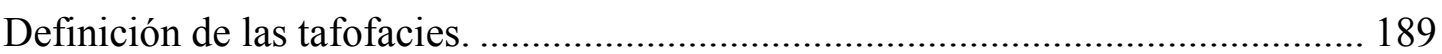

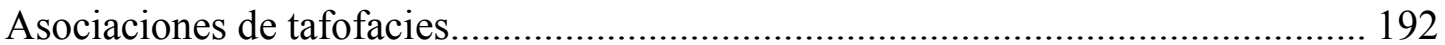

Comparación con los modelos sedimentarios de ambientes geotérmicos del Macizo

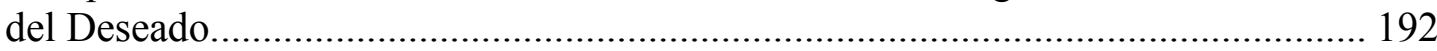

Interpretación del yacimiento Laguna Flecha Negra.............................................. 197 
Ana Julia Sagasti - Estudio paleobotánico, paleoecológico y paleoambiental...

X. Reconstrucción ecológica de las paleocomunidades ............................................. 202

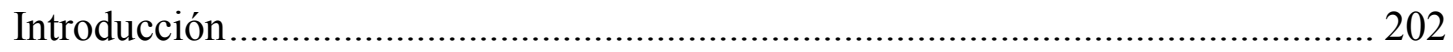

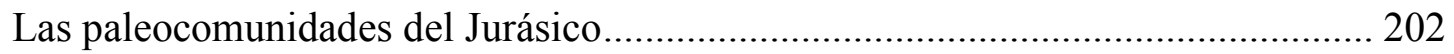

Análisis estructural de las paleocomunidades ...................................................... 207

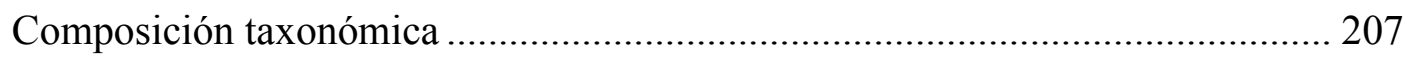

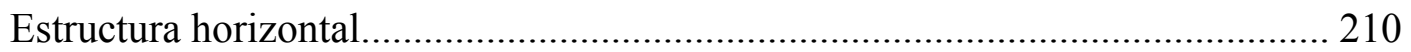

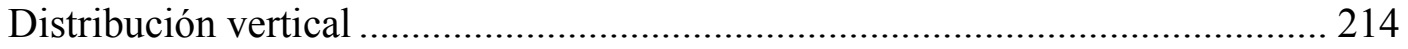

Diversidad de las asociaciones florísticas del Jurásico en Argentina....................... 222

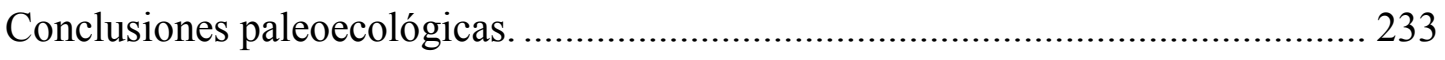

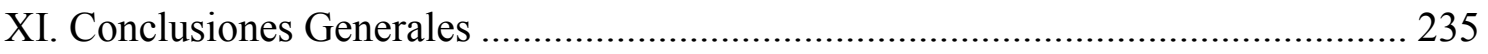

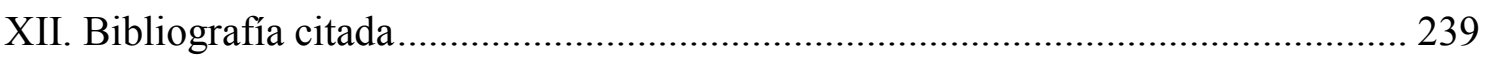


Ana Julia Sagasti - Estudio paleobotánico, paleoecológico y paleoambiental...

\section{Resumen}

El presente trabajo corresponde al "Estudio paleobotánico, paleoecológico y paleoambiental en la localidad de Laguna Flecha Negra, Macizo del Deseado, Jurásico Superior, Provincia de Santa Cruz, Argentina”, con el propósito principal de profundizar el conocimiento de las floras jurásicas de Patagonia, en cuanto a los taxones presentes, su distribución areal, fisonomía y condiciones ambientales, especialmente aquellas afectadas por los eventos volcánicos y epitermales vinculados a la génesis del Macizo del Deseado, la ruptura del sudoeste de Gondwana y la apertura del océano protoatlántico.

Durante el viaje de campo realizado a la zona de Laguna Flecha Negra, se reconocieron los niveles donde afloran las Formaciones Bajo Pobre y Chon Aike, se levantó el perfil sedimentologógico de la localidad, se reconocieron los estratos portadores de impresiones, impresiones-compresiones y permineralizaciones vegetales mencionados en un trabajo exploratorio previo, además se identificaron las relaciones verticales y horizontales entre los mismos. Todos los estratos fueron muestreados en cuanto a la diversidad fosilífera y condiciones tafonómicas de los restos vegetales. En total se obtuvieron 112 ejemplares de restos vegetales fosilizados como impresionescompresiones, 135 muestras de permineralizaciones individuales y en masa, y 25 fragmentos de tocones colectados en el bosque in situ.

Los estudios sedimentológicos realizados permiten reconocer una secuencia volcaniclástica, asignable a la Formación Chon Aike, que se deposita de manera discordante sobre un domo andesítico de la Formación Bajo Pobre. En los cuerpos de roca correspondientes a la Formación Chon Aike predominan los depósitos de caída, que contienen la mayoría de los niveles portadores de fósiles.

En la Formación Chon Aike se reconocieron 5 estratos fosilíferos. Los niveles fosilíferos hallados por otros autores fueron correlacionados con los estratos estudiados en este trabajo. El estrato fosilífero 5 representa un horizonte con un bosque in situ, constituído por troncos y tocones permineralizados. El estudio sistemático de la paleoflora permitió identificar 20 taxones preservados como impresiones e impresiones/compresiones, que se 
Ana Julia Sagasti - Estudio paleobotánico, paleoecológico y paleoambiental...

citan por primera vez para la formación Chon Aike: Korallipteris potrerillensis, Coniopteris hymenophylloides, Otozamites sueroi, Otozamites sanctae-crucis, Otozamites albosaxatilis, cf. Otozamites bumburyanus var. major, Ptilophyllum hislopi, Araucarites cutchensis, Araucarites phillipsi, Araucarites sp. (conos), Brachyphyllum sp., Pagiophyllum cf. crassifolium, Brachyphyllum lotenaense, Pararaucaria patagonica, Scleropteris vincei, Sphenopteris cf. nordenskjöldii, Elatocladus cf. planus, Elatocladus confertus y estructuras reproductivas pinnadas de afinidad con las pteridospermas. El estudio anatómico de maderas permineralizadas permitió reconocer 4 especies de Agathoxylon: Agathoxylon arayaii, Agathoxylon cf floresii, Agathoxylon jurassicum y Agathoxylon matildense, además de materiales indeterminables de afinidad con el clado de las Araucariaceae. Las especies identificadas han sido descriptas previamente para yacimientos jurásicos de Gondwana, y su presencia es consistente con las reconstrucciones realizadas por otros autores, que reconocen a las maderas de Araucariaceae como elemento dominante y cosmopolita para este período. El estudio de la xilotafoflora permitió a su vez reconocer la presencia de Cupressinoxylon sp., Protaxodioxylon sp. y Protocupressinoxylon sp. como elementos de la comunidad boscosa.

Para el estudio de interacciones multitróficas, se analizó un eje de Agathoxylon con restos de microorganismos que incluyen actinomicetes, hongos, galerías de artrópodos y un diverso set de patrones de degradación consistente con pudrición fúngica. Se evaluaron las afinidades sistemáticas de los restos de microorganismos y las trazas fósiles, así como las evidencias de reacción de la planta hospedadora. Se proponen relaciones de parasitismo, saprotrofismo y aparente mutualismo entre los distintos componentes de la cohorte.

En los estudios tafonómicos se definieron 11 tafofacies. Se encontraron diferencias tafonómicas laterales y verticales entre los distintos niveles de la Formación Chon Aike, relacionadas con cambios en el tipo de aporte de sedimentos volcaniclásticos (de caída y de flujo) y distancia a las emanaciones hidrotermales del sistema geotérmico.

Se estudió un bosque permineralizado in situ. La información cuantitativa (densidad, altura inferida, clases de diámetro) permitió reconocer la madurez del bosque. El análisis anatómico, morfológico y sistemático de los restos 
vegetales, integrado con la información tafonómica, permitió reconocer tres tipos de paleocomunidades desarrolladas en el área de la localidad Laguna Flecha Negra.

Para el análisis de los elencos paleoflorísticos del Jurásico de la Argentina, se realizó una matriz de presencia/ausencia de taxones por provincia y por época. A esta matriz se le aplicó el algoritmo de análisis de curvas de diversidad del programa PAST. Este estudio permitió evaluar los cambios en las paleocomunidades conocidas para las tres épocas del Jurásico, en los distintos depocentros de la Argentina. Se propone una interpretación de estas variaciones en el marco de los modelos climáticos y biogeográficos conocidos para este Período. El análisis de los cambios en la diversidad específica para los afloramientos jurásicos de la Argentina, muestra un pico en el Jurásico Inferior, concentrado en las provincias de Neuquén y Chubut. El Jurásico Medio muestra una diversidad moderada para las paleofloras, que se observa en todos los depocentros de la época. Para el Jurásico Superior, se conocen registros en las provincias de Chubut y Santa Cruz, los cuales presentan una diversidad de alta a moderada, con su mayor desarrollo concentrado en la provincia de Santa Cruz. 
Ana Julia Sagasti - Estudio paleobotánico, paleoecológico y paleoambiental...

\section{Abstract.}

This contribution belongs to the study of the "Paleobotany, paleoecology and paleoenvironments of the Laguna Flecha Negra Locality, Deseado Massif, Late Jurassic, Santa Cruz Province, Argentina.". The objective of this contribution is the study of the flora and paleoenvironments from the Jurassic, Laguna Flecha Negra locality, taking into consideration the recorded taxa, their areal distribution, fisiognomy and environmental conditions, to improve knowledge of Jurassic floras of Patagonia especially those related to the volcanic and epithermal events of the final stages of the Deseado Massif, the breakdown of southwestern Gondwana and the opening of the proto-atlantic ocean.

During the field trip to the Laguna Flecha Negra zone, outcrop of Bajo Pobre and Chon Aike Formations were logged. Previously studied levels were recognized, and their vertical and lateral relationships were identified. Fossiliferous strata were identified and sampled; diversity and taphonomic conditions were pondered. Altogether, a total of one hundred and twelve samples of impression-compresions, one hundred and thirty five permineralizations, both individual and massive, and twenty five fragments of in situ stumps were collected.

Sedimentological studies allow recognizing a volcaniclastic sequence belonging to the Chon Aike Formation, with an unconformably lying on the andesitic dome of Bajo Pobre Formation. The rocks belonging to the Chon Aike Formation are of volcaniclastic origin, mainly ashfall deposit, and these preserve most of the fossil bearing levels.

Five fossiliferous strata were defined for the Chon Aike Formation. The fossiliferous levels found by other authors were correlated with the strata studied herein. The fossiliferous stratum five represents a horizon with an in situ forest formed of permineralized trunks and stumps. The systematic study of the paleoflora allowed to identify 20 taxa preserved as impression/compressions, that are cited for the first time for the Chon Aike Formation: Korallipteris potrerillensis, Coniopteris hymenophylloides, Otozamites sueroi, Otozamites sanctae-crucis, Otozamites albosaxatilis, cf. Otozamites bumburyanus var. major, Ptilophyllum hislopi, Araucarites cutchensis, Araucarites phillipsi, 
Ana Julia Sagasti - Estudio paleobotánico, paleoecológico y paleoambiental...

Araucarites sp. (cones), Brachyphyllum sp., Pagiophyllum cf. crassifolium, Brachyphyllum lotenaense, Pararaucaria patagonica, Scleropteris vincei, Sphenopteris cf. nordenskjöldii, Elatocladus cf. planus, Elatocladus confertus and pinnate reproductive structures related to Pteridosperms. The anatomical study of permineralized woods allowed recognising 4 species of Agathoxylon: Agathoxylon arayaii, Agathoxylon cf. floresii, Agathoxylon jurassicum and Agathoxylon matildense, and samples that can not be determined at the generic level but show anatomical affinities with the Araucariaceae. The recognized species have been previously described in Jurassic localities of Gondwana, and their presence is consistent with reconstructions by other authors, that recognice Araucariaceae woods as a dominant and cosmopolitan element for this period. The paleoxilological analysis has also allowed to recognice the presence of Cupressinoxylon sp., Protaxodioxylon sp. and Protocupressinoxylon sp. as components of the forest community.

The study of multitrophic interactions was carried out on an infected Agathoxylon axis with micro-organisms remains that includes actinomycetes, fungal structures, variously bored by xylophagous arthropods and displayinh a diverse set of degradation patterns consistent with fungal rot. Systematic affinities were evaluated for the micro-organisms and fossil traces, and host reaccion evidence was pondered. This work suggests the stablishment of parasitism, saprotrofism and apparent mutualism relationships between members of the cohort.

The taphonomic study defined eleven tafofacies. Lateral and vertical taphonomic differences were found between levels of the Chon Aike Formation. These are related to changes in the sedimentary input (volcanic flux and ash fall) and distance to the geothermal system.

An autocthonous petrified forest was studied. Quantitative information of the forest (density, height inferred from the diameter, diameter classes) allowed to recognize the maturity of the forest. The analysis of the anatomy, morphology and systematics of the plant remains, along with taphonomic information leads to reconstruct three paleocomunities in the area of Laguna Flecha Negra.

For the analysis of Jurassic assemblages of Argentina a presence/absence matrix of taxa per province and epoch was carried out. This matrix was analized with the Diversity algoritm of the software PAST. This study 
Ana Julia Sagasti - Estudio paleobotánico, paleoecológico y paleoambiental...

allowed the evaluation of changes of the impression/compression paleocomunities known for early, middle and upper Jurassic floras from Argentina. An interpretation of these variations is proposed in the context of climatic and biogeographic models known for this Period. This analysis showed a peak in species diversity for the Lower Jurassic, concentrated in the Neuquen and Chubut Provinces. Middle Jurassic floras have a moderate diversity in the paleofloras, which can be observed in all depocenters for this epoch. Upper Jurassic floras are known from Chubut and Santa Cruz Provinces, and those have a high to moderate diversity, being Santa Cruz floras the most represented. 


\section{Introducción}

\section{Relevancia del problema.}

Santa Cruz es probablemente la provincia argentina que posee la mayor cantidad de rocas mesozoicas con registros fósiles de plantas, en sus diferentes tipos de preservación (Archangelsky \& Archangelsky, 2002). En esta provincia se han hallado depósitos correspondientes a los tres períodos del Mesozoico; el Jurásico y Cretácico han sido los más ampliamente estudiados. Los trabajos realizados por investigadores extranjeros en el siglo XX fueron relativamente escasos. El mayor desarrollo de investigaciones en esta provincia se dió a partir de los estudios realizados por geólogos de la Dirección de Minas y Yacimientos Petrolíferos Fiscales en la segunda mitad del siglo XX, que aportaron al conocimiento de la riqueza de los yacimientos paleobotánicos en esta región de la Patagonia (Archangelsky y Archangelsky, 2002).

Las maderas fósiles de Gondwana están entre las primeras que fueron estudiadas (Philippe et al., 2004). Los trabajos pioneros fueron realizados por investigadores europeos, que analizaron la anatomía de maderas fósiles de Tasmania, Sudamérica e islas del Hemisferio Sur (e.g. Unger, 1850; Kraus, 1870; Gothan, 1908, 1925). Recién a principios del siglo veinte, se empezaron a formar grupos de investigación en países con yacimientos mesozoicos del Gondwana, enfocados a los análisis xilológicos (e.g. Sahni, 1920). India, Argentina y Brasil, se destacan por haber mantenido equipos de trabajo en paleobotánica por extensos períodos de tiempo. Esto ha resultado en que la producción de conocimiento sobre las maderas mesozoicas tenga un carácter concentrado geográficamente e irregularmente distribuído (Philippe et al., 2004).

Los bosques petrificados de Araucaria mirabilis (Speg.) Windhausen, ubicados en el noreste de la provincia de Santa Cruz, y asignables estratigráficamente a la Formación La Matilde, han sido profusamente estudiados por la preservación excepcional de sus conos, y la presencia de troncos y ramas petrificadas de enormes dimensiones (Wieland, 1935; Fossa- 
Ana Julia Sagasti - Estudio paleobotánico, paleoecológico y paleoambiental...

Mancini, 1941; Calder, 1953; Zamuner y Falaschi, 2005; Falaschi, 2009). Los troncos hallados en esta zona son de dimensiones gigantescas, pero su pobre preservación anatómica ha impedido una asignación y comparación precisa, ubicándolos normalmente en los taxones fósiles Araucarioxylon Kraus (nombre ilegítimo, reemplazado por Agathoxylon Hartig) y Dadoxylon Endlicher (Gotham, 1925; Wieland, 1935; Mansfeld, 1948; Calder, 1953; Selmeier, 1992). Más recientemente, Zamuner y Falaschi (2005) realizan un estudio de detalle de materiales colectados en el Monumento Nacional Bosques Petrificados (Provincia de Santa Cruz, Formación La Matilde), y describen la especie Agathoxylon matildense. Posteriormente, Falaschi et al. (2011) realizan un análisis arquitectural en el que determinan el modo de crecimiento de las Araucariaceae registradas en el Monumento Natural Bosques Petrificados (Santa Cruz). Hasta el momento, no se conocen restos de leños permineralizados para la Formación Chon Aike.

En la provincia de Santa Cruz, los yacimientos del Jurásico MedioSuperior del Grupo Bahía Laura, contienen una abundante, diversa y a menudo bien conservada flora de Gondwana (Channing et al. 2007; Guido et al., 2010; García Massini et al., 2016). Hasta la fecha, se han registrado yacimientos de floras fósiles en ambientes volcánicos en la región noroeste de la provincia, en la Formación La Matilde, en el Cerro Cuadrado, Cerro Madre e Hija y en la región sureste del Gran Bajo de San Julián. La única flora que se ha descrito para la Formación Chon Aike comprende una flora de Bennettitales que se describió en la Estancia Bajo Pellegrini (de Barrio et al. 1982).

El yacimiento de Laguna Flecha Negra, situado aproximadamente a 100 km al NNE de Gobernador Gregores, provincia de Santa Cruz, Argentina, ha sido objeto de un estudio reciente (Channing et al., 2007). Estas investigaciones, de carácter preliminar, analizaron la fábrica sedimentaria y las características geoquímicas de los cherts sugiriendo depósitos epitermales en superficie, en depresiones sobre la llanura de inundación que contienen abundantes restos vegetales en variado estado de preservación.

Laguna Flecha Negra resulta de particular interés no sólo desde el punto de vista sistemático sino también paleoecológico, por preservar plantas con varios procesos de fosilización: permineralizaciones de maderas y tallos, un bosque en posición de vida, permineralizaciones en masa, moldes, 
Ana Julia Sagasti - Estudio paleobotánico, paleoecológico y paleoambiental...

carbonizaciones, impresiones e impresiones/compresiones. El estudio morfológico de detalle de los restos preservados como impresiones, impresiones/compresiones y moldes, permitirá evaluar la composición taxonómica de la paleoflora preservada en niveles formados por depósitos volcaniclásticos de caída. Los restos de permineralizaciones individuales y en masa, serán analizados anatómica y morfológicamente para estableces sus afinidades sistemáticas. El estudio total permite reconocer y sugerir, a través de la evaluación de todos los tipos fosilíferos, un panorama integrado de la tafoflora para la reconstrucción de la paleocomunidad. En ambientes con influencia geotérmica, los procesos tafonómicos preservan selectivamente plantas de acuerdo a su anatomía, estatura y a la geoquímica del medio. La presencia de cherts con abundantes restos vegetales es una fuente muy importante de información por la calidad del registro.

Por medio de los análisis anatómico-morfológicos y paleoecológicos del bosque in situ se determinan: caracteres adaptativos, densidad de árboles, altura del canopeo, heterogeneidad espacial, interacciones entre sedimento y plantas, gradientes ecológicos e interacciones troficas (con hongos y/o animales). La evaluación de los procesos tafonómicos y paleoecológicos permite tener una ventana hacia el pasado con alto grado de detalle que posibilita una reconstrucción mucho más completa de los ambientes de la región.

En el Jurásico se observa una homogeneidad general de las zonas climáticas con referencia al paleoecuador. Rees et al (2000) establecen que en las latitudes altas de ambos hemisferios las paleocomunidades se encontraban caracterizadas por una diversidad relativamente baja de especies, con la dominancia de Gingkoales y coníferas macrófilas, así como helechos. La mayoría de las localidades del sur de Gondwana pertenecen al Clima Templado Cálido, con excepción de las floras de Argentina y la Península Antártica que han sido asignadas al Clima Subtropical con estación seca (e.g. Iglesias et al., 2011). En el Jurásico Medio (180 Ma.), la actividad magmática comienza a intensificarse en Patagonia y en varias áreas gondwánicas, y se desarrollan enormes áreas volcánicas (Spalletti y Franzese, 2007), afectando la distribución y las características de las comunidades vegetales. En consecuencia, las floras de Patagonia comienzan a divergir de las Laurásicas. 
Ana Julia Sagasti - Estudio paleobotánico, paleoecológico y paleoambiental...

Los ambientes boscosos incluyen coníferas, como las Araucariaceae, Cheirolepidiaceae, Podocarpaceae y algunas Cupressaceae sensu lato, que ocuparon regiones altas (Quattrocchio et al., 2007). En áreas abiertas se desarrollaron pequeños árboles de Cycadales y Bennettitales, junto con Pteridospermas. Las "pteridofitas" eran menos diversas y estaban representadas principalmente por helechos (Osmundaceae, Gleicheniaceae) y Equisetaceae (Del Fueyo et al., 2007).

\section{Objetivos}

\section{Objetivo general:}

- Estudiar la composición florística de las paleocomunidades preservadas en la localidad Laguna Flecha Negra, en cuanto a los taxones presentes, distribución areal y fisonomía de las paleofloras registradas.

\section{Objetivos específicos:}

- Estudiar la morfología y anatomía de la Flora hallada en la localidad Laguna Flecha Negra para establecer la afinidad sistemática de sus componentes.

- Analizar la sedimentología de las secuencias portadoras de restos vegetales para establecer si se encuentran diferencias entre las comunidades preservadas (tafocenosis).

- Analizar la composición porcentual de los distintos órdenes sobre el yacimiento total, para interpretar la fisonomía de la paleocomunidad.

- Determinar las facies, tafofacies y paleoambientes en Laguna Flecha Negra, para establecer las condiciones en las cuales se formó el yacimiento fósil y cómo fue afectada la preservación de los distintos órganos vegetales en función de los procesos volcánicos y epitermales del Macizo del Deseado. 


\section{Hipótesis.}

\section{Hipótesis principal}

- La composición sistemática de las floras jurásicas de Laguna Flecha Negra es indicadora de las condiciones ambientales en las que se desarrollaron las paleocomunidades.

\section{Hipótesis auxiliares}

- Los caracteres morfológicos y anatómicos de las plantas tienen valor sistemático y filogenético, así como de indicadores paleoambientales.

- Los distintos microambientes sedimentarios favorecen la formación de diversos tipos de fósiles, creando un tamiz tafonómico que preserva órganos selectivamente.

- La textura, litología y estructuras sedimentarias de los cuerpos de roca son indicativos del aporte sedimentario, el medio y energía de transporte y tipo de ambiente de depositación. Esta información sirve para comprender las condiciones en las que vivían las plantas de la comunidad y las condiciones bajo las cuales se formó el yacimiento fósil. 


\section{Antecedentes geológicos}

\section{Provincia Geológica Macizo del Deseado.}

Dentro del cuadro estratigráfico de la Provincia de Santa Cruz, el Jurásico está ampliamente representado por un conjunto de rocas volcánicas en las que predominan las efusivas. Previamente a ellas, existía una cuenca alargada en sentido meridional, cuyos depósitos van del Paleozoico al Jurásico, (Lesta y Ferello, 1972). El Macizo del Deseado es un bloque estructural positivo ubicado en proximidad a la costa atlántica entre los $47^{\circ}$ y $48^{\circ} \mathrm{S}$. La mayor parte está cubierta por rocas volcánicas, mayormente piroclásticas, del Jurásico Medio y Tardío (Riccardi y Damborenea, 1993). Corresponde a una de las "Provincias Geológicas Argentinas" (Ramos, 1999) situada en la región sur de la Patagonia Argentina, desarrollada entre el río Deseado y el río Chico, en la provincia de Santa Cruz. Geológicamente se encuentra limitada en el norte por la Meseta Patagónica Norte y la cuenca del Golfo de San Jorge, y en el sur por la Meseta Patagónica Sur (Fig. 3.1).

El Macizo del Deseado ha sido considerado desde el trabajo de Harrington (1962) como un nesocratón, es decir como un área persistentemente subpositiva, relativamente estable y poco deformable tangencialmente. Su comportamiento temporalmente positivo y rígido marca un neto contraste con el régimen subsidente de las vecinas cuencas pericratónicas del Golfo de San Jorge y Austral o Magallánica (De Giusto et al., 1980). Sus rasgos estructurales están íntimamente ligados al desarrollo del orógeno de la Cordillera Patagónica Austral durante el Paleozoico, conjuntamente con la evolución de la dorsal meso oceánica atlántica durante gran parte del Mesozoico y Cenozoico (de Barrio et al., 1999).

El Jurásico-Cretácico representa un lapso de gran importancia en la evolución tecto-magmática del Macizo del Deseado. La sucesión de eventos volcánico-piroclásticos acaecidos durante esos períodos señala una compleja y continua historia geológica que se ha desarrollado en vastas áreas conformándose un paisaje dominado por extensas unidades volcanogénicas de variada naturaleza (de Barrio et al., 1999). 
Ana Julia Sagasti - Estudio paleobotánico, paleoecológico y paleoambiental...

El inicio de la actividad volcánica ocurre durante el Jurásico Temprano, sus depósitos están representados por las dioritas y granitos del Complejo La Leona, que intruyen a las sedimentitas permo-triásicas en la porción central del Macizo del Deseado (de Guisto et al., 1980). Las rocas se corresponden con una serie monzonítica calcoalcalina con alto contenido de potasio que precede al vulcanismo del Jurásico Medio - Jurásico Tardío (Rapela y Pankhurst, 1996).

Durante el Jurásico Medio a Tardío, un extenso evento volcánico de naturaleza bimodal tuvo lugar en la Patagonia (incluyendo al Macizo del Deseado) extendiéndose hasta la Península Antártica, a partir de esto se originó la denominada Provincia Silícica Chon Aike (Pankhurst et al., 1998, 2000). Este vulcanismo se enmarca en una tectónica extensional en un ambiente de retroarco difuso, relacionado con los primeros estadios del desmembramiento del sudeste de Gondwana y la apertura del proto-océano atlántico (Pankhurst et al., 2000; Riley et al., 2001; Ramos, 2002; Richardson y Underhill, 2002). El proceso extensional fue simultáneo con la erupción de las vulcanitas jurásicas y finaliza aproximadamente junto con este evento (Echavarría et al., 2005). Las edades U-Pb en circones estiman que este vulcanismo se desarrolló durante aproximadamente $30 \mathrm{Ma}$ (178-151 Ma), con un período de actividad pico de aproximadamente $10 \mathrm{Ma}$. (Pankhurst et al., 2000).

En el Macizo del Deseado, este evento está representado por una suite volcánica denominada Complejo Volcánico Bahía Laura (Feruglio, 1949; Guido et al., 2006). Este complejo incluye a las formaciones Bajo Pobre, Cerro León, Chon Aike y La Matilde caracterizado por las estrechas relaciones estratigráficas que existen entre las unidades (Echeveste et al., 2001; Guido, 2004; Ruiz et al., 2008). La Formación Bajo Pobre está compuesta por rocas volcánicas calcoalcalinas, intermedias a básicas y rocas volcaniclásticas mayormente andesíticas (Panza y Haller, 2002). La Formación Cerro León corresponde a los equivalentes subvolcánicos de las rocas de la Formación Bajo Pobre (de Barrio et al., 1999; Jovic et al., 2008). Las formaciones Chon Aike y La Matilde fueron las primeras en ser reconocidas como constituyentes del Grupo Bahía Laura y las que más han sido estudiadas desde el punto de vista paleontológico. 
Ana Julia Sagasti - Estudio paleobotánico, paleoecológico y paleoambiental...

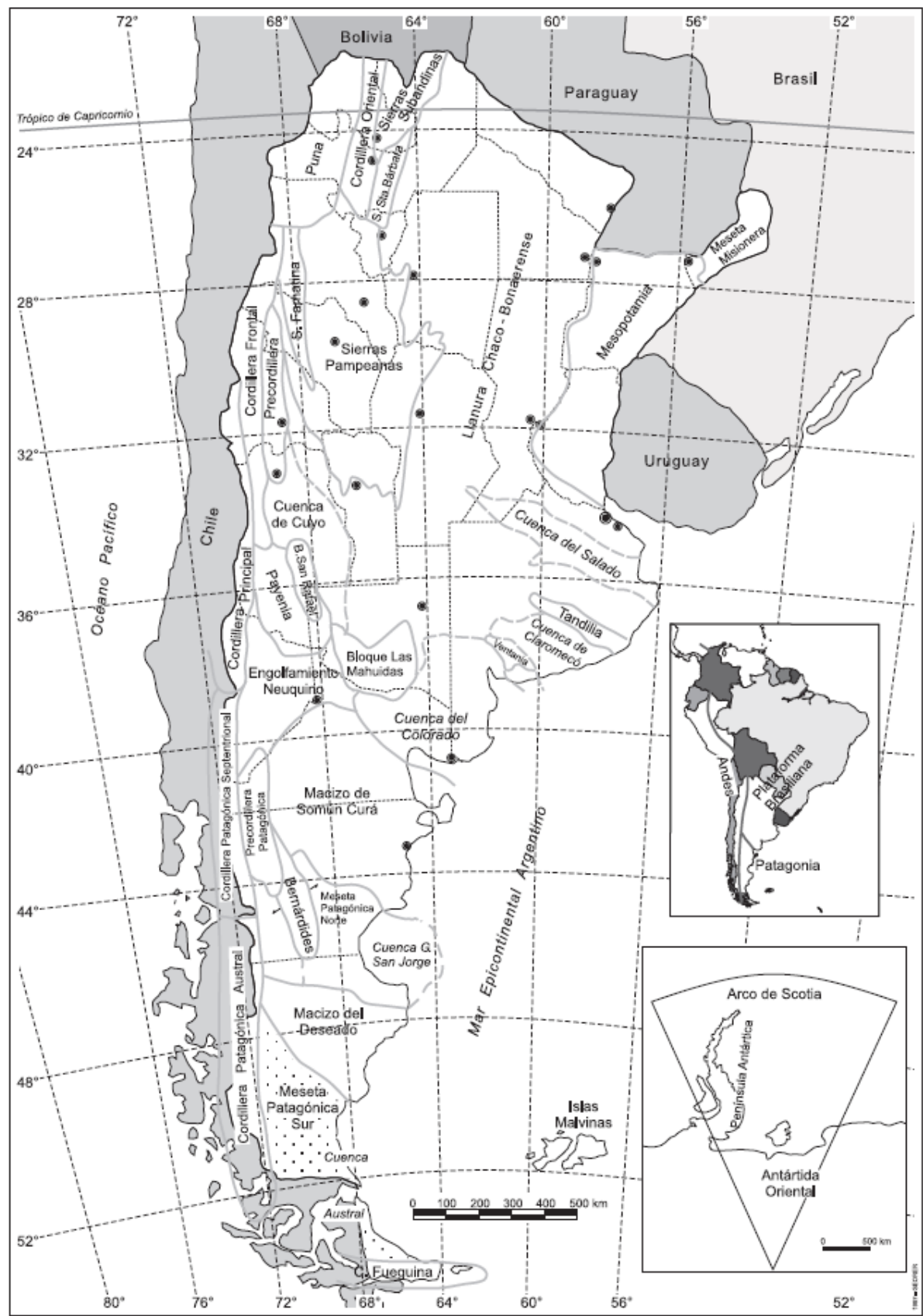

Figura. 3.1. Provincias geológicas del territorio argentino. Ubicación del Macizo del Deseado. Tomado de Ramos (1999).

\section{Historia geológica del Grupo Bahía Laura.}

El Grupo Bahía Laura es el equivalente a las antiguas denominaciones: Serie Porfírica y Complejo Porfírico de la Patagonia Extra-Andina, ubicadas en las provincias de Chubut y Santa Cruz, entre los paralelos $40^{\circ}$ a $50^{\circ}$ de latitud sur (Fig. 3.2). Esta unidad constituye el acontecimiento geológico más 
Ana Julia Sagasti - Estudio paleobotánico, paleoecológico y paleoambiental...

importante dentro del Nesocratón del Deseado, y se trata de un complejo piroclástico-volcánico-sedimentario de enorme desarrollo en dicha provincia geológica (Riccardi y Damborenea, 1993).

El denominado "Complejo Porfírico de la Patagonia Extra-Andina" fue señalado por primera vez por Darwin (1838), quién lo reconoció en los alrededores de Puerto Deseado. “...A la altura de 60 a 90 metros sobre algunas masas de pórfido, se extiende una vasta llanura, que es peculiar y característica de Patagonia...". A partir de las observaciones recogidas por sus compañeros de viaje y muestras recogidas por Stokes en Puerto Santa Elena, Camarones, Malaspina y al Sur de las Tetas de Pineda, pudo identificarlo en varios trechos de la costa, desde puntas Unión y Tombo (4350'S), hasta cerca de la Isla de los Pingüinos (48³6'S), reconociendo su identidad con la análoga formación de Puerto Deseado.

Las exploraciones de Carlos Ameghino permitieron identificar los principales afloramientos del Complejo Porfírico, tanto a lo largo de la costa como en el interior de la Patagonia. En 1906, Florentino Ameghino reconoce que no es posible fijar con acierto la edad del complejo, pero señala que seguramente son anteriores a la de la formación que denomina "Grès Bigarrés" o Chubutense, referida al Cretácico inferior, y son por lo tanto precretácicos, tal vez Jurásicos. Posteriormente, Delhaes (1913) considera que corresponden a una edad Neotriásica (Rético) a partir del hallazgo de Estheria mangaliensis Jones en una perforación en Puerto San Julian. Esta postura fue sostenida durante años, junto con Wichmann (1922) y Windhausen (1931).

En 1949, Feruglio realiza un estudio del Complejo y señala: “...En la zona costanera situada entre el Cabo Raso y la Isla Quintana, así como en la que se extiende, a lo largo de la costa, desde Puerto Deseado hasta cerca de San Julián, se presentan grandes mantos y masas de pórfido cuarcífero y rocas análogas, en su mayor parte de color rojo violáceo, que alternan con tobas $y$ brechas cementadas. Estas rocas parecen constituir la porción inferior del complejo volcánico en estudio. Rocas parecidas se observan también en el valle inferior del Río Pintura, donde hay pórfidos y tobas más o menos descompuestas, blanquecinas, grises, rojizas y más comúnmente azuladas; a lo largo del camino desde Colonia Pellegrini al Cañadón del Arroyo Pirámides; en el trecho inferior del valle del Río Chico y en el del Río Chubut. Las masas 
Ana Julia Sagasti - Estudio paleobotánico, paleoecológico y paleoambiental...

porfíricas, más resistentes a la degradación, forman con frecuencia relieves o pequeños cerros peñascosos, que sobresalen a guisa de islotes, como los que se elevan aislados en la zona costanera entre el paralelo $44^{\circ}$ y las Tetas de Pineda, y en las mesetas al Norte y al Sur del curso inferior del Río Deseado; mientras que a lo largo de la costa constituyen promontorios, o islas rocosas, a veces escarpadas. En otras partes (especialmente en la región situada al Sur del Río Deseado) consiste esta serie en mantos de pórfido cuarcífero blanco, gris, verdoso, rojizo o colorado, a veces de disyunción prismática y generalmente alterado, que alternan con bancos de tobas blancas, amarillentas, verdosas, rojas y violáceas, terrosas y más frecuentemente litoideas, por lo general de grano fino, pero a veces brechosas. Donde predominan las tobas, éstas se presentan dispuestas más o menos distintamente en capas y bancos de posición subhorizontal o con inclinaciones superiores a $10^{\circ}$, como se puede observar en el Gran Bajo de San Julián, y a lo largo de la costa entre Bahía Bustamante y la Punta Ulloa, donde las tobas afectan inclinaciones de $20^{\circ}$ hasta $35^{\circ}$ al SE. Estas inclinaciones parecen en gran parte originarias, o sea, debidas a la posición acumbente de las camadas de productos piroclásticos. [...] Las discordancias, como suele acontecer en las formaciones volcánicas, son frecuentes en relación con la sucesión irregular de los paroxismos volcánicos. Debido a la posición en conjunto subhorizontal, o poco inclinada, de toda esta formación, y a la falta de cortes naturales muy profundos, no es fácil medir el espesor de la formación en su conjunto. Por otra parte, el mismo complejo ha sido repetida y profundamente afectado por la denudación, antes y después de que se depositasen los mantos sedimentarios del Cretáceo superior y del Terciario, al punto que en varios lugares ha quedado al descubierto el basamento cristalino sobre el cual se asienta. En Camarones se han atravesado con un sondeo $914 \mathrm{~m}$ de rocas porfíricas. En San Julián se atravesó la misma formación por un espesor máximo de $215 \mathrm{~m}$. En la perforación de Springhill, en la Isla Grande Tierra del Fuego, al Sur de la entrada oriental del Estrecho de Magallanes, se han perforado muchos cientos de metros de este complejo, quizá cerca de $1000 \mathrm{~m} . . . "$

Feruglio (1949) propone para el Complejo Porfírico, la denominación de Bahía Laura y la define de la siguiente manera: “...se compone de coladas y masas de pórfidos cuarcíferos, queratófiros cuarcíferos y queratófiros rojos, 
Ana Julia Sagasti - Estudio paleobotánico, paleoecológico y paleoambiental...

violáceos, verdosos, grises y blancos; de vitriófiros, de tobas litoideas y terrosas de coloración varia, brechas, tufitas, etc. En la zona situada a ambos lados del Río Genua, y en la serranía del Cerro Negro (44 lat.), abundan las porfiritas, asociadas con pórfiros y ortófiros. [...] Su espesor varía de un sitio a otro: desde algunos cientos de metros puede llegar a más de 1000. Los terrenos en cuestión ocupan vastas extensiones entre los paralelos $40^{\circ}$ y $45^{\circ}$, donde descansan directamente sobre las rocas cristalinas del basamento; y entre los ríos Deseado y Chico de Santa Cruz. De allí se extienden, debajo del manto de sedimentos cretáceos y terciarios, por lo menos hasta Río Gallegos. [...] El mismo complejo volcánico está recubierto en clara discordancia por terrenos de edad muy diversa: en el interior de la Meseta, entre los paralelos $43^{\circ}$ y $48^{\circ}$, por los sedimentos continentales del Chubutense (Estratos con Dinosaurios); en la zona costanera por sedimentos marinos y continentales del Cretáceo superior y del Terciario; en las perforaciones de Puerto Croig, Cañadón de los Palos (Cabo Buentiempo) y Spring Hill por sedimentos marinos del Cretáceo inferior o medio..."

En 1956, Stipanicic y Reig realizan un reconocimiento geológico en la zona centro-boreal de Santa Cruz, con el objetivo de obtener los argumentos que permitiesen orientar las investigaciones en detalle para resolver el problema de la estratigrafía y cronología del denominado "Complejo Porfírico" de la Patagonia Extra-Andina. Estos autores señalan: “...Se pudo evidenciar que los grandes mantos y masas de pórfiros cuarcíferos, queratófiros y porfiritas que alternan muy compactas, ocupan la parte inferior del complejo y se distribuyen predominantemente a lo largo de la costa atlántica, desde los afloramientos de Puerto Deseado hacia el Sur, pasando por Bahía Laura, Chon Aike, etc., hasta Cabo Dañoso. En cambio, los grupos en esencia sedimentarios, que apenas presentan alguna participación ígnea en forma de mantos de escasa potencia, corresponden a niveles más altos de la "Serie Porfírica" y muestran sus afloramientos hacia el oeste de la costa atlántica (Malacara, Bajo del Tordillo, Laguna Fea, Gran Bajo de San Julián, Cerro Madre e Hija, Bellavista, Estancia Alma Gaucha, Meseta J. Baqueró, etc.).

Dentro de este sector prevalentemente clástico, Stipanicic y Reig (1956) reconocen dos grupos, que muestran diferente repartición geográfica, así como distintas edades y posiciones estratigráficas. $Y$ reconocen: "Al oeste y en forma 
Ana Julia Sagasti - Estudio paleobotánico, paleoecológico y paleoambiental...

inmediata a los afloramientos de vulcanitas de la costa atlántica asoma un complejo compuesto de tobas, tobas limosas y arenosas, areniscas tobáceas, conglomerados y lutitas tobáceas, en parte laminares, que en conjunto muestran una fuerte compacidad y litificación. Este grupo se extiende hasta el meridiano $69^{\circ}$, aproximadamente, y comprende los afloramientos de Malacara, Laguna Fea, La Matilde, Bajo del Tordillo, Gran Bajo San Julián, Estancia La Trabajosa y los yacimientos de los "bosques petrificados" del Cerro Madre e Hija, Bellavista, Alma Gaucha, etc. Al oeste de los 69, en cambio, asoman paquetes sedimentarios donde predominan los bancos de limos y areniscas tobáceas muy poco cementados y apenas litificados, friables, entre los que intercalan paquetes espesos y masivos de arcillas en parte bentoníticas, tiernas, sueltas, y de tobas muy finas, completamente alteradas y caolinizadas (Cerro Cuadrado, Meseta de J. Baqueró)."

Stipanicic y Reig (1956) establecen la denominación: Chon Aikense para las vulcanitas de la costa, Matildense para el sector medio, esencialmente sedimentario, de Malacara, La Matilde, la zona de los bosques petrificados y del Gran Bajo de San Julián y Baqueroense para la parte clástica más alta de Cerro Cuadrado y la Meseta de Baqueró. Confirman la independencia de estos tres grupos en función de sus diferentes distribuciones geográficas, composiciones litológicas y porque el contenido paleontológico del Matildense y el Baqueroense señalan edades diferentes. Además, estos autores plantean la posibilidad de la existencia de una discordancia separando el Chon Aikense del Matildense, y otra en el techo de esta última, separándola del Baqueroense. En base al estudio de los fósiles vegetales, estos autores ubican al Matildense en los niveles más altos del Mesojurásico (Calloviano), o a lo sumo, en los más bajos del Suprajurásico (Oxfordiano).

Ugarte (1966), utilizó los términos Serie de Chon Aike para la facies volcánica y Serie de La Matilde para la facies sedimentaria y sostuvo la conveniencia de considerar dichas unidades como una unidad-roca mayor, denominable Complejo Bahía Laura cuando no se distinguen sus miembros. Archangelsky (1967) adecuó las series a la nomenclatura estratigráfica, denominándolas Formaciones Chon Aike y La Matilde. Lesta y Ferello (1972) proponen el término Grupo Bahía Laura, sosteniendo la coetaneidad de las Formaciones Chon Aike y La Matilde en función de la interestratificación entre 
Ana Julia Sagasti - Estudio paleobotánico, paleoecológico y paleoambiental...

ambas, e incluyeron a las lavas intermedias a básicas de la Formación Bajo Pobre en la parte basal del grupo.

Las rocas del Grupo Bahía Laura se componen principalmente de riolitas, ricas en potasio, que pertenecen a la serie calcoalcalina y son de tipo peraluminoso (Pankhurst y Rapela, 1995). Los estudios realizados en este Grupo señalan que se habría formado durante un período de alrededor de 25 Ma, en un ambiente extensional del Jurásico Medio a Tardío (177.8 a 153.4 Ma, según Féraud et al., 1999 y Pankhurst et al., 2000), por un proceso de mezcla, asimilación y homogeneización de los fundidos vinculados genéticamente a la Formación Bajo Pobre (Riley et al., 2001).

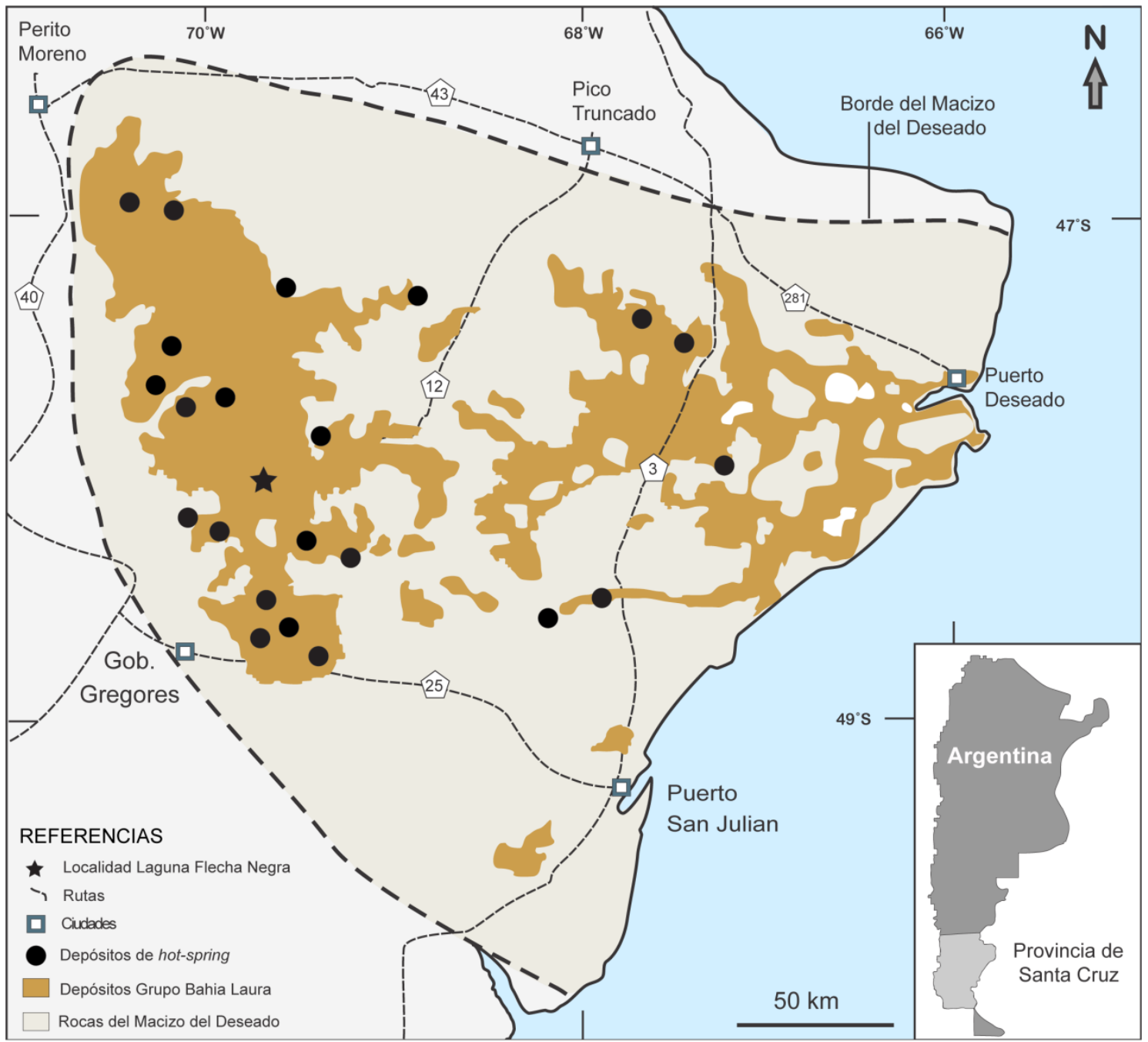

Figura 3.2. Mapa geológico del Macizo del Deseado mostrando los afloramientos del Grupo Bahía Laura y las localidades con depósitos de hot-spring. Modificado de Sagasti et al. (2016). 
Ana Julia Sagasti - Estudio paleobotánico, paleoecológico y paleoambiental...

\section{Formación La Matilde}

La Formación La Matilde fue definida por Stipanicic (En: Stipanicic y Reig, 1956) en los alrededores de la Estancia La Matilde, departamento Deseado, $66^{\circ} 50^{\prime}$ de longitud oeste y $48^{\circ} 25^{\prime}$ de latitud sur. Estos autores realizaron el siguiente perfil levantado en la quebrada de La Matilde.

Arriba:

$R$ : Rodados y gravas sueltos, correspondientes al relleno del pequeño valle de la Quebrada de La Matilde. RECIENTE DISCORDANCIA ANGULAR

JL: Lutitas tobáceas, compactas, con estratificación paralela muy bien definida, laminares, gris oscuras y gris claras, en parte bandeadas con estos tonos, con superficie meteorizada gris-amarillento clara, a veces manchada de pardo ocráceo. Uno que otro nivel puede ser finamente arenoso. Del N. F. I, situado entre 1,5 y 2,00 m por arriba de la base del complejo lutítico, proceden los ejemplares casi completos de Notobatrachus degiustoi Reig, los que se asocian con Hausmannia (Protorhipis) de-ferrariisii Fer. y Cladophlebis sp. En el N. F. II, y a 15 metros estratigráficos por arriba del N. F. I. también aparecen huesos sueltos de Notobatrachus degiustoi Reig, junto con las mismas plantas antes citadas. En todo el espesor de JL hay impresiones de Estheria sp., las que predominan en ciertos niveles. Este paquete lutítico es conocido en la literatura geológica con el nombre de "esquistos con Estheria". Afloran $20 \mathrm{~m}$.

JA: Tobas arenosas y limosas, grises, amarillentas y rosadas claras, discretamente compactadas, masivas en la parte inferior y mejor estratificadas hacia arriba, donde forman bancos bien definidos y hasta laminares. $30 \mathrm{~m}$.

JC: Conglomerado verdoso, con areniscas gruesas entrecruzadas y areniscas tobiferas gruesas en la base, también verdosas (2-3 m). Los rodados del conglomerado alcanzan diámetros de hasta $4 \mathrm{~cm}$ y son de pórfiro cuarcífero, porfiritas, tobas porfíricas y porfiríticas y de calcedonia. $15 \mathrm{~m}$.

JT: Espeso complejo, esencialmente compuesto por bancos potentes de tobas compactas, de fractura irregular, de estratificación no definida y por lo común masivos, de grano fino a mediano, con abundantes cristales grandes y angulosos de cuarzo y otros de feldespatos rosados, a veces alterados, de 
Ana Julia Sagasti - Estudio paleobotánico, paleoecológico y paleoambiental...

hasta $6 \mathrm{~mm}$ de largo. Coloración general gris clara y gris amarillenta clara, a excepción de dos niveles tobíferos verdosos ( $v$ en el perfil), de 1 y $3 \mathrm{~m}$ de potencia y de los sectores más compactos, de coloración violácea, que podrían corresponder a mantos porfiríticos muy alterados, en parte caolinizados. Las superficies meteorizadas muestran una coloración predominantemente amarilla clara, en parte algo ocrácea.

En varios niveles hay impresiones vegetales indeterminables, troncos carbonizados y silicificados y bancos de tobas muy finas con gran cantidad de concreciones esferulíticas (e en el perfil), las que alcanzan tamaños de hasta $10 \mathrm{~mm}$.

En los casi 30 metros inferiores algunos bancos de tobas están muy alterados, casi caolinizados y otros llevan rodaditos de pórfiro cuarcífero, porfiritas, calcedonia, tobas porfíricas y porfiríticas, de hasta $30 \mathrm{~mm}$ de diámetro. 110 metros, base no aflorante.

\section{Formación Chon Aike.}

La Formación Chon Aike (Stipanicic y Reig, 1956; Archangelsky, 1967) está ampliamente desarrollada en gran parte del Macizo del Deseado. Sus afloramientos principales se pueden agrupar en tres grandes regiones: a) región centro austral, incluyendo los afloramientos desde el Valle del Zanjón del Pescado, Cerro Vanguardia, Gobernador Moyano, hasta Gobernador Gregores y el Gran Bajo de San Julián, b) región nororiental, sector costero de la provincia, desde el Cabo Blanco y Puerto Deseado, hasta Bahía Laura y el Cabo Curioso, y c) Región Occidental, desde Perito Moreno hasta La Manchuria (de Barrio et al., 1999). La localidad y sección tipo se ubican en la costa atlántica al sur de Bahía Laura, $48^{\circ} 30^{\prime}$ de latitud sur y $66^{\circ} 45^{\prime}$ de longitud oeste.

Las ignimbritas se disponen como mantos compactos y espesos que forman grandes paredones y crestas muy abruptas. El espesor de los mantos oscila entre los 5 y $15 \mathrm{~m}$, pudiendo llegar en los casos más extremos hasta los 30 y $40 \mathrm{~m}$. Su color dominante en afloramiento es castaño oscuro a rojizo, a veces gris oscuro, mientras que en corte fresco las rocas son de color gris claro 
Ana Julia Sagasti - Estudio paleobotánico, paleoecológico y paleoambiental...

y rosadas hasta rojizo-moradas. Las ignimbritas son bien porfíricas, integradas por abundantes fenocristales de cuarzo (de 1 a $8 \mathrm{~mm}$ ), con escasos feldespatos blancos (frescos o alterados) y láminas euhedrales de biotita de hasta 2 a $3 \mathrm{~mm}$. Contienen fiammes y fragmentos pumíceos muy alterados o pigmentados por óxidos de hierro, así como pocos litoclastos grises o morados de rocas volcánicas y tobas.

Intercalados entre las ignimbritas hay bancos de aglomerados y brechas volcánicas y de lapillitas, tobas y tufitas. Los primeros presentan colores claros y están compuestos por grandes clastos de andesitas y tobas en una matriz piroclástica. Las tobas son finas, friables, de tonos blanco-amarillentos hasta rosados; pueden llegar a ser muy lajosas. Las tufitas constituyen bancos macizos de uno a dos metros de espesor, son rocas de grano fino a mediano, a veces grueso. En cuanto a la coloración, presentan tonos gris blanquecino a castaño, y por su composición son líticas o cuarzo-líticas. Las rocas lávicas, principalmente riolitas biotíticas, son a menudo rocas bien fluidales, con bandeamiento casi siempre con inflexiones y repliegues, y con variable inclinación. Son por lo general muy porfíricas, con abundantes cristales de cuarzo y de feldespatos (sanidina y/o plagioclasa), con biotitas subordinadas en una pasta afanítica fluidal muy alterada o silicificada (de Barrio et al., 1999). La Formación Chon Aike se interdigita lateralmente con las tobas y tufitas de la Formación La Matilde. Una relación de discordancia angular separa a la Formación Chon Aike de las unidades infrayacentes, y en particular de la Formación Bajo Pobre. En su techo, una nueva relación de discordancia angular separa al Grupo Bahía Laura de las unidades post jurásicas.

Cuando el Chon-Aikense fue definido en la costa atlántica, se lo consideró compuesto fundamentalmente por rocas volcánicas porfíricas ("pórfiros cuarcíferos" y "porfiritas" según la nomenclatura de la época). Posteriormente, a medida que los autores fueron reconociendo los afloramientos situados en el centro-oeste de la provincia de Santa Cruz, comenzaron a caracterizar a la Formación como compuesta dominantemente por ignimbritas riolíticas (Riccardi y Damborenea, 1993). 
Ana Julia Sagasti - Estudio paleobotánico, paleoecológico y paleoambiental...

\section{Antecedentes paleobotánicos.}

\section{Reseña del estudio de las megafloras jurásicas en la Argentina}

En Argentina se han registrado floras liásicas en las provincias de Neuquén, Río Negro, San Juan, Mendoza, Chubut y Santa Cruz (Tabla 4.1). En 1933, Feruglio realiza un estudio de la flora liásica registrada en el valle del Río Genoa en el cual describe Todites (Asplenites) macrocarpa Oldham y Morris, Sphenopteris aff. nordenskjöldii Halle, Sphenopteris sp., Microphyllopteris cf. pectinata Hector, Taeniopteris berryi Feruglio, Linguifolium steinmanni Solms, Nilssonia taenipteroides Halle, Nilssonia kurtzi Feruglio, Elatocladus patagonicus Feruglio, Cladophlebis piatnitzkyi Feruglio, Thinnfeldia ? sp., Cordaites? sp., Pelourdea aff. megaphylla Phill., Ginkgoites crassipes Feistm., Elatocladus hallei Feruglio, Otozamites genuensis Feruglio. Posteriormente (1951), el mismo autor reconoce nuevas formas en el valle del Río Genoa. Este análisis identifica Lepidodendron (vel Sigillaria) sp., Phyllotheca (vel Schizoneura) patagónica Feruglio, Pecopteris sp. I, Pecopteris sp. II, Glossopteris indica Schimper, Cordaites hislopi Bunb., Ginkgoites eximia Feruglio, Paranocladus ? hallei Feruglio, Genoites patagonica Feruglio, Barakaria dichotoma (Feistm.) Sew. et Sahni, Samaropsis (vel Cardiocarpus) argentina Feruglio y Cordaicarpus patagonicus Feruglio, la composición de esta flora, indica una edad pérmica para el yacimiento.

Los estudios en la zona de Piedra Pintada (provincia del Neuquén) comienzan con los trabajos de Kurtz (1902), Frenguelli (1941) y Orlando (1946). En esta localidad, Frenguelli (1941) estudia una flora de dipteridáceas en la que describe las especies Dictyophyllum rothi, Dictyophyllum apertum, Thaumatopteris eximia, Clathropteris kurtzi y Clathropteris ingens y ejemplares de afinidad dudosa del género Thaumatopteris. Posteriormente, Herbst (1966a) re-examina los materiales provenientes de esta localidad, estudiados por Kurtz (1902), Orlando (1946) y Frenguelli $(1941,1947)$. Herbst (1966a) reconoce las especies Equisetites frenguellii Orlando, Cladophlebis oblonga Halle, Cladophlebis grahami (Halle) Frenguelli, Cladophlebis pintadensis Herbst, Dictyophyllum rothi Frenguelli, D. apertum Frenguelli, Thaumatopteris eximia 
Ana Julia Sagasti - Estudio paleobotánico, paleoecológico y paleoambiental...

Frenguelli, Clathropteris obovata Oishi, Goeppertella neuqueniana Herbst, Scleropteris vincei Herbst, Sagenopteris rhoifolia Presley, Sagenopteris sp., Otozamites ameghinoi Kurtz, Otozamites barthianus Kurtz, Otozamites bunburyanus var. major Kurtz, Otozamites simonatoi Orlando, Desmiophyllum sp., Araucarites sp., Brachyphyllum sp. y Pagiophyllum sp. Esta asociación florística es asignada al Liásico en función de elementos característicos de esta época (e.g. Clathropteris obovata, Goeppertella), y por la presencia de invertebrados en los niveles marinos de la secuencia (e.g. Oxynoticeras oxynotum). En 2006, Gnaedinger describe los primeros restos de maderas para la Formación Piedra Pintada, representados por Araucarioxylon (Agathoxylon) termieri (Attims) Gnaedinger y Prototaxoxylon pintadense Gnaedinger.

También en la provincia de Neuquén, Frenguelli (1937) describe una flórula del Jurásico Inferior-Medio en Paso Flores. Allí reconoce Danaeopsis cf. cacheutensis Kurtz, Cladophlebis australis (Morris) Seward, Taeniopteris cf. marayesica Geinitz, Dicroidium lancifolium (Morris) Gotham, Podozamites elongatus (Morris) Feistmantel, Podozamites sp., Desmiophyllum sp., Ginkgo taeniata (Geinitz), Ginkgo crassipes cf. Feistmantel, Stenopteris elongata (Carruthers) Seward y Czekanowskia murrayana (Lindley y Hutton) Seward. Estudios posteriores de la Formación Paso Flores, determinaron una edad Triásica Superior para la unidad, la cual se evidencia particularmente por la presencia de diversas especies del género fósil Dicroidium (Frenguelli, 1948; Morel et al., 1992; Ganuza et al., 1992; Artabe et al., 1994).

En la zona de Plaza Huincul (Neuquén), Menéndez (1956) describió una flora contenida en testigos de perforaciones del Bajo de los Baguales, y determinó las siguientes formas: Todites williamsoni (Brongniart) Seward, Cladophlebis denticulata (Brongniart) Fontaine, Thaumatopteris sp., Sphenopteris bagualensis Menéndez, Ptilophyllum hislopi (Oldham) Seward, Elatocladus heterophylla Halle, Brachyphyllum ? sp. y Sagenopteris nilssoniana (Brongniart) Ward. Menéndez realizó un análisis sobre las relaciones de esta flora, y concluyó que su mayor afinidad es con aquella de Bahía Esperanza, de la Tierra de Graham (Antártida) y que pertenecen al Jurásico Medio. Posteriormente, Baldoni (1978) amplía estos estudios registrando Sphenopteris (Coniopteris?) permira Frenguelli, Sphenopteris sp., Otozamites linearis Halle, 
Ana Julia Sagasti - Estudio paleobotánico, paleoecológico y paleoambiental...

Sagenopteris sp., Brachyphyllum neuquinum Baldoni y Tomaxellia crassa Baldoni, y concluye una edad mesojurásica (Bajociana) para esta asociación.

Ferello (1947) estudia la tafoflora de la Formación Piedra del Águila (provincia del Neuquén), que fuera descubierta por Groeber. Allí se reconoce una asociación de Bennettitales conformada por Otozamites oldhami Feistmantel, Otozamites obtusus (Lindley y Hutton), Otozamites groeberi Ferello, Ptilophyllum sp. cf Ptilophyllum cutchense Morris, Ptilophyllum acutifolium Morris y la presencia de Araucarites sp. En 1966 (b), Herbst reconoce Equisetites sp., Cladophlebis sp. cf. C. haiburnensis (Lindley y Hutton) Brongniart, Cladophlebis, sp. cf. C. indica (Oldham y Morris) Feistmantel, Otozamites cf. hislopi y Sphenopteris sp. Finalmente, Spalletti et al. (2010) confirman la afinidad del taxón fósil de frondes de Osmundaceae, asignándolo con certeza a Cladophlebis indica (Oldham y Morris) Feistmantel. A su vez, identifican Scleropteris sp., Otozamites bechei, Cladophlebis haiburnensis y Otozamites hislopi. En ese mismo trabajo, Spalletti et al. realizan una datación U-Pb SHRIMP en circones identificados en tobas vítreas, que arrojan una edad de 191,7 \pm 2,8 Ma, correspondiente al Sinemuriano.

En la provincia de Chubut, Herbst (1964a) estudia la flora liásica de C. Meschio en la Sierra de Pampa de Agnia. Allí reconoce Goeppertella macroloba Herbst, Sphenopteris sp., Ptilophyllum cutchense Morris, Sagenopteris cf. rhoifolia Presley, Pagiophyllum sp. y Desmiophyllum sp. El autor asigna una edad liásica, aunque los elementos presentes no conllevan un fuerte valor estratigráfico (Herbst, 1964a). En 1966, Herbst amplía los estudios del Grupo Pampa de Agnia, describiendo: Equisetites sp., Cladophlebis sp., Thaumatopteris sp., Coniopteris meschiana Herbst, Scleropteris vincei Herbst, Ginkgoites cf. digitata (Brongniart), Sagenopteris rhoifolia Presley, Otozamites albosaxatilis Herbst, Otozamites hislopi (Oldham) Feistmantel, Otozamites cf. hislopi (Oldham) Feistmantel, Otozamites cf. oldhami Feistmantel, Otozamites chubutensis Herbst, Otozamites sueroi Herbst, Elatocladus confertus (Oldham) Halle y Brachyphyllum sp. De las formas determinadas con certeza, Herbst señala que se reconocen 4 taxones que corresponden a elementos típicos de asociaciones liásicas y mesojurásicas del mundo, particularmente de Gondwana. En Argentina, estos elementos son característicos de las floras del 
Ana Julia Sagasti - Estudio paleobotánico, paleoecológico y paleoambiental...

Liásico, y se encuentran asociados a una fauna de invertebrados que respalda esta datación.

En la Formación Cañadón Asfalto (Chubut), Escapa et al. (2008) definen la especie Austrohamia minuta Escapa, Cúneo y Axsmith, a partir del estudio de ramas foliosas y conos micro y megasporangiados. Escapa (2008) estudia una tafoflora compuesta por Equisetum (?) sp. A, B, C y D, Dictyophyllum (Clathropteroides) obovata Oishi, Dictyophyllum (Clathropteroides) sp., Goeppertella sp. A, B y C, Todites sp., Osmundopsis (?) sp., Microphyllopteris sp., Cladophlebis denticulada Brongniart, Cladophlebis sp. A y B, Sphenopteris sp. A y B, Sphenopteris nordenskjöldii Halle, Weltrichia (?) sp., Zamites cf. gigas, Zamites pusillus Halle, Sagenopteris nilssoniana (Brongniart) Ward, Caytonanthus sp., Austrohamia minuta Escapa, Cúneo y Axsmith, Elatides sp., Araucaria cf. cutchensis (Feistmantel) Pant y Srivastava, Araucaria sp. A, B y C, Araucarites sp., Pararaucaria sp., Masculostrobus sp. A y B, Elatocladus confertus (Oldham y Morris) Halle, Elatocladus casamiquelensis Herbst y Anzótegui, Brachyphyllum cf. lotenaense, Pachypteris indica (Oldham y Morris) Bose y Roy, Pachypteris sp. y Archangelskya furcata (Halle) Herbst emend. Rees y Cleal. Posteriormente, Bodnar et al. (2013) describen restos de maderas de coníferas que identifican como Brachyoxylon currumilii Bodnar, Escapa, Cúneo y Gnaedinger. Escapa et al. (2013) estudian restos de conos permineralizados en la Formación Cañadón Calcáreo y definen la especie Pararaucaria delfueyoi Escapa, Cúneo, Rothwell y Stockey. En la localidad Cerro Bayo, Choo et al. (2008) reconocen la presencia de Clathropteris meniscioides (Brongniart) Brongniart. También en Cerro Bayo, Escapa et al. (2014) definen la especie Marattiopsis patagonica Escapa, Bomfleur, Cúneo y Scasso, hallazgo que amplía el registro de Marattiales para el Mesozoico de Gondwana. Posteriormente, Elgorriaga et al. (2015) describen la especie Equisetum dimorphum Elgorriaga, Escapa, Bomfleur, Cúneo y Ottone, a partir del estudio de impresiones y moldes de todos sus órganos aéreos (e.g. ejes, verticilos de hojas, diafragmas nodales, estróbilos).

En la Formación Nestares (límite entre las provincias de Río Negro y Neuquén) realizaron estudios paleobotánicos macroflorísticos Arrondo y Petriella (1980), Artabe (1982), Petriella y Arrondo (1982), Arrondo et al. (1991), Herbst y Gnaedinger (2002) y Morel et al. (2013). Se reconoce para esta 
Ana Julia Sagasti - Estudio paleobotánico, paleoecológico y paleoambiental...

unidad, una flora conformada por Equisetites frenguelli Orlando, Neocalamites carrerei (Zeiller) Halle, Marattia muensteri (Goeppert) Zeiller, Cladophlebis mendozaensis (Geinitz) Frenguelli, Cladophlebis oblonga Halle, Gleichenites cf. sanmartini Halle emend. Herbst, Goeppertella diazii Arrondo y Petriella, Archangelskya protoloxsoma (Kurtz) Herbst, Scleropteris vincei Herbst, Sagenopteris nilssoniana (Brongniart) Ward, Kurtziana brandmayri Frenguelli, Kurtziana cacheutensis (Kurtz) Frenguelli, Nilssonia taeniopteroides Halle, Taeniopteris sp., Otozamites albosaxatilis Herbst, Otozamites ameghinoi Kurtz, Otozamites bechei Brongniart, Otozamites bengalensis Oldham y Morris, Otozamites hislopii (Oldham) Feistmantel, Ptilophyllum acutifolium Morris, Araucarites phillipsi Carruthers, Podozamites elongatus (Morris) Feistmantel, Elatocladus confertus (Oldham y Morris) Halle y Elatocladus planus (Feistmantel) Seward. Los elementos que caracterizan esta asociación fueron comparados por Morel et al. (2013) con aquellos estudiados en la Formación El Freno y el cerro La Brea, hallándose una compatibilidad del $50 \%$ y $25 \%$, respectivamente.

La flora de la Formación El Freno (Jurásico Temprano de Mendoza) fue estudiada por Herbst (1964b), quién determina los siguientes taxones: Equisetites sp., Neocalamites carrerei (Zeiller) Halle, Marattia münsteri (Goeppert) Zeiller, Cladophlebis (Todites?) ugartei Herbst, Cladophlebis antárctica Nathorst, Cladophlebis cf. mesozoica Kurtz, Dictyophyllum atuelense Herbst, Dictyophyllum rothi Frenguelli, Archangelskya proto-loxsoma (Kurtz), Archangelskya furcata (Halle), Taeniopteris sp. a y b., Sagenopteris sp. cf. S. rhoifolia Presley, Otozamites cf. albosaxatilis Herbst, Otozamites bechei Brongniart, Otozamites hislopi (Oldham) Feistmantel, Ptilophyllum acutifolium Morris, Otozamites sp. cf. O. bunburyanus var. major Kurtz, Pterophyllum princeps (Oldham y Morris), Elatocladus confertus (Oldham) Halle, y ?Pagiophyllum sp. Posteriormente, Artabe et al. (2005) analizan los afloramientos de esta Formación en el Cerro La Brea e identifican Equisetites sp., Rienitsia colliveri Herbst, Cladophebis oblonga Halle, Dictyophyllum (D.) atuelense Herbst, Archangelskya proto-loxsoma (Kurtz) Herbst, Scleropteris vincei Herbst, Ptilophyllum acutifolium Morris, Williamsonia sp., Taeniopteris sp. y Elatocladus confertus Oldham y Morris. Spalletti et al. (2007), realizan estudios en los niveles plantíferos aflorantes en el valle superior del río Atuel, 
Ana Julia Sagasti - Estudio paleobotánico, paleoecológico y paleoambiental...

ampliando el conocimiento paleoflorístico para esta unidad con el reconocimiento de Cladophlebis mendozaensis (Geinitz), Dejerseya lobata (Jones y de Jersey) Herbst y Kurtziana brandmayri Frenguelli. En 2013, Lanés et al. estudian los afloramientos de la Formación El Freno en el Valle de Las Leñas y reconocen especímenes de Dictyophylum (Dictyophylum) sp., Goeppertella sp. y restos de Equisetópsidas indeterminados. Gnaedinger et al. (2015) analizan restos permineralizados de coníferas e identifican Agathoxylon liguaensis Torres y Philippe y Podocarpoxylon atuelensis Gnaedinger; estos restos presentan a su vez, evidencias de pudrición fúngica ejercida por basidiomicetes.

En la provincia de San Juan, Volkheimer et al. (1978) y Herbst (1980) estudian la flora de la Formación Los Patos. En 1994, Álvarez et al. readecuan la nomenclatura estratigráfica para esta unidad, por considerarla de validez nula bajo el Código Argentino de Estratigrafía (CAE, 1992). Estos autores dividen los niveles que habían sido incluídos dentro de la Formación Los Patos, en dos unidades: Formación Rancho de Lata y Formación Los Patillos. La Formación Rancho de Lata incluye rocas depositadas durante el intervalo Triásico Medio-Superior a Jurásico Inferior Temprano, y contiene una flora integrada por Dicroidium sp., Cordaicarpus sp., tallos de esfenofitas y fragmentos de coniferópsidas (Sección inferior, Triásica). La sección superior de la Formación Rancho de Lata contiene una abundante megaflora estudiada por Herbst (1980), que incluye: Equisetites sp., Cladophlebis sp. cf. C. kurtzi Frenguelli, Pachypteris sanjuanina Herbst, Otozamites volkheimeri Herbst, Brachyphyllum menendezi Herbst, cf. Pagiophyllum sp. y una fructificación de aparente afinidad Pteridopsmermophyta. La Formación Los Patillos corresponde a rocas epiclásticas de origen marino, y su sección inferior corresponde a lo que fuera denominado como Miembro Superior de la Formación Los Patos por Volkheimer et al. (1978), y corresponde al intervalo Pliensbachiano superior a Caloviano inferior (Álvarez et al., 1994).

El sector mendocino de la Formación Los Patillos se correlaciona con las Formaciones Las Chilcas (Reijenstein, 1967), El Cholo (Stipanicic y Bonetti, 1970) y Puesto Araya (Volkheimer, 1978), que presentan una fauna de moluscos y braquiópodos, y zonas de carbón (Lagarreta et al., 1993). 
En el cordón de Esquel (Chubut), Cazaubón (1947) describió una flora compuesta por Woodwardites frenguelli Cazaubón, Alethopteris ? sp., Ctenis patagonica Cazaubón, Dictyozamites falcatus (Morris) Oldham y Dictyozamites hallei Cazaubón. En el año 1949, Stipanicic y Menéndez transfieren la especie Woodwardites frenguelli al género Goeppertella, creando la combinación Goeppertella frenguelliana (Cazaubón) Stipanicic y Menéndez.

En la provincia de Santa Cruz se encuentran registros liásicos en la Estancia La Juanita (Grupo Bahía Laura) y en la Formación Roca Blanca. Arrondo (1972) es el primero en realizar estudios en la zona de la Estancia la Juanita. En esta región afloran sedimentitas liásicas que contienen una flora pobre compuesta por: Goeppertella sp. y Elatocladus sp. En 1984, Petriella y Arrondo analizan esta tafoflora con mayor detalle, reconociendo Goeppertella herbstii Arrondo y Petriella, Elatocladus planus (Feistmantel) Seward y Scleropteris vincei Herbst. En la Formación Roca Blanca se realizaron una serie de estudios (e.g. Herbst, 1965; Stipanicic y Bonetti, 1970) en los que se identificaron: Equisetites patagonica Herbst, Cladophlebis oblonga Halle, Coniopteris leucopetraea Herbst, Thaumatopteris rocablanquensis Herbst, Clathropteris sp., Rhizomopteris sp., Spiropteris sp., Sagenopteris cf. rhoifolia Presley, Otozamites albosaxatilis Herbst, Brachyphyllum sp., Pagiophyllum sp., Strobilites y Cycadolepis. En 2009, Herbst y Gnaedinger reconocen el primer registro de maderas gimnospérmicas para la Formación Roca Blanca. En este estudio, identifican Agathoxylon protoaraucana (Brea) Gnaedinger y Herbst, Prototaxoxylon pintadense Gnaedinger y Baieroxylon sp. cf. B. chilensis Torres y Phillipe. En esta misma localidad, Gnaedinger (2012) define la especie Baieroxylon rocablanquense Gnaedinger, que amplía la diversidad de Ginkgoales conocida para esta unidad. 
Ana Julia Sagasti - Estudio paleobotánico, paleoecológico y paleoambiental...

Tabla 4.1. Megafloras del Jurásico Inferior de Argentina. Las especies que han sido asignadas con dudas en los respectivos estudios se señalan como "cf".

\begin{tabular}{|c|c|c|c|c|c|}
\hline Taxón Jurásico Inferior & $\begin{array}{l}\stackrel{\mathbb{N}}{N} \\
\frac{0}{0} \\
\frac{0}{0} \\
\Sigma\end{array}$ & $\begin{array}{l}\frac{5}{\sqrt{0}} \\
\frac{2}{3} \\
\frac{5}{\sqrt{0}} \\
\mathcal{c}\end{array}$ & $\begin{array}{l}\frac{\sigma}{\Phi} \\
\frac{\partial}{0} \\
\frac{0}{2}\end{array}$ & $\begin{array}{l}\frac{\vec{J}}{0} \\
\frac{0}{D} \\
\frac{D}{U}\end{array}$ & 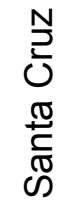 \\
\hline Neocalamites carrerei & $\mathrm{X}$ & & $\mathrm{X}$ & & \\
\hline Equisetites frenguelli & & & $\mathrm{X}$ & & \\
\hline Equisetites patagonica & & & & & $\mathrm{X}$ \\
\hline Equisetites sp. & $X$ & $X$ & $X$ & $X$ & \\
\hline Rienitsia colliveri & $\mathrm{X}$ & & & & \\
\hline Marattia münsteri & $X$ & & $\mathrm{X}$ & & \\
\hline Gleichenites cf. sanmartini & & & $\mathrm{X}$ & & \\
\hline Cladophlebis antárctica & $\mathrm{X}$ & & & & \\
\hline Cladophlebis denticulata & & & $\mathrm{X}$ & & \\
\hline Cladophlebis grahami & & & $\mathrm{X}$ & & \\
\hline Cladophlebis mendozaensis & $\mathrm{X}$ & & $\mathrm{X}$ & & \\
\hline Cladophlebis cf. mesozoica & $\mathrm{X}$ & & & & \\
\hline Cladophlebis pintadensis & & & $\mathrm{X}$ & & \\
\hline Cladophlebis (Todites?) ugartei & $\mathrm{X}$ & & & & \\
\hline Cladophlebis oblonga & $\mathrm{X}$ & & $\mathrm{X}$ & & $\mathrm{X}$ \\
\hline Cladophlebis sp. cf. C. kurtzi & & $\mathrm{X}$ & & & \\
\hline Cladophlebis sp. cf. C. haiburensis & & & $\mathrm{X}$ & & \\
\hline Cladophlebis sp. cf. C. indica & & & $\mathrm{X}$ & & \\
\hline Cladophlebis haiburnensis & & & $\mathrm{X}$ & & \\
\hline Cladophlebis indica & & & $\mathrm{X}$ & & \\
\hline Cladophlebis sp. & & & $\mathrm{X}$ & $\bar{X}$ & \\
\hline Todites williamsoni & & & $\mathrm{X}$ & & \\
\hline Dejerseya lobata & $\mathrm{X}$ & & & & \\
\hline Sphenopteris sp. & & & $\mathrm{X}$ & & \\
\hline Sphenopteris (Coniopteris?) permira & & & $\mathrm{X}$ & & \\
\hline Sphenopteris bagualensis & & & $\mathrm{X}$ & & \\
\hline Pachypteris sanjuanina & & $\mathrm{X}$ & & & \\
\hline Sagenopteris rhoifolia & $\mathrm{Cf}$ & & $\mathrm{X}$ & $\bar{X}$ & cf \\
\hline Sagenopteris nilssoniana & & & $X$ & & \\
\hline
\end{tabular}


Ana Julia Sagasti - Estudio paleobotánico, paleoecológico y paleoambiental...

\begin{tabular}{|c|c|c|c|c|}
\hline Sagenopteris sp. & & $\mathrm{X}$ & $X$ & \\
\hline Desmiophyllum sp. & & $\mathrm{X}$ & $\mathrm{X}$ & \\
\hline Dictyophyllum apertum & & $\mathrm{X}$ & & \\
\hline Dictyophyllum atuelense & $\mathrm{X}$ & & & \\
\hline Dictyophyllum rothii & $\mathrm{X}$ & $\mathrm{X}$ & & \\
\hline Dictyophyllum sp. & & $\mathrm{X}$ & & \\
\hline Clathropteris kurtzi & & $\mathrm{X}$ & & \\
\hline Clathropteris ingens & & $\mathrm{X}$ & & \\
\hline Clathropteris obovata & & $\mathrm{X}$ & $\mathrm{X}$ & \\
\hline Clathropteris sp. & & & & $\mathrm{X}$ \\
\hline Thaumatopteris rocablanquensis & & & & $\mathrm{X}$ \\
\hline Thaumatopteris eximia & & $\mathrm{X}$ & & \\
\hline Thaumatopteris sp. & & $\mathrm{X}$ & $\mathrm{X}$ & \\
\hline Coniopteris meschiana & & & $\mathrm{X}$ & \\
\hline Coniopteris leucopetraea & & & & $\mathrm{X}$ \\
\hline Goeppertella macroloba & & & $\mathrm{X}$ & \\
\hline Goeppertella neuqueniana & & $\mathrm{X}$ & & \\
\hline Goeppertella diazii & & $\mathrm{X}$ & & \\
\hline Goeppertella frenguelliana & & & $\mathrm{X}$ & \\
\hline Goeppertella herbstii & & & & $\mathrm{X}$ \\
\hline Archangelskya protoloxsoma & $\mathrm{X}$ & $\mathrm{X}$ & & \\
\hline Archangelskya furcata & $\mathrm{X}$ & & $\mathrm{X}$ & \\
\hline Alethopteris sp. & & & cf & \\
\hline Scleropteris vincei & $\mathrm{X}$ & $\mathrm{X}$ & $\mathrm{X}$ & $\mathrm{X}$ \\
\hline Scleropteris sp. & & $\mathrm{X}$ & & \\
\hline Ptilophyllum acutifolium & $\mathrm{X}$ & $\mathrm{X}$ & & \\
\hline Ptilophyllum cutchense & & $\mathrm{X}$ & $\mathrm{X}$ & \\
\hline Ptilophyllum sp. cf. P. cutchense & & $\mathrm{X}$ & & \\
\hline Ptilophyllum hislopi & & $\mathrm{X}$ & & \\
\hline Ptilophyllum sp. & & $\mathrm{X}$ & & \\
\hline Otozamites albosaxatilis & $\mathrm{Cf}$ & $\mathrm{X}$ & $\mathrm{X}$ & \\
\hline Otozamites barthianus & & $\mathrm{X}$ & & \\
\hline Otozamites bechei & $\mathrm{X}$ & $\mathrm{X}$ & & \\
\hline Otozamites bengalensis & & $\mathrm{X}$ & & \\
\hline Otozamites ameghinoi & & $\mathrm{X}$ & & \\
\hline
\end{tabular}


Ana Julia Sagasti - Estudio paleobotánico, paleoecológico y paleoambiental...

\begin{tabular}{|c|c|c|c|c|c|}
\hline Otozamites bunburyanus var. mayor & $\mathrm{Cf}$ & & $\mathrm{X}$ & & \\
\hline Otozamites simonatoi & $\mathrm{X}$ & & $\mathrm{X}$ & & \\
\hline Otozamites linearis & & & $\mathrm{X}$ & & \\
\hline Otozamites hislopi & $\mathrm{X}$ & & $\mathrm{X}$ & $\mathrm{X}$ & \\
\hline Otozamites cf. hislopi & & & $\mathrm{X}$ & & \\
\hline Otozamites obtusus & & & $\mathrm{X}$ & & \\
\hline Otozamites groeberi & & & $\mathrm{X}$ & & \\
\hline Otozamites oldhami & & & $\mathrm{X}$ & cf & \\
\hline Otozamites sueroi & & & & $\mathrm{X}$ & \\
\hline Otozamites chubutensis & & & & $\mathrm{X}$ & \\
\hline Otozamites volkheimeri & & $\mathrm{X}$ & & & \\
\hline Pterophyllum prínceps & $\mathrm{X}$ & & & & \\
\hline Dictyozamites falcatus & & & & $\mathrm{X}$ & \\
\hline Dictyozamites hallei & & & & $\mathrm{X}$ & \\
\hline Dictyozamites sp. & & & $\mathrm{X}$ & & \\
\hline Williamsonia sp. & $\mathrm{X}$ & & $\mathrm{X}$ & & \\
\hline Cycadolepis sp. & & & & & $\mathrm{X}$ \\
\hline Strobilites sp. & & & & & $\mathrm{X}$ \\
\hline Araucarites phillipsi & & & $\mathrm{X}$ & & \\
\hline Araucarites sp. & & & $\mathrm{X}$ & & \\
\hline Brachyphyllum sp. & & & $\mathrm{X}$ & $\mathrm{X}$ & \\
\hline Brachyphyllum neuquinum & & & $\mathrm{X}$ & & \\
\hline Brachyphyllum menendezii & & $\mathrm{X}$ & & & \\
\hline Pagiophyllum sp. & $?$ & $\mathrm{X}$ & $\mathrm{X}$ & $\mathrm{X}$ & \\
\hline Podozamites elongatus & & & $\mathrm{X}$ & & \\
\hline Taeniopteris sp. & $\mathrm{X}$ & & $\mathrm{X}$ & & \\
\hline Elatocladus heterophyllus & & & $\mathrm{X}$ & & \\
\hline Elatocladus confertus & $\mathrm{X}$ & & $\mathrm{X}$ & $\mathrm{X}$ & \\
\hline Elatocladus planus & & & $\mathrm{X}$ & & $\mathrm{X}$ \\
\hline Nilssonia taenipteroides & & & $\mathrm{X}$ & & \\
\hline Kurtziana cacheutensis & & & $\mathrm{X}$ & & \\
\hline Kurtziana brandmayrii & $\mathrm{X}$ & & $\mathrm{X}$ & & \\
\hline Rhizomopteris sp. & & & & & $\mathrm{X}$ \\
\hline Spiropteris sp. & & & & & $\mathrm{X}$ \\
\hline Ctenis patagonica & & & & $\mathrm{X}$ & \\
\hline
\end{tabular}


Ana Julia Sagasti - Estudio paleobotánico, paleoecológico y paleoambiental...

\begin{tabular}{|c|c|c|c|c|}
\hline Cycadites sp. & & $\mathrm{X}$ & & \\
\hline Taxites sp. & & $\mathrm{X}$ & & \\
\hline Tomaxellia crassa & & $\mathrm{X}$ & & \\
\hline Ginkgoites cf. digitata & & & $\mathrm{X}$ & \\
\hline Baieroxylon rocablanquense & & & & $\mathrm{X}$ \\
\hline Baieroxylon sp. cf. B. chilensis & & & & $\mathrm{X}$ \\
\hline Prototaxoxylon pintadense & & $\mathrm{X}$ & & $\mathrm{X}$ \\
\hline Agathoxylon protoaraucana & & & & $\mathrm{X}$ \\
\hline Dictyophylum (Dictyophylum) sp. & $\mathrm{X}$ & & & \\
\hline Goeppertella sp. & $\mathrm{X}$ & & & \\
\hline Agathoxylon liguaensis & $\mathrm{X}$ & & & \\
\hline Podocarpoxylon atuelensis & $\mathrm{X}$ & & & \\
\hline Austrohamia minuta & & & $\mathrm{X}$ & \\
\hline Brachyoxylon currumilii & & & $\mathrm{X}$ & \\
\hline Pararaucaria delfueyoi & & & $\mathrm{X}$ & \\
\hline Clathropteris meniscioides & & & $\mathrm{X}$ & \\
\hline Marattiopsis patagonica & & & $\mathrm{X}$ & \\
\hline Equisetum dimorphum & & & $\mathrm{X}$ & \\
\hline Agathoxylon termieri & & $\mathrm{X}$ & & \\
\hline Equisetum sp. A & & & $\mathrm{Cf}$ & \\
\hline Equisetum sp. B & & & Cf. & \\
\hline Equisetum sp. C & & & $\mathrm{Cf}$ & \\
\hline Equisetum sp. D & & & $\mathrm{Cf}$ & \\
\hline $\begin{array}{l}\text { Dictyophyllum (Clathropteroides) } \\
\text { obovata }\end{array}$ & & & $\mathrm{X}$ & \\
\hline Dictyophyllum (Clathropteroides) sp. & & & $\mathrm{X}$ & \\
\hline Goeppertella sp. A & & & $\mathrm{X}$ & \\
\hline Goeppertella sp. B & & & $\mathrm{X}$ & \\
\hline Goepertella sp. C & & & $\mathrm{X}$ & \\
\hline Todites sp. & & & $\mathrm{X}$ & \\
\hline Osmundopsis sp. & & & $\mathrm{Cf}$ & \\
\hline Microphyllopteris sp. & & & $X$ & \\
\hline Cladophlebis denticulada & & & $\mathrm{X}$ & \\
\hline Cladophlebis sp. A & & & $\mathrm{X}$ & \\
\hline Cladophlebis sp. B & & & $\mathrm{X}$ & \\
\hline
\end{tabular}


Ana Julia Sagasti - Estudio paleobotánico, paleoecológico y paleoambiental...

\begin{tabular}{|c|c|}
\hline Sphenopteris sp. A & $X$ \\
\hline Sphenopteris sp. B. & $\mathrm{X}$ \\
\hline Sphenopteris nordenskjöldii & $\mathrm{X}$ \\
\hline Weltrichia sp. & Cf. \\
\hline Zamites cf. gigas & $\mathrm{X}$ \\
\hline Zamites pusillus & $\mathrm{X}$ \\
\hline Sagenopteris nilssoniana & $\mathrm{X}$ \\
\hline Caytonanthus sp. & $\mathrm{X}$ \\
\hline Elatides sp. & $\mathrm{X}$ \\
\hline Araucaria cf. cutchensis & $\mathrm{X}$ \\
\hline Araucaria sp. A & $\mathrm{X}$ \\
\hline Araucaria sp. B & $\mathrm{X}$ \\
\hline Araucaria sp. C & $X$ \\
\hline Araucarites sp. & $\mathrm{X}$ \\
\hline Pararaucaria sp. & $\mathrm{X}$ \\
\hline Masculostrobus sp. A & $X$ \\
\hline Masculostrobus sp. B & $\mathrm{X}$ \\
\hline Elatocladus confertus & $\mathrm{X}$ \\
\hline Elatocladus casamiquelensis & $\mathrm{X}$ \\
\hline Brachyphyllum cf. lotenaense & $\mathrm{X}$ \\
\hline Pachypteris indica & $\mathrm{X}$ \\
\hline Pachypteris sp. & $\mathrm{X}$ \\
\hline
\end{tabular}

El registro para el Jurásico Medio se puede encontrar en las provincias de Neuquén, Chubut y Santa Cruz (Riccardi et al. 1990) (Tabla 4.2). En Neuquén se conocen megafloras fósiles para las localidades de Bajo de los Baguales (Menéndez, 1956), Plaza Huincul (Stipanicic y Bonetti, 1970), Picun Leufú (e.g. Orlando, 1946; Baldoni, 1977) y Mina La Perla (Baldoni, 1981). En Chubut, Cortés y Baldoni (1984) describen megafloras para la Formación Puelman en Estancia San José y Cañadón Asfalto en Puesto Vistosa. En Santa Cruz se registran varios afloramientos del Grupo Bahía Laura.

La tafoflora de Bajo de los Baguales fue estudiada por Menéndez (1956), quien reconoce Todites williamsoni (Brongniart) Seward, Cladophlebis denticulada (Brongniart) Fontaine y Elatocladus heterophyllus Halle. 
En la localidad Arroyo Picún Leufú (Neuquén), Orlando (1946) describe una flórula compuesta por las especies Otozamites simonatoi Orlando, Brachyphyllum sp., Taxites sp. y Cycadites sp. Posteriormente, Groeber et al. (1953) estudian restos vegetales a 50 y $125 \mathrm{~m}$ por debajo del piso de la Formación Lotena, se reconocen: Dictyophyllum sp., Cladophlebis sp., Sphenopteris sp., Ptylophyllum sp., Dictyozamites sp. y Williamsonia sp. Esta flora fue referida al Eocaloviano por su posición estratigráfica. Estos elementos están contenidos en sedimentos correspondientes a la Formación Lajas (Baldoni, 1981)

Frenguelli (1949) estudió restos vegetales hallados por Flores en la formación Cañadón Asfalto (Chubut) y reconoció: Equisetites approximatus Nathorst, Sphenopteris patagonica Halle, Sphenopteris hallei Frenguelli, Scleropteris cf. furcata Halle, Cladophlebis grahami Frenguelli, Pagiophyllum divaricatum y Araucarites cutchensis Feistmantel.

En 1963, Bonetti describe una flórula mesojurásica en el Cañadón del Zaino (Chubut) compuesta por los siguientes elementos: Cladophlebis denticulata (Brongniart) Fontaine, Cladophlebis cf. antarctica Nathorst, Clathropteris cf. kurtzi Frenguelli, Thaumatopteris sp., Sphenopteris nordenskjoldii Halle, Scleropteris furcata Halle, Sagenopteris nilssoniana (Brongniart) Ward, Otozamites sanctae-crucis Feruglio, Williamsonia cf. gigas (Lindley y Hutton) Carrhuters, Zamites cf. gigas Lindley y Hutton, Elatocladus confertus (Oldham y Morris) Halle, Pagiophyllum feinsmanteli Halle, Carpolithus sp. y ? Feruglioa sp. De la correlación de los restos descriptos surge una evidente relación con la flora fósil de Bahía Esperanza (Antártida), se le asigna una edad Jurásica Media y se incorpora a la Formación La Matilde. 
Ana Julia Sagasti - Estudio paleobotánico, paleoecológico y paleoambiental...

Tabla 4.2. Megafloras del Jurásico Medio de Argentina. Las especies que han sido asignadas con dudas en los respectivos estudios se señalan como "cf".

\begin{tabular}{|c|c|c|c|}
\hline Taxón Jurásico medio & $\begin{array}{l}\frac{\bar{d}}{\frac{D}{\partial}} \\
\frac{0}{\partial} \\
\frac{0}{z}\end{array}$ & $\begin{array}{l}\text { 苛 } \\
\frac{0}{2} \\
\frac{1}{0}\end{array}$ & 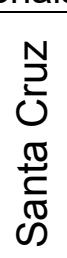 \\
\hline Carpolitthus sp & & $X$ & \\
\hline Taxites sp. & $\mathrm{X}$ & & \\
\hline Cycadites sp. & $X$ & & \\
\hline Gleichenites taquetrensis & & $X$ & \\
\hline Gleichenites juliensis & & & $X$ \\
\hline Osmundites patagonica & & & $\mathrm{X}$ \\
\hline Todites williamsoni & $X$ & & $\mathrm{X}$ \\
\hline Cladophlebis australis & & & $\mathrm{X}$ \\
\hline Cladophlebis denticulada & $\mathrm{X}$ & $\mathrm{X}$ & \\
\hline Cladophlebis indica & & & $\mathrm{X}$ \\
\hline Cladophlebis patagonica & & $\mathrm{X}$ & $X$ \\
\hline Cladophlebis antárctica & & $c f$ & Cf. \\
\hline Cladophlebis copiosa & & & Cf. \\
\hline Cladophlebis cf. kurtzi & & $\mathrm{X}$ & \\
\hline Cladophlebis grahami & & $X$ & \\
\hline Cladophlebis sp. & $\mathrm{X}$ & & \\
\hline Clathropteris obovata & & $\mathrm{X}$ & \\
\hline Scleropteris sp. a & & & $\mathrm{x}$ \\
\hline Scleropteris vincei & & & Cf. \\
\hline Scleropteris furcata & & $\mathrm{X}$ & \\
\hline Scleropteris lotenaensis & $X$ & & \\
\hline Scleropteris cf furcata & & $\mathrm{X}$ & \\
\hline Sphenopteris bagualensis & $X$ & & \\
\hline Sphenopteris delicatula & & & $\bar{X}$ \\
\hline Sphenopteris goeppertti & & & $X$ \\
\hline Sphenopteris hallei & & $\mathrm{X}$ & \\
\hline Sphenopteris patagonica & & $\mathrm{X}$ & $\mathrm{X}$ \\
\hline Sphenopteris picunleufuensis & $X$ & & \\
\hline
\end{tabular}


Ana Julia Sagasti - Estudio paleobotánico, paleoecológico y paleoambiental...

\begin{tabular}{|c|c|c|c|}
\hline Sphenopteris permira & $\mathrm{X}$ & & \\
\hline Sphenopteris sanjulianensis & & & $\mathrm{X}$ \\
\hline Sphenopteris nordenskjoldii & & $\mathrm{X}$ & \\
\hline Sphenopteris sp. & $\mathrm{X}$ & $\mathrm{X}$ & \\
\hline Thaumatopteris sp. & & $\mathrm{X}$ & \\
\hline Ptilophyllum antarcticum & & & $\mathrm{X}$ \\
\hline Ptilophyllum patagonica & & & $\mathrm{X}$ \\
\hline Ptilophyllum sp. & $\mathrm{X}$ & & \\
\hline Elatocladus casamiquelensis & & $\mathrm{X}$ & \\
\hline Elatocladus confertus & & $\mathrm{X}$ & $\mathrm{Cf}$ \\
\hline Elatocladus heterophyllus & $\mathrm{X}$ & & $\mathrm{X}$ \\
\hline Elatocladus longifolium & $\mathrm{X}$ & & \\
\hline Sagenopteris nilssoniana & $\mathrm{X}$ & $\mathrm{X}$ & \\
\hline Sagenopteris rhoifolia & & $\mathrm{X}$ & \\
\hline Otozamites barthianus & & & Cf. \\
\hline Otozamites bunburyanus var. major & & & $x$ \\
\hline Otozamites linearis & $\mathrm{X}$ & & \\
\hline Otozamites santaecrucis & & $\mathrm{X}$ & $\mathrm{X}$ \\
\hline Otozamites simonatoi & $\mathrm{X}$ & & \\
\hline Otozamites traversoi & $\mathrm{X}$ & & \\
\hline Otozamites waltonii & & & $\mathrm{X}$ \\
\hline Dictyozamites sp. & $\mathrm{X}$ & & \\
\hline Williamsonia of gigas & & $\mathrm{X}$ & \\
\hline Williamsonia sp. & $\mathrm{X}$ & & \\
\hline Equisetites sp. & & $\mathrm{X}$ & $\mathrm{X}$ \\
\hline Sagenopteris phillipsi & & & $X$ \\
\hline Sagenopteris sp. & $\mathrm{X}$ & & \\
\hline Coniopteris hymenophylloides & & & $\mathrm{X}$ \\
\hline Brachyphyllum feistmantellii & & $\mathrm{X}$ & $\mathrm{X}$ \\
\hline Brachyphyllum lotenaense & $\mathrm{X}$ & & \\
\hline Brachypyllum neuquinum & $\mathrm{X}$ & & \\
\hline Brachyphyllum ramosum & $\mathrm{X}$ & & \\
\hline Brachyphyllym sp. & $\bar{X}$ & & $\mathrm{X}$ \\
\hline
\end{tabular}


Ana Julia Sagasti - Estudio paleobotánico, paleoecológico y paleoambiental...

\begin{tabular}{|l|c|c|c|}
\hline Tomaxellia crassa & $\mathrm{X}$ & & \\
\hline Araucarites cutchensis & & $\mathrm{X}$ & $\mathrm{X}$ \\
\hline Araucarites mirabilis & & & $\mathrm{X}$ \\
\hline Araucarites sanctae-crucis & & & $\mathrm{X}$ \\
\hline Araucarites sp. & $\mathrm{X}$ & & $\mathrm{X}$ \\
\hline Equisetites minimus & & & $\mathrm{X}$ \\
\hline Equisetites approximatus & & $\mathrm{X}$ & \\
\hline Pagiophyllum divaricatum & & $\mathrm{X}$ & \\
\hline Pagiophyllum feistmantelii & & $\mathrm{X}$ & $\mathrm{X}$ \\
\hline Arthrotaxis ungeri & & & $\mathrm{X}$ \\
\hline ?Palissya confertus & & $\mathrm{X}$ & \\
\hline ?Palissya jabalpurensis & & $\mathrm{X}$ & \\
\hline Zamitescf gigas & & $\mathrm{X}$ & \\
\hline Zamites antarcticus & & & $\mathrm{X}$ \\
\hline Feruglioa sp. & & $\mathrm{X}$ & \\
\hline Hausmannia (Protorhipis) de ferrarisii & & & $\mathrm{X}$ \\
\hline Podocarpus palissyafolia & & & $\mathrm{X}$ \\
\hline Masculostrobus altoensis & & $\mathrm{X}$ \\
\hline Pararaucaria patagónica & & $\mathrm{X}$ \\
\hline Dictyophyllum sp. & & $\mathrm{X}$ \\
\hline Matonidium goepertii & & \\
\hline
\end{tabular}

Yacimientos del Jurásico Superior se conocen para las provincias de Chubut y Santa Cruz (Riccardi et al., 1990) (Tabla 4.3). En 1981, Baldoni estudia la tafoflora de "Mina La Perla", correspondiente a la Formación Lotena, y define: Scleropteris lotenaense, Otozamites traversoi, Brachyphyllum ramosum.

La tafoflora de la Formación Taquetrén (Jurásico Superior de la provincia de Chubut) fue estudiada por Bonetti (1963), Herbst y Anzótegui (1968) y Baldoni (1977). Esta flora está compuesta por: Cladophlebis denticulada (Brongniart) Fontaine, Gleichenites taquetrensis Herbst, Scleropteris furcata Halle, Araucarites sp., Cladophlebis cf. antarctica, Clathropteris obovata Oishi, Thaumathopteris sp., Sphenopteris nordenskjöldii Halle, Sagenopteris rhoifolia 
Ana Julia Sagasti - Estudio paleobotánico, paleoecológico y paleoambiental...

Presley, Archangelskya furcata (Halle) Herbst, Zamites pusillus Halle, Williamsonia cf. gigas, Zamites cf. gigas Lindley y Hutton, Elatocladus confertus (Oldham y Morris) Halle, Elatocladus casamiquelensis Herbst, Pagiophyllum feistmantelli y Equisetites sp.

En 1953, Calder publica los resultados del estudio del bosque petrificado de Cerro Cuadrado, donde se registran conos megasporangiados, maderas, ramas y renovales correspondientes a las especies Araucarites sanctaecrucis Calder, Araucaria mirabilis Spegazzini y Pararaucaria patagonica Wieland. En 1960, Menéndez describe conos microsporangiados de coníferas en la localidad Cerro Alto (probablemente Fm La Matilde), que designa como Masculostrobus altoensis. En 2009, Falaschi et al. describen una equisetal fértil para la Formación La Matilde que denominan Equisetites minimus.

En la localidad del Gran Bajo de San Julián, en la Provincia de Santa Cruz, Feruglio (1951) reconoce Hausmannia (Protorhipis) de-ferrariisii Feruglio, cf. Athrotaxis ungeri (Halle) Florin, escamas ovulíferas de Araucaria, Cladophlebis patagonica Frenguelli (vel australis Morris), Sphenopteris delicatula Feruglio, Ruffordia goepperti (Dunker) Seward, Otozamites sanctaecrucis Feruglio; Archangelsky y De la Sota (1962) describen un estípite petrificado asignable al género Osmundites. Herbst, (1962) define Gleichenites juliensis para esta localidad. Posteriormente, Herbst y Zalazar (1998) realizan una revisión de la flora colectada en esta localidad, identificando: Equisetites sp., Cladophlebis patagonica (Frenguelli) Herbst, Cladophlebis cf. antarctica (Nathorst) Halle, Cladophlebis cf. copiosa Frenguelli, Scleropteris sp. a, Scleropteris cf. vincei Herbst, Sphenopteris cf. delicatula Feruglio, Otozamites sanctae-crucis Feruglio, Otozamites cf. barthianus Kurtz, Otozamites bunburyanus var. major Kurtz, Zamites antarcticus Halle, Brachyphyllum sp., Sphenopteris sanjulianensis Feruglio, Ruffordia goeppertii (Dunker) Seward y Pagiophyllum sp. En lo que respecta al registro de maderas permineralizadas, se conocen una serie de estudios realizados en el Gran Bajo de San Julián (Gnaedinger, 2004; Gnaedinger y Herbst, 2006; Gnaedinger, 2007 a y b). Gnaedinger y Herbst (2006) identifican Prototaxoxylon intertrappeum Prakash y Srivastava, Prototaxoxylon uniseriale Prasad, y Prototaxoxylon acevedoae Gnaedinger y Herbst, todas ellas pertenecientes a la Familia Taxaceae. Gnaedinger (2007a) Podocarpoxylon feruglioi, Podocarpoxylon 
Ana Julia Sagasti - Estudio paleobotánico, paleoecológico y paleoambiental...

austroamericanum, Circoporoxylon sanjuliense y Circoporopitys argentinum, además propone la especie Circoporopitys shanense (Sahni) Gnaedinger. También en el Gran Bajo de San Julián, Gnaedinger (2007b) señala la presencia de Planoxylon australe (Salard) Vozenin-Serra Salard-Cheboldaeff, Protelicoxylon feriziense (Fahkr y Marguerier) Philippe y Herbstiloxylon patagonicum Gnaedinger. Gnaedinger (2012) describe restos de leños de Ginkgoales asignables a la especie Ginkgomyeloxylon tanzanii Giraud y Hankel.

Tabla 4.3. Megafloras del Jurásico Superior de Argentina. Las especies que han sido asignadas con dudas en los respectivos estudios se señalan como "cf".

\begin{tabular}{|c|c|c|}
\hline Taxón Jurásico superior & $\begin{array}{l}\frac{\hbar}{3} \\
\frac{0}{\partial} \\
\frac{1}{0}\end{array}$ & $\underset{\substack{\frac{\pi}{N}}}{\stackrel{N}{N}}$ \\
\hline Todites williamsoni & & $\mathrm{X}$ \\
\hline Archangelskya furcata & $\mathrm{X}$ & \\
\hline Cladophlebis denticulada & $\mathrm{X}$ & \\
\hline Cladophlebis cf. antarctica & $\mathrm{X}$ & $\mathrm{X}$ \\
\hline Cladophlebis patagonica & & $\mathrm{X}$ \\
\hline Cladophlebis cf. copiosa & & $X$ \\
\hline Cladophlebis sp. & & $\mathrm{X}$ \\
\hline Millerocaulis zamunerae & & $X$ \\
\hline Gleichenites juliensis & & $X$ \\
\hline Gleichenites taquetrensis & $\mathrm{X}$ & \\
\hline Clathropteris obovata & $\mathrm{X}$ & \\
\hline Sagenopteris rhoifolia & $\mathrm{X}$ & \\
\hline Ticoa magallánica & & $\mathrm{X}$ \\
\hline Otozamites cf. barthianus & & $\mathrm{X}$ \\
\hline Otozamites bunburyanus var. major & & $\mathrm{X}$ \\
\hline Otozamites sanctae-crucis & & $\mathrm{X}$ \\
\hline Cycadites sp & & $\mathrm{X}$ \\
\hline Pseudoctenis eathiensis & & $\mathrm{X}$ \\
\hline Dictyozamites cazaubonii & & $X$ \\
\hline Dictyozamites crassinervis & & $\mathrm{X}$ \\
\hline
\end{tabular}


Ana Julia Sagasti - Estudio paleobotánico, paleoecológico y paleoambiental...

\begin{tabular}{|c|c|c|}
\hline Dictyozamites falcatus & & $\mathrm{X}$ \\
\hline Dictyozamites inmamurae & & $\mathrm{X}$ \\
\hline Dictyozamites ishikawaensis & & $\mathrm{X}$ \\
\hline Dictyozamites latifolium & & $\mathrm{X}$ \\
\hline Pterophyllum barrealense & & $\mathrm{X}$ \\
\hline Zamites antarcticus & & $\mathrm{X}$ \\
\hline Zamites pusillus & $\mathrm{X}$ & \\
\hline Zamites cf. gigas & $X$ & \\
\hline Zamites sp. & & $\mathrm{X}$ \\
\hline Williamsonia cf. gigas & $\mathrm{X}$ & \\
\hline Ptilophyllum antarcticum & & $\mathrm{X}$ \\
\hline Cycadolepis involuta & & $X$ \\
\hline Brachyphyllum feistmanteli & & $X$ \\
\hline Araucarites chilensis & & $x$ \\
\hline Araucarites sp. & $\mathrm{X}$ & $\mathrm{X}$ \\
\hline Thaumathopteris sp. & $X$ & \\
\hline Hausmannia de-ferrariissii & & $\mathrm{X}$ \\
\hline Athrotaxis ungeri & & Cf. \\
\hline Sphenopteris delicatula & & $\mathrm{X}$ \\
\hline Sphenopteris sanjulianensis & & $\mathrm{X}$ \\
\hline Sphenopteris nordenskjöldii & $X$ & \\
\hline Sphenopteris cf. delicatula & & $\mathrm{X}$ \\
\hline Ruffordia goepperti & & $\mathrm{X}$ \\
\hline Osmundites & & $X$ \\
\hline Equisetum thermale & & $\mathrm{X}$ \\
\hline Equisetites sp. & $X$ & $X$ \\
\hline Scleropteris furcata & $\mathrm{X}$ & \\
\hline Scleropteris sp. A & & $\mathrm{X}$ \\
\hline Scleropteris cf. vincei & & $\mathrm{X}$ \\
\hline Elatocladus confertus & $\mathrm{X}$ & \\
\hline Elatocladus casamiquelensis & $\mathrm{X}$ & \\
\hline Brachyphyllum sp. & & $\mathrm{X}$ \\
\hline Pagiophyllum feistmantelli & $\mathrm{X}$ & \\
\hline
\end{tabular}


Ana Julia Sagasti - Estudio paleobotánico, paleoecológico y paleoambiental...

\begin{tabular}{|c|c|}
\hline Pagiophyllum sp. & $\mathrm{X}$ \\
\hline Pachypteris crassa & $\mathrm{X}$ \\
\hline Prototaxoxylon intertrappeum & $\mathrm{X}$ \\
\hline Prototaxoxylon uniseriale & $\mathrm{X}$ \\
\hline Prototaxoxylon acevedoae & $\mathrm{X}$ \\
\hline Podocarpoxylon feruglioi & $\mathrm{X}$ \\
\hline Podocarpoxylon austroamericanum & $\mathrm{X}$ \\
\hline Circoporoxylon sanjuliense & $\mathrm{X}$ \\
\hline Circoporopitys argentinum & $\mathrm{X}$ \\
\hline Circoporopitys shanense & $\mathrm{X}$ \\
\hline Planoxylon feriziense & $\mathrm{X}$ \\
\hline Herbstiloxylon patagonicum & $\mathrm{X}$ \\
\hline Ginkgomyeloxylon tanzanii & $\mathrm{X}$ \\
\hline Podocarpus palissyafolia & $\mathrm{X}$ \\
\hline Araucarites mirabilis & $\mathrm{X}$ \\
\hline Agathoxylon matildense & $\mathrm{X}$ \\
\hline
\end{tabular}

Diversos autores (e.g. ver Baldoni 1981) estudiaron los bosques petrificados de la Formación La Matilde. Entre los elementos descriptos en los bosques in situ, se reconocen: Podocarpus palissyafolia (Berry) Florin, Araucarites mirabilis (Spegazzini) Florin, Agathoxylon matildense Zamuner y Falaschi, Prototaxoxylon intertrappeum Prakash y Sriastava, Prototxoxylon uniseriale Prasad, Prototaxoxylon acevedoae Gnaedinger y Herbst, entre otros.

\section{Floras estudiadas en ambientes con influencia geotérmica del Macizo del Deseado.}

El sistema geotérmico del Macizo del Deseado ha sido extensamente estudiado en función de su geología y mineralogía, debido a las aplicaciones económicas de los yacimientos metalíferos (e.g. Schalamuk et al., 1997, 1999a, 1999b; Guido et al., 2010; Guido y Campbell, 2011). Sin embargo, los estudios sobre yacimientos fósiles vinculados a los ambientes de hot-spring han tomado relevancia recién en los últimos diez años. 
Ana Julia Sagasti - Estudio paleobotánico, paleoecológico y paleoambiental...

En 2007, Channing et al. realizan un estudio preliminar de la Localidad Laguna Flecha Negra, que sienta el precedente para el desarrollo de esta Tesis Doctoral.

En el yacimiento aflorante en San Agustín, Channing et al. (2011) definen la especie Equisetum thermale a partir de numerosos ejes preservados como permineralizaciones con gran detalle anatómico, en los niveles de chert allí registrados. Zamuner et al. (2011) señalan la presencia de Pachypteris crassa, Dictyozamites falcatus, Araucarites cutchensis, Brachyphyllum sp. y Equisetum aff. E. thermale. En esta misma localidad, García Massini et al. (2012a) describen restos de coelomycetes, Microthyriales (ascomicetes) y una diversidad de hongos, quitridiomicetes, protistas y estructuras similares a ellos como parásitos en Equisetum y asociados a plantas en descomposición y coprolitos de artrópodos.

En los depósitos aflorantes en la localidad de La Bajada se registra un ambiente geotérmico correspondiente a la Formación La Matilde, en el que se han descripto restos de Osmundales del género Cladophlebis y la especie Millerocaulis zamunerae (Sagasti et al., 2016). En esta misma localidad, García Massini et al. (2016) registran una flora con elementos asignables al género Equisetum, fragmentos de Araucariaceae y Cheirolepidiaceae, así como también estructuras reproductivas y vegetativas de hongos, oomycetes, cianobacterias, algas, amebas terrestres, ciliados y restos de afinidad taxonómica incierta. Los organismos aparecen como entidades dispersas en la matriz silícea y asociados simbióticamente a plantas y otros restos orgánicos.

\section{Estudios previos de la Flora Fósil de la Formación Chon Aike.}

Dentro del cuadro estratigráfico del Grupo Bahía Laura, la mayor cantidad de estudios paleobotánicos se ha desarrollado en afloramientos de la Formación La Matilde, especialmente en relación a los bosques petrificados de la Patagonia (e.g. Spegazzini, 1924; Wieland, 1929; Frenguelli, 1933; Zamuner y Falaschi, 2005; Falaschi, 2009; Falaschi et al., 2011). Para la formación Chon Aike, de Barrio et al. (1982) describen una flora de impresiones de hojas en los alrededores de la Estancia Bajo Pellegrini en la que reconocen: Cycadites sp., 
Ana Julia Sagasti - Estudio paleobotánico, paleoecológico y paleoambiental...

Pseudoctenis eathiensis (Richards) Seward, Dictyozamites cazaubonii Archangelsky y Baldoni, Dictyozamites crassinervis Menéndez emend de Barrio, Arrondo, Artabe y Petriella, Dictyozamites falcatus (Morris) Oldham, Dictyozamites inmamurae Oishi y Kimura, Dictyozamites ishikawaensis Kimura y Sekido, Dictyozamites latifolium Menéndez y Pterophyllum barrealense Frenguelli y Bonetti. Estos autores señalan que la tafoflora analizada sería equiparable a la de Rajmahal Hill de India y la de Utano de Japón, ambas meso a suprajurásicas. La composición de esta flora muestra una baja diversidad, tanto genérica como a nivel de grupos, en comparación con las megafloras conocidas para la formación La Matilde. En este sentido, esta Tesis Doctoral contribuye al conocimiento de las floras de la Formación Chon Aike a partir del estudio de la localidad Laguna Flecha Negra. 


\section{Materiales y métodos}

\section{Área estudiada.}

Los análisis se desarrollaron en la localidad Laguna Flecha Negra, región situada alrededor de los $69^{\circ} \mathrm{W}$ y de los $47^{\circ} \mathrm{S}$, en el Macizo del Deseado. Aproximadamente $100 \mathrm{~km}$ al NNE de Gobernador Gregores, provincia de Santa Cruz, Argentina (Fig. 5.1 y 5.2).

Esta zona, encuadrada en la carta topográfica 4969-I (Gobernador Gregores) en escala 1:250.000 (Panza y Marín, 1998), se encuentra en los alrededores de la Estancia El Fénix y es referida también como la Laguna de Los Troncos. Las sedimentitas estudiadas pertenecen al Complejo Bahía Laura, constituido, de base a techo, por las Formaciones Bajo Pobre, Chon Aike y La Matilde. Se analizaron las rocas que conforman la Formación Chon Aike y las plantas fósiles contenidas en ellas.

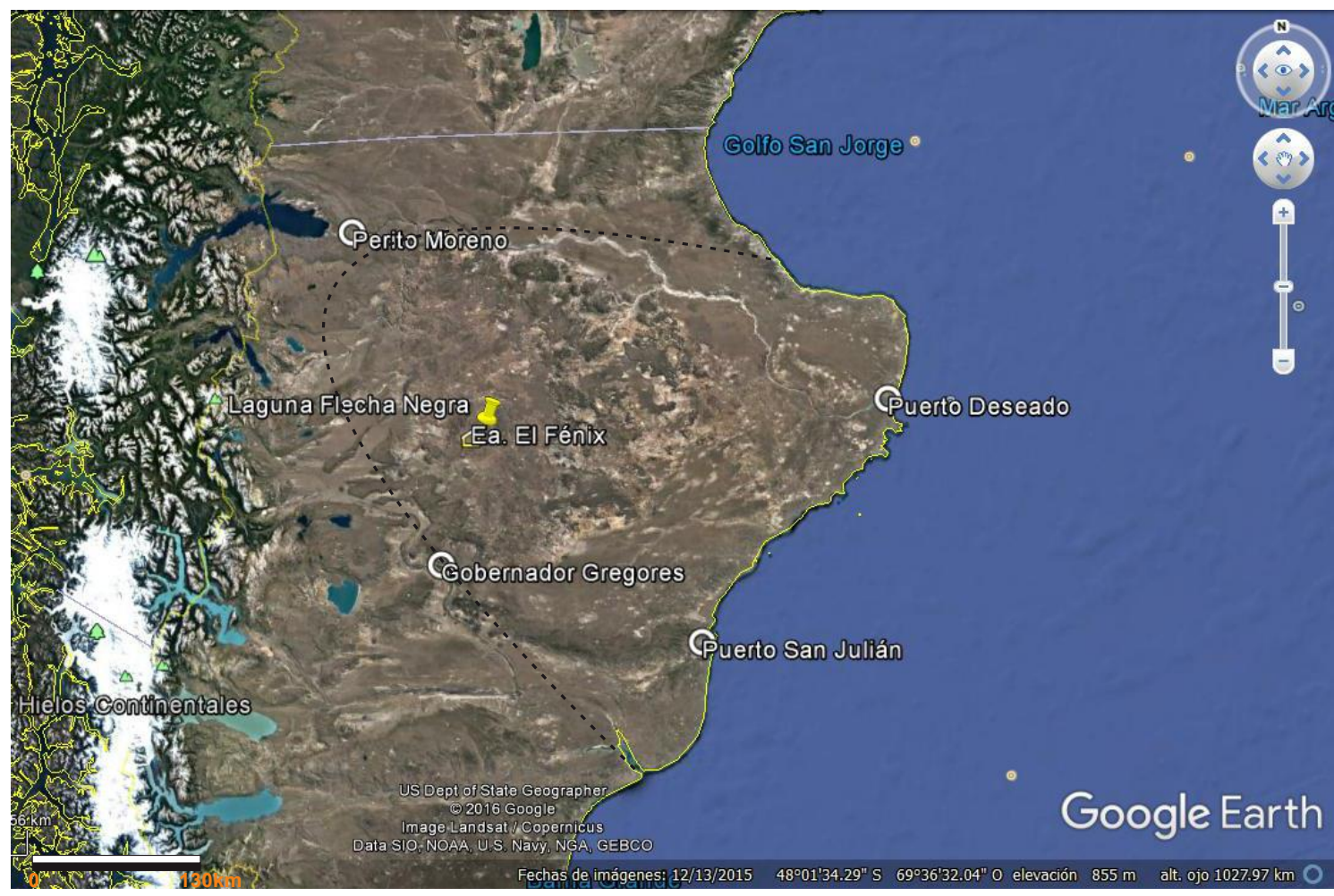

Figura 5.1. Mapa del Macizo del Deseado mostrando la ubicación de la localidad Laguna Flecha Negra. Modificado de Google Earth Pro (2017). 
Ana Julia Sagasti - Estudio paleobotánico, paleoecológico y paleoambiental...
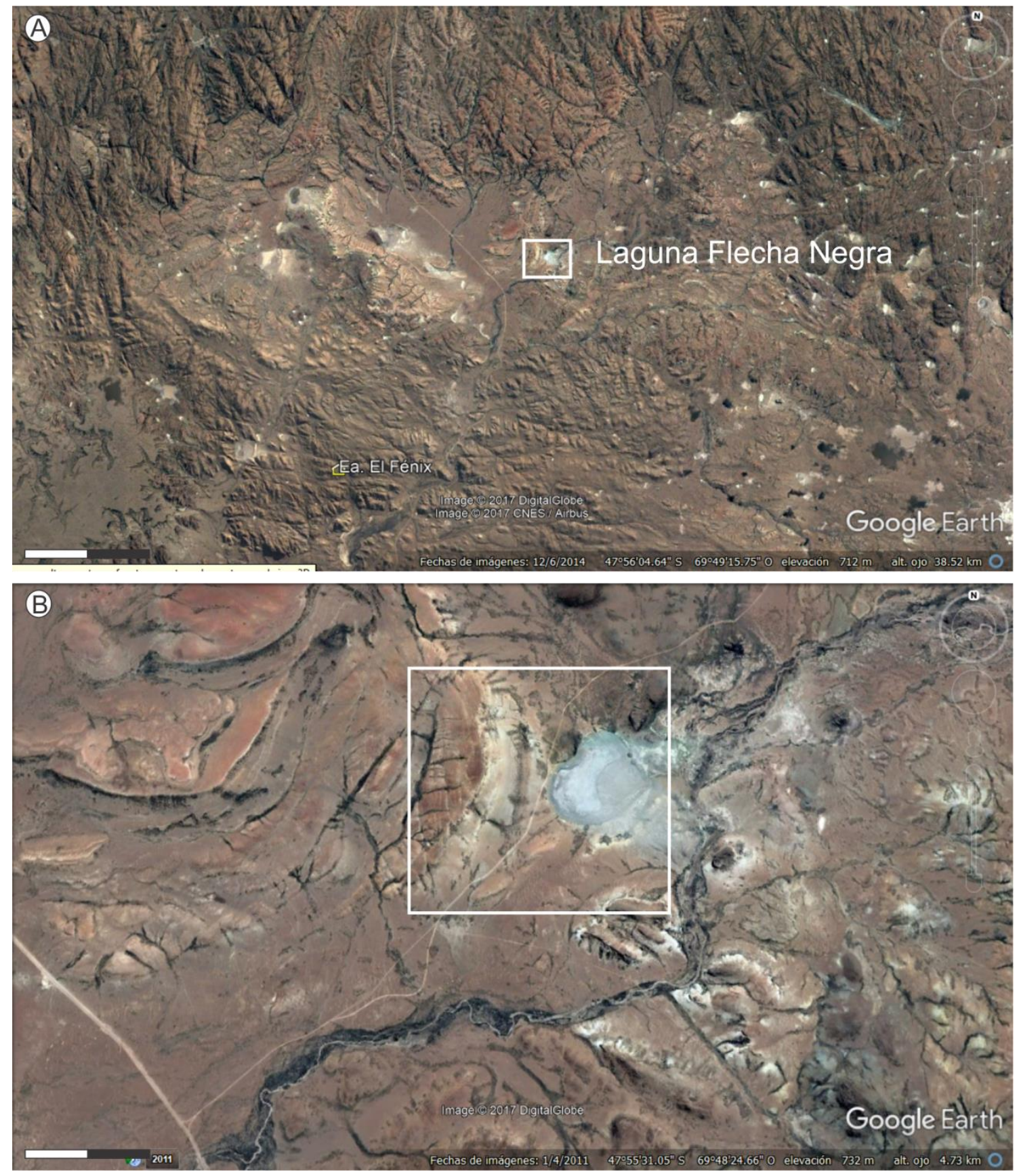

Figura 5.2. Mapas de ubicación de la localidad Laguna Flecha Negra. A. Posición respecto de la Estancia El Fénix. Escala: $6 \mathrm{~km}$ B. Detalle de la localidad Laguna Flecha Negra y sus accesos. Escala: 800 m. Modificado de Google Earth Pro (2017).

\section{Tareas efectuadas en el campo.}

Se realizó un viaje de campo al área de estudio (27 de febrero al 3 de marzo de 2014), integrado por el Dr. Juan L. García Massini, el Dr. Ignacio H. Escapa, la Dra. Josefina Bodnar, el Lic. Andrés Elgorriaga y quién escribe. En 
primer lugar, se reconocieron los sitios donde están expuestas las formaciones Bajo Pobre y Chon Aike, se precisó su ubicación mediante instrumental de Sistema de Posicionamiento Global (GPS) y se sacaron fotos de las vistas generales con cámara fotográfica Lumix Panasonic. Para completar el análisis regional de la formación Chon Aike, se relevó y esquematizó la columna estratigráfica general, reconociendo el contacto con la unidad infrayacente, y los niveles fosilíferos aflorantes.

Se realizó un examen detallado de la Formación Chon Aike, para el cual se levantó el perfil sedimentológico en la localidad Laguna Flecha Negra, teniendo en cuenta granulometría, color, composición, estructuras sedimentarias primarias y geometría de los cuerpos, así como también los contactos y pasajes verticales entre los cuerpos de roca sucesivos; y el contenido paleontológico. En este perfil se reconocieron los estratos portadores de impresiones-compresiones y permineralizaciones vegetales mencionados en el estudio preliminar de la localidad realizado por Channing et al. (2007). Estos niveles fueron muestreados en cuanto a la diversidad fosilífera $y$ condiciones tafonómicas (estado de preservación, abundancia y densidad de los fósiles). En total, se obtuvieron 112 ejemplares de restos vegetales fosilizados como impresiones-compresiones, 135 muestras de permineralizaciones individuales y en masa y 25 fragmentos de tocones colectados en el bosque in situ. Las impresiones-compresiones fueron extraídas de las rocas por medio de cinceles y piqueta, se envolvieron con papel, cinta adhesiva y bolsas de nylon y fueron rotuladas según el nivel de origen y el número de colección en campo. De las permineralizaciones se obtuvieron fragmentos mediante cortafierros, piqueta y martillos. De los ejemplares colectados se detalló: tipo de fosilización, nivel dentro del perfil, tipo de órgano o parte de la planta preservada y determinación sistemática preliminar.

Se identificó un nivel de bosque in situ (en posición de vida) que fue relevado y mapeado con GPS. Se midió el diámetro de los ejemplares, y se observó el estado general de los ejemplares, identificando tocones caídos y en posición de vida. Se reconoció el carácter autóctono de los individuos que conformaron esta paleocomunidad y se tomaron 25 muestras para el estudio en gabinete. 
Ana Julia Sagasti - Estudio paleobotánico, paleoecológico y paleoambiental...

\section{Tareas en laboratorio y gabinete}

\section{Preparación e ilustración del material}

Sedimentitas: los datos de GPS colectados en el viaje de campo, más la información tomada de mapas geológicos previos e imágenes de Google Earth Pro (@Google Earth Pro, 2017) permitieron ubicar con precisión la localidad muestreada. El perfil sedimentológico relevado fue ilustrado con el programa CorelDraw X7, en una escala de 1:250.

Fósiles: el material fósil colectado fue preparado según el tipo de fosilización. Las impresiones-compresiones fueron limpiadas mecánicamente con cinceles y agujas. Para resaltar la venación en algunos ejemplares se los sumergió en agua a la hora de tomar las fotografías. Para ilustrar los ejemplares, se los fotografió con cámara digital Canon EOS 6D con un lente Canon EF 24-70 mm LII USM, distancia focal de $70 \mathrm{~mm}$ e ISO $=100$. En los casos que fue necesario resaltar caracteres de los materiales, se realizaron dibujos sobre las fotografías utilizando software CorelDraw X7.

Los ejemplares permineralizados son de composición silícea y presentan una calidad de preservación variable. La histología en detalle se estudió mediante la realización de cortes delgados petrográficos en los tres planos básicos usados en histología vegetal (Transversal, Longitudinal Radial y Longitudinal Tangencial). Los materiales fueron cortados en rodajas con una sierra con cuchilla metálica de borde diamantado, se realizó un pulido con polvos abrasivos (carborundum: carburo de silicio) de tamaño de grano decreciente, posteriormente fueron montados sobre portaobjetos con un adhesivo firme de tipo epoxi-resina. Cada sección se pulió y rebajó hasta un espesor que permitiera la observación por transparencia bajo el microscopio óptico (entre 30 y $40 \mu \mathrm{m}$ ). Parte de los cortes fueron cubiertos con epoxi-resina y cubreobjetos. Las permineralizaciones individuales de tallos tienden a la fractura cuando se realizan los cortes, es debido a ello que no se han podido recuperar los tres planos de corte en algunos de los ejemplares. Los cortes fueron estudiados con microscopio óptico Leica DM2500 y fotografiados con cámara digital Leica DMC2900 utilizando el software Leica Application Suite 
V.4.8.0. Con las fotografías se confeccionaron láminas utilizando programas de software Adobe Photoshop CS6 y CorelDraw X7. Para la confección de ilustraciones de anatomía de detalle y presencia de microorganismos, se editaron las fotos con la técnica de photo-stacking (Piper, 2010) con software Adobe Photoshop CS6. Los cortes fueron realizados por el Técnico Ricardo Ponti, el laboratorio de Petrotomía del Museo de La Plata y el Técnico Sergio de la Vega del Centro Regional de Investigaciones Científicas y Transferencia Tecnológica de La Rioja (CRILAR-CONICET).

Los materiales megascópicos y microscópicos serán depositados luego de su estudio, en la Colección de Paleobotánica del Museo Padre Jesús Molina de la provincia de Santa Cruz, bajo las siglas MPM-PB 15829-15959. Además de estos materiales, se revisaron fósiles recolectados en la misma localidad y estudiados preliminarmente por Channing et al. (2007), que serán igualmente depositados en la Colección de Paleobotánica del Museo Padre Jesús Molina (MPM-PBXXX a MPM-PBXX1).

\section{Análisis y determinación del material}

Sedimentitas: para la definición de facies sedimentarias se utilizó el criterio de Walker (1992), Reading y Level (1996); Scasso y Limarino (1997) y Miall (2006). Para el análisis e interpretación de las asociaciones de facies, se utilizó el criterio de Guido (2004).

Fósiles: para la descripción de las expansiones laminares y estructuras reproductivas (impresiones-compresiones) se aplicaron los términos brindados por el diccionario de botánica de Font Quer (1982, 2000). Para el estudio de los troncos (permineralizaciones) se empleó la terminología de los glosarios de anatomía de maderas (Eckhold, 1921; Boureau, 1956; Richter et al., 2004), y el atlas de anatomía de maderas de Greguss (1955). La medida de los distintos elementos morfológicos y anatómicos se obtuvo en base a un registro de 30 mediciones. Para los materiales megascópicos se utilizaron reglas y calibres para medir sobre el fósil, o mediante mediciones sobre las fotografías usando software de CorelDraw X7. Para realizar las mediciones sobre los cortes 
Ana Julia Sagasti - Estudio paleobotánico, paleoecológico y paleoambiental...

petrográficos se utilizó el software Leica Application Suit V.4.8.0 de la cámara Leica DMC2900.

Para el tratamiento nomenclatural se utilizó el International Code of Nomenclature for algae, fungi and plants (Melbourne Code, McNeill et al., 2012), el International Code of Phylogenetic Nomenclature (Cantino y de Queiroz, 2010; Cantino et al. 2007) y el Indices Nominum Supragenericorum Plantarum Vascularium (Reveal, 2007). Los criterios sistemáticos supragenéricos fueron tomados de Archangelsky (1970), Stewart y Rothwell (1993), Kenrick y Crane (1997), Smith et al. (2006), Taylor et al. (2009). Los taxones fósiles de maderas de coníferas fueron clasificados siguiendo la propuesta de Philippe y Bamford (2008).

\section{Terminología utilizada.}

Para la descripción de los elementos anatómicos diagnósticos de maderas gimnospérmincas, se utilizaron los glosarios de términos utilizados para describir maderas (Eckhold, 1921; Boureau, 1956; Richter et al., 2004) y el atlas de anatomía de maderas de Greguss (1955). Las punteaduras de las paredes radiales de las traqueidas son caracterizadas en el leño temprano. Se clasifican en primer instancia, considerando la cantidad de series: una, o dos o más series por traqueida. En el caso de observarse más de una serie, se tiene en cuenta el arreglo de las punteaduras. Éste puede ser: opuesto (e.g. especies de Larix en las Pinaceae, múltiples géneros de Cupressaceae), o alternas (ocurre normalmente en géneros de la familia Araucariaceae, para el caso de las Pinaceae con arreglo alterno, pueden distinguirse por su borde generalmente redondeado y su mayor tamaño en comparación con Araucariaceae) (Fig. 5.3).

Las punteaduras araucarioides corresponden a punteaduras areoladas dos o más veces seriadas, alternas y comprimidas, tomando una forma aproximadamente hexagonal (Eckhold, 1921; Boureau, 1956; Philippe y Bamford, 2008). Es uno de los tipos de punteadura más antiguos, pudiendo encontrarse en Pteridospermas, Cordaitales y géneros de la familia Araucariaceae (Boureau, 1956). Raramente, se observa en los géneros Cedrus y Podocarpus, pero caracteriza principalmente, maderas extintas, 
Ana Julia Sagasti - Estudio paleobotánico, paleoecológico y paleoambiental...

particularmente mesozoicas, donde puede asociarse con punteaduras abietinoides, conformando un arreglo de punteaduras mixtas (Boureau, 1956).

El término abietinoide se utiliza para referirse a punteaduras areoladas de contorno redondeado, espaciadas, uniseriadas, cuando biseriadas opuestas, nunca comprimidas. Las cuales pueden o no, presentar barras de Sanio y que se observan en leños homoxilados de coníferas (Eckhold, 1921; Boureau, 1956; Philippe y Bamford, 2008). 
Ana Julia Sagasti - Estudio paleobotánico, paleoecológico y paleoambiental...
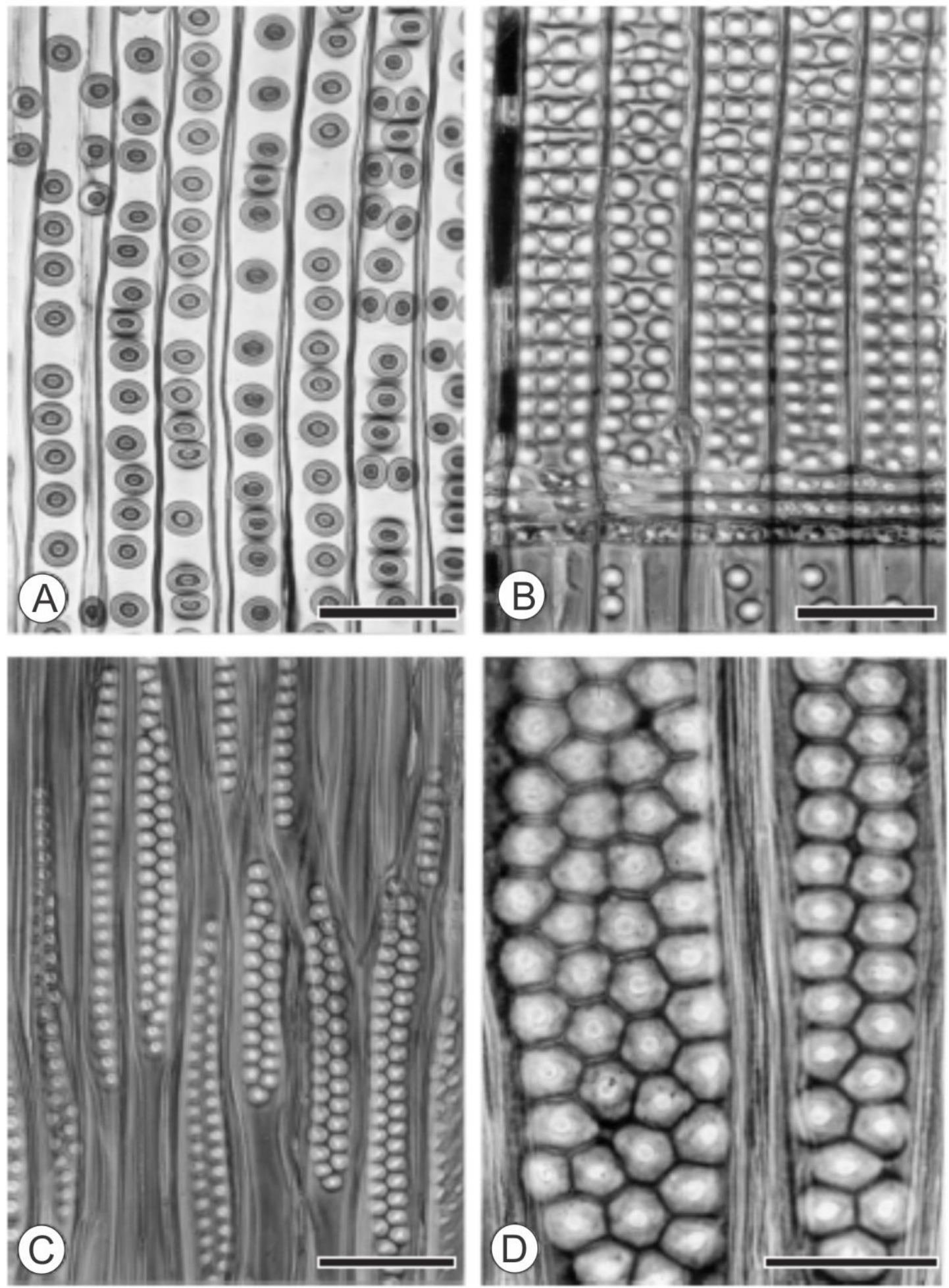

Figura 5.3. Tipos de punteaduras en las paredes radiales de las traqueidas. A. Traqueidas mayormente uniseriadas, Pinus sylvestris. Escala: $100 \mu \mathrm{m}$. B. Traqueidas

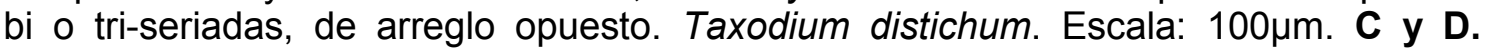
Traqueidas bi- a n-seriadas, de arreglo alterno. Araucaria angustifolia. Escalas: 7.

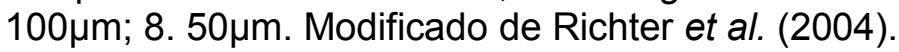

Con punteaduras mixtas, se refiere a un arreglo observado en los leños coniferofíticos, en los que se encuentran punteaduras radiales araucarioides y 
abietinoides en distintas zonas del mismo leño (Eckhold, 1921; Boureau, 1956; Philippe y Bamford, 2008). Este tipo de punteaduras caracteriza al grupo de las "Protopinaceae".

Finalmente, se reconocen las punteaduras de tipo Xenoxylon, en las cuales se puede observar un arreglo de punteaduras areoladas uniseriadas, fuertemente comprimidas, tomando una forma rectangular, dos veces más anchas que altas (Müller-Stoll, 1951; Philippe y Bamford, 2008).

En los leños de gimnospermas, la configuración de los campos de cruzamiento es fundamental para la asignación sistemática de los taxones. Se define un campo de cruzamiento como el área delimitada por la intersección de las paredes de una traqueida axial con las paredes de una célula radial, y deben observarse en el leño temprano (Richter et al., 2004). La superposición de la/s punteadura/s areolada/s de las traqueidas, con la/s punteadura/s simples de las células parenquimáticas, genera una punteadura compleja de morfología diferente a la de las punteaduras independientes de cada célula. La tabla 5.1 resume los diferentes tipos de campos de cruzamiento que pueden observarse en leños de gimnospermas, señalando sus variantes y afinidades sistemáticas. 


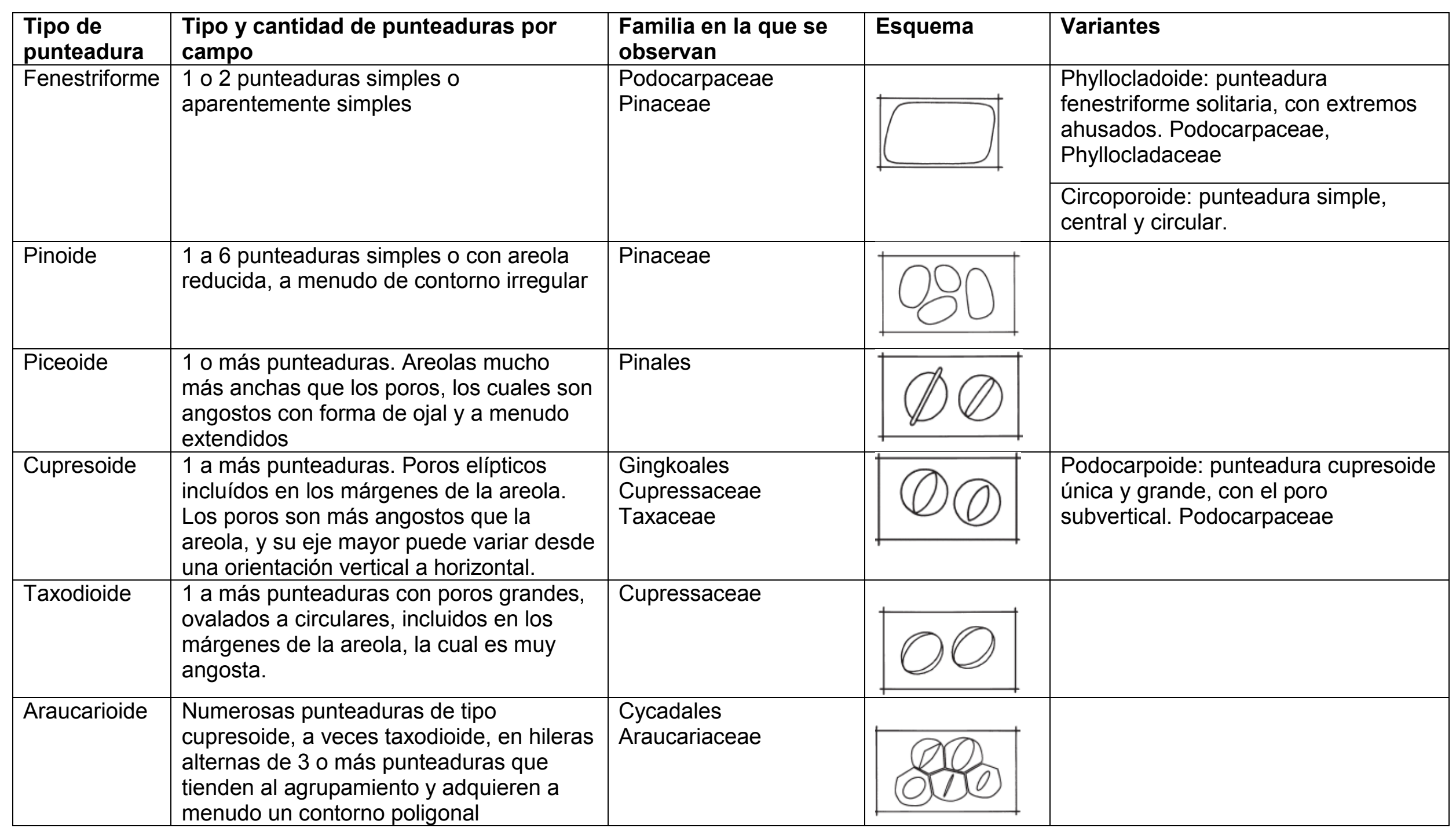

Tabla 5.1. Tipos de campos de cruzamiento observados en el leño temprano de Gimnospermas (Richter et al., 2004). 
Ana Julia Sagasti - Estudio paleobotánico, paleoecológico y paleoambiental...

\section{Interacciones multitróficas en leños degradados.}

Se realizaron cortes seriados de un leño de Araucariaceae, en los tres planos anatómicos utilizados en maderas (transversal, longitudinal radial y longitudinal tangencial). El leño preserva evidencias de degradación de sus tejidos y galerías excavadas en el xilema secundario. Se estudiaron los distintos patrones de degradación y se compararon con aquellos producidos por hongos xilófagos en la actualidad, siguiendo el criterio de Schwarze et al. (2007). Para la comparación de filamentos y estructuras reproductivas fósiles de hongos y bacterias se utilizaron Fossil Fungi (Taylor et al., 2015) y The Prokaryotes (Dworkin et al., 2006). Las trazas producto de la actividad de artrópodos fueron analizados siguiendo el criterio de Genise (1995) y Grimaldi y Engel (2005).

\section{Estudios tafonómicos y paleoecológicos}

Los tipos de fósiles se clasificaron siguiendo el criterio de Archangelsky (1970), Willis y McElwain (2002) y Taylor et al. (2009). Para la definición de tafofacies, se aplicó una combinación de códigos de letras para los estilos preservacionales y las litofacies siguiendo el criterio de Speyer y Brett (1986, 1988), Guido (2004) y Colombi y Parrish (2008). Se consideraron los siguientes atributos: facies sedimentarias, tipo de fosilización, densidad y grado de fragmentación. Se compararon con los modelos sedimentarios de ambientes geotermales del Macizo del Deseado de Guido et al. (2010), Guido y Campbell (2011); y con el análisis de Channing y Edwards (2013) para ambientes geotermales modernos.

\section{Reconstrucción ecológica de las paleocomunidades.}

La definición de las paleocomunidades se realizó teniendo en cuenta las tafocenosis preservadas. Se siguió la metodología aplicada por Artabe et al. (2001): a) asignación sistemática del material, b) determinación de hábitos de 
vida, c) abundancia y, d) tipo de preservación. La clasificación de la vegetación se realizó utilizando un criterio fisionómico-estructural.

Para el análisis estructural del bosque se realizó un análisis de la estructura horizontal y densidad con el programa de software QGis (V.2.18.11). Para los cálculos de altura se aplicaron las ecuaciones de Niklas (1993, 1994a y b).

Se evaluaron los cambios en la diversidad de las paleofloras de yacimientos Jurásicos y sus variaciones en las distintas épocas. Para ello se realizó una matriz de presencia/ausencia de taxones por provincia y por época del Jurásico, utilizando el software PAST (Hammer et al., 2001). Aquellos taxones citados como "confer" fueron considerados como presencias. Con el uso de la herramienta "Curvas de Diversidad" del paquete "Strat", se evaluó la abundancia de especies. Finalmente se graficaron las curvas de diversidad con el uso del software Excell (2010). 


\section{Marco geológico}

\section{Sistema geotérmico del Jurásico de Santa Cruz.}

Durante el Jurásico Medio a Tardío se desarrollaron eventos de extensión, magmatismo y un alto gradiente térmico produciendo las volcanitas del Grupo Bahía Laura. Adicionalmente, este evento en el Macizo del Deseado generó mineralización hidrotermal, que incluye numerosos hot-springs desarrollados en extensos campos geotermales (Guido y Schalamuk, 2003; Guido y Campbell, 2011).

Los depósitos de hot-springs del Macizo del Deseado comprenden mayormente travertinos (precipitado químico de composición carbonática), algunos sinters (de composición silícea) y cherts silíceos generados por la actividad geotérmica, alojados en tobas, brechas y sedimentos volcaniclásticos retrabajados por ambientes fluviolacustres en un área de $230 \times 230$ km (Guido y Campbell, 2011). Estas rocas fueron posteriormente cubiertas por una sucesión de sedimentos cretácicos y cenozoicos, formados en ambientes continentales y de margen marino pasivo que se exhumaron con mínima alteración estructural para exponer los depósitos epitermales en una amplia área del Macizo del Deseado (Guido et al., 2010).

Los hot-springs terrestres se desarrollan en áreas topográficamente bajas donde el nivel freático intercepta la superficie, a partir de sistemas hidrotermales que típicamente poseen manifestaciones en superficie (Sillitoe, 1993). Se producen principalmente en regiones volcánicamente activas donde la actividad hidrotermal también puede formar depósitos metalíferos en profundidad (Sillitoe, 1993). Los fluidos geotérmicos son emitidos a partir de conductos o spring vents en la superficie terrestre, enfriándose a medida que son emitidos $\left(\sim 100^{\circ} \mathrm{C}\right.$ a ambiente) a través de canales, hacia piletones, terrazas y desbordando distalmente conformando una zona pantanosa con influencia geotérmica, mientras mineraliza y entrampa materiales bióticos o abióticos interceptados por el flujo (Walter, 1976; Guido y Campbell, 2011; Guido et al., 2010).

La mayor parte de los depósitos hidrotermales del Macizo del Deseado se sitúan en la zona oeste de esta provincia geológica (Guido y Schalamuk, 
Ana Julia Sagasti - Estudio paleobotánico, paleoecológico y paleoambiental...

2003), con algunos asomos en los límites norte y sur (Guido y Campbell, 2011). Hasta el momento se conocen veintitrés localidades con depósitos de hotsprings del Jurásico, dentro de las cuales se cuenta a la localidad Laguna Flecha Negra, objeto de esta Tesis.

\section{Geología de la localidad Laguna Flecha Negra}

La flora registrada en la localidad Laguna Flecha Negra se encuentra contenida en sedimentos fluviales, lentes de chert y tobas riolíticas (Fig. 6.1). La secuencia reconocida comienza con un domo andesítico atribuido a la Formación Bajo Pobre. El tope de la secuencia está cubierto al norte y al oeste por la Ignimbrita Flecha Negra (Echeveste et al., 2001) que representa el miembro más joven de la Formación Chon Aike en esta localidad.

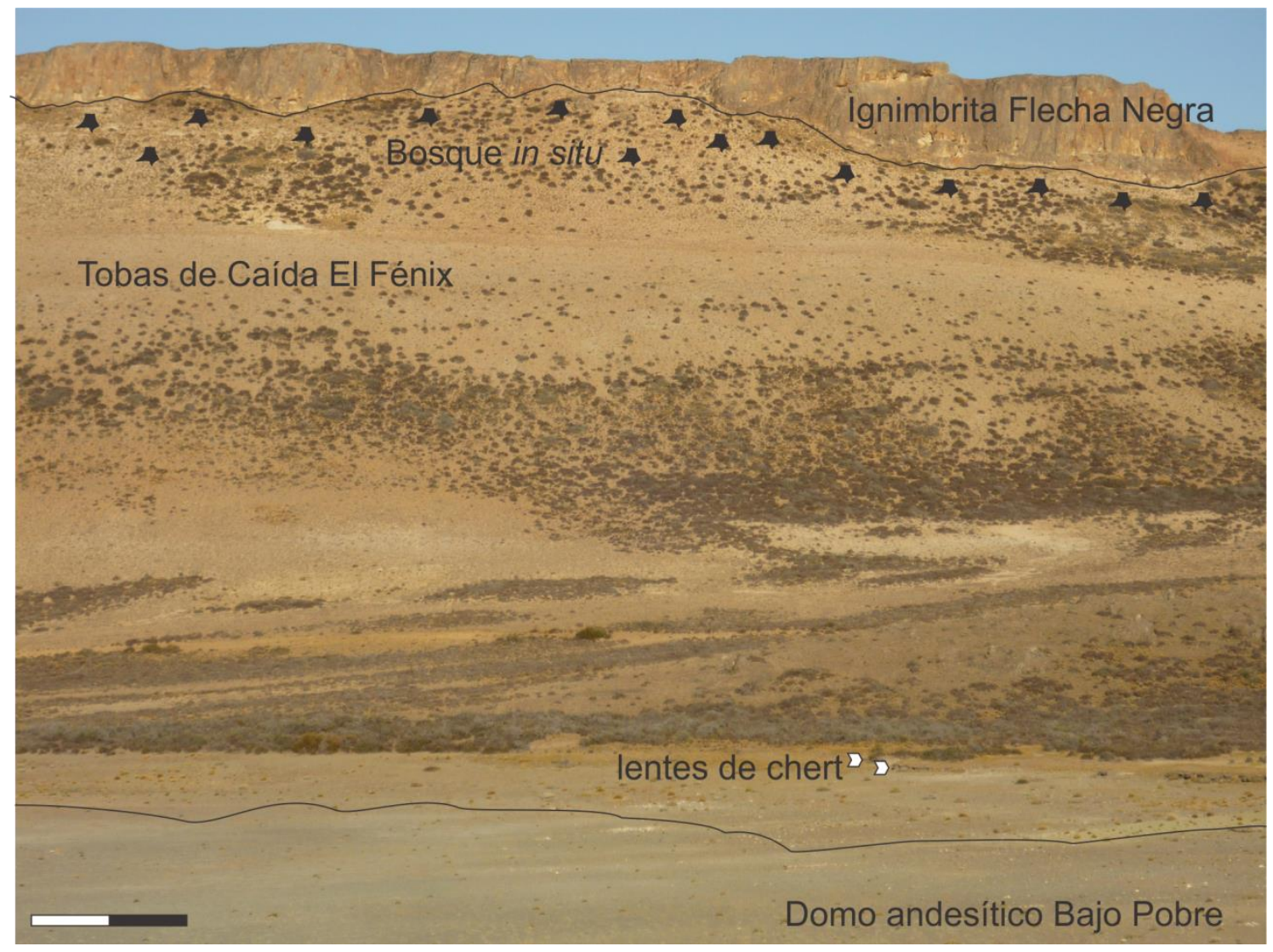

Figura 6.1. Barranca oeste de la localidad Laguna Flecha Negra. Escala: $15 \mathrm{~m}$. 
Ana Julia Sagasti - Estudio paleobotánico, paleoecológico y paleoambiental...

\section{Sucesión volcaniclástica de base a techo (Figura 6.2).}

Base. Lavas andesíticas con presencia sectorizada de xenolitos angulares básicos. Alteración desde biotitas degradadas hasta fragmentos lávicos verdeazulados. Márgenes intensamente meteorizados.

Disconformidad marcada.

12,5 m de areniscas gruesas masivas, blancuzcas. Meteorización marcada por un moteado anaranjado. Clastos volcánicos angulosos y cristales de feldespato erosionados. Dos lentes de chert de $20 \mathrm{~cm}$ de espesor, interdigitados con areniscas con raíces permineralizadas. Impresiones y moldes de maderas, y fragmentos de ejes permineralizados de tamaño medio.

$5 \mathrm{~m}$ de areniscas finas y limolitas oscuras. Base de limolitas gris oscuro con laminación fina paralela (1-3 mm). Sigue con paquetes de 10-35 mm, granodecrecientes de arena fina a limo con laminación entrecruzada que se hace paralela hacia el tope. Superficies de estratificación con clastos volcánicos fuertemente meteorizados, partículas de ceniza y escamas de mica. Flora de impresiones-compresiones muy bien preservada.

$15 \mathrm{~m}$ de tobas blancas masivas. Granodecrecientes desde tobas gruesas a finas, rematando en horizontes delgados con abundancia de lapilli. El tope de la unidad preserva un bosque permineralizado en posición de vida asociado con escasas impresiones de ramas portando pocas hojas.

$12,5 \mathrm{~m}$ de ignimbrita riolítica, rosada que yace generando una inconformidad con los sedimentos subyacentes.

La secuencia aflorante comienza con una serie de lavas que forman parte del complejo andesítico Bajo Pobre. Al este de la laguna, las lavas contienen xenolitos angulares de composición básica, mientras que al oeste se observan lavas masivas sin xenolitos. El margen oeste se encuentra bastante 
Ana Julia Sagasti - Estudio paleobotánico, paleoecológico y paleoambiental...

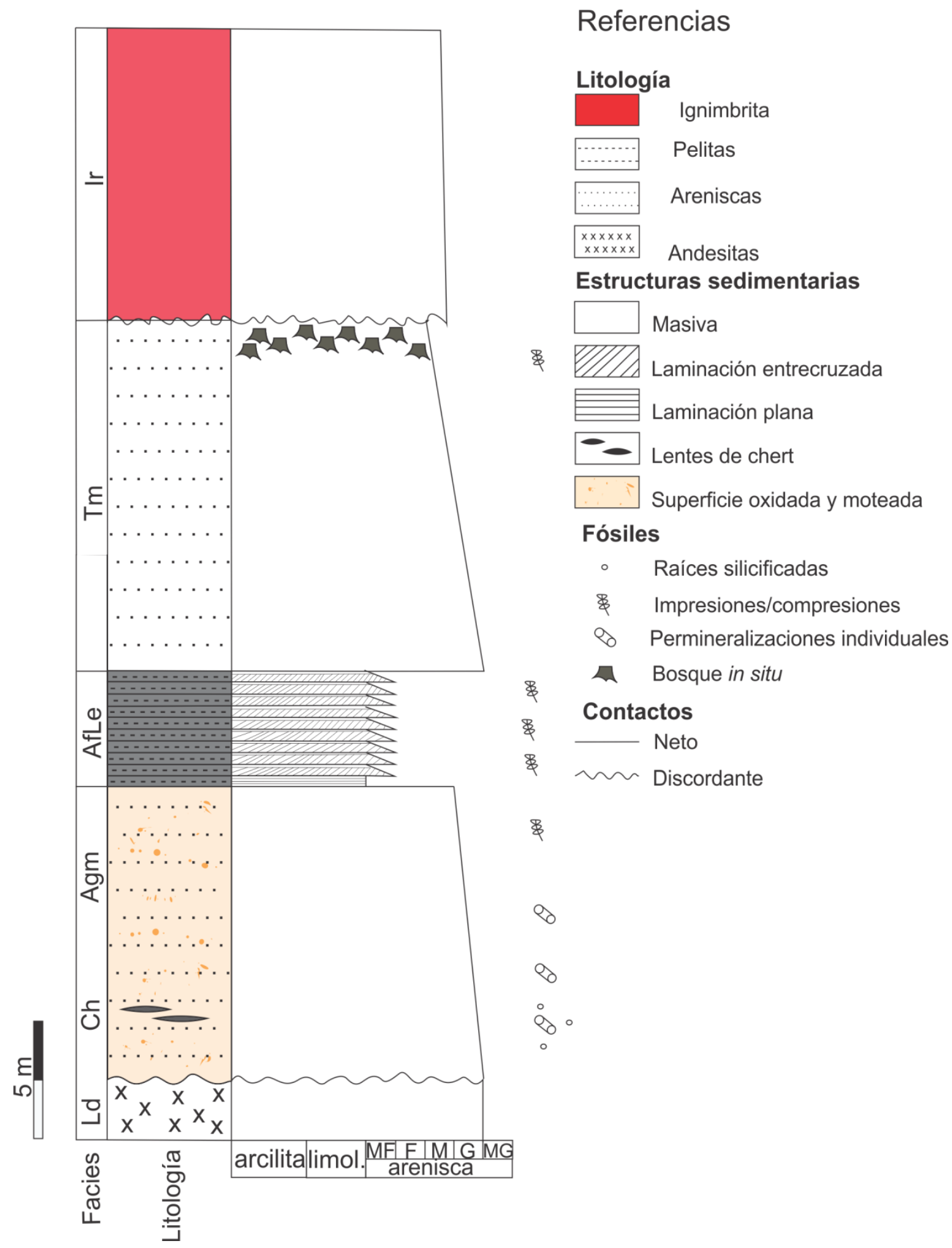

Figura 6.2. Perfil esquemático de la secuencia jurásica aflorante en la localidad Laguna Flecha Negra. 

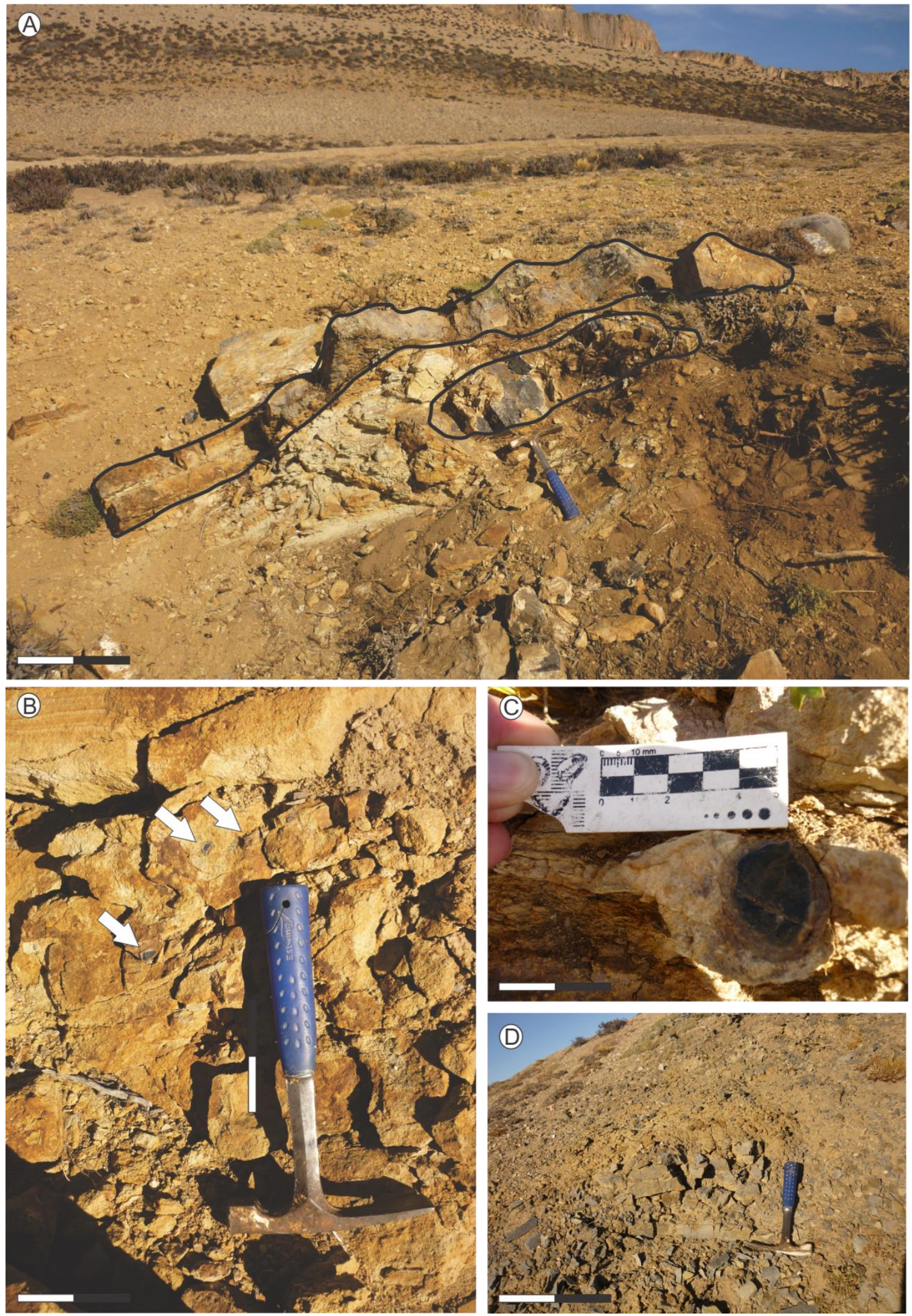

Figura 6.3. Niveles basales aflorantes en la zona noroeste de la localidad Laguna Flecha Negra. A. Areniscas gruesas con lentes de chert, escala: $30 \mathrm{~cm}$. B. Nivel de areniscas gruesas con raíces permineralizadas (flechas blancas), escala: $10 \mathrm{~cm}$. C. Detalle de raíces permineralizadas, escala $3 \mathrm{~cm}$ D. Nivel de pelitas con flora de impresiones-compresiones, escala $20 \mathrm{~cm}$. 


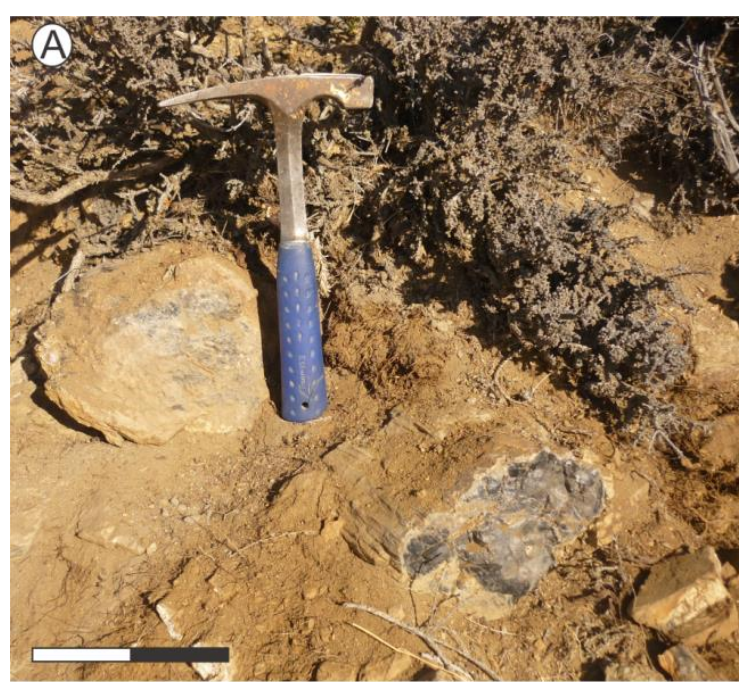

(B)
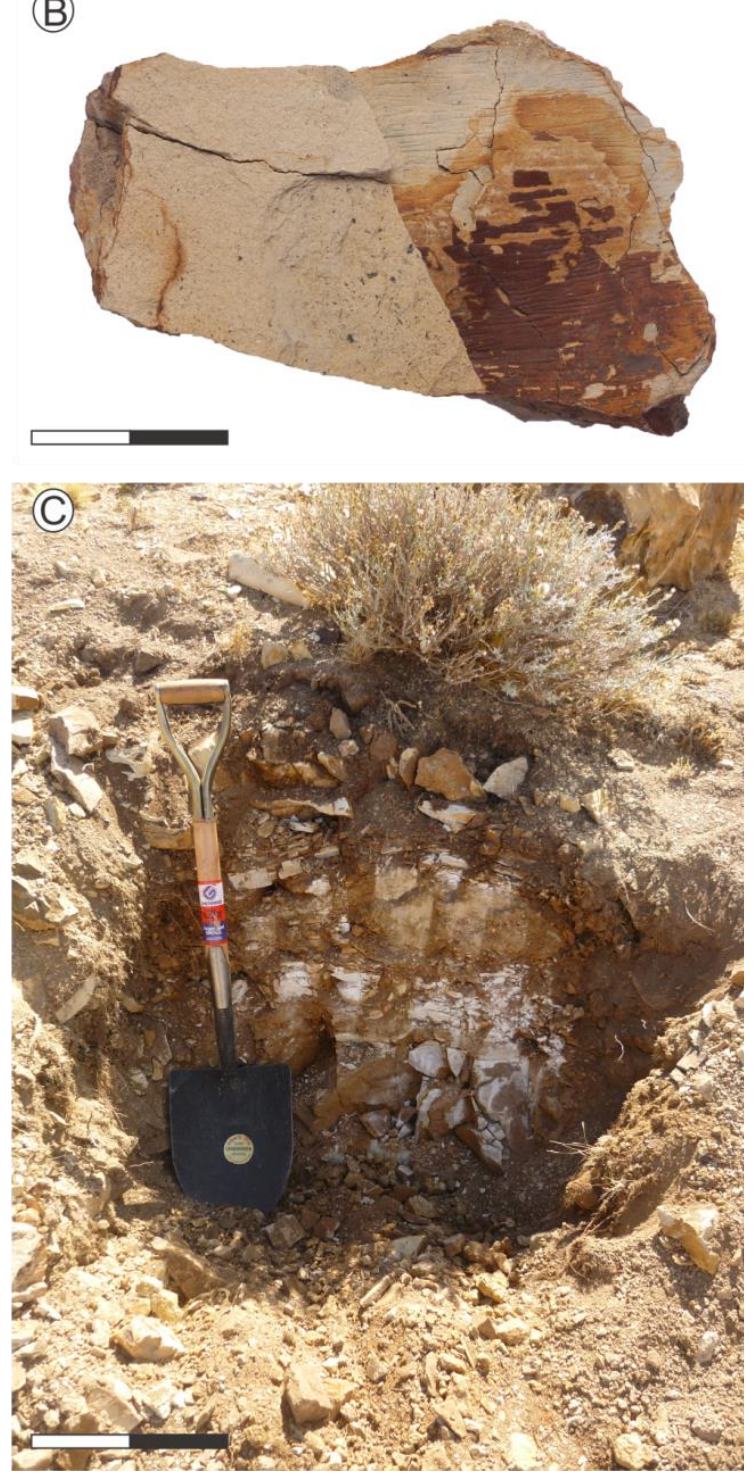

Figura 6.4. A. Ramas permineralizadas. E.: $15 \mathrm{~cm}$. B. Molde de madera. MPM PB $15895 \mathrm{E}:$ :4cm. C. Tobas con estratificación poco marcada. E.: $30 \mathrm{~cm}$. alterado, presentando desde biotitas degradadas hasta amplias zonas con fragmentos lávicos de coloración verde-azulada. Los márgenes de estos domos aflorantes se encuentran intensamente meteorizados, produciendo residuos friables rojoanaranjados. Esta unidad culmina con una disconformidad sobre la que se depositan los sedimentos correspondientes a la Formación Chon Aike.

En los márgenes de la Laguna Flecha Negra el paisaje ha formado una serie de barrancas topográficas en las que se pueden reconocer los distintos niveles de la secuencia clástica. La sección comienza con 12,5 m de areniscas gruesas masivas, blancuzcas con rasgos de meteorización marcado por un moteado anaranjado. La presencia de clastos volcánicos angulosos y cristales de feldespato erosionados sugiere que se habrían formado por erosión y retrabajo de las lavas de la Formación Bajo Pobre (Channing et al., 2007). Este nivel presenta una estructura interna masiva y una alta porosidad que habría favorecido la circulación de fluidos fuertemente cargados con minerales, llevando al desarrollo de 
Ana Julia Sagasti - Estudio paleobotánico, paleoecológico y paleoambiental...

permineralizaciones individuales y en masa.

En la zona noroeste de la laguna se observa el nivel de areniscas gruesas con lentes de chert de unos $20 \mathrm{~cm}$ de espesor (Fig. 6.3.A), interdigitados con un horizonte que presenta raíces permineralizadas (Fig.6.3.B,C). En el margen sudoeste las areniscas no presentan rasgos de silicificación, por lo que se interpreta que los fluidos hidrotermales estarían restringidos geográficamente. La geometría lenticular de las capas de chert señala la zona de influencia de estos fluidos que habrían migrado siguiendo la paleopendiente de la región. Estas areniscas gruesas preservan, a su vez, impresiones y moldes de maderas (Fig. 6.4.B), impresiones de hojas pobremente preservadas, y fragmentos de ejes permineralizados de tamaño mediano (Fig. 6.4.A), probablemente ramas. El estado general de preservación de los órganos bidimensionales colectados en este nivel es relativamente pobre. Esto se debe en parte a la granulometría del sedimento que conformó estos fósiles, que al ser gruesa preserva la morfología general de los restos, pero no registra detalles de venación conspicuos. Por otro lado, las altas temperaturas de los fluidos podrían haber favorecido la carbonización de maderas que se preservan como moldes/compresiones. En la zona sudoeste de la Laguna Flecha Negra, este nivel de areniscas gruesas a finas, se encuentra bien consolidado y preserva una flora de impresiones con un estado de preservación relativamente bueno. La exposición al ambiente ha meteorizado las sedimentitas, que presentan coloraciones anaranjadas en el campo, pero cuando son fracturadas muestran la coloración blanquecina original del sedimento.

Suprayacen concordantemente unos cinco metros de areniscas finas y limolitas oscuras (Fig. 6.3.D). La base de la unidad presenta limolitas gris oscuro, con laminación fina paralela $(1-3 \mathrm{~mm})$. Por encima se reconocen paquetes de 10-35 mm, con una secuencia granodecreciente de arena fina a limo que muestra laminación entrecruzada que se hace paralela hacia el tope. Las superficies de estratificación pueden mostrar clastos volcánicos fuertemente meteorizados, partículas de ceniza y escamas de mica. Este horizonte presenta una flora de impresiones-compresiones muy bien preservada. En este nivel se evidencian pulsos de depósitos de caída relativamente distales (evidenciado por la granulometría de las cenizas), que 
Ana Julia Sagasti - Estudio paleobotánico, paleoecológico y paleoambiental...

pierden energía progresivamente, lo cual puede apreciarse por la estructura granodecreciente de los paquetes y el paso de laminación entrecruzada a paralela.

Por encima de las limolitas se observa un aumento en la actividad eruptiva en la región evidenciado por la presencia de horizontes masivos de ceniza volcánica blanca (Fig. 6.3.C). El contacto entre la secuencia clástica y las tobas es difícil de seguir ya que se encuentra cubierto por detrito moderno en casi toda la loma mapeada. En las zonas expuestas, se observa una relación concordante. El nivel de tobas tiene una potencia de 15 metros y muestra una estratificación muy poco marcada. Internamente, se observa una estructura masiva. Se puede observar una alternancia de tobas gruesas que se hacen más finas hacia el tope, rematando en horizontes delgados con abundancia de lapilli. El carácter general de la unidad es granodecreciente. La coloración es de blancuzca a gris, presentando zonas fuertemente meteorizadas. El tope de esta unidad presenta un horizonte en el que se ha preservado un bosque en posición de vida que se extiende en una longitud de aproximadamente $1 \mathrm{~km}$. Este nivel representa una etapa de mayor eruptividad en la región, con un amplio desarrollo tanto en la vertical como en la zona mapeada.

La secuencia culmina con el desarrollo de la Ignimbrita Flecha Negra (Echeveste et al. 2001), que presenta una potencia de $12,5 \mathrm{~m}$ en este sector. Se trata de una ignimbrita riolítica, color rosado, que se extiende sobre una serie de lomas en toda la localidad. En el perfil oeste de la localidad Laguna Flecha Negra, la base de la ignimbrita contacta con el nivel de tobas masivas en la zona donde se preservan los tocones del bosque in situ (éste se reconoce por la presencia de ejemplares en posición de vida). Este nivel representa la etapa piroclástica de flujo del evento volcánico registrado en la región.

\section{Análisis de facies de la localidad Laguna Flecha Negra (Tabla 6.1).}

Walker (1992) define el concepto de facies como un cuerpo de roca caracterizado por una combinación particular de litología y estructuras físicas y biológicas que le otorgan un aspecto (facies) distinto al de los cuerpos de roca adyacentes. Para la caracterización de las rocas clásticas, se requiere una 


\begin{tabular}{|c|c|c|c|c|}
\hline CÓDIGO & TEXTURA & ESTRUCTURA & ESPESOR & GEOMETRÍA \\
\hline Ld & $\begin{array}{l}\text { Lavas andesíticas con } \text { conolitos } \\
\text { angulares básicos. Alteración desde } \\
\text { biotitas degradadas hasta fragmentos } \\
\text { lávicos verde-azulados. } \\
\text { meteorización en los márgenes. }\end{array}$ & - & $?$ & Dómica \\
\hline Agm & $\begin{array}{l}\text { Areniscas gruesas, blancuzcas. Clastos } \\
\text { volcánicos angulosos y cristales de } \\
\text { feldespato erosionados. Raíces } \\
\text { permineralizadas, impresiones y moldes } \\
\text { de maderas, y fragmentos de ejes } \\
\text { permineralizados de tamaño medio. }\end{array}$ & Masiva & $12,5 \mathrm{~m}$ & Tabular \\
\hline $\mathrm{Ch}$ & $\begin{array}{l}\text { Capas de chert con abundante contenido } \\
\text { de detritos vegetales. }\end{array}$ & $\begin{array}{l}\text { Detritos vegetales } \\
\text { distribuidos de manera } \\
\text { laminar. }\end{array}$ & $20 \mathrm{~cm}$ & Lenticular \\
\hline AfLe & $\begin{array}{l}\text { Areniscas finas y limolitas oscuras. } \\
\text { Superficies de estratificación con clastos } \\
\text { volcánicos fuertemente meteorizados, } \\
\text { partículas de ceniza y escamas de mica. } \\
\text { Flora de impresiones-compresiones muy } \\
\text { bien preservada. }\end{array}$ & $\begin{array}{l}\text { Granodecreciente de } \\
\text { arena fina a limo. } \\
\text { Laminación } \\
\text { entrecruzada que se } \\
\text { hace paralela al tope. }\end{array}$ & $10-35 \mathrm{~cm}$ & Tabular \\
\hline $\mathrm{Tm}$ & $\begin{array}{l}\text { Tobas blancas, de gruesas a finas, } \\
\text { rematando en horizontes delgados con } \\
\text { abundancia de lapilli. Tope de la } \\
\text { secuencia con un bosque } \\
\text { permineralizado en posición de vida y } \\
\text { escasas impresiones de ramas portando } \\
\text { pocas hojas. }\end{array}$ & $\begin{array}{l}\text { Masiva en rasgos } \\
\text { generales. } \\
\text { Granodecreciente. }\end{array}$ & $15 \mathrm{~m}$. & Tabular \\
\hline Ir & Ignimbrita riolítica rosada. & Eutaxítica & $12,5 \mathrm{~m}$ & $\begin{array}{l}\text { Tabular que se adelgaza } \\
\text { hacia el sur. }\end{array}$ \\
\hline
\end{tabular}

Tabla 6.1. Código de facies para la secuencia aflorante en la localidad Laguna Flecha Negra. 
Ana Julia Sagasti - Estudio paleobotánico, paleoecológico y paleoambiental...

identificación inicial de la litología en términos de la composición, textura, estructuras sedimentarias, geometría de los bancos, paleocorrientes y contenido de fósiles (Scasso y Limarino, 1997). El análisis de estos atributos permite definir con detalle las facies presentes en una secuencia de rocas, lo cual es fundamental para determinar el origen de estos depósitos.

\section{Discusión.}

El Grupo Bahía Laura está representado por un conjunto de rocas volcánicas jurásicas de composición ácida que conforma el evento de mayor representatividad e importancia de la provincia geológica Macizo del Deseado (Guido, 2004).

En 2004, Guido realiza un análisis de las secuencias preservadas en el Grupo Bahía Laura, realizando una subdivisión litofacial del volcanismo jurásico del Macizo del Deseado (Tabla 6.2). En este trabajo se determinan dos facies (volcaniclásticas y efusivas) y varias subfacies dentro de ellas. Las facies volcaniclásticas comprenden todos los depósitos volcánicos fragmentarios e incluye tanto las rocas piroclásticas (producidas por erupciones explosivas) como las rocas volcánicas redepositadas o retrabajadas (tufitas). Las rocas piroclásticas pueden agruparse en tres subfacies: piroclásticas de flujo, de caída y de surge. Estas rocas están compuestas por piroclastos, dentro de los cuales se pueden diferenciar fragmentos juveniles del magma (pómez y trizas vítreas), cristaloclastos (cristales, de carácter fragmentario, de cuarzo, feldespato potásico, plagioclasas y mafitos) y fragmentos líticos de variada composición. La división genética en tres subfacies está sustentada en el modo de transporte y depositación de los materiales volcánicos fragmentarios (Guido, 2004). En el caso de las rocas volcánicas retrabajadas, el autor las reúne en las subfacies epiclástica. Este conjunto de rocas aparece interestratificado, lo que imposibilita la diferenciación en subfacies.

La facies efusiva incluye rocas coherentes, no fragmentarias, formadas por enfriamiento y solidificación del magma, sin eventos explosivos asociados (Guido, 2004). El Grupo Bahía Laura fue formado por eventos de magmatismo ácido, con altos contenidos de volátiles, por lo que la cámara magmática tiene que sufrir un importante proceso de pérdida de gases para perder explosividad 
Ana Julia Sagasti - Estudio paleobotánico, paleoecológico y paleoambiental...

y originar efusiones lávicas. Esto coincide con las observaciones de campo realizadas por el autor, en las cuales las rocas de la facies efusiva tienden a ser menos abundantes y póstumas respecto de los materiales piroclásticos (producidos por el evento eruptivo explosivo con que inicia la actividad del sistema). Dentro de la facies efusiva, se reconocen dos subfacies. Las rocas lávicas extrusivas, que forman coladas o cuerpos dómicos, se agrupan en la subfacies lávica. En la subfacies subvolcánica se incluye rocas hipabisales, que no extruyeron en superficie y se consolidaron a poca profundidad. Estos son diques, criptodomos y cuerpos porfíricos de emplazamiento somero (Guido, 2004).

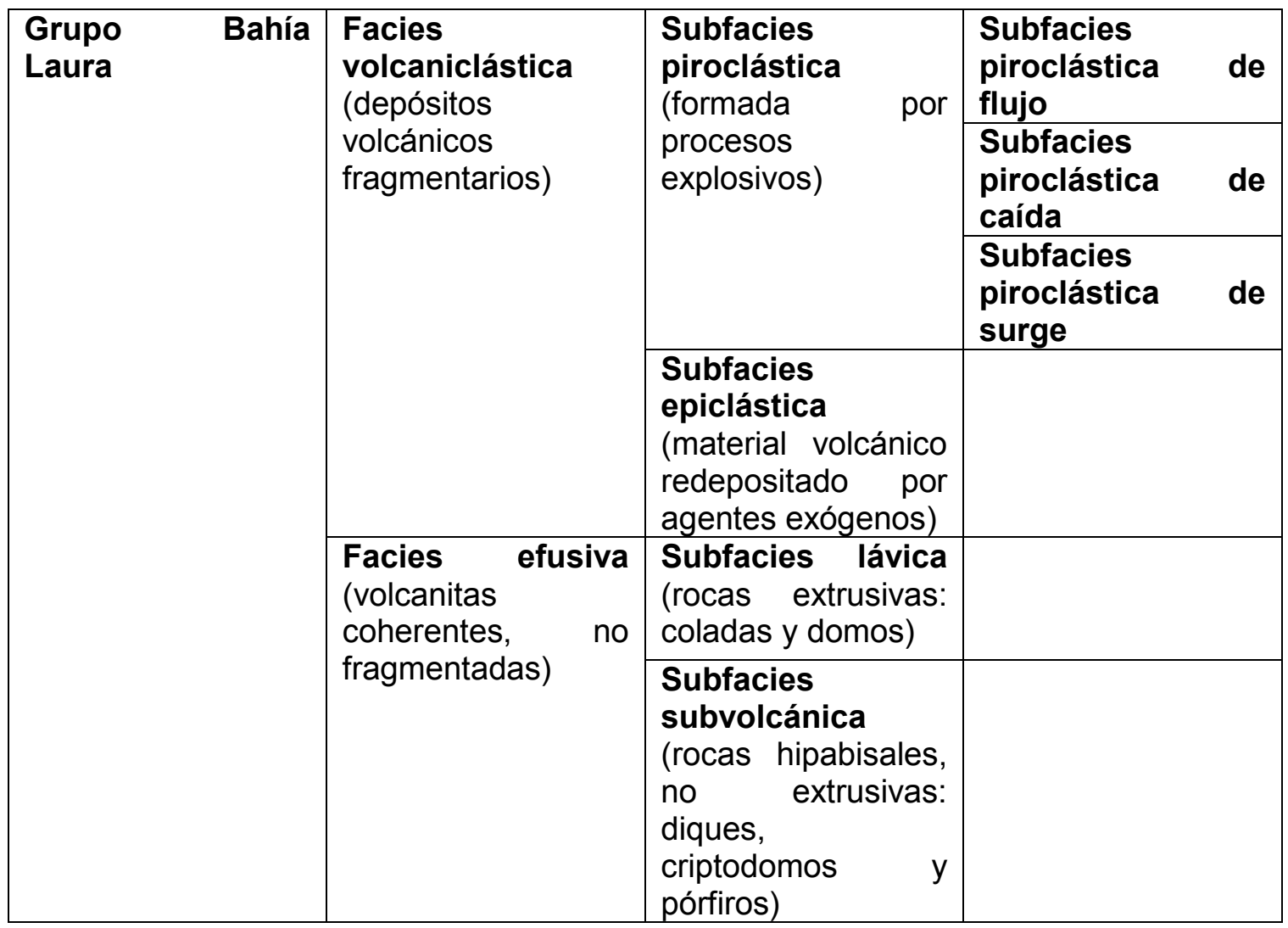

Tabla 6.2. Subdivisión litofacial propuesta para el volcanismo ácido jurásico del Macizo del Deseado. Modificado de Guido, 2004.

Dentro de este contexto, se pueden analizar las facies definidas para los depósitos de la localidad Laguna Flecha Negra. La facies Ld puede interpretarse como un depósito efusivo de la subfacies lávica y corresponde a la Formación Bajo Pobre. Las facies Agm, AfLe y Tm pueden compararse con la subfacies piroclástica de caída definida por Guido (2004). Estos cuerpos de roca corresponden a la etapa explosiva del evento volcaniclástico del Jurásico 
Medio-Superior que conformó el Grupo Bahía Laura. Tanto la facies Ch como Ir pueden compararse con la subfacies piroclástica de flujo definida por Guido (2004) ya que presentan evidencia de movilización de fluídos tanto por la organización de los detritos vegetales en la facies Ch como por la presencia de estructura eutaxítica observada en Ir. En la secuencia analizada en la localidad Laguna Flecha Negra no se observaron subfacies de surge, epiclástica ni subvolcánica.

Echeveste et al. (1999) analizaron las relaciones estratigráficas entre las ignimbritas tardías de alto grado de la Formación Chon Aike, reconociendo tres unidades: Ignimbrita Las Lajas, Ignimbrita Valenciana e Ignimbrita Flecha Negra. A partir de la observación de formas lobulares en la porción sur de la ignimbrita Valenciana y el análisis de la geometría de la ignimbrita Flecha Negra, sumado a la eventual relación con un conducto situado en su porción norte, los autores interpretan el sentido de los flujos de norte a sur. La presencia de depósitos de chert restringidos a la zona noroeste de la localidad Laguna Flecha Negra es coherente con la hipótesis planteada por estos autores. Se sostiene entonces que los flujos hidrotermales desarrollados en profundidad que acompañaron al proceso volcánico de la zona han seguido la paleopendiente de la región, aflorando en la localidad Laguna Flecha Negra y entrampando material vegetal que se preserva en estas permineralizaciones en masa. La influencia de estos fluidos habría producido a su vez, la preservación de ejes de coníferas como permineralizaciones individuales de ramas y raíces que se observan en el nivel de areniscas basal en la localidad (facies Agm), interdigitados con las capas de chert.

\section{Conclusiones}

En la localidad Laguna Flecha Negra se observa una secuencia volcaniclástica atribuible a la Formación Chon Aike (Jurásico Medio-Superior). Aquí se preserva una flora con variado grado de preservación en la que se observan taxones típicos del Jurásico Medio-Tardío de Patagonia (ver capítulo VII).

La secuencia estudiada en la localidad Laguna Flecha Negra registra una serie de episodios eruptivos de caída que llevaron a la preservación de la 
Ana Julia Sagasti - Estudio paleobotánico, paleoecológico y paleoambiental...

comunidad vegetal que habitaba en la región. Los distintos estilos preservacionales y su significado tafonómico serán analizados en el capítulo IX. La comparación de estos depósitos con el análisis de facies elaborado por Guido (2004), permite identificar una secuencia volcaniclástica que se deposita sobre un domo andesítico de la Formación Bajo Pobre, que puede ser clasificado como subfacies lávicas. En los cuerpos de roca correspondientes a la Formación Chon Aike predominan los depósitos de caída con niveles piroclásticos de flujo que aparecen: por un lado interdigitando con areniscas gruesas masivas (facies de chert, $\mathrm{Ch}$ ) en la base de la secuencia, y finalmente constituyen el tope de la secuencia con la Ignimbrita Flecha Negra (facies Ir). 


\section{Sistemática paleobotánica}

\section{Introducción.}

En este capítulo se incluyen las descripciones e ilustraciones de los materiales preservados como impresiones, compresiones y permineralizaciones en la localidad Laguna Flecha Negra. Todos los materiales proceden de niveles estratigráficamente asignables a la Formación Chon Aike. Se incluye para cada taxón identificado, el correspondiente número de repositorio. Las descripciones fueron realizadas sobre el ejemplar de referencia, se señalan las diferencias que pudieran existir con el resto de los ejemplares asignados al taxón. Se incluyen observaciones y comparaciones para cada taxón y una discusión sobre las especies o géneros fósiles en cuestión.

División Tracheophyta

Subdivisión Euphyllophytina

Clase Polypodiopsida

Orden Gleicheniales

Familia Gleicheniaceae

Gleicheniaceae indet

Orden Cyatheales

Familia Dicksoniaceae

Género Coniopteris

Coniopteris hymenophylloides

Incertae sedis

Género Korallipteris

Korallipteris potrerillensis

Clase Cycadeoideopsida (=Bennettitopsida)

Orden Cycadeoideales

Incertae sedis

Género Otozamites

Otozamites albosaxatilis

Otozamites sanctae crucis 
Ana Julia Sagasti - Estudio paleobotánico, paleoecológico y paleoambiental...

Otozamites sueroi

Cf. Otozamites bunburyanus var. major

Género Ptilophyllum

Ptilophyllum hislopi

Clase Coniferopsida

Orden Coniferales

Familia Araucariaceae

Género Araucarites

Araucarites cutchensis

Araucarites phillipsii

Araucarites sp.

Género Agathoxylon

Agathoxylon arayaii

Agathoxylon cf. floresii

Agathoxylon jurassicum

Agathoxylon matildense

Leños de Araucariaceae indet

Familia Cupressaceae sensu lato

Género Protaxodioxylon

Protaxodioxylon sp.

Familia Cupressaceae sensu stricto

Género Cupressinoxylon

Cupressinoxylon sp.

Familia Cheirolepidiaceae

Género Protocupressinoxylon

Protocupressinoxylon sp.

Género Pararaucaria

Pararaucaria patagonica

Incertae sedis

Género Brachyphyllum

Brachyphyllum lotenaense

Brachyphyllum sp.

Género Pagiophyllum

Pagiophyllum cf. crassifolium 
Ana Julia Sagasti - Estudio paleobotánico, paleoecológico y paleoambiental...

\section{Género Elatocladus}

Elatocladus confertus

Elatocladus cf. planus

Impresiones de ramas foliosas

Permineralizaciones de ramas foliosas

Leños gimnospérmicos de afinidad incierta

Género Scleropteris

Scleropteris vincei

Género Sphenopteris

Sphenopteris cf. nordenskjöldii

Hojas plurinervias de afinidad incierta

Estructura reproductiva pinnada indet. $A$

Estructura reproductiva pinnada indet. $B$

Raíz diarca indet.

División Tracheophyta Sinnott ex Cavalier-Smith 1998.

Subdivisión Euphyllophytina Kenrick y Crane 1997

Clase Polypodiopsida Cronquist, Takhtajan y Zimmerman 1966

\section{Orden Gleicheniales Link 1833}

\section{Familia Gleicheniaceae Presley, 1825}

Incertae sedis.

Gleicheniaceae indet.

Figura. 7.1.A

Ejemplar de referencia. MPM PB 16022

Localidad. Laguna Flecha Negra

Horizonte estratigráfico. Lentes de chert

Descripción. Corte transversal de pecíolo de 0,6 $\mathrm{mm}$ de diámetro.Traza vascular en forma de $C$ con los extremos curvados hacia afuera, de 0,3 mm de diámetro, con un espesor de 10,25 $\mu \mathrm{m}$. La corteza es parenquimática, con células redondeadas de lumen amplio, en buen estado de preservación, con un diámetro que oscila entre $4 \mu \mathrm{m}$ y $12 \mu \mathrm{m}$. En la corteza se pueden observar 
trazas esclerenquimáticas de $30 \mu \mathrm{m}$ de diámetro, en posición abaxial a la traza peciolar. Epidermis pluriestratificada, de $20 \mu \mathrm{m}$ de espesor.

Comentarios. Los miembros de la familia Gleicheniaceae presentan pecíolos con trazas vasculares sólidas o en forma de $\mathrm{C}$ con sus extremos enrollados (Taylor et al., 2008). Millay y Taylor (1990) describen la especie Antarctipteris sclericaulis del Triásico de Antártida y señalan su posible afinidad con las Gleicheniaceae. Esta especie está caracterizada por pecíolos con trazas vasculares en forma de $\mathrm{C} \circ \mathrm{V}$, que producen pínnas con trazas en forma de $\mathrm{V} \mathrm{o}$ W, con los extremos curvados hacia afuera. Los pecíolos son de sección circular, con una corteza parenquimática y suelen presentar trazas de esclerénquima alrededor de la traza vascular. Vera (2010) describe el género Gleicheniaceae del Cretácico de Santa Cruz a partir del estudio de restos carbonizados de rizomas y pecíolos. Este género se diferencia de los restos estudiados en Laguna Flecha Negra, por la presencia de una corteza peciolar de carácter netamente esclerenquimático y una traza vascular en forma de $\mathrm{C}$ con los extremos curvados hacia dentro, y no hacia afuera. Los materiales de Laguna Flecha Negra son escasos y no pueden clasificarse dentro de los géneros conocidos de pecíolos de Gleicheniaceae, aunque su afinidad con la familia es evidente.

\section{Orden Cyatheales Frank in Leunis 1877}

\section{Familia Dicksoniaceae Schomburgk 1848, nomina conservanda}

Género Coniopteris Brongniart emend. Harris 1961.

Especie tipo. Coniopteris murrayana (Brongniart) Brongniart emend. Harris 1961.

Coniopteris hymenophylloides (Brongniart) Seward emend Harris 1961.

Figura. 7.1.B.

Ejemplar de referencia. MPM PB 15967.

Ejemplares adicionales. MPM PB 15968.

Localidad. Laguna Flecha Negra.

Horizonte estratigráfico. Areniscas gruesas

Descripción. Fragmentos de frondes fértiles al menos bipinnadas, probablemente tripinnadas. Dimensiones completas desconocidas, el ejemplar 
Ana Julia Sagasti - Estudio paleobotánico, paleoecológico y paleoambiental...

estudiado tiene $2 \mathrm{~cm}$ de largo por $3,3 \mathrm{~cm}$ de ancho. Pinnas de 2,2 cm de largo por 0,5 cm de ancho, insertas de manera alterna con un ángulo de $50^{\circ}$, separadas por 0,6 cm a un lado del raquis. Pínnulas de lámina reducida a un eje portador de soros marginales en forma de copa; alternas, insertas al eje de las pinnas en ángulos de $40^{\circ}$, separadas a intervalos de $0,3 \mathrm{~cm}$ a un lado del eje.

Observaciones. La asignación genérica para los taxones fósiles de hojas pertenecientes a la familia Dicksoniaceae se basa en la caracterización de las estructuras reproductivas (Gee, 1989). Las frondes estériles asociadas a Coniopteris se describen dentro del taxón fósil Sphenopteris. Mientras que las frondes fértiles correspondientes al género Coniopteris presentan indusios formados como una copa continua, a diferencia del género Dicksonia en el cual los indusios están formados por dos valvas (Gee, 1989).

Comparaciones. El material estudiado se diferencia de $C$. meridionalis del Jurásico Tardío- Cretácico Temprano de Antártida (Gee, 1989) ya que éste presenta pinnas fértiles y estériles intercaladas, así como esporangios reniformes en las pinnas fértiles. Ninguno de estos caracteres es observado en el material de Laguna Flecha Negra. A su vez, es diferenciable de $C$. murrayana ya que esta especie presenta pínnulas fértiles levemente reducidas, con soros ubicados en los lóbulos basales acroscópicos. El material estudiado es comparable con C. hymenophylloides ya que presenta la lámina de las pínnulas fértiles fuertemente reducidas a poco más que un eje conformado por la vena media y muy poco desarrollo de lámina, portando en su extremo distal, un soro con forma de copa que puede ser esférico, elíptico o levemente reniforme. Las pínnulas de C. hymenophylloides salen del raquis de la pinna en ángulos de entre 40 y $50^{\circ}$, a intervalos de $0,5 \mathrm{~cm}$ a un lado. Estos caracteres permiten asignar con certeza el material colectado en Laguna Flecha Negra a la especie Coniopteris hymenophylloides.

\section{Incertae sedis.}

Género Korallipteris Vera y Passalia, 2012.

Especie tipo. Korallipteris argentinica (Berry emend. Herbst) Vera y Passalia 2012. 
Ana Julia Sagasti - Estudio paleobotánico, paleoecológico y paleoambiental...

\section{Korallipteris potrerillensis (Herbst) Vera y Passalia 2012.}

Figura 7.1. C-D.

Ejemplar de referencia. MPM PB 15965.

Especímenes adicionales. MPM PB 15966.

Localidad. Laguna Flecha Negra

Horizonte estratigráfico. Areniscas gruesas

Descripción. El ejemplar estudiado corresponde a segmentos de fronde estéril, al menos bipinnada, a probablemente tripinnada. Segmento de mayor tamaño preservado, de $5 \mathrm{~cm}$ de largo por $0,8 \mathrm{~cm}$ de ancho máximo. Raquis aparentemente liso, de $0,1 \mathrm{~cm}$ de ancho. Pinnas imparipinadas, lineares, insertas con un ángulo que oscila entre $50^{\circ}-60^{\circ}$, de manera alterna. Pinnas contiguas separadas por no más de 0,1-0,2 cm. Pinnas de aspecto pectinoide, de $0,6 \mathrm{~cm}$ de largo por $0,2 \mathrm{~cm}$ de ancho, imparipinnadas. Pínnulas aparentemente subalternas, insertas al raquis por toda la base, con ángulo de 45ํ5ㄴ: de tipo pecopterídeo (márgenes enteros, paralelos, ápice redondeado). Pínnulas contiguas algo confluentes en la base, pudiendo estar en contacto pero no imbricadas. Las pínulas presentan dimensiones casi uniformes a lo largo de la pinna, disminuyendo gradualmente su tamaño hacia el ápice. Pínnulas mayores grandes de $0,1 \mathrm{~cm}$ de ancho por 0,1 cm de largo; relación largo-ancho 1:1. Pínnulas distales $0,05 \mathrm{~cm}$ largo por 0,05 cm de ancho, manteniendo la misma relación largo-ancho que en el resto de la pinna. El tamaño reducido de las pínulas y el estado de preservación del material no permiten observar la venación de las mismas.

Observaciones. El taxón fossil Gleichenites ha sido utilizado para incluir frondes similares a la actual Gleichenia. Este género fue propuesto por Goeppert (1836) para incluir frondes de helechos mesozoicos. Posteriormente, los ejemplares referidos por el autor fueron reconocidos como frondes de pteridospermas paleozoicas, por lo que Arber (1917) crea el género Microphyllopteris para nominar frondes pinnadas, bipinnadas o dicotómicas, portando pínulas pequeñas semejantes a la actual Gleichenia. Por su lado, Seward (1926) realiza una diagnosis del género para incluir helechos mesozoicos, aunque ésta no fue aceptada por algunos autores (e.g. Crabtree, 1988; Cantrill, 1998) que señalan que no es aplicable en ausencia de caracteres diagnósticos de las Gleicheniaceae, tales como las yemas 
Ana Julia Sagasti - Estudio paleobotánico, paleoecológico y paleoambiental...

durmientes. Por otro lado, algunos especímenes descriptos por Arber como Microphyllopteris se han reinterpretado como pertenecientes a pteridospermas mesozoicas del género Pachydermophyllum (Retallack, 1981). En función de esta complejidad nomenclatural, Vera y Passalia (2012), establecen el género Korallipteris para nominar taxones fósiles de frondes fértiles o estériles, varias veces pinnadas, que portan pínnulas pecopterídeas pequeñas, en las que no se puede observar una yema durmiente. La diagnosis de este nuevo género incluye frondes fértiles con soros en la cara abaxial de las pínnulas, lo cual permite ubicarlas dentro de las Polypodiopsida, aunque las afinidades familiares no pueden establecerse de manera certera en el caso de materiales estériles como los encontrados en la localidad Laguna Flecha Negra.

Comparaciones. El género Korallipteris incluye a las especies Korallipteris juliensis (Herbst) Vera y Pasalía del Jurásico Medio-Superior de Santa Cruz, Korallipteris medinae (Ruiz) Vera y Pasalía del Cretácico de Santa Cruz, Korallipteris piatnitzky (Berry) Vera y Pasalía del Cretácico de Santa Cruz, Korallipteris potrerillensis (Herbst) Vera y Pasalía del Triásico Medio de Mendoza, Korallipteris quilacoyensis (Leppe y Moisan) Vera y Pasalía del Triásico Superior de Chile, Korallipteris unisora (Cantrill y Nagalingum) Vera y Pasalía del Cretácico Superior de Antártida y Korallipteris vegagrandensis (Herbst) Vera y Pasalía del Cretácico de Santa Cruz. Los ejemplares estudiados difieren de Korallipteris juliensis (Herbst) Vera y Passalia, del Jurásico de la formación La Matilde en que esta especie presenta pínnulas insertas con un ángulo de $60-70^{\circ}$, de $0,33 \mathrm{~cm}$ largo por $0,15 \mathrm{~cm}$ ancho, con una relación largo-ancho en pínnulas adultas $=2: 1$. Comparten con Korallipteris vegagrandis (Herbst) Vera y Passalia la forma, dimensiones y ángulo de inserción de las pínnulas, aunque difieren en el ángulo de inserción de las pinnas y en la ausencia de la quilla característica observada en los materiales de Baqueró. Los ejemplares de Laguna Flecha Negra pueden ser comparados con Korallipteris potrerillensis (Herbst) Vera y Passalia, ya que presentan un raquis angosto, pinas lineares que disminuyen su ancho hacia el ápice, pinnas que salen con ángulos de $50^{\circ}-60^{\circ}$, separadas y alternas. Las pínnulas son pecopterídeas subopuestas, de dimensiones y morfología similares. Se observa una pequeña diferencia en el ángulo de inserción de las mismas, de $55^{\circ}-60^{\circ}$ en el material de Mendoza, y de $45^{\circ}-55^{\circ}$ en los ejemplares aquí 
Ana Julia Sagasti - Estudio paleobotánico, paleoecológico y paleoambiental...

estudiados. Sin embargo, esta puede considerarse una diferencia menor que no justifica segregar las especies.

\section{Clase Cycadeoideopsida (=Bennettitopsida) Scott, 1923}

\section{Orden Cycadeoideales sensu Stewart y Rothwell, 1993}

\section{Incertae sedis}

En ausencia de cutículas, la distinción entre los taxones fósiles Zamites, Otozamites y Ptilophyllum es muy difícil (Rees y Cleal, 2004). Esta dificultad se profundiza cuando la base de las pínnulas está pobremente desarrollada o cubierta por la roca de caja (Halle, 1913; Harris, 1969). Person y Delevoryas (1982) desarrollaron un criterio para separar estos taxones en función de la venación y la forma de la base de las pinnas. Esto fue posteriormente completado por Gee (1989) y Rees y Cleal (2004). La tabla 7.1 resume los caracteres morfológicos utilizados para distinguir estos tres taxones fósiles foliares en ausencia de cutículas.

\begin{tabular}{|c|c|c|c|}
\hline & Zamites & Otozamites & Ptilophyllum \\
\hline $\begin{array}{l}\text { Base del margen } \\
\text { acroscópico }\end{array}$ & $\begin{array}{l}\text { Típicamente } \\
\text { contraída }\end{array}$ & Contraída & Contraída \\
\hline $\begin{array}{l}\text { Base del margen } \\
\text { basiscópico }\end{array}$ & $\begin{array}{l}\text { Típicamente } \\
\text { contraída }\end{array}$ & Contraída & Decurrente \\
\hline $\begin{array}{l}\text { Curvatura de las } \\
\text { venas acroscópicas }\end{array}$ & Basípeta & Acropéta & Basípeta \\
\hline $\begin{array}{l}\text { Curvatura de las } \\
\text { venas basiscópicas }\end{array}$ & Acrópeta & Acrópeta & Basípeta \\
\hline $\begin{array}{l}\text { Simetría de la base } \\
\text { de la pinna }\end{array}$ & $\begin{array}{l}\text { Típicamente } \\
\text { simétrica }\end{array}$ & Asimétrica & Asimétrica \\
\hline $\begin{array}{l}\text { Presencia de } \\
\text { aurícula }\end{array}$ & $\begin{array}{l}\text { Típicamente } \\
\text { ausente }\end{array}$ & $\begin{array}{l}\text { Presente en el } \\
\text { margen } \\
\text { acroscópico }\end{array}$ & $\begin{array}{l}\text { Típicamente } \\
\text { ausente. }\end{array}$ \\
\hline
\end{tabular}

Tabla 7.1. Caracterización de las pinnas de Zamites, Otozamites y Ptilophyllum (Modificado de Rees y Cleal, 2004). 
Ana Julia Sagasti - Estudio paleobotánico, paleoecológico y paleoambiental...


Figura 7.1. Paleoflora de la localidad Laguna Flecha Negra. A. Gleicheniaceae indet. CT pecíolo. MPM PB 16022. B. Coniopteris hymenophylloides. MPM PB 15967. C. Korallipteris potrerillensis MPM PB 15966. D. Korallipteris potrerillensis MPM PB 15965 E. Otozamites albosaxatilis MPM PB 15841 F. Otozamites sanctae-crucis MPM PB 15837. 
Ana Julia Sagasti - Estudio paleobotánico, paleoecológico y paleoambiental...

\section{Género Otozamites Braun en Münster 1843}

Especie tipo.Otozamites obtusus (Lindley y Hutton) Brongniart 1849

Otozamites albosaxatilis Herbst, 1965.

Figura.7.1.E

Ejemplar de referencia. MPM PB 15841

Ejemplares adicionales. MPM PB 15842-15843.

Localidad. Laguna Flecha Negra

Horizonte estratigráfico. Pelitas oscuras

Descripción. Fragmento de hoja monopinnada, de $13 \mathrm{~cm}$ de largo por 1,7 cm de ancho. Raquis de 0,2 cm de ancho, estriado. Con pinnas insertas sobre la cara adaxial del raquis, de manera subalterna, con un ángulo de inserción de $60^{\circ}$. Las pinnas son levemente falcadas, con ápice redondeado, de $1,1 \mathrm{~cm}$ de largo por 0,5 cm de ancho. Presentan una aurícula bien marcada que cubre el margen basiscópico de la pinna siguiente. Al menos 6 venas ingresan en cada pinna, abriéndose en sentido acrópeto.

Comparaciones. Los materiales colectados en Laguna Flecha Negra pueden compararse con Otozamites albosaxatilis Herbst del Liásico de Chubut. Comparten el ángulo de inserción $\left(60^{\circ}-70^{\circ}\right.$ en los materiales originales), el raquis angosto, forma de las pinnas y tipo de venación. Las pinnas son levemente más pequeñas que aquellas descriptas por Herbst (1965, 1966b), aunque los materiales originales presentan variación de tamaño a lo largo de la hoja y el autor señala la variabilidad natural en la especie.

Comentarios. Los materiales adicionales se preservan en su cara abaxial, el raquis cubre la base de las pinnas imposibilitando la observación de las mismas. Estrictamente, no pueden observarse las bases auriculadas de estos ejemplares. Debido a que comparten características en la morfología de las pinnas, el tamaño y ángulo de inserción, se opta por tratarlas dentro de la misma especie. Otozamites albosaxatilis fue descripta previamente en el Liásico de Roca Blanca y Pampa de Agnia, es un elemento típico de muchas asociaciones liásicas y mesojurásicas del mundo, especialmente de Gondwana. 
Ana Julia Sagasti - Estudio paleobotánico, paleoecológico y paleoambiental...

\section{Otozamites sanctae-crucis Feruglio, 1951.}

Figura.7.2.B

Ejemplar de referencia. MPM PB 15837.

Especímenes adicionales. MPM PB 15838-15840; MPM PB 15971-15972

Localidad. Laguna Flecha Negra

Horizonte estratigráfico. Pelitas negras

Descripción. Fragmento de hoja monopinnada de $6,1 \mathrm{~cm}$ de largo por $1,1 \mathrm{~cm}$ de ancho. Raquis de 0,2 cm ancho, estriado. Pinnas linear lanceoladas a falcadas, de ápice agudo. De 0,9 cm de largo por 0,3 cm de ancho. Se insertan sobre la cara adaxial del raquis, de manera alterna, con un ángulo de alrededor de $30^{\circ}-40^{\circ}$. Las pinnas presentan una aurícula suave pero evidente, que cubre levemente el margen basiscópico contraído de la pinna siguiente. Entre 4 y 5 venas ingresan en la base de la pinna, abriéndose acróspicamente hacia el ápice.

Comentarios. Al igual que en los ejemplares de Otozamites sueroi, se observa una pequeña variación en el tamaño de las pinnas; oscilando entre 0,7 y $1 \mathrm{~cm}$ de largo, por 0,3-0,35 de ancho. Se sigue el mismo criterio.

Comparaciones. El material estudiado en la localidad Laguna Flecha Negra presenta las características descriptas por Feruglio (1951) para identificar a Otozamites sanctae-crucis. Este autor identifica dos tipos dentro de esta especie, pero no realiza una separación taxonómica ya que considera estas variaciones como debidas a la ontogenia o a la zona de la fronde preservada (siendo como en otras especies, la zona media la de mayor desarrollo). Los ejemplares aquí estudiados son comparables con el primer tipo descripto por Feruglio, que presenta pínnas más cortas y de ápice agudo. En Argentina, esta especie se registra en el Gran Bajo de San Julián (Feruglio, 1951; Herbst y Zalazar, 1998) en depósitos asignables a la Formación La Matilde y en yacimientos Cretácicos en la Formación Springhill y la Península Antártica (Halle, 1913). 
Ana Julia Sagasti - Estudio paleobotánico, paleoecológico y paleoambiental...

\section{Otozamites sueroi Herbst, 1966}

Figuras. 7.2.A.

Ejemplar de referencia. MPM-PB 15829 impronta y contraimpronta.

Especímenes adicionales. MPM-PB 15830-15836; MPM-PB-15969-15970

Localidad. Laguna Flecha Negra

Horizonte estratigráfico. Pelitas oscuras

Descripción. Fragmento de hoja monopinnada de $16 \mathrm{~cm}$ de largo por 1,3 cm de ancho. Raquis de $0,2 \mathrm{~cm}$ de ancho. Las pinnas se insertan subalternas sobre la línea media de la cara superior del raquis, con un ángulo de $50^{\circ}-60^{\circ}$, de $0,8 \mathrm{~cm}$ de largo por $0,4 \mathrm{~cm}$ de ancho, que se hacen levemente más pequeñas hacia el ápice de la hoja. Pinnas ligeramente falcadas, con el ápice redondeado, de base asimétrica, con aurícula conspicua en el margen acroscópico que cubre el margen basiscópico de la pinna siguiente. Se observan entre 6 y 8 venas que inervan cada pinna, abriéndose en abanico, acrópetamente.

Comentarios. Las pinnas de los materiales adicionales oscilan entre los 0,6 y $0,8 \mathrm{~cm}$ de largo. Esto puede deberse al estado fragmentario de los restos. Es común observar en las especies de Otozamites una variación en el tamaño de las pinnas dentro de la misma hoja. Normalmente éstas alcanzan su máximo desarrollo en la zona media, haciéndose más pequeñas hacia el ápice. Debido a que todos los ejemplares aquí descriptos comparten la forma general de las pinnas, ángulo de inserción y venación, se opta por incluirlos dentro de la misma especie y se interpretan como distintas porciones de la lámina pinnada.

Observaciones. Según el criterio de Gee (1989), Otozamites se diagnostica en presencia de base de las pinnas asimétrica con ambos márgenes contraídos, curvatura acrópeta de las venas basales y presencia de una aurícula en el margen basal acroscópico. Estos caracteres, permiten diferenciar de los géneros Zamites y Ptilophyllum en ausencia de cutículas. Otozamites sueroi fue descripta para el Liásico de la provincia de Chubut en asociación con elementos que pueden observarse en la Flora de Laguna Flecha Negra (e.g. Scleropteris vincei, Otozamites albosaxatilis, Elatocladus confertus y Brachyphyllum sp.).

Comparaciones. Se diferencia de Otozamites hislopi porque éste presenta pinnas largas, con una relación largo:ancho 4:1, a diferencia del material de 
Laguna Flecha Negra, cuya relación es 2:1. Los materiales pueden compararse con Otozamites sueroi Herbst del Liásico de Pampa de Agnia ya que comparten el raquis ancho, pinnas con relación largo:ancho $2: 1$, forma y venación de las pinnas. Se diferencian en que presentan un ángulo de inserción levemente menor ( $70^{\circ}$ en los materiales originales). Debido a que no pueden compararse con otras especies del Jurásico, se opta por incluir los materiales de Laguna Flecha Negra en esta especie considerando la variación en la inserción como una característica menor, ya que en los materiales originales se observa una variación en el ángulo de inserción a lo largo de la hoja, que se hace más agudo hacia el ápice.

Cf. Otozamites bunburyanus var. major Kurtz, 1902

Figura.7.2.B

Ejemplar de referencia. MPM PB 15844

Especímenes adicionales. MPM PB 15973

Localidad. Laguna Flecha Negra

Horizonte estratigráfico. Pelitas oscuras

Descripción. Fragmento de hoja monopinnada de 4,8 cm de largo por $1 \mathrm{~cm}$ de ancho. Raquis de 0,25 cm de ancho, estriado. Se preserva la cara abaxial, por lo que no se observa la base de las pinnas. Pinnas subcirculares, de 0,5 cm de largo por 0,5 cm de ancho, insertas de manera aparentemente alterna y casi perpendicular al raquis. Se observan 10 venas en cada pinna, que irradian acróspicamente.

Observaciones. Si bien el material preserva su cara adaxial, lo cual impide observar la base de las pinnas, la forma general y el tamaño de las mismas permiten separarlas de los géneros Zamites y Ptilophyllum. A pesar de ello, y debido a la poca representatividad de la especie en el yacimiento de Laguna Flecha Negra, se opta por asignar el material con dudas a Otozamites bunburyanus var. major del Jurásico del Gran Bajo de San Julián, en la medida que no se encuentren nuevos ejemplares en el sitio. 
Ana Julia Sagasti - Estudio paleobotánico, paleoecológico y paleoambiental...
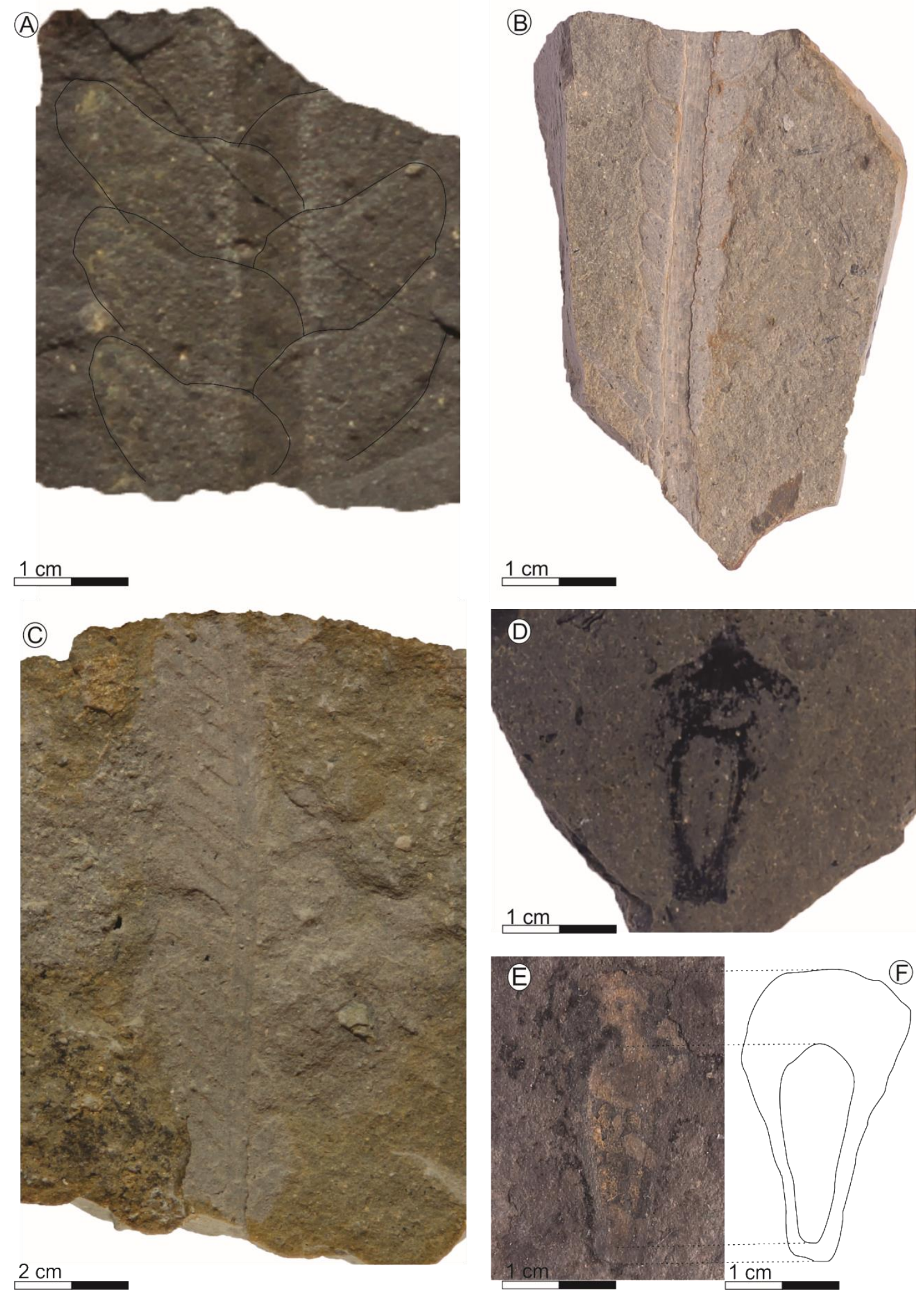

Figura 7.2. Paleoflora de Laguna Flecha Negra. A. Otozamites sueroi MPM PB 15832. B. Cf. Otozamites bunburyanus var. major MPM PB 15844. C. Ptilophyllum hislopii MPM PB 15846. D. Araucarites cutchensis MPM PB 15856. E. Araucarites phillipsii MPM PB 15854. F. Araucarites phillipsii esquema. 
Ana Julia Sagasti - Estudio paleobotánico, paleoecológico y paleoambiental...

\section{Género Ptilophyllum Morris en Grant 1840}

Especie tipo. Ptilophyllum acutifolium Morris en Grant 1840.

Figura. 7.2.C.

$$
\text { Ptilophyllum hislopi (Oldham) Seward, } 1910 .
$$

Ejemplar de referencia. MPM PB 15845

Especímenes adicionales. MPM PB 15846

Localidad. Laguna Flecha Negra

Horizonte estratigráfico. Areniscas gruesas

Descripción. Fragmento de hoja monopinnada de $4,5 \mathrm{~cm}$ de largo por $1,4 \mathrm{~cm}$ de ancho. Raquis de 0,15 cm de ancho, estriado. Pinnas lineares, de márgenes paralelos, con ápice agudo, insertas sobre la cara adaxial del raquis. De 0,7 cm de largo por 0,2 cm de ancho. Se insertan de manera subalterna, formando un ángulo de $35^{\circ}-55^{\circ}$ con el raquis. Las pinnas presentan una base asimétrica, con el margen acroscópico contraído y el margen basiscópico decurrente, sin desarrollo de aurícula. El estado de preservación no permite observar la venación.

Comparaciones. El género Ptilophyllum fue creado para incluir hojas monopinnadas donde las pinnas se insertan a la superficie adaxial del raquis con un ángulo de inserción variable (Watson y Sincock 1992). Se caracterizan por tener una base asimétrica con margen basiscópico decurrente y acroscópico constricto. Las venas ingresan por todo el ancho de la base, son paralelas al margen y pueden dividirse cerca del ápice. El material estudiado se asemeja a Ptilophyllum acutifolium Morris ya que presenta hojas lanceoladas, con un raquis algo mayor a $0,1 \mathrm{~cm}$ con la superficie superior prácticamente recubierta por la base de las pinnas. Las láminas de las pinnas presentan márgenes paralelos de ápice agudo. Esta especie fue descripta por Ferello (1947) en el Liásico de Piedra del Águila, pero los materiales estudiados por el autor presentan pinnas de mayor tamaño (2 cm de largo por 0,45 cm de ancho) y un ángulo de inserción bastante mayor $\left(72^{\circ}\right)$ a los materiales colectados en Laguna Flecha Negra. Los materiales pueden compararse con los restos de Ptilophyllum hislopi (Oldham) Seward que fueran descriptos por Menéndez (1956) en la Flora del Bajo de los Baguales (Liásico del Neuquén). Esta especie presenta un raquis cubierto por pínnas, que en su parte más ancha 
tiene $0,2 \mathrm{~cm}$, las pinnas se insertan formando un ángulo de $60^{\circ}$, de manera alterna, siendo de 0,12 a 0,15 cm de largo por 0,3 cm de ancho en su base, con bordes paralelos hasta la proximidad de su ápice agudo, base simétrica con esquinas redondeadas, sin aurículas y sin superponerse entre sí. Las características generales son idénticas a aquellas observadas en el material de Laguna Flecha Negra. Las variaciones en el tamaño de las pinnas no son significativas y podrían deberse al estadio ontogenético o la porción de la hoja que se habría preservado. Se observa una pequeña diferencia en el ángulo de inserción de las pinnas, siendo mayor hacia la base $\left(\sim 55^{\circ}\right)$ y agudizándose hacia el ápice, hecho que suele observarse en los taxones fósiles monopinnados de frondes cicadofíticas. Los ejemplares colectados se encontraron en areniscas medias a gruesas, sin presencia de película carbonosa, por lo que no pueden analizarse los detalles cuticulares.

Comentarios. El material adicional se preserva sobre su cara abaxial, por lo que no puede observarse la base de las pinnas. Comparte las características generales de tamaño, forma de las pinnas y ángulo de inserción con MPM PB 15845, por lo que se lo incluye tentativamente en esta misma especie.

\section{Clase Coniferopsida Gifford y Foster 1989 \\ Orden CONIFERALES sensu Stewart y Rothwell 1993}

Familia Araucariaceae Henkel y Hochstetter 1865

Género Araucarites Presl, en Sternberg 1838

Especie tipo. Araucarites goeppertii Presl, en Stenberg 1838.

Figura. 7.2.D

Araucarites cutchensis. Feistmantel, 1877.

Ejemplar de referencia. MPM PB 15847.

Especímenes adicionales. MPM PB 15848; MPM PB 15974

Localidad. Laguna Flecha Negra

Horizonte estratigráfico. Pelitas oscuras

Descripción. Bráctea subtriangular de apariencia leñosa. Base de 0,3 cm de ancho, altura $1,3 \mathrm{~cm}$, ancho máximo $0,8 \mathrm{~cm}$ a $1,1 \mathrm{~cm}$ de altura. Presenta una lígula triangular conspicua. Semilla platispérmica invertida en la zona proximal 
Ana Julia Sagasti - Estudio paleobotánico, paleoecológico y paleoambiental...

de la bráctea, de $0,3 \mathrm{~cm}$ de ancho por $0,8 \mathrm{~cm}$ de alto, más anchos en el extremo chalazal, aguzándose gradualmente hacia el extremo micropilar.

Comentarios. El material adicional presenta una morfología general muy similar a MPM PB 15847, levemente más grande. Bráctea con base de 0,5 cm, ancho máximo de $1,5 \mathrm{~cm}$ a $1,5 \mathrm{~cm}$ de altura; altura máxima $1,9 \mathrm{~cm}$. Semilla oblonga de $0,5 \mathrm{~cm}$ de ancho por $1,1 \mathrm{~cm}$ de alto. El ejemplar MPM PB 15848, tiene una base de $0,8 \mathrm{~cm}$, ancho máximo de $1,5 \mathrm{~cm}$ a $1,1 \mathrm{~cm}$ de altura, y un alto total de $1,7 \mathrm{~cm}$, con una semilla de $0,6 \mathrm{~cm}$ de ancho por $0,9 \mathrm{~cm}$ de alto. En este ejemplar la lígula es más redondeada que en el material de referencia.

Comparaciones. El material puede clasificarse dentro de la especie Araucarites cutchensis Feistmantel, ya que presenta aspecto leñoso, lígula conspicua en el centro del ápice, similares dimensiones tanto de la bráctea como de la semilla, que no se dispersa de manera independiente sino como parte del complejo. Esta especie es característica del Jurásico Tardío-Cretácico Temprano de la India (Bose y Maheshwari, 1973). Se registra también en la Formación Cañadón Asfalto (Chubut) (Frenguelli, 1949; Cortés y Baldoni, 1984) y con dudas en el Jurásico Inferior de Bahía Esperanza (Antártida) (Rees y Cleal, 2004).

Figura. 7.2. E-F.

\section{Araucarites phillipsii Carruthers 1869.}

Ejemplar de referencia. MPM PB 15849

Especímenes adicionales. MPM PB 15850-15858.

Localidad. Laguna Flecha Negra

Horizonte estratigráfico. Pelitas oscuras

Descripción. Bráctea cuneiforme sin base preservada, de aspecto papiráceo. Porción angosta de 0,3 cm de ancho, ápice de 0,8 cm de ancho, alto $2 \mathrm{~cm}$. Semilla rectangular poco marcada, ocupa casi toda la bráctea; de $0,3 \mathrm{~cm}$ de ancho por 1,3 cm de alto. No se observa lígula.

Comentarios. En los materiales adicionales, la semilla es platispérmica, invertida, inserta siempre en la base de la bráctea, no siempre ocupa todo el alto de la bráctea. Las dimensiones varían levemente, de 0,3 a 0,5 cm en la base $(0,44 \mathrm{~cm}$ en promedio), 0,9 a $1,4 \mathrm{~cm}$ de ancho máximo $(1,1 \mathrm{~cm}$ en 
Ana Julia Sagasti - Estudio paleobotánico, paleoecológico y paleoambiental...

promedio), y 1,5 a $2 \mathrm{~cm}$ de alto (1,74 $\mathrm{cm}$ en promedio). En general no se observan los ápices o no muestran una lígula marcada.

Observaciones. El género Araucarites fue usado inicialmente por Endlicher (1837) de manera informal, para referirse a ciertos troncos fósiles de coníferas del Carbonífero. Esta propuesta fue utilizada escasamente y en 1993 Philippe realiza una revisión de los taxones de leños coniferoides, y descarta su uso en este sentido. En 1838, Presl propone el género Araucarites para referir a fósiles de estróbilos femeninos y escamas ovulíferas dispersas con afinidad con las Araucariaceae. Debido al uso dado a ese taxón fósil, Zijlstra y van Konijnenburg-van Cittert (2000) proponen la conservación del nombre Araucarites para referirse a conos femeninos y brácteas dispersas de Araucariaceae y preservados como impresiones - compresiones. Las brácteas dispersas se caracterizan por ser generalmente leñosas, cuneiformes, están fusionadas a la escama ovulífera que porta un único óvulo y en algunos casos presentan una lígula distal libre (Cleal y Rees 2003).

Comparaciones. La especie Araucarites phillipsii fue utilizada para describir conos femeninos, brácteas dispersas y renovales. Aquí se aplica para las escamas dispersas que aparecen en abundancia en el nivel de pelitas oscuras de la localidad Laguna Flecha Negra. Comparten con los ejemplares de Carruthers las dimensiones generales, forma de cuña, con el ancho máximo bien cerca del ápice, una semilla de posición central, embebida, que ocupa gran parte de la bráctea y alas membranosas, no coriáceas. Esta especie fue descripta en la provincia del Neuquén por Arrondo y Petriella (1980) quienes señalan fuertes similitudes con los materiales identificados como Araucarites sp. por Herbst (1966b) en el Liásico de Piedra Pintada.

Figura.7.3.A-C

\section{Araucarites sp. (conos)}

Ejemplar de referencia. MPM PB 15985

Especímenes adicionales. MPM PB 16021

Localidad. Laguna Flecha Negra

Horizonte estratigráfico. Areniscas gruesas y Pelitas oscuras.

Descripción. En el ejemplar MPM PB 15985 se observa una rama foliosa bifurcada en el ápice, asociado a esta rama, se encuentra un cono circular, de 
$1,2 \mathrm{~cm}$ de diámetro que porta escamas romboidales minúsculas $(0,1 \mathrm{~cm}$ de ancho por $0,5 \mathrm{~cm}$ de largo) dispuestas espiraladamente. En el caso de MPM PB 16021 se preserva un cono subcircular, de 1,2 cm de ancho por 1,5 cm de largo, con escamas romboidales dispuestas espiraladamente, de manera adpresa, con ápice agudo apenas libre. En ninguno de los casos se puede diferenciar presencia del tríptico estructural típico de coníferas (bráctea, escama ovulífera, óvulo) debido a la pobre preservación del material.

Comentarios. Estas muestras pueden compararse con conos de la familia Araucariaceae. No se han encontrado restos con evidencia de estructura interna. En función de la organización compacta de las brácteas, y el tamaño pequeño de ellas y el cono en general, se sugiere que se trataría de estróbilos inmaduros. La ausencia de tríptico estructural podría indicar un estado de desarrollo muy inicial, o, probablemente, que se trate de conos microsporangiados. Por otro lado, la escasa cantidad de ejemplares, con características morfológicas de difícil evaluación no permite realizar una asignación específica para las muestras.

\section{Género Agathoxylon Hartig 1848}

Especie tipo. Agathoxylon cordaiatum Hartig 1848.

Figura. 7.3.C-E

Agathoxylon arayaii Torres et al. 1982.

Ejemplar de referencia. MPM PB 15929

Localidad. Laguna Flecha Negra

Horizonte estratigráfico. Areniscas gruesas

Descripción. Leño picnoxílico, homoxilado, representado exclusivamente por xilema secundario de tipo coniferoide. No se recuperó corte transversal del ejemplar. Las punteaduras de las paredes radiales de las traqueidas son areoladas, dominantemente uniseriadas, comprimidas, cuando biseriadas, subalternas, de tipo araucarioide. Las mismas miden entre $0,55 \mu \mathrm{m}$ de alto por $0,76 \mu \mathrm{m}$ de ancho y $0,71 \mu \mathrm{m}$ de alto por $1,07 \mu \mathrm{m}$ de ancho (en promedio 0,64 $\mu \mathrm{m} \times 0,88 \mu \mathrm{m})$. El poro de las punteaduras mide entre $0,28 \mu \mathrm{m}$ de alto por 0,4 $\mu \mathrm{m}$ de ancho, y 0,38 $\mu \mathrm{m}$ de alto por 0,59 $\mu \mathrm{m}$ de ancho (en promedio 0,33 $\mu \mathrm{m}$ de alto por $0,45 \mu \mathrm{m}$ de ancho). Las paredes tangenciales de las traqueidas no 

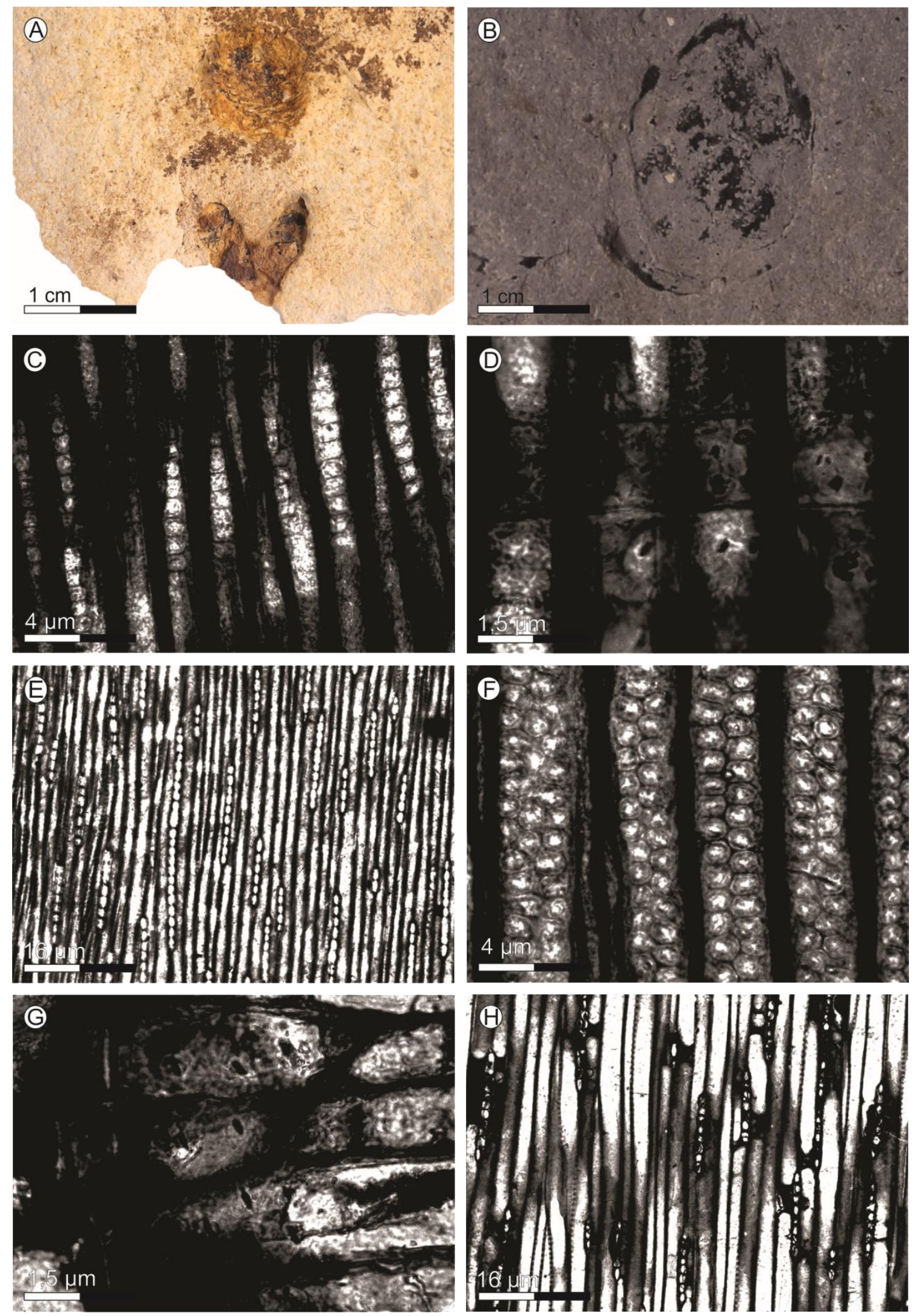

Figura 7.3. Paleoflora de Laguna Flecha Negra. A. Araucarites sp. MPM PB 15985. B. Araucarites sp. MPM PB 16021. C-E. Agathoxylon arayaii MPM PB 15929. C. Punteaduras de las traqueidas. D. Campos de cruzamiento. E. Radios uniseriados. FH. Agathoxylon cf. floresii F. Punteaduras de las traqueidas MPM PB 15896. G. Detalle campos de cruzamiento MPM PB 15928. H. Radios uniseriados MPM PB 15907. 
Ana Julia Sagasti - Estudio paleobotánico, paleoecológico y paleoambiental...

presentan punteaduras. No se observa parénquima axial. Los campos de cruzamiento presentan de 2 a 4 punteaduras cupresoides (sensu Richter et al., 2004) dispuestas en una o dos hileras, adoptando una disposición araucarioide (sensu Philippe y Bamford, 2008). Las punteaduras de los campos miden entre $0,22 \mu \mathrm{m} \times 0,14 \mu \mathrm{m}$ y $0,37 \mu \mathrm{m} \times 0,27 \mu \mathrm{m}$ (en promedio $0,30 \mu \mathrm{m} \times 0.20 \mu \mathrm{m}$ ). Los radios leñosos son heterocelulares, uniseriados y de medianos a altos. Su altura oscila entre 2 y 24 células, en promedio 7 células. Las células del parénquima radial tienen una sección transversal que oscila entre $0,47 \mu \mathrm{m}$ de ancho por $0,95 \mu \mathrm{m}$ de ancho y $1,5 \mu \mathrm{m}$ de ancho por $1,78 \mu \mathrm{m}$ de alto (en promedio $0,95 \mu \mathrm{m}$ de ancho por $1,36 \mu \mathrm{m}$ de alto). Las traqueidas radiales se localizan en la parte media del radio. Las paredes de las células del parénquima radial son distintivamente lisas, no perforadas.

Comentarios. Según la diagnosis de Hartig (1848), el género Agathoxylon se usa para referirse a leños de coníferas con radios uniseriados, sin canales resiníferos, con presencia de parénquima axial y campos de cruzamiento con punteaduras contiguas. Según la revisión de maderas mesozoicas coniferofíticas realizada por Philippe y Bamford (2008), el parénquima axial puede o no estar presente, y en cualquier caso no es particularmente abundante ni de disposición notoria. La ausencia de parénquima axial en el material de Laguna Flecha Negra podría deberse al estado de preservación de los materiales, o a una verdadera ausencia en los ejemplares estudiados.

Comparaciones. La presencia de punteaduras de las traqueidas de tipo araucarioides, y campos de cruzamiento con punteaduras cupresoides de arreglo araucarioide, permiten clasificar el material dentro del género Agathoxylon Hartig, según el criterio de Philippe y Bamford (2008). El material puede compararse con Agathoxylon arayaii Torres et al. (1982) ya que comparten punteaduras de las paredes radiales de las traqueidas uni 0 biseriadas, alternas, de tipo araucarioide; radios uniseriados con 1 a 25 células de alto (8-10 en promedio) y 2 a 6 punteaduras (mayormente entre 2 y 4) por campo de cruzamiento. Este material fue descripto por Torres et al. (1982, 1994, 2000) para el Jurásico y Cretácico de Antártida. 
Ana Julia Sagasti - Estudio paleobotánico, paleoecológico y paleoambiental...

Agathoxylon cf. floresii Torres y Lemoigne 1989

Figura. 7.3.F-H

Ejemplar de referencia. MPM PB 15907

Especímenes adicionales. MPM PB 15896, 15928.

Localidad. Laguna Flecha Negra

Horizonte estratigráfico. Areniscas gruesas

Descripción. Leño picnoxílico, homoxilado, representado exclusivamente por xilema secundario de tipo coniferoide. Debido al estado de preservación de los materiales, que tienden a la fractura al ser cortados, no se recuperó corte transversal de los ejemplares. Las punteaduras de las paredes radiales de las traqueidas son areoladas, dominantemente biseriadas, en algunas zonas triseriadas, siempre alternas y comprimidas, de patrón araucarioide. Las mismas miden entre $0,74 \mu \mathrm{m}$ de alto por $0,93 \mu \mathrm{m}$ de ancho y $0,95 \mu \mathrm{m}$ de alto por $1,2 \mu \mathrm{m}$ de ancho (en promedio $0.83 \mu \mathrm{m} \times 1,05 \mu \mathrm{m}$ ). Las paredes tangenciales de las traqueidas no presentan punteaduras. No se observa parénquima axial. Los campos de cruzamiento presentan de 4 a 5 punteaduras cupresoides dispuestas en dos hileras, contiguas y comprimidas, de arreglo araucarioide (Richter et al., 2004; Philippe y Bamford, 2008). Las punteaduras de los campos de cruzamiento miden entre $0,36 \mu \mathrm{m} \times 0,21 \mu \mathrm{m}$ y $0,55 \mu \mathrm{m} \times 0,45 \mu \mathrm{m}$ (en promedio $0,43 \mu \mathrm{m} \times 0,29 \mu \mathrm{m})$. Los radios leñosos son heterocelulares, uniseriados y bajos. Su altura oscila entre 1 y 12 células, en promedio 6 células. Las células del parénquima radial tienen una sección transversal que oscila entre $0,24 \mu \mathrm{m}$ de ancho por $0,36 \mu \mathrm{m}$ de alto y $0,47 \mu \mathrm{m}$ de ancho por $0,59 \mu \mathrm{m}$ de alto (en promedio $0,37 \mu \mathrm{m}$ de ancho $\times 0,45 \mu \mathrm{m}$ de alto). Las traqueidas radiales se localizan en la parte media del radio. Las paredes de las células del parénquima radial son distintivamente lisas, no perforadas. Se observan contenidos opacos dentro de los radios y placas de resina en las traqueidas.

Comparaciones. Las características anatómicas observables de los ejemplares, permiten clasificarlos dentro del género Agathoxylon Hartig, siguiendo el criterio de Philippe y Bamford (2008). El material estudiado puede compararse con Agathoxylon floresii Torres y Lemoigne (1989), del Cretácico Superior de Antártida. Esta especie comparte con el material de Laguna Flecha Negra, la presencia de punteaduras araucarioides biseriadas, radios 
Ana Julia Sagasti - Estudio paleobotánico, paleoecológico y paleoambiental...

uniseriados de 2 a 15 células de alto (4-7 en promedio) y 1 a 4 punteaduras cupresoides por campo de cruzamiento. A su vez, presenta abundantes contenidos resinosos en las traqueidas. La diagnosis original incluye la presencia de punteado tangencial y parénquima axial, que no se observan en los ejemplares estudiados, aunque estas ausencias podrían deberse al estado de preservación de los materiales aquí analizados. Torres y Lemoigne (1989) señalan la ausencia de anillos de crecimiento demarcados, carácter que no puede ser evaluado ya que no se han recuperado cortes transversales de los ejemplares de Laguna Flecha Negra. Se opta por asignar con dudas a la especie Agathoxylon floresii.

\section{Agathoxylon jurassicum Bhardwaj 1953}

Figura. 7.4. A-D

Ejemplar de referencia. MPM PB 15908

Especímenes adicionales. MPM PB 15921 y 15927.

Localidad. Laguna Flecha Negra

Horizonte estratigráfico. Areniscas gruesas.

Descripción. Leño picnoxílico, homoxilado, representado exclusivamente por xilema secundario de tipo coniferoide. Presenta anillos de crecimiento definidos, de ancho variable (23-78 células). Espesor de la capa de leño tardío de 1 a 3 células, con transición abrupta entre el leño temprano y el leño tardío. Las traqueidas tienen una sección transversal subcircular, levemente cuadrada, muy pocas células de contorno rectangular. Traqueidas del leño temprano con un diámetro radial que oscila entre $0,8 \mu \mathrm{m}$ y $2,45 \mu \mathrm{m}$, en promedio $1,6 \mu \mathrm{m}$. El diámetro tangencial de las traqueidas del leño temprano oscila entre 0,6 $\mu \mathrm{m}$ y 2,7 $\mu \mathrm{m}$, en promedio 1,7 $\mu \mathrm{m}$. El espesor de la doble pared de las traqueidas del leño temprano oscila entre 0,2 $\mu \mathrm{m}$ y 0,45 $\mu \mathrm{m}$, en promedio 0,32 $\mu \mathrm{m}$. Las traqueidas del leño tardío presentan un diámetro radial que oscila entre 0,29 $\mu \mathrm{m}$ y $0,6 \mu \mathrm{m}$, en promedio $0,43 \mu \mathrm{m}$; el diámetro tangencial oscila entre $0,8 \mu \mathrm{m}$ y $1,7 \mu \mathrm{m}$, en promedio $1,36 \mu \mathrm{m}$. El espesor de la doble pared de las traqueidas del leño tardío oscila entre $0,5 \mu \mathrm{m}$ y $1,33 \mu \mathrm{m}$, en promedio 0,76 $\mu \mathrm{m}$. Las punteaduras de las paredes radiales de las traqueidas son areoladas, predominantemente uniseriadas, comprimidas, dos veces más anchas que altas, de tipo xenoxylon (en MPM PB 15976), o punteaduras bi a triseriadas, 
alternas, comprimidas, de tipo araucarioide (en MPM PB 15989 y 15995). Las mismas miden entre $0,58 \mu \mathrm{m}$ de alto por $0,7 \mu \mathrm{m}$ de ancho y $0,86 \mu \mathrm{m}$ alto por 1,16 $\mu \mathrm{m}$ de ancho (en promedio $0,74 \mu \mathrm{m} \times 0,97 \mu \mathrm{m}$ ). El poro de las punteaduras mide entre $0,25 \mu \mathrm{m}$ de ancho por 0,2 $\mu \mathrm{m}$ de alto y 0,4 $\mu \mathrm{m}$ de ancho por 0,3 $\mu \mathrm{m}$ de alto, en promedio 0,34 $\mu \mathrm{m} \times 0,26 \mu \mathrm{m}$. Las paredes tangenciales de las traqueidas no presentan punteaduras. No se observa parénquima axial. Los campos de cruzamiento presentan de 4 a 6 punteaduras cupresoides (sensu Richter et al., 2004), dispuestas en dos o tres hileras, de manera alterna y contigua, adoptando una disposición araucarioide (sensu Philippe y Bamford, 2008). Las punteaduras de los campos de cruzamiento miden entre 0,33 $\mu \mathrm{m}$ de diámetro mayor por 0,26 $\mu \mathrm{m}$ de diámetro menor, y 0,64 $\mu \mathrm{m}$ de diámetro mayor por 0,62 $\mu \mathrm{m}$ de diámetro menor (en promedio 0,2 $\mu \mathrm{m}$ de diámetro mayor por $0,15 \mu \mathrm{m}$ de diámetro menor). El poro de las punteaduras de los campos de cruzamiento mide entre $0,21 \mu \mathrm{m} \times 0,12 \mu \mathrm{m}$ y 0,45 $\mu \mathrm{m} \times 0,14$ $\mu \mathrm{m}$ (en promedio 0,3 $\mu \mathrm{m} \times 0,14 \mu \mathrm{m}$. Los radios leñosos son homocelulares, uniseriados, con 1 a 14 células de alto (4 en promedio), separadas por 1 a 3 traqueidas. Las células del parénquima radial tienen una sección transversal que oscila entre 0,65 $\mu \mathrm{m}$ de ancho por $1,22 \mu \mathrm{m}$ de alto y 1,03 $\mu \mathrm{m}$ de ancho por $1,78 \mu \mathrm{m}$ de alto (en promedio $0,86 \mu \mathrm{m} \times 1,5 \mu \mathrm{m}$ ). Las paredes de las células del parénquima radial son distintivamente lisas, no perforadas. Comparaciones. La presencia de punteaduras araucarioides o de tipo xenoxylon y campos de cruzamiento con numerosas punteaduras cupresoides, dispuestas de manera contigua, permiten clasificar el material dentro del género Agathoxylon Hartig, siguiendo el criterio de Philippe y Bamford (2008). El material puede compararse con Dadoxylon (Agathoxylon) jurassicum Bhardwaj 1953, por la presencia de punteaduras radiales uni o biseriadas, contiguas y comprimidas, de tipo araucarioide, radios homocelulares, uniseriados con 1 a 11 células de alto (4 en promedio), 4 a 8 punteaduras areoladas, en 2 a 4 hileras y la ausencia de parénquima axial. Este taxón fósil fue descripto para el Jurásico y Cretácico inferior de India. 
Ana Julia Sagasti - Estudio paleobotánico, paleoecológico y paleoambiental...

\section{Agathoxylon matildense Zamuner y Falaschi 2005}

Figura. 7.4.E-H

Ejemplar de referencia. MPM PB 15905

Localidad. Laguna Flecha Negra

Horizonte estratigráfico. Areniscas gruesas

Descripción. Leño picnoxílico, homoxilado, representado exclusivamente por xilema secundario de tipo coniferoide. Presenta anillos de crecimiento definidos, de espesor variable (20 a 54 células). Espesor de la capa de leño tardío de 1 a 2 células, con transición abrupta entre el leño temprano y el leño tardío. Las traqueidas tienen una sección transversal subredondeada a levemente achatada en sentido radial. Traqueidas del leño temprano con un diámetro radial que oscila entre 0,67 $\mu \mathrm{m}$ y 1,53 $\mu \mathrm{m}$ (en promedio 1,11 $\mu \mathrm{m}$ ), diámetro tangencial entre 0,76 $\mu \mathrm{m}$ y 1,9 $\mu \mathrm{m}$ (en promedio 1,19 $\mu \mathrm{m}$ ); espesor de la doble pared entre 0,29 $\mu \mathrm{m}$ y 0,57 $\mu \mathrm{m}$ (en promedio 0,42 $\mu \mathrm{m}$ ). Traqueidas del leño tardío con un diámetro radial entre $0,29 \mu \mathrm{m}$ y $0,57 \mu \mathrm{m}$ (en promedio 0,41 $\mu \mathrm{m}$ ); diámetro tangencial entre $0,86 \mu \mathrm{m}$ y $1,24 \mu \mathrm{m}$ (en promedio $1 \mu \mathrm{m}$ ); espesor de la doble pared entre 0,48 $\mu \mathrm{m}$ y $1,05 \mu \mathrm{m}$ (en promedio 0,73 $\mu \mathrm{m}$ ). Las punteaduras de las paredes radiales de las traqueidas son areoladas, predominantemente uniseriadas, cuando biseriadas, alternas, siempre comprimidas, de tipo araucarioide. Las mismas miden entre 0,78 $\mu \mathrm{m}$ de ancho por $0,57 \mu \mathrm{m}$ de alto y $0,9 \mu \mathrm{m}$ de ancho por $0,7 \mu \mathrm{m}$ de alto (en promedio 0,82 $\mu \mathrm{m} \times 0,64 \mu \mathrm{m})$. El poro de las punteaduras mide entre 0,21 $\mu \mathrm{m}$ de ancho por 0,16 de alto y 0,37 $\mu \mathrm{m}$ de alto por 0,26 $\mu \mathrm{m}$ de ancho (en promedio 0,27 $\mu \mathrm{m} x$ $0,22 \mu \mathrm{m})$. Las paredes tangenciales de las traqueidas no presentan punteaduras. No se observa parénquima axial. Los campos de cruzamiento presentan cuatro punteaduras cupresoides (sensu Richter et al., 2004), dispuestas de manera alterna y algo contigua, adoptando un patrón araucarioide (sensu Philippe y Bamford, 2008). Las punteaduras de los campos de cruzamiento miden entre $0,33 \mu \mathrm{m}$ de diámetro mayor por $0,19 \mu \mathrm{m}$ de diámetro menor y $0,52 \mu \mathrm{m}$ de diámetro mayor por 0,31 de diámetro menor (en promedio $0,38 \mu \mathrm{m} \times 0,25 \mu \mathrm{m})$. El poro de las punteaduras mide entre $0,19 \mu \mathrm{m} \times$ $0,07 \mu \mathrm{m}$ y $0,28 \mu \mathrm{m} \times 0,16 \mu \mathrm{m}$ (en promedio $0,22 \mu \mathrm{m} \times 0,1 \mu \mathrm{m}$ ). Los radios leñosos son homocelulares, uniseriados, con 1 a 7 células de alto (3 en promedio). Las células del parénquima radial miden entre $0,48 \mu \mathrm{m}$ de ancho 

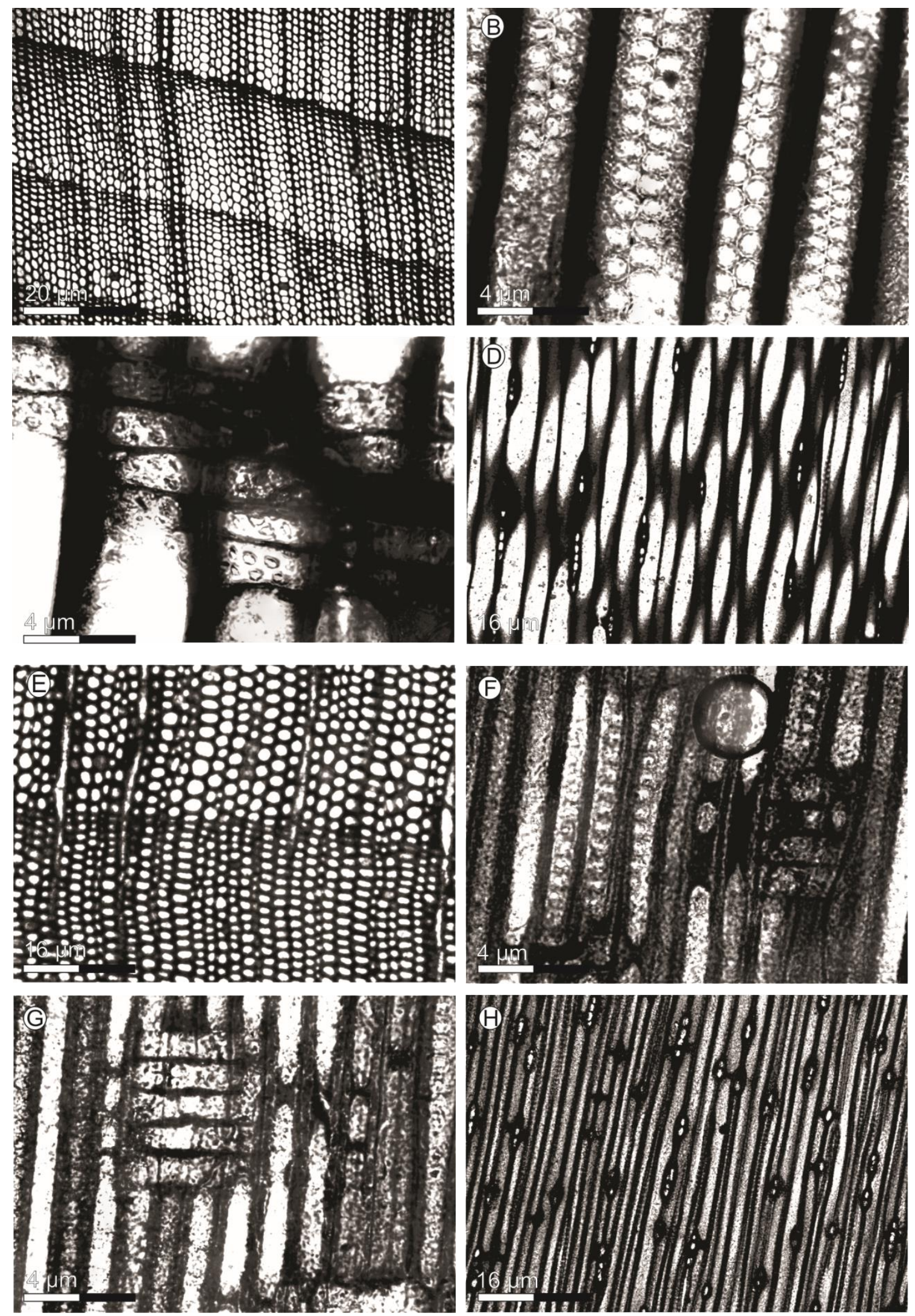

Figura 7.4. A-D. Agathoxylon jurassicum MPM PB 15921. A. CT Anillos de crecimiento definidos. B. CLR Punteaduras de las traqueidas. C. CLR Campos de cruzamiento. D. CLT Radios uniseriados. E.H. Agathoxylon matildense MPM PB 15905. E. CT Anillos de crecimiento definidos. F. CLR Punteaduras de las traqueidas, cuñas de resina en las traqueidas axiales. G. CLR Campos de cruzamiento. H. CLT Radios uniseriados. 
Ana Julia Sagasti - Estudio paleobotánico, paleoecológico y paleoambiental...

por $0,86 \mu \mathrm{m}$ de alto y $0,86 \mu \mathrm{m} \times 1,43 \mu \mathrm{m}$, en promedio $0,65 \mu \mathrm{m} \times 1,12 \mu \mathrm{m}$. Las paredes del parénquima radial son distintivamente lisas, no perforadas. Abundantes placas de resina en las traqueidas del sistema axial.

Comparaciones. La presencia de punteaduras araucarioides y campos de cruzamiento con punteaduras cupresoides dispuestas de manera alterna, algo comprimida, permiten clasificar este ejemplar dentro del género Agathoxylon Hartig, según el criterio de Philippe y Bamford (2008). El material puede compararse con Agathoxylon matildense Zamuner y Falaschi (2005) ya que comparten punteaduras radiales de las traqueidas uniseriadas, circulares, contiguas, raramente biseriadas; radios uniseriados bajos (1-4 [2-3] en los materiales de La Matilde), 4 a 5 punteaduras cupresoides de disposición irregular y ausencia de punteado tangencial y parénquima axial. Se diferencian en la formación de anillos de crecimiento con pasaje abrupto entre el leño temprano y tardío, y el menor desarrollo de leño tardío, que es de 1 a 2 células en el ejemplar estudiado, mientras que en los ejemplares estudiados por Zamuner y Falaschi, puede llegar hasta 7 células.

\section{Araucariaceae indet.}

Figura. 7.5.A-D

Ejemplar de referencia. MPM PB 15935

Especímenes adicionales. MPM PB 15962, 15897.

Localidad. Laguna Flecha Negra

Horizonte estratigráfico. Tobas blancas. Areniscas gruesas.

Descripción. Leño picnoxílico, homoxilado, representado exclusivamente por xilema secundario de tipo coniferoide. Presenta anillos de crecimiento definidos, de espesor variable (17 a 22 células). Espesor de la capa de leño tardío de 1 a 4 células, con transición abrupta entre el leño temprano y el leño tardío. Las traqueidas tienen una sección transversal subcircular. Traqueidas del leño temprano con un diámetro radial que oscila entre $1,21 \mu \mathrm{m}$ y $2,3 \mu \mathrm{m}$ (en promedio 1,6 $\mu \mathrm{m}$ ), diámetro tangencial entre $0,97 \mu \mathrm{m}$ y $1,7 \mu \mathrm{m}$ (en promedio $1,33 \mu \mathrm{m}$ ), espesor de la doble pared entre 0,24 $\mu \mathrm{m}$ y $0,36 \mu \mathrm{m}$ (en promedio $0,29 \mu \mathrm{m})$. Traqueidas del leño tardío con un diámetro radial entre $0,24 \mu \mathrm{m}$ y $0,48 \mu \mathrm{m}$ (en promedio $0,39 \mu \mathrm{m}$ ), diámetro tangencial entre $0,73 \mu \mathrm{m}$ y $1,21 \mu \mathrm{m}$ (en promedio $0.99 \mu \mathrm{m}$ ), espesor de la doble pared entre $0,48 \mu \mathrm{m}$ y $0,73 \mu \mathrm{m}$ (en 
promedio 1,08 $\mu \mathrm{m})$. Las punteaduras de las paredes radiales de las traqueidas son areoladas, predominantemente biseriadas, alternas, a veces uniseriadas, siempre comprimidas, de tipo araucarioide. Las mismas miden entre 0,7 $\mu \mathrm{m}$ de ancho por 0,76 $\mu \mathrm{m}$ de alto y 0,9 $\mu \mathrm{m}$ de ancho por 0,86 $\mu \mathrm{m}$ de alto (en promedio $0,82 \mu \mathrm{m} \times 0,8 \mu \mathrm{m})$. El poro de las punteaduras mide entre $0,26 \mu \mathrm{m}$ de ancho por $0,24 \mu \mathrm{m}$ de alto y $0,38 \mu \mathrm{m}$ de ancho por 0,33 $\mu \mathrm{m}$ de alto (en promedio 0,31 $\mu \mathrm{m} \times 0,28 \mu \mathrm{m})$. Las paredes tangenciales de las traqueidas no presentan punteaduras. No se observa presencia de parénquima axial. El corte longitudinal radial no pudo realizarse con precisión, por lo que no se observan los campos de cruzamiento de manera adecuada para su definición. Los radios leñosos son uniseriados, bajos, con 1 a 16 células de alto (6 en promedio) y paredes aparentemente lisas. Las células del parénquima radial miden entre $0,86 \mu \mathrm{m}$ de ancho por $1,05 \mu \mathrm{m}$ de alto y 1,63 $\mu \mathrm{m}$ de ancho por $1,82 \mu \mathrm{m}$ de alto (en promedio 1,07 $\mu \mathrm{m} \times 1,44 \mu \mathrm{m}$ ).

Comparaciones. La imposibilidad de evaluar los campos de cruzamiento en detalle impide realizar asignaciones a nivel genérico. La presencia de un leño picnoxílico, homoxilado, con punteaduras de las traqueidas de tipo araucarioide, permiten señalar la afinidad con la familia Araucariaceae. 

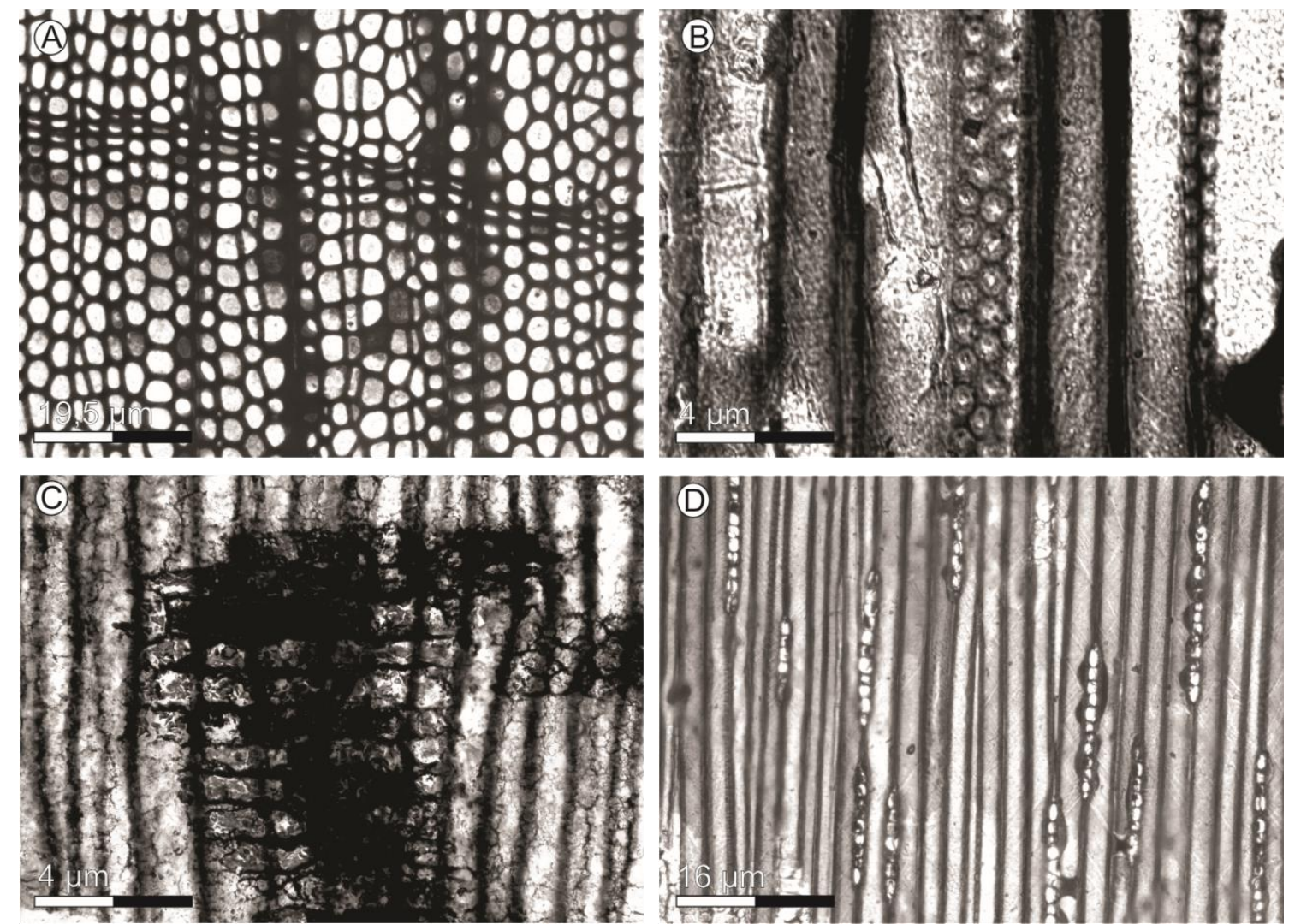

Figura 7.5. A-D. Araucariaceae indet. A. CT Anillos de crecimiento demarcados MPM PB 15897. B. CLR Punteaduras de las traqueidas MPM PB 15897. C. CLR Campos de cruzamiento con contenídos resiníferos. MPM PB 15962. D. CLT Radios uniseriados. MPM PB 15897.

\section{Familia Cupressaceae (s. I.) Gray sensu Farjon, 2005}

\section{Género Protaxodioxylon Bamford y Philippe, 2001}

Especie tipo. Protaxodioxylon romanensis (Philippe) Bamford y Philippe, 2001

\section{Protaxodioxylon sp.}

Figura. 7.6. A-F

Ejemplar de referencia.MPM PB 15937

Especímenes adicionales. MPM PB 15923, 15940, 15942, 15944, 15953, 15955

Localidad. Laguna Flecha Negra

Horizonte estratigráfico. Tobas blancas. Areniscas gruesas.

Descripción. Leño picnoxílico, homoxilado, representado exclusivamente por xilema secundario de tipo coniferoide. Presenta anillos de crecimiento definidos, de espesor variable (15 a 32 células). Espesor de la capa de leño tardío de 1 a 2 células, con transición abrupta. Las traqueidas tienen una sección transversal poligonal a subredondeada. Traqueidas del leño temprano 
Ana Julia Sagasti - Estudio paleobotánico, paleoecológico y paleoambiental...

con un diámetro radial que oscila entre $0,78 \mu \mathrm{m}$ y 1,21 $\mu \mathrm{m}$ (en promedio 1,01 $\mu \mathrm{m}$ ), diámetro tangencial entre 0,48 $\mu \mathrm{m}$ y 1,09 $\mu \mathrm{m}$ (en promedio 0,72 $\mu \mathrm{m}$ ), espesor de la doble pared entre 0,12 $\mu \mathrm{m}$ y 0,24 $\mu \mathrm{m}$ (en promedio 0,22 $\mu \mathrm{m}$ ). Traqueidas del leño tardío con un diámetro radial entre $0,12 \mu \mathrm{m}$ y 0,36 $\mu \mathrm{m}$ (en promedio $0,24 \mu \mathrm{m}$ ), diámetro tangencial entre $0,36 \mu \mathrm{m}$ y $0,73 \mu \mathrm{m}$ (en promedio $0,57 \mu \mathrm{m}$ ), espesor de la doble pared entre 0,24 $\mu \mathrm{m}$ y $0,6 \mu \mathrm{m}$ (en promedio 0,4 $\mu \mathrm{m})$. Las punteaduras de las paredes radiales de las traqueidas son areoladas, predominantemente uniseriadas $(70 \%)$, contiguas $(70 \%)$, cuando biseriadas (30\%) son alternas, de tipo mixto. Las mismas miden entre 0,74 $\mu \mathrm{m}$ de ancho por $0,6 \mu \mathrm{m}$ de alto y $1,36 \mu \mathrm{m}$ de ancho por $1,15 \mu \mathrm{m}$ de alto (en promedio 1,02 $\mu \mathrm{m} \times 0,84 \mu \mathrm{m})$. El poro de las punteaduras mide entre $0,19 \mu \mathrm{m}$ de ancho por $0,19 \mu \mathrm{m}$ de alto y $0,83 \mu \mathrm{m}$ de ancho por $0,69 \mu \mathrm{m}$ de alto (en promedio $0,43 \mu \mathrm{m}$ $\mathrm{x} 0,42 \mu \mathrm{m})$. Las paredes tangenciales de las traqueidas no presentan punteaduras. No se observa presencia de parénquima axial. Los campos de cruzamiento presentan una a dos punteaduras taxodioides grandes, alineadas, espaciadas. Las punteaduras de los campos de cruzamiento miden entre 0,43 $\mu \mathrm{m}$ de diámetro mayor por $0,28 \mu \mathrm{m}$ de diámetro menor y $0,95 \mu \mathrm{m}$ de diámetro mayor por 0,81 $\mu \mathrm{m}$ de diámetro menor (en promedio 0,73 $\mu \mathrm{m} \times 0,52 \mu \mathrm{m}$ ). El poro de las punteaduras mide entre $0,31 \mu \mathrm{m}$ por $0,21 \mu \mathrm{m}$ y $0,74 \mu \mathrm{m}$ por 0,45 $\mu \mathrm{m}$ (en promedio 0,53 $\mu \mathrm{m} \times 0,3 \mu \mathrm{m}$ ). Los radios leñosos son homocelulares, uniseriados bajos a medios, de 2 a 37 células de altura (10 en promedio), separados por 2 o 3 traqueidas. Las paredel de las células del parénquima radial son distintivamente lisas, no perforadas.

Comparaciones. Según el criterio de Philippe y Bamford (2008), la presencia de punteaduras de las paredes radiales de las traqueidas de tipo mixto y campos de cruzamiento con una o dos punteaduras taxodioides, alineadas y espaciadas, se corresponde con la diagnosis del género fósil Protaxodioxylon Bamford y Philippe (2001). Este género se caracteriza por la presencia de un leño homoxilado, picnoxílico, con punteaduras de las paredes radiales de las traqueidas de tipo mixto y campos de cruzamiento de tipo taxodioide, i.e. 1 a 5 oculiporos en una o más filas horizontales, con el diámetro del poro mayor al ancho de una de las areolas (Philippe, 1995), el eje del poro tiene una posición de horizontal a levemente oblicua (Bamford y Philippe, 2001). 

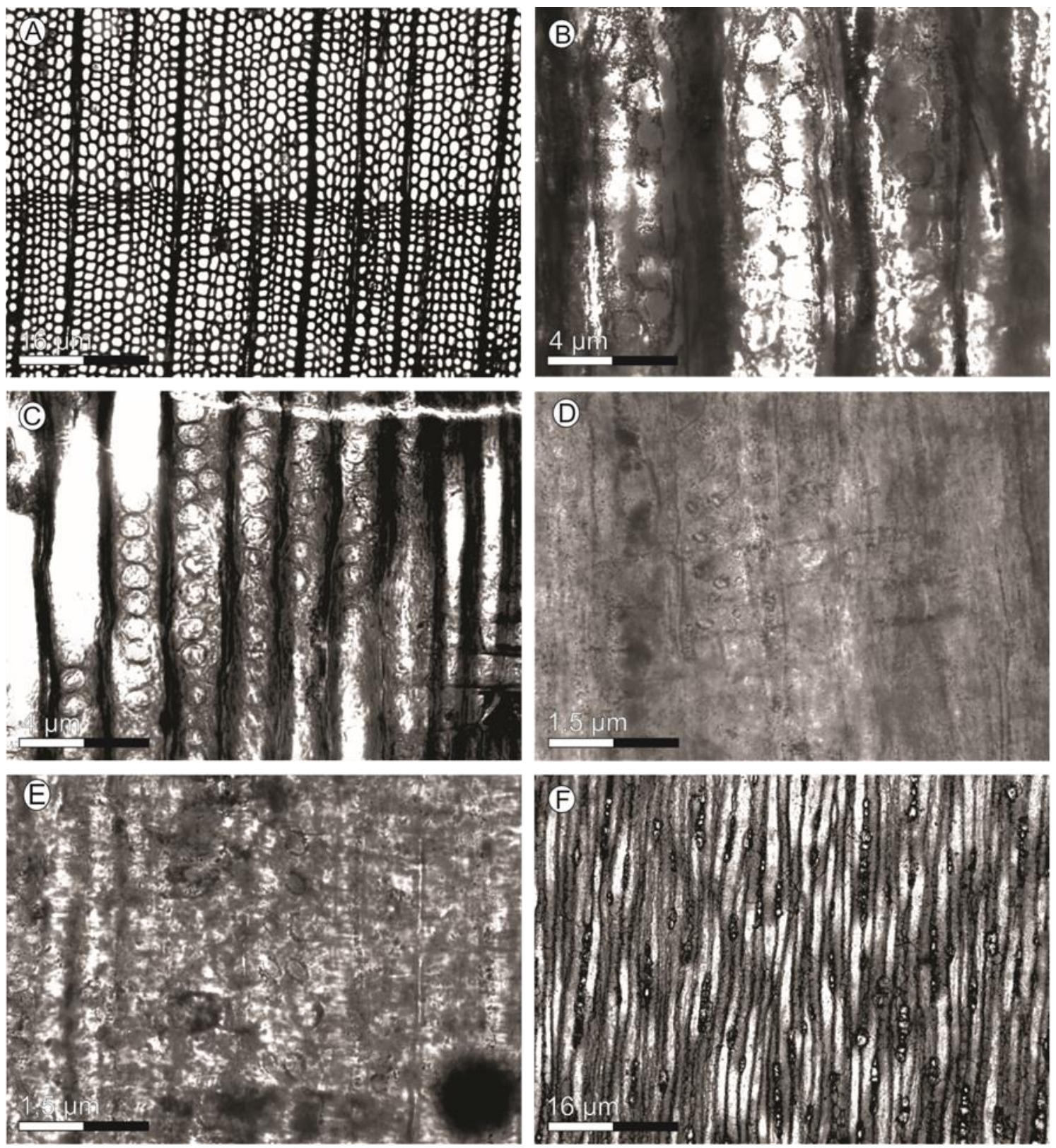

Figura 7.6. Paleoflora de Laguna Flecha Negra. Protaxodioxylon. A. CT anillos de crecimiento demarcados. MPM PB 15923. B. CLR Punteaduras de las paredes radiales de las traqueidas. MPM PB 15937 C. CLR Punteaduras de las paredes radiales de las traqueidas MPM PB 15923. D. CLR campos de cruzamiento taxodioides MPM PB 15944 E. CLR campos de cruzamiento taxodioides MPM PB 15937. F. CLT radios uniseriados MPM PB 15923. 
Ana Julia Sagasti - Estudio paleobotánico, paleoecológico y paleoambiental...

\section{Familia Cupressaceae sensu stricto (sensu Pilger), 1926 o Podocarpaceae Page, 1990.}

Género Cupressinoxylon Göppert, 1850 nom. cons. prop.

Especie tipo Cupressinoxylon gothanii Krausel in Jahrb (1920) typ. cons.

Figura. 7.8. A-C.

\section{Cupressinoxylon sp.}

Ejemplar de referencia. MPM PB 15922

Localidad. Laguna Flecha Negra

Horizonte estratigráfico. Areniscas gruesas

Descripción. Leño picnoxílico, homoxilado, representado exclusivamente por xilema secundario de tipo coniferoide. Presenta anillos de crecimiento definidos, de espesor variable, de transición abrupta, con 1 a 3 células de leño tardío. Las traqueidas tienen una sección transversal subcircular. Traqueidas del leño temprano con un diámetro radial que oscila entre 1,15 $\mu \mathrm{m}$ y 2,68 $\mu \mathrm{m}$ (en promedio 1,67 $\mu \mathrm{m}$ ), diámetro tangencial entre 1,05 $\mu \mathrm{m}$ y 1,62 $\mu \mathrm{m}$ (en promedio 1,29 $\mu \mathrm{m}$ ), espesor de la doble pared de 0,28 $\mu \mathrm{m}$ a 0,48 $\mu \mathrm{m}$ (en promedio 0,42$)$. Traqueidas del leño tardío con un diámetro radial entre 0,28 $\mu \mathrm{m}$ y $0,48 \mu \mathrm{m}$ (en promedio $0,37 \mu \mathrm{m}$ ), diámetro tangencial entre $0,38 \mu \mathrm{m}$ y 0,86 $\mu \mathrm{m}$ (en promedio 0,54 $\mu \mathrm{m}$ ), espesor de la doble pared de $0,67 \mu \mathrm{m}$ a $1,53 \mu \mathrm{m}$

(en promedio $1,1 \mu \mathrm{m}$ ). Las punteaduras de las paredes radiales de las traqueidas son areoladas, uniseriadas, espaciadas, de tipo abietinoide. Las mismas miden entre $0,85 \mu \mathrm{m}$ de ancho por $0,76 \mu \mathrm{m}$ de alto y $1,28 \mu \mathrm{m}$ de ancho por 1,21 $\mu \mathrm{m}$ de alto (en promedio 1,09 $\mu \mathrm{m} \times 0,94 \mu \mathrm{m}$ ). El poro de las punteaduras mide entre $0,21 \mu \mathrm{m}$ de ancho por $0,19 \mu \mathrm{m}$ de alto y $0,4 \mu \mathrm{m}$ de ancho por $0,26 \mu \mathrm{m}$ de alto (en promedio $0,28 \mu \mathrm{m} \times 0,22 \mu \mathrm{m}$ ). Las paredes tangenciales de las traqueidas no presentan punteaduras. No se observa presencia de parénquima axial. Los campos de cruzamiento presentan una punteadura cupresoide que mide entre $0,5 \mu \mathrm{m}$ de diámetro mayor por 0,38 $\mu \mathrm{m}$ de diámetro menor y $0,57 \mu \mathrm{m}$ de diámetro mayor por $0,47 \mu \mathrm{m}$ de diámetro menor (en promedio $0,52 \mu \mathrm{m} \times 0,43 \mu \mathrm{m}$ ). El poro de las punteaduras mide entre $0,28 \mu \mathrm{m} \times 0,16 \mu \mathrm{m}$ y $0,31 \mu \mathrm{m} \times 0,21 \mu \mathrm{m}$ (en promedio $0,3 \mu \mathrm{m} \times 0,18 \mu \mathrm{m}$ ). Los radios leñosos son uniseriados, homocelulares, de paredes lisas. 
Ana Julia Sagasti - Estudio paleobotánico, paleoecológico y paleoambiental...

Comparaciones. La presencia de punteaduras abietinoides y campos de cruzamiento con una punteadura cupresoide, permiten clasificar el material dentro del género Cupressinoxylon Göeppert, según el criterio de Philippe y Bamford (2008). La diagnosis original, incluye características de la corteza y médula de los ejes, sin embargo, Philippe y Bamford (2008) señalan que puede utilizarse el término para nominar leños secundarios, a partir del protologo de la diagnosis original.

\section{Familia Cheirolepidiaceae Takhtajan}

Protocupressinoxylon (Eckhold) Bodnar, 2017.

Especie tipo. Protocupressinoxylon malayense Roggeveen

$$
\text { Protocupressinoxylon sp. }
$$

Figura. 7.7.A-D

Ejemplar de referencia. MPM PB 15937

Especímenes adicionales. MPM PB 15957

Localidad. Laguna Flecha Negra

Horizonte estratigráfico. Tobas blancas

Descripción. Leño picnoxílico, homoxilado, representado exclusivamente por xilema secundario de tipo coniferoide. Presenta anillos de crecimiento definidos, de espesor variable (9 a 28 células). Espesor de la capa de leño tardío de 1 a 2 células, con transición abrupta entre el leño temprano y el leño tardío. Las traqueidas tienen una sección transversal rectangular. Traqueidas del leño temprano con un diámetro radial que oscila entre $3,45 \mu \mathrm{m}$ y $5 \mu \mathrm{m}$ (en promedio $4,22 \mu \mathrm{m}$ ), diámetro tangencial entre $2,5 \mu \mathrm{m}$ y $3,7 \mu \mathrm{m}$ (en promedio $3,06 \mu \mathrm{m}$ ); espesor de la doble pared entre $0,48 \mu \mathrm{m}$ y $0,8 \mu \mathrm{m}$ (en promedio 0,64 $\mu \mathrm{m})$. Traqueidas del leño tardío con un diámetro radial entre $0,24 \mu \mathrm{m}$ y 0,48 $\mu \mathrm{m}$ (en promedio $0,37 \mu \mathrm{m}$ ), diámetro tangencial oscila entre $0,73 \mu \mathrm{m}$ y 1,2 $\mu \mathrm{m}$ (en promedio $1,02 \mu \mathrm{m}$ ), espesor de la doble pared entre 0,6 $\mu \mathrm{m}$ y 1,2 $\mu \mathrm{m}$ (en promedio $0,74 \mu \mathrm{m}$ ). Las punteaduras de las paredes radiales de las traqueidas son areoladas, predominantemente biseriadas $(70 \%)$, alternas, a veces uniseriadas, contiguas (30\%), de tipo mixto. Las mismas miden entre 1,24 $\mu \mathrm{m}$ de ancho por $0,95 \mu \mathrm{m}$ de alto y $1,78 \mu \mathrm{m}$ de ancho por $1,2 \mu \mathrm{m}$ de alto (en promedio $1,44 \mu \mathrm{m} \times 1,05 \mu \mathrm{m})$. El poro de las punteaduras mide entre $0,76 \mu \mathrm{m}$ 
Ana Julia Sagasti - Estudio paleobotánico, paleoecológico y paleoambiental...

por $0,45 \mu \mathrm{m}$ y $1,21 \mu \mathrm{m}$ por $0,78 \mu \mathrm{m}$ (en promedio $0,95 \mu \mathrm{m} \times 0,62 \mu \mathrm{m}$ ). Las paredes tangenciales de las traqueidas no presentan punteaduras. No se observa presencia de parénquim axial. Los campos de cruzamiento presentan dos punteaduras cupresoides alineadas, espaciadas. Las punteaduras de los campos de cruzamiento miden entre $0,5 \mu \mathrm{m}$ de diámetro mayor por 0,4 $\mu \mathrm{m}$ de diámetro menor y $0,76 \mu \mathrm{m}$ de diámetro mayor y 0,62 $\mu \mathrm{m}$ de diámetro menor (en promedio $0,63 \mu \mathrm{m} \times 0,51 \mu \mathrm{m}$ ). El poro de las punteaduras de los campos mide entre 0,24 $\mu \mathrm{m} \times 0,19 \mu \mathrm{m}$ y 0,59 $\mu \mathrm{m} \times 0,45 \mu \mathrm{m}$ (en promedio 0,45 $\mu \mathrm{m} \times$ $0,28 \mu \mathrm{m})$. Los radios leñosos son homocelulares, uniseriados, con 1 a 16 células de alto (5 en promedio). Las células del parénquima radial son distintivamente lisas, no perforadas.

Comparaciones. Según el criterio de Philippe y Bamford (2008), la presencia de punteaduras mixtas en las paredes radiales de las traqueidas, campos de cruzamiento cupresoides con punteaduras espaciadas y la ausencia de zonación clara en el punteado de las traqueidas, permite reconocer estos materiales dentro del género Protocupressinoxylon. Este género fue establecido por Eckhold (1921) para leños fósiles de coníferas que presentan anillos de crecimiento más o menos definidos, punteaduras de las traqueidas con arreglo mixto, paredes del parénquima radial lisas, ausencia de canales resiníferos, campos de cruzamiento de tipo cupressoide y parénquima axial ocasionalmente presente. Este género fue creado en la Tesis Doctoral de Eckhold (1921) y no se encuentra correctamente tipificado. Es por ello que el nombre Protocupressinoxylon ha sido utilizado indistintamente para nominar especies con campos de cruzamiento con dos patrones de organización de las punteaduras cupressoides: 1 a 4 punteaduras espaciadas por campo de cruzamiento, y leños con campos de cruzamiento con más de 4 punteaduras cupressoides que tienden a disponerse de manera agrupada y comprimida (Philippe, 1995). Sin embargo, Richter et al. (2004) definen este último arreglo como araucarioide. Philippe y Bamford (2008) señalan que aquellas especies que presentan campos de cruzamiento con arreglo araucarioide pueden definirse dentro del género Brachyoxylon Hollick y Jeffrey. Debido a esta complejidad nomenclatural Bodnar (2017) propone la conservación y neotipificación del género Protocupressinoxylon para incluir aquellos leños fósiles de coníferas que presentan punteaduras mixtas, campos de 
Ana Julia Sagasti - Estudio paleobotánico, paleoecológico y paleoambiental...

cruzamiento con punteaduras cupressoides espaciadas, paredes del parénquima radial lisas y ausencia de canales resiníferos.
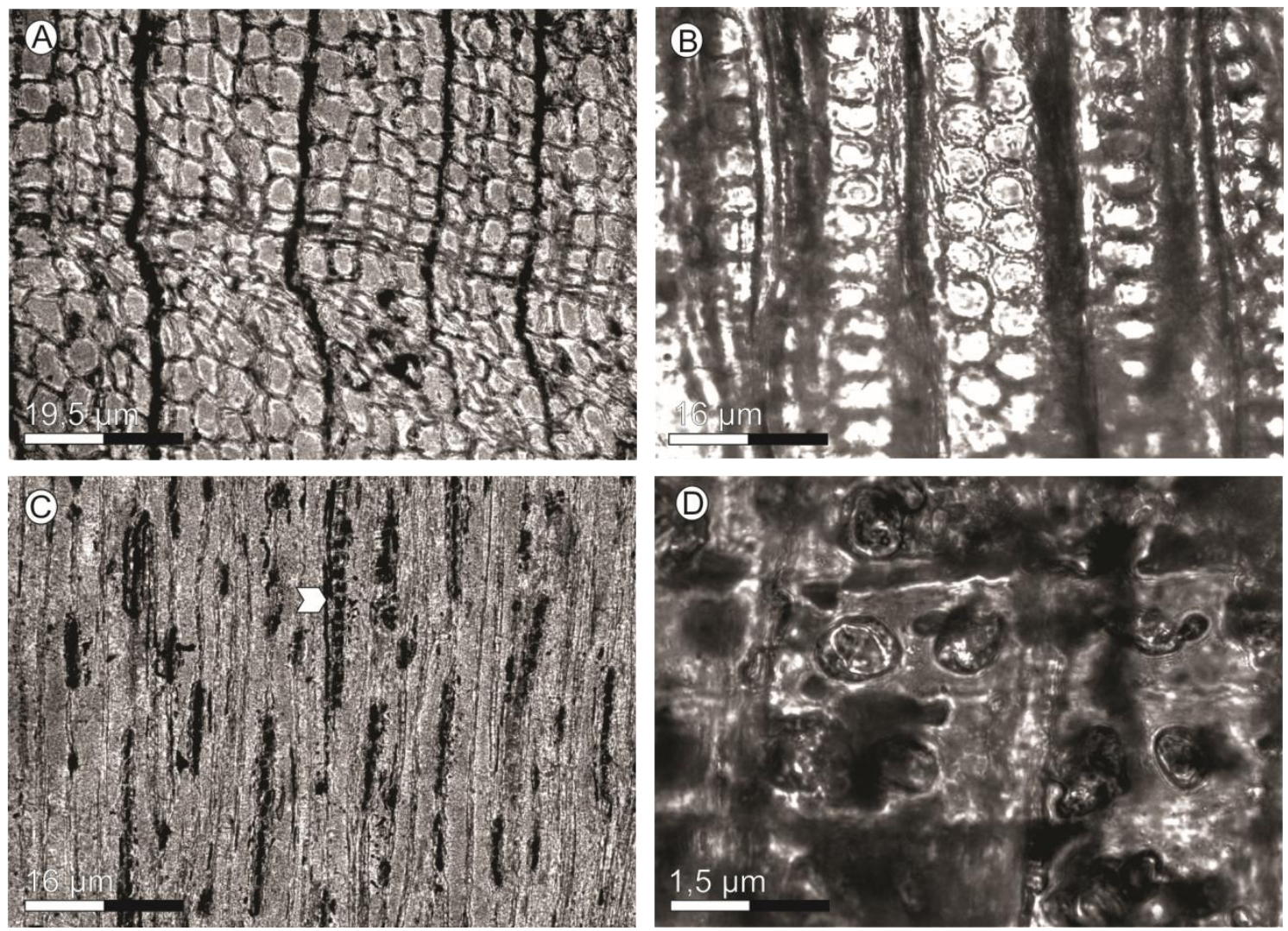

Figura 7.7. Paleoflora de Laguna Flecha Negra. Protocupressinoxylon sp. A. CT anillos de crecimiento. MPM PB 15897. B. CLR punteaduras de las paredes radiales de las traqueidas. MPM PB 15897. C. CLT radios uniseriados. MPM PB 15962. D. CLR campos de cruzamiento cupressoides. MPM PB 15962.

Género Pararaucaria Wieland emend Escapa, Rothwell, Stockey y Cúneo 2012. Especie tipo. Pararaucaria patagonica.

Pararaucaria patagonica. (Wieland) Escapa, Rothwell, Stockey y Cúneo, 2012.

Figura. 7.8. D-E

Ejemplar de referencia. MPM PB 15868

Especímenes adicionales. MPM PB 15869; 15975

Localidad. Laguna Flecha Negra

Horizonte estratigráfico. Areniscas gruesas

Descripción. Cono femenino de forma cilíndrica, de 4,5 cm de largo por $1,7 \mathrm{~cm}$ de ancho en la zona media. Se trata de un eje leñoso sobre el que se disponen múltiples complejos bráctea/escama ovulífera con una filotaxis helicoidal. Escama ovulífera de $0,5 \mathrm{~cm}$ de ancho por $0,5 \mathrm{~cm}$ de alto en la parte central. La 
Ana Julia Sagasti - Estudio paleobotánico, paleoecológico y paleoambiental...

escama ovulífera presenta tres lóbulos, el central es el de mayor tamaño. La bráctea tecrtriz no puede observase claramente, en la zona donde debiera encontrarse suele verse una depresión que podría indicar que la misma se haya perdido en el proceso de fosilización y/o exhumación. En el ejemplar MPM PB 15975 se puede observar el cono en sección, lo que permite evidenciar la presencia de un óvulo por escama ovulífera. Este ejemplar es más pequeño, alcanzando apenas $1,2 \mathrm{~cm}$ de largo por $0,7 \mathrm{~cm}$ de ancho, por lo que podría representar un estadío inmaduro del cono megasporangiado. Los óvulos son ovalados, de 0,2 cm de largo por 0,1 cm de ancho.

Observaciones. La especie Pararaucaria patagonica fue descripta por primera vez por Wieland (1929) para nominar conos megasporangiados permineralizados de dudosa afinidad, hallados en los bosques petrificados de Cerro Cuadrado, Santa Cruz. En esta localidad se han hallado numerosos ejemplares que llevaron a sucesivas descripciones de material asignable a este taxón fósil (e.g. Wieland 1935; Calder, 1953; Stockey, 1977) y posteriores discusiones sobre sus afinidades dentro del clado de las Coníferas (e.g. Archangelsky, 1968; Miller, 1977). Se debe a Escapa et al. (2012) la resolución de las relaciones sistemáticas de estos conos. A partir del análisis de la morfología y anatomía de restos permineralizados colectados en la formación La Matilde, los autores confirman la afinidad de Pararaucaria patagonica con la familia Cheirolepidiaceae en función de la presencia de tres lóbulos distales en la escama ovulífera, la presencia de semillas no aladas y una o dos semillas invertidas por escama ovulífera, ubicadas en una posición proximal al lóbulo central.

Comparaciones. Se conocen cuatro especies pertenecientes al género Pararaucaria: Pararaucaria carrii Stockey y Rothwell, del Jurásico Medio de Oregon, Pararaucaria collinsonae Steart, Spencer, Kenrick, Needham y Hilton, del Jurásico Superior de Inglaterra, Pararaucaria delfueyoi, Escapa, Cúneo, Rothwell y Stockey, del Jurásico Superior de Chubut y Pararaucaria patagonica del Jurásico Medio-Superior de Santa Cruz. Pararaucaria carrii está representada por conos megasporangiados de 2,8 cm de alto por 1,3 cm de ancho, compuestos por un eje que porta complejos bráctea/escama dispuestos helicoidalmente, con escamas ovulíferas grandes y brácteas amplias y achatadas. Pararaucaria carrii se conoce por el estudio de un único cono, 
preservado anatómicamente, que se encuentra desgastado, con evidencias de transporte previo al enterramiento, por lo que no se conoce su morfología externa (Stockey y Rothwell, 2013), lo cual impide compararlo con los materiales de Laguna Flecha Negra. Pararaucaria collinsonae se diferencia en su forma esferoidal, con un diámetro máximo entre 1,23 y $1,30 \mathrm{~cm}$, y un alto máximo de 1,24 cm, 3,6 veces más corto que el material estudiado en Laguna Flecha Negra. Pararaucaria delfueyoi, por su perte, presenta dimensiones mayores a los ejemplares aquí analizados; esta especie alcanza $8 \mathrm{~cm}$ de largo por 3-4 cm de ancho. Los materiales estudiados en Laguna Flecha Negra se encuentran como impresiones en un estado de preservación de regular (MPM PB 15868) a malo (MPM PB 15869) o como moldes en areniscas bien consolidadas y con una fuerte cementación silícea que muestran detalles de la morfología y organización interna (MPM PB 15975). Los materiales sobre los que se ha definido la especie se encuentran como permineralizaciones, algunas de ellas con excelente registro de la anatomía. A pesar de las diferencias en el estado de preservación entre los materiales de La Matilde y aquellos estudiados aquí, se pueden observar las características generales de los ejemplares que coinciden con la diagnosis de Pararaucaria patagonica: los ejemplares de la Formación La Matilde son de forma cónica a ovoidal, de 2,3 a $5,1 \mathrm{~cm}$ de largo por 1,3 a $3 \mathrm{~cm}$ de ancho máximo, con ejes delicados que portan complejos bráctea/escama en arreglo helicoidal, la escama ovulífera presenta tres lóbulos distales y se apoya sobre una bráctea tectriz ancha y de consistencia leñosa. 
Ana Julia Sagasti - Estudio paleobotánico, paleoecológico y paleoambiental...
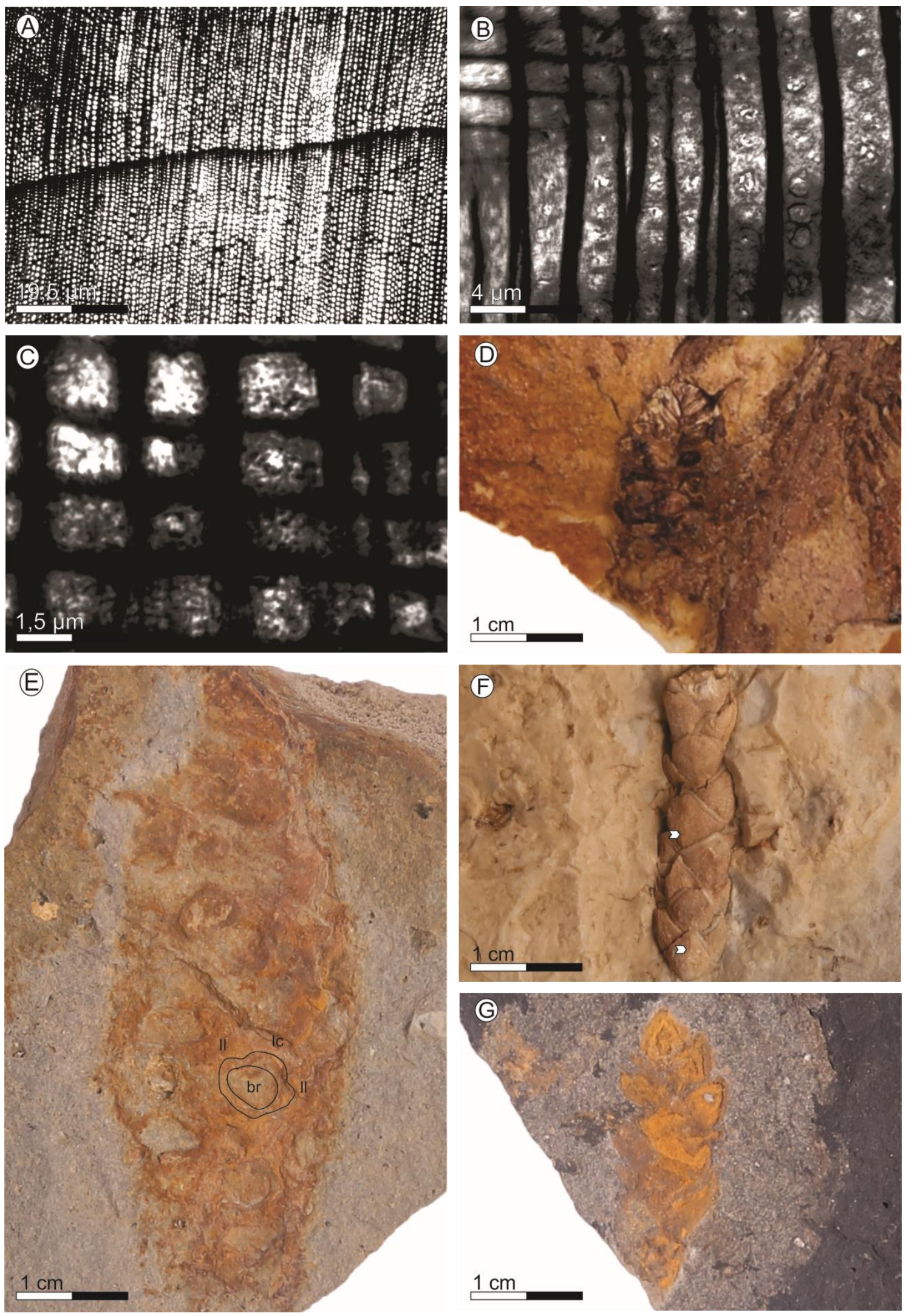

Figura 7.8. Paleoflora de Laguna Flecha Negra. A-C. Cupressinoxylon sp. MPM PB 15922. A. CT anillos de crecimiento. B. CLR Punteaduras de las traqueidas. C. CLR campos de cruzamiento. D. Pararaucaria patagonica MPM PB 15975. E. Pararaucaria patagonica MPM PB 15868. LI: lóbulo lateral, lc: lóbulo central, br: bráctea. F. Brachyphyllum lotenaense MPM PB 15982. G. Brote apical de Brachyphyllum lotenaense MPM PB 15881. 
Ana Julia Sagasti - Estudio paleobotánico, paleoecológico y paleoambiental...

\section{Familia incierta}

Género Brachyphyllum Brongniart emend. Harris 1979

Especie tipo. Brachyphyllum mamillare (Brongniart ex Lindley et Hutton) Harris 1979.

Brachyphyllum lotenaense Baldoni 1980.

Figura. 7.8.F-G

Ejemplar de referencia. MPM PB 15982

Especímenes adicionales. MPM PB 15870-15881; 15832; 15864; 1598315992.

Localidad. Laguna Flecha Negra

Horizonte estratigráfico. Areniscas gruesas y pelitas oscuras

Descripción. Fragmentos de ramas foliosas de $0,4 \mathrm{~cm}$ de ancho por 1,8 cm de largo, con hojas coriáceas, romboidales, adpresas, dispuestas helicoidalmente. Hojas de 0,3 cm de ancho por 0,3 cm de largo, de ápice agudo. Las hojas son adpresas al eje, entran en contacto entre sí y son homomórficas. Las hojas son coriáceas, con desarrollo de una quilla. No se observa la venación.

Comentarios. Se observa una variación menor en las dimensiones de los ejemplares adicionales, oscilando entre los 0,65 y 0,8 cm de ancho con longitudes preservadas que llegan hasta los $8 \mathrm{~cm}$. El ejemplar MPM PB 15871 presenta las hojas más grandes observadas, de $0,3 \mathrm{~cm}$ de ancho por 0,6 cm de largo. En todos los casos, las hojas son romboidales, con quilla, de ápice agudo que en ningún caso está libre. El ejemplar MPM PB 15990 se encuentra ramificado, con ramas alternas saliendo con un ángulo que oscila entre $55^{\circ}$ y $65^{\circ}$. En las figuras 7.3.E y $\mathrm{F}$ se observa la porción apical de ramas foliosas de tipo Brachyphyllum en las que se aprecia un ensanchamiento del eje formando una estructura apical de forma cilidro-ovalada con hojas escuamiformes adpresas dispuestas espiraladamente. Dimensiones de la estructura: $0,8 \mathrm{~cm}$ de ancho por 1,6 cm de largo. Hojas coriáceas, romboidales, de unos $0,3 \mathrm{~cm}$ de ancho por 0,4 cm de largo, con ápice agudo, apenas libre. El ejemplar MPM PB 15986 presenta dimensiones levemente menores, el eje es de $0,4 \mathrm{~cm}$ de ancho por 1,4 cm de largo, con hojas de 0,25 cm de ancho por 0,2 cm de largo, con el ápice agudo y adpreso, nunca libre. En MPM PB 15985 (Fig. 7.3.G) el eje se bifurca antes de desarrollar este ensanchamiento, presentando dos "conitos" de 
Ana Julia Sagasti - Estudio paleobotánico, paleoecológico y paleoambiental...

0,4 cm de ancho por 0,8 cm de ancho, asociado a este ejemplar, se encuentra un cono megasporangiado de tipo Araucarites. Estas estructuras pueden interpretarse como brotes apicales de las ramas foliosas de Brachyphyllum lotenaense.

Comparaciones. El material descripto se puede comparar con las ramas de tercer y cuarto orden de Brachyphyllum lotenaense Baldoni (1980) ya que esta especie presenta ramas de tercer orden de $0,5 \mathrm{~cm}$ de ancho y cuarto orden de 0,3 cm de ancho, hojas pequeñas escuamiformes, de márgenes enteros, insertas con filotaxis espiralada, adpresas a algo abiertas, de contorno rómbico, ápice agudo y tamaño más frecuente de 0,3 cm de largo por 0,3 cm de ancho. Todos estos caracteres pueden observarse en los materiales de Laguna Flecha Negra, por lo que se los incluye en esta especie. Los autores no señalan la afinidad familiar de la especie.

Figura. 7.9. A-C

\section{Brachyphyllum sp.}

Ejemplar de referencia. MPM PB 15859

Especímenes adicionales. MPM PB 15860-15862; MPM PB 15976-15981.

Localidad. Laguna Flecha Negra

Horizonte estratigráfico. Areniscas gruesas y pelitas oscuras

Descripción. Fragmentos de ramas foliosas de $1 \mathrm{~cm}$ de ancho por $7,5 \mathrm{~cm}$ de largo, con hojas coriáceas, romboidales, adpresas, dispuestas helicoidalmente. Hojas de 0,4 cm de ancho por 0,4 cm de largo, de ápice agudo, no presentan quilla. Las hojas son adpresas al eje, entran en contacto entre sí y son homomórficas. No se observa la venación, lo cual podría ser producto del espesor de las hojas y el tamaño de grano de la roca en la que se preservan. En ninguno de los ejemplares se encontraron cutículas asociadas.

Observaciones. Se registra una variación menor en las dimensiones de los ejemplares adicionales, oscilando entre 0,6 y 1,3 cm de ancho con longitudes preservadas que llegan hasta los 8,5 cm. El ejemplar MPM PB 15977 presenta las hojas más grandes observadas, de 0,7 cm de ancho por 0,65 cm de largo (Fig. 7.9.C). En todos los casos, las hojas son romboidales, sin quilla, de ápice agudo que en ningún caso está libre. Los ejemplares MPM PB 15978 y MPM 
Ana Julia Sagasti - Estudio paleobotánico, paleoecológico y paleoambiental...

PB 15981 presentan ramificaciones laterales que salen con ángulos de $60^{\circ}-80^{\circ}$ (Fig. 7.9.B).

Comentarios. El taxón fósil Brachyphyllum se utiliza para referir a ejes con hojas dispuestas helicoidalmente, más anchas que largas y con el ápice libre y pequeño (Harris, 1979). Harris (op. cit.) señala las dificultades para diferenciar de manera consistente los múltiples taxones fósiles de foliaje de coníferas caracterizados por hojas cortas, aciculares, de disposición helicoidal. De los tres géneros fósiles más comunes, redefine Brachyphyllum Brongniart como ramas foliosas que portan hojas que no llegan a ser más largas que el ancho basal, Pagiophyllum Heer como ramas foliosas portando hojas más largas que su ancho basal, y más anchas horizontalmente que gruesas; y Geinitzia Endlicher como ramas foliosas que portan hojas más largas que anchas pero con igual grosor en sentido horizontal y vertical. Aunque esta definición provee una distinción simple para diferenciar taxones fósiles, Harris (1979) señala que incluso dentro de un mismo fósil, algunas hojas trascienden estos límites arbitrarios. Observación que también realiza Stockey (1982). La asignación genérica resulta más difícil cuando no se preserva materia orgánica y las ramas están fuertemente comprimidas. Se conocen numerosos géneros adicionales para ramas de Coníferas con hojas aciculares o escuamiformes, pero típicamente se diferencian en base a caracteres cuticulares o estructuras reproductivas en conexión orgánica (Harris, 1979). Harris (1979) señala que la especie Brachyphyllum muensteri resultó ser follaje perteneciente a Hirmerella, perteneciente a la familia Cheilolepidiaceae,

Comparaciones. Se conocen varias especies de este género para el Jurásico y Cretácico de la Argentina. B. ramosum Baldoni, B. lotenaense Baldoni, $B$. neuquinum Baldoni, del Jurásico de la Provincia de Neuquén. Se diferencia de $B$. ramosum ya que esta especie presenta hojas más largas que anchas y se define sobre caracteres cuticulares. B. lotenaense presenta ramas foliosas menores, con hojas de menor tamaño, aunque comparten el ángulo de ramificación. B. neuquinum se diferencia porque presenta 1/2-1/3 del ápice libre, carácter que no se observa en los materiales aquí descriptos. Por otro lado, puede segregarse de Brachyphyllum sp. descripto para el Jurásico inferior de Bahía Botánica y Bahía Esperanza (Rees y Cleal, 2004), ya que las hojas no son tan adpresas, sino que presentan una porción libre, están siempre 
Ana Julia Sagasti - Estudio paleobotánico, paleoecológico y paleoambiental...

separadas entre sí y presentan una quilla central. La ausencia de caracteres cuticulares impide realizar comparaciones con otras especies descriptas para el Mesozoico, por lo que se trata a estos materiales como Brachyphyllum sp.

Género Pagiophyllum Heer emend. Harris, 1979.

Especie tipo. Pagiophyllum circinicum (Saporta) Heer, 1881.

Figura. 7.9.D

\section{Pagiophyllum cf. crassifolium Schenk}

Ejemplar de referencia. MPM PB 15993.

Especímenes adicionales. MPM PB 15863-15867; 15852; 15994-15995.

Localidad. Laguna Flecha Negra

Horizonte estratigráfico. Pelitas oscuras

Descripción. Se trata de fragmentos de ramas foliosas portando hojas helicoidalmente. Ramas de $13,7 \mathrm{~cm}$ de largo máximo por $1,1 \mathrm{~cm}$ de ancho. Las hojas presentan una base ancha $(0,4 \mathrm{~cm})$, lámina curvada con el ápice libre y agudo, levemente aciculares, superpuestas. Se distribuyen en una hélice simple, con $1+2$ parásticas generando una distribución pseudo-decusada. Hojas levemente coriáceas, de 0,4 cm de ancho en la base por 0,7 cm de largo, se insertan con un ángulo de $55^{\circ}-60^{\circ}$, curvándose hacia el extremo. El ápice de las ramas se encuentra rodeado por hojas fuertemente adpresas. El ejemplar MPM PB 15995 se encuentra ramificado, con ramas que salen con ángulo de $40^{\circ}-50^{\circ}$.

Observaciones. Estos materiales pueden asignarse al género Pagiophyllum siguiendo el criterio de Harris (1979) ya que se trata de ejes foliosos que portan helicoidalmente hojas más largas que su cojinete basal, y menos coriáceas que aquellas asignadas a Brachyphyllum. Este mismo criterio es el que sigue Stockey (1982) para discriminar los taxones fósiles de ramas foliosas de la familia Araucariaceae.

Comparaciones. Rees y Cleal (2004) describen fragmentos de ramas foliosas no ramificadas asignables con dudas a Pagiophyllum crassifolium Schenk en el Jurásico de Bahía Botánica y Bahía Esperanza. Estos materiales se caracterizan por presentar hojas con arreglo helicoidal, separadas, insertas con un ángulo de $50^{\circ}-65^{\circ}$, con ápice libre. Las hojas son falcadas, lanceoladas con una marcada expansión de la base, similar a lo que se observa en los 
Ana Julia Sagasti - Estudio paleobotánico, paleoecológico y paleoambiental...
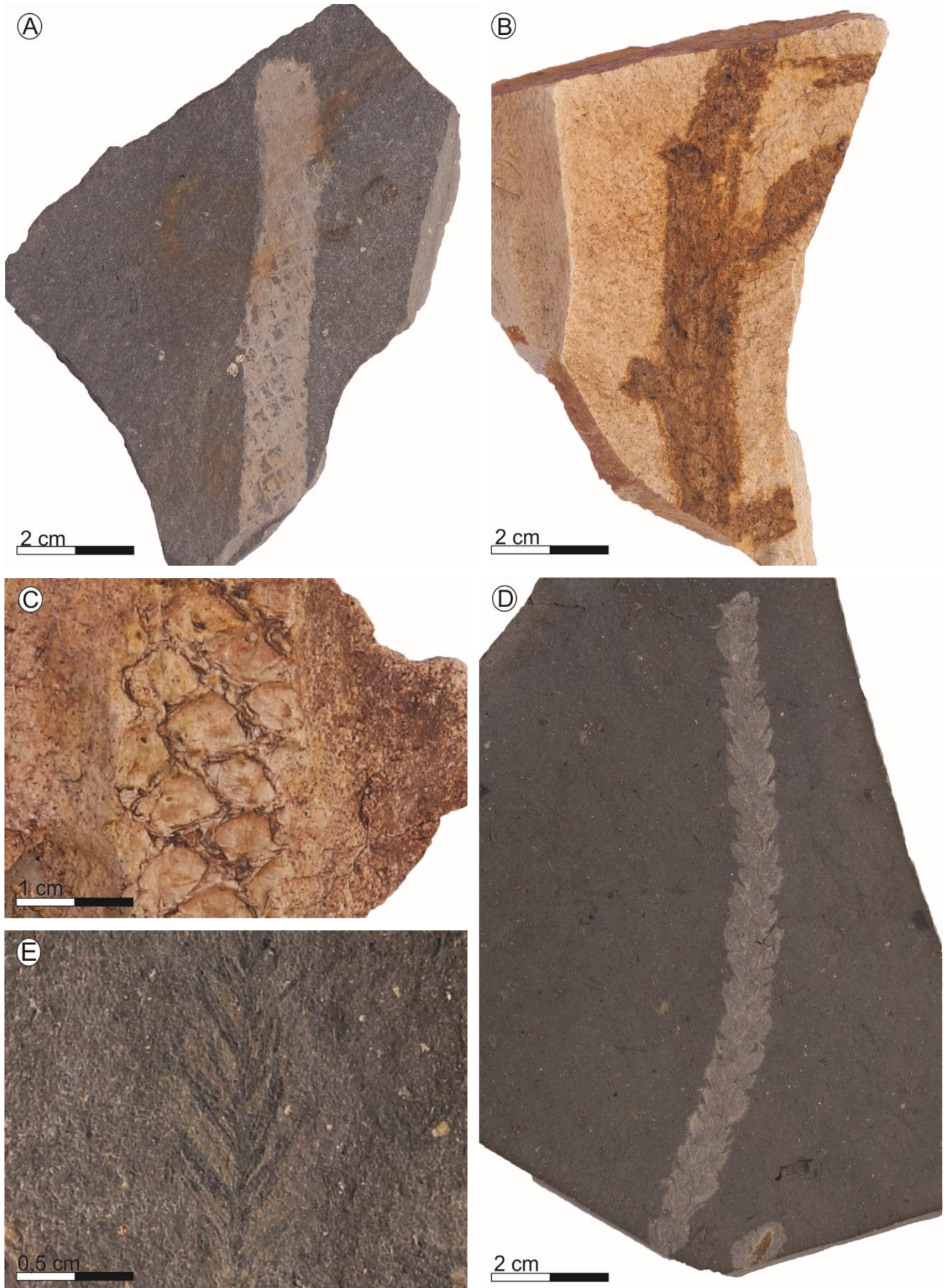

Figura 7.9. Paleoflora de Laguna Flecha Negra. A. Brachyphyllum sp. MPM PB 15859. B. Brachyphyllum sp. MPM PB 15981. C. Brachyphyllum sp. MPM PB 15977. D. Pagiophyllum cf. crassifolium. MPM PB 15993. E. Elatocladus confertus MPM PB 15890. 
Ana Julia Sagasti - Estudio paleobotánico, paleoecológico y paleoambiental...

restos colectados en Laguna Flecha Negra. Al igual que los materiales aquí descriptos, los ejemplares de Antártida no presentan cutícula preservada, lo cual impide realizar una diagnosis certera de los restos. Debido a las características morfológicas preservadas, se sigue el criterio de Rees y Cleal (2004) para la asignación específica.

Género Elatocladus Halle 1913 emend. Harris 1979.

Especie tipo Elatocladus heterophylla Halle 1913.

Elatocladus confertus (Oldham y Morris) Halle 1913.

Figuras.7.9.E

Ejemplar de referencia. MPM PB 15890

Especímenes adicionales. MPM PB 15891-15893; 15998-16001.

Localidad. Laguna Flecha Negra

Horizonte estratigráfico. Pelitas oscuras

Descripción. Fragmento de rama flexuosa, de 1,4 cm de largo por 0,05 cm de ancho, portando helicoidalmente hojas sésiles espaciadas a superpuestas, insertas en ángulos de $50^{\circ}$. Hojas de lámina linear-lanceolada, levemente falcadas, con márgenes paralelos, de ápice agudo, con base decurrente sobre el tallo. Hojas uninervias de $0,3 \mathrm{~cm}$ de largo por $0,05 \mathrm{~mm}$ de ancho.

Comparaciones. El material estudiado se asemeja a Elatocladus confertus ya que presentan hojas linear-lanceoladas, de base decurrente, márgenes paralelos, ápice agudo y dimensiones similares. Se diferencian de esta especie en que no se observan estrías en el eje principal, aunque esto podría deberse a las pequeñas dimensiones de los ejemplares colectados. El material descripto se asemeja a Elatocladus longifolius en la disposición, forma y ángulo de inserción de las hojas, aunque éstas presentan un tamaño levemente menor (0,5-1 cm de largo y 0,15-0,2 cm de ancho en el material descripto por Baldoni). El material de Laguna Flecha Negra puede compararse con Elatocladus mcCoyi por su base decurrente, pero presenta hojas de menor tamaño $(0,7-1,1$ $\mathrm{cm}$ de largo por $0,7-0,1 \mathrm{~cm}$ de ancho en $E$. mcCoyi) y que no son marcadamente falcadas. A su vez, puede compararse con $E$. planus y $E$. tenerrima, estas especies son muy similares entre sí, siendo la principal diferencia la presencia o no de vena media. Petriella y Arrondo (1984) señalan que podría tratarse de sinónimos y esta diferencia deberse a la preservación de 
Ana Julia Sagasti - Estudio paleobotánico, paleoecológico y paleoambiental...

los materiales. Los ejemplares aquí descriptos pueden diferenciarse de estas especies ya que ellas presentan hojas bien lineares, de márgenes rectos y paralelos y disposición mucho menos espaciada. Se asignan entonces a Elatocladus confertus, la ausencia de estrías en el eje podría deberse al estadio ontogenético de los ejemplares ya que se trata de especímenes pequeños y fragmentarios.

Comentarios. Este material es identificable como Elatocladus confertus que es una especie relativamente variable según la descripción de Halle (1913). Esta es la especie de Elatocladus más frecuentemente citada en estratos jurásicos de Gondwana. La descripción coincide con los ejemplares citados para otras localidades jurásicas por Frenguelli (1949), Herbst (1964, 1966a), Bonetti (1963), Arrondo y Petriella (1980), Baldoni (1981), Baldoni y Olivero (1983), Artabe et al. (2005) y Morel et al. (2013).

Elatocladus cf. planus (Feistmantel) Seward.

Figuras.7.10.A

Ejemplar de referencia. MPM PB 15888

Especímenes adicionales. MPM PB 15889; 15996-15997.

Localidad. Laguna Flecha Negra

Horizonte estratigráfico. Pelitas oscuras

Descripción. Fragmento de rama de $1,5 \mathrm{~cm}$ de largo por 0,1 cm de ancho, portando helicoidalmente hojas sésiles espaciadas, insertas en ángulos de $30-$ $40^{\circ}$. Hojas de lámina linear, con márgenes paralelos, sin ápice preservado, con base ampliamente decurrente sobre el tallo; miden $0,5-0,8 \mathrm{~cm}$ de largo y $0,05-$ $0,1 \mathrm{~cm}$ de ancho. No se observa la venación.

Observaciones. El taxón fósil Elatocladus fue introducido por Halle (1913) para denominar ramas foliosas estériles de coniferales, con disposición dorsiventral o radial, que no pueden ser referidas a otros géneros establecidos. Florin (1958) se refiere al género Elatocladus detallando la cutícula epidérmica para cada especie. Posteriormente, Harris (1979) enmienda el género para asignar ejes portando hojas de manera espiralada (raramente opuesta), hojas elongadas, achatadas dorsiventralmente, divergiendo del eje, con base fuertemente contraída formando un corto pedicelo que se adhiere a un cojinete 
Ana Julia Sagasti - Estudio paleobotánico, paleoecológico y paleoambiental...

basal, lámina uninervia, sin incluir la cutícula. Debido al nivel de preservación de las muestras estudiadas, se sigue este último criterio.

Comparaciones. El material estudiado se asemeja a Elatocladus mcCoyi (Florin) en sus dimensiones $(0,7-0,11 \mathrm{~cm}$ de largo, 0,07-0,1 cm de ancho) y en presentar una base ampliamente decurrente sobre el eje. Pero se diferencia de ésta por presentar láminas lineares y no falcadas, y un menor ángulo de inserción $\left(40^{\circ}\right.$ vs $50-75^{\circ}$ en $E$. mcCoyi). Los restos aquí estudiados son comparables con Elatocladus planus (Feinsmantel) Seward porque comparten las siguientes características: hojas lineales, estrechas, densamente dispuestas sobre las ramas, aunque no pueden ser determinadas con certeza ya que no se observa el ápice de las hojas ni la vena media, y presentan una base decurrente que no ha sido mencionada para E. planus.

\section{Ramas foliosas indet.}

Figura.7.10.B-C.

Ejemplar de referencia. MPM PB 15882

Especímenes adicionales. MPM PB 15883-15885; 15975; 16002-16003.

Localidad. Laguna Flecha Negra

Horizonte estratigráfico. Areniscas gruesas y pelitas oscuras

Descripción. Fragmentos de impresiones e impresiones-compresiones de ramas foliosas flexuosas y delicadas, frecuentemente ramificadas. De 2,8 cm de largo por 0,2 cm de ancho. Las mayores llegan a 3,5 cm de largo por 0,3 cm de ancho. Hojas aciculares dispuestas espiraladamente, adpresas al eje. Hojas de menor tamaño de 0,3 $\mathrm{mm}$ de largo por 0,05 $\mathrm{cm}$ de ancho. Se insertan sobre el eje con un ángulo de aproximadamente $3^{\circ}$. Dos tipos de ramificación: en zonas aparentemente apicales, las ramas salen con un ángulo de $5^{\circ}-10^{\circ}$, en zonas aparentemente medias, irradian hasta tres ramas, con ángulos de $20^{\circ}$, $50^{\circ}$ y $190^{\circ}$ (Fig. 7.10.B).

Comentarios. Los materiales aquí descriptos son de carácter fragmentario, pequeños, con ramas y hojas de tamaño minúsculo, y sin preservación de caracteres epidérmicos que permitan realizar comparaciones. En vistas de estas limitaciones preservacionales, sólo se puede afirmar su afinidad con las coníferas micrófilas, sin poder especificar sus relaciones familiares ni ubicarlas dentro de los taxones fósiles conocidos para ramas foliosas de coníferas. 
Ana Julia Sagasti - Estudio paleobotánico, paleoecológico y paleoambiental...
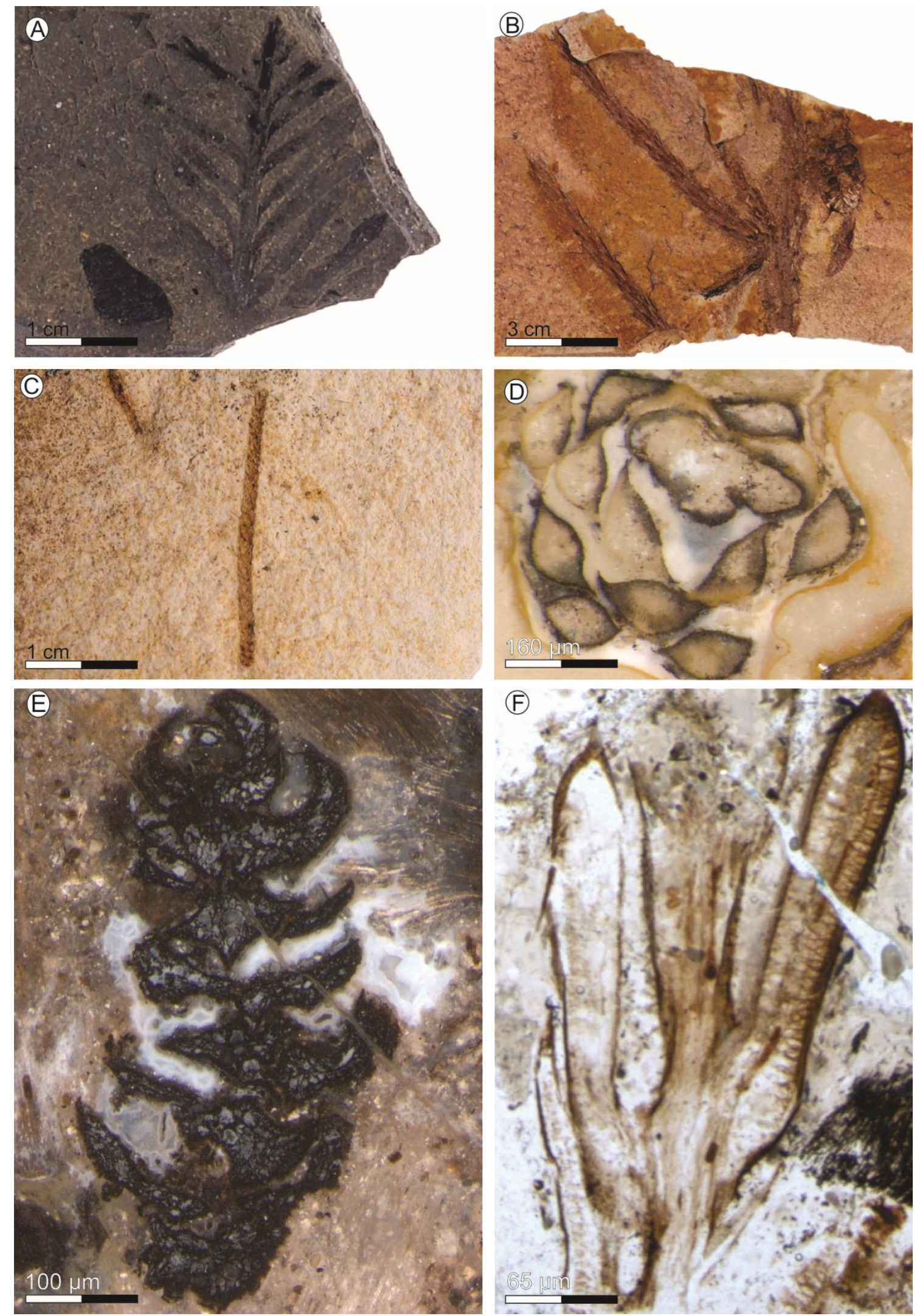

Figura. 7.10. Paleoflora de Laguna Flecha Negra. A. Elatocladus cf. planus MPM PB 15888. B. Impresiones de ramas foliosas de coníferas. MPM PB 15975. C. Impresiones de ramas foliosas de coníferas MPM PB 16002. D-F. Ramas foliosas de coníferas preservadas como permineralizaciones en masa. D. MPM PB 16025. E. MPM PB 16023. F. MPM PB 16026. 
Ana Julia Sagasti - Estudio paleobotánico, paleoecológico y paleoambiental...

\begin{tabular}{|l|l|l|l|l|}
\hline Elatocladus Halle 1913 & $\begin{array}{l}\text { Simetría } \\
\text { radial }\end{array}$ & $\begin{array}{l}\text { Hojas } \\
\text { adpresas }\end{array}$ & $\begin{array}{l}\text { Hojas cortas y } \\
\text { falcadas }\end{array}$ & $\begin{array}{l}\text { Disposición } \\
\text { espiralada }\end{array}$ \\
\cline { 2 - 5 } & $\begin{array}{l}\text { Simetría } \\
\text { bilateral }\end{array}$ & $\begin{array}{l}\text { Hojas no } \\
\text { adpresas }\end{array}$ & $\begin{array}{l}\text { Hojas chatas, } \\
\text { largas y menos } \\
\text { falcadas }\end{array}$ & $\begin{array}{l}\text { Disposición } \\
\text { en un plano }\end{array}$ \\
\hline $\begin{array}{l}\text { Brachyphyllum } \\
\text { 1979 }\end{array}$ & $\begin{array}{l}\text { Simetría } \\
\text { radial } \\
\text { emend. Harris 1979 }\end{array}$ & $\begin{array}{l}\text { Hojas } \\
\text { adpresas }\end{array}$ & $\begin{array}{l}\text { Hojas } \\
\text { romboidales } \\
\text { con o sin quilla }\end{array}$ & $\begin{array}{l}\text { Disposición } \\
\text { helicoidal. }\end{array}$ \\
\hline Pagiophyllum Heer & Simetría & $\begin{array}{l}\text { Hojas } \\
\text { adpresas }\end{array}$ & $\begin{array}{l}\text { Hojas } \\
\text { escuamiformes } \\
\text { oblanceoladas }\end{array}$ & $\begin{array}{l}\text { Disposición } \\
\text { helicoidal }\end{array}$ \\
\hline Ramas foliosas indet. & $\begin{array}{l}\text { Simetría } \\
\text { radial }\end{array}$ & $\begin{array}{l}\text { Hojas } \\
\text { adpresas, } \\
\text { a veces } \\
\text { con el }\end{array}$ & $\begin{array}{l}\text { Hojas } \\
\text { aciculares }\end{array}$ & $\begin{array}{l}\text { Disposición } \\
\text { helicoidal. }\end{array}$ \\
libre & & \\
\hline
\end{tabular}

Tabla 7.2. Comparación de los géneros de ramas foliosas de Coniferales encontrados como impresiones e impresiones-compresiones en la Localidad Laguna Flecha Negra (Formación Chon Aike).

Ramas permineralizadas indet.

Figura. 7.10.D-F

Ejemplar de referencia. MPM PB 16023

Especímenes adicionales. MPM PB 16025-16026.

Localidad. Laguna Flecha Negra

Horizonte estratigráfico. Lentes de chert

Descripción. Permineralizaciones en masa de ramas foliosas. En la Fig. 7.10.D se puede observar una rama foliosa en sección transversal, de 0,48 mm de diámetro, con un eje central que no preserva la anatomía, y una serie de hojas de sección romboidal, dispuestas espiraladamente. Las hojas miden alrededor de 0,17 $\mathrm{mm}$ de ancho por 0,076 mm de espesor. En la Fig. 7.10.E se observa una rama foliosa en sección longitudinal tangencial. La misma mide $0,53 \mathrm{~mm}$ de largo por $0,24 \mathrm{~mm}$ de ancho máximo. Hojas de sección romboidal 
Ana Julia Sagasti - Estudio paleobotánico, paleoecológico y paleoambiental...

con los extremos alargados e inclinados hacia el extremo apical de la rama. Las hojas son adpresas, con el extremo apical apenas libre. En la Fig. 7.10.F. se observa una rama foliosa en sección longitudinal radial, de 0,36 $\mathrm{mm}$ de largo por 0,21 $\mathrm{mm}$ de ancho máximo. Eje de 0,04 $\mathrm{mm}$ de ancho. Hojas alongadas, de disposición subalterna, de 0,27 $\mathrm{mm}$ de largo por 0,045 $\mathrm{mm}$ de ancho. Se observa una capa de parénquima en empalizada en la cara abaxial de la hoja.

Comentarios. Los materiales aquí descriptos presentan un estado de preservación variable. Si bien se pueden observar la presencia de células parenquimáticas en buen estado y en algunos casos de distribución organizada, no se han observado las trazas vasculares de los ejes ni las hojas. Esto puede deberse al ángulo en que han sido cortado los ejemplares ya que por su naturaleza robusta, sería esperable observar la organización de las células xilemáticas. La morfología general de los elementos preservados como permineralizaciones en masa, permite comparar estos componentes con los géneros de ramas foliosas preservados como impresiones e impresionescompresiones en la localidad Laguna Flecha Negra. Los elementos ilustrados en las Fig. 7.10.D y E pueden compararse con los géneros Brachyphyllum y Pagiophyllum por la disposición espiralada de las hojas, sección transversal de las mismas, disposición adpresa al eje y un ápice que puede o no estar parcialmente libre. En la Fig.10.F se observa una rama foliosa con hojas dispuestas de manera mucho más laxa, alargadas y de disposición subalterna. Este elemento puede compararse con el género Elatocladus presente en la megaflora de impresiones-compresiones de Laguna Flecha Negra. La imposibilidad de observar la anatomía vascular de estos ejemplares y la ausencia de estructuras reproductivas asociadas, impide realizar una asignación confiable de los mismos, aunque se señala la afinidad con los elementos estudiados como megaflora de impresiones e impresionescompresiones.

\section{Leños gimnospérmicos de afinidad incierta}

Figura. 7.11.A-D

Ejemplar de referencia. MPM PB 15936

Especímenes adicionales. MPM PB 15941, 15943 
Ana Julia Sagasti - Estudio paleobotánico, paleoecológico y paleoambiental...

Localidad. Laguna Flecha Negra

Horizonte estratigráfico. Tobas blancas

Descripción. Leño picnoxílico, homoxilado, representado exclusivamente por xilema secundario de tipo coniferoide. Presenta anillos de crecimiento poco definidos, con 1 a 2 células de aparente leño tardío. Fuerte deformación de la sección transversal de los ejemplares, que en algunos casos impide observar los anillos de crecimiento. Los radios leñosos son uniseriados, de 1 a 16 células de altura (7 en promedio).

Comentarios. El estado de preservación del material es muy pobre. Se observa fuerte degradación y deformación de los tejidos. La presencia de un leño picnoxílico y homoxilado permite señalar su afinidad con el clado de las gimnospermas, pero al no poder observarse detalles de la anatomía en corte longitudinal tangencial, no se pueden evaluar las afinidades a nivel de Orden. Sin embargo, y debido a la composición de la paleoflora estudiada en la localidad Laguna Flecha Negra, sería esperable que se trate de coníferas.
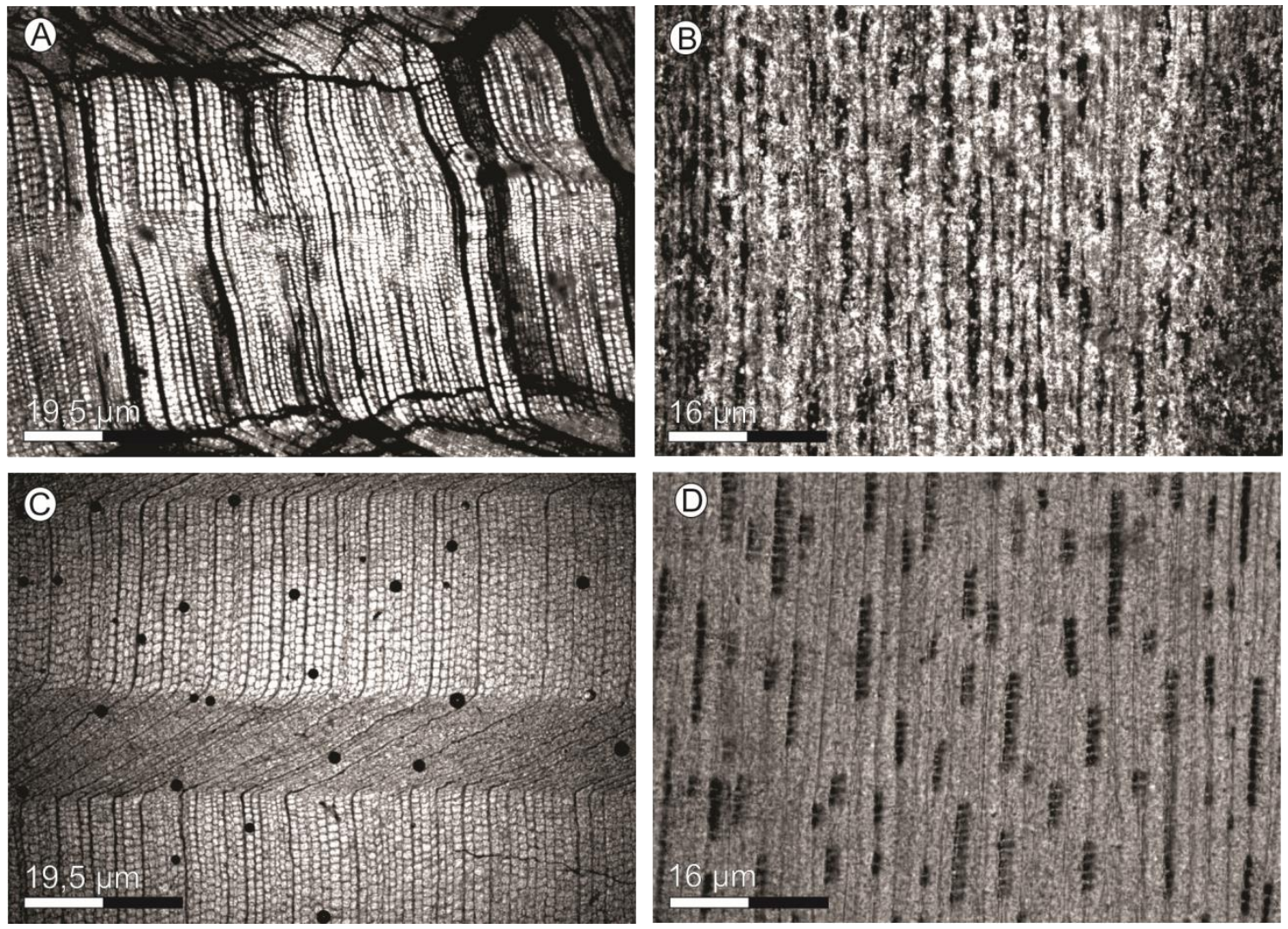

Figura. 7.11. Paleoflora de Laguna Flecha Negra. Leños gimnospérmicos de afinidad incierta. A. CT leño fuertemente deformado se observa un aparente anillo de crecimiento. MPM PB 15936. B. CLT radios uniseriados. MPM PB 15936. C. CT leño fuertemente deformado, no se observan anillos de crecimiento. MPM PB 15943. D. CLT radios uniseriados pobremente preservados. MPM PB 15943. 
Ana Julia Sagasti - Estudio paleobotánico, paleoecológico y paleoambiental...

\section{Incertae sedis}

Género Scleropteris Saporta 1873

Especie tipo. Scleropteris pomelii Saporta 1873

\section{Scleropteris vincei Herbst 1966a}

Figura.7.12 y 7.13. A-C.

Ejemplar de referencia. MPM PB 16004

Especímenes adicionales. MPM PB 16005-16018; 15967.

Descripción. Fragmentos de frondes al menos tripinnadas. El mayor, de 7,5 $\mathrm{cm}$ de largo por 7,6 cm de ancho (preserva una sola serie de pinnas). Ancho estimado de al menos $15,2 \mathrm{~cm}$. Raquis de $0,3 \mathrm{~cm}$ de ancho, liso. Pinnas imparipinnadas (MPM PB 16010), lanceoladas de 6,5 cm de largo por $\sim 2,5 \mathrm{~cm}$ de ancho, insertas con un ángulo de $60^{\circ}-70^{\circ}$ en forma alterna. Pínnulas lanceoladas de $2,2 \mathrm{~cm}$ de largo por $0,4 \mathrm{~cm}$ de ancho en la zona media, imparipinnadas, insertas de manera subopuesta o alterna, con ángulo de $60^{\circ}$. Pinnululas flabeliformes, subromboidales con ápice agudo y base constricta, con margen basiscópico decurrente y acroscópico contraído, e insertas con un ángulo que oscila entre $45^{\circ}-50^{\circ}$; miden hasta $0,3 \mathrm{~cm}$ de largo por $0,2 \mathrm{~cm}$ de ancho. Venación radiante desde la base y dicotomizada en abanico.

Comparaciones. En Argentina se han descripto tres especies asignables a este taxón fósil de frondes: Scleropteris grandis en la Formación Paso Flores (Artabe et al., 1994), Scleropteris vincei en la Formacion Piedra Pintada, Formación Cabeza del Cristiano, Grupo Pampa de Agnia, Formación Nestares, Alicurá y Grupo Bahía Laura, Estancia La Juanita (Herbst, 1966a, 1966b; Arrondo y Petriella, 1980; Petriella y Arrondo, 1984) y Scleropteris lotenaense en la Formación Cerro Lotena (Baldoni, 1980). Scleropteris vincei puede diferenciarse de $S$. grandis y $S$. lotenaense por la presencia de frondes coriáceas de menor tamaño. S. vincei se distingue de S. grandis por presentar pinnululas basales no diferenciadas y venación esfenopteroide. Scleropteris vincei fue citada con dudas para la Formación La Matilde (Herbst y Zalazar, 1998). Artabe et al. (2005) han señalado la afinidad de este taxón con el grupo de las pteridospermas, la ausencia de caracteres cuticulares y estructuras reproductivas asociadas no permiten ubicarlo dentro de ninguna de las familias conocidas para el Mesozoico de Gondwana. 
Ana Julia Sagasti - Estudio paleobotánico, paleoecológico y paleoambiental...

(A)

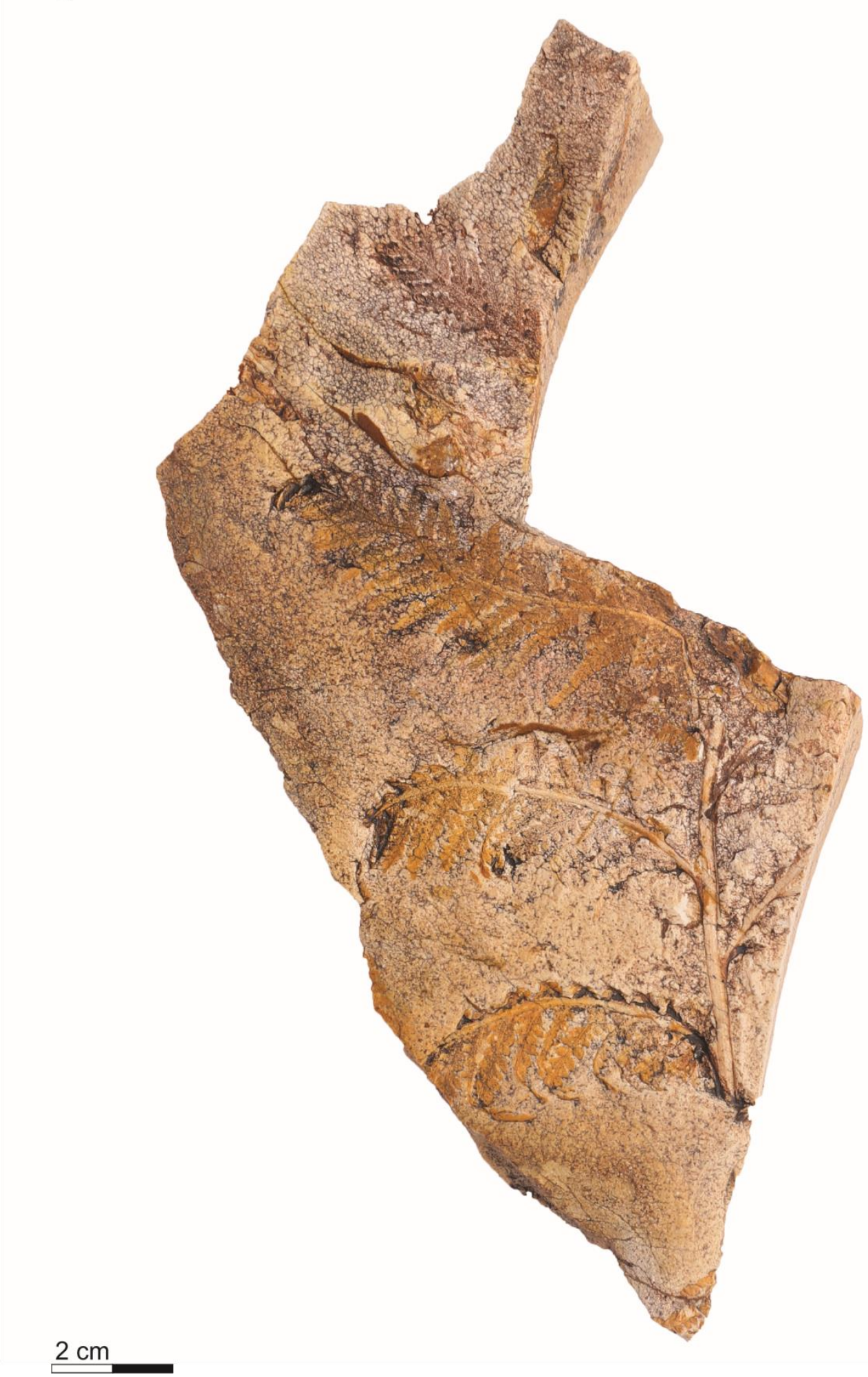

Figura 7.12. Scleropteris vincei Herbst. Fragmento de fronde, vista general. MPM PB 16004. 
Ana Julia Sagasti - Estudio paleobotánico, paleoecológico y paleoambiental...

\section{Género Sphenopteris Sternberg 1825}

Especie tipo. Sphenopteris elegans (Brongniart) Sternberg 1825.

Sphenopteris cf. nordenskjöldii Halle emend Rees and Cleal.

Figuras.7.13.D-E.

Ejemplar de referencia. MPM PB 15886

Especímenes adicionales. MPM PB 15887, 16007; 16019-16020.

Localidad. Laguna Flecha Negra

Horizonte estratigráfico. Areniscas gruesas y pelitas oscuras.

Descripcion. Fragmentos de fronde, al menos tripinnada, de $2 \mathrm{~cm}$ de largo por $1 \mathrm{~cm}$ de ancho, imparipinnadas. Pinnas multilobadas con base angosta, dispuestas de manera alterna, insertas con un ángulo de $30^{\circ}$, de $0,5 \mathrm{~cm}$ de largo por 0,3 cm de ancho. En el material adicional MPM PB 16007 se puede observar la reducción de la lámina de las pinnas de último orden, que apenas rodea el ancho de las venas en cada lóbulo.

Observaciones. El taxón fósil Sphenopteris ha sido identificado como follaje de diversas Pteridospermas así como algunos helechos verdaderos (Taylor et al. 2009). En sentido amplio se aplica para diversos tipos foliares, caracterizados por pínnulas constrictas en la base, predominantemente del Paleozoico Tardío aunque algunas sobreviven hacia el Mesozoico. Van Amerom (1975) propone utilizar el término Sphenopteris sensu lato para formas foliares fósiles cuyas estructuras reproductivas no se conocen, mientras que aquellas formas en conexión orgánica con estructuras reproductivas gimnospérmicas se asignan a Sphenopteris sensu stricto o a Eusphenopteris.

Comparaciones. El material estudiado se puede diferenciar fácilmente de Sphenopteris bagualensis Menéndez (1956) ya que no se observa raquis estriado y las pinnas no son claramente coriáceas ni presentan lóbulos apiculados. No se cuenta con detalles cuticulares para comparar, pero las diferencias morfológicas permiten segregarla de esta especie. Los ejemplares estudiados son similares a Sphenopteris nordenskjöldii descripto por Bonetti (1963) para el Jurásico Medio de la provincia de Chubut. Esta especie presenta frondes tripinnadas, con raquis alado cuyas pinnas se resuelven en una serie de segmentos lineares y estrechos, cada uno con una sola vena media. El ápice de los segmentos es claramente obtuso. En el material de Laguna Flecha 
Ana Julia Sagasti - Estudio paleobotánico, paleoecológico y paleoambiental...

Negra no se observa el raquis alado, aunque las restantes características morfológicas son comparables con S. nordenskjöldii. Debido a la escasa cantidad de ejemplares y el carácter fragmentario de los mismos, se postula que la ausencia de raquis alado podría deberse al estado de preservación de los materiales, particularmente por tratarse de restos pequeños de la zona apical de las frondes. En función de esto, se asigna los materiales con dudas a S. nordenskjöldii.

Figura. 7.14. A-B.

$$
\text { Hojas plurinervias de afinidad incierta }
$$

Ejemplar de referencia. MPM PB 16023

Especímenes adicionales. MPM PB 16022

Localidad. Laguna Flecha Negra.

Horizonte estratigráfico. Lentes de chert.

Descripción. Fragmentos de hojas plurinervias preservados como permineralizaciones silíceas en masa. En la Fig. 7.11.A se observa una pinna en sección paradermal de carácter fragmentario. Longitud máxima estimada $0,15 \mathrm{~mm}$, ancho máximo estimado $0,082 \mathrm{~mm}$. Se observan 5 venas que se dividen dicotómicamente hacia la mitad del largo de la pinna, se estima la presencia de al menos 3 venas más. No se observan células epidérmicas, cutícula ni estomas preservados. En la Fig. 7.11.B se ilustra el fragmento de una hoja plurinervia en corte transversal de 0,75 $\mathrm{mm}$ de largo por 0,13 $\mathrm{mm}$ de ancho. Se preserva el molde de cuatro haces vasculares reniformes en los que no se observa la anatomía. El mesófilo está representado por parénquima esponjoso, no se preservan estomas.

Comentarios. Dentro del detrito vegetal fragmentario preservado en los lentes de chert aflorantes en la localidad Laguna Flecha Negra se pueden reconocer fragmentos de pinnas plurinervias de afinidad incierta. Estos restos no presentan anatomía vascular preservada y su morfología se reconoce de manera parcial. Esto impide realizar una determinación sistemática de los elementos. Pinnas plurinervias se observan en helechos, cycadales, gingkoales, cycadoideales y pteridospermas. 
Ana Julia Sagasti - Estudio paleobotánico, paleoecológico y paleoambiental...

(A)

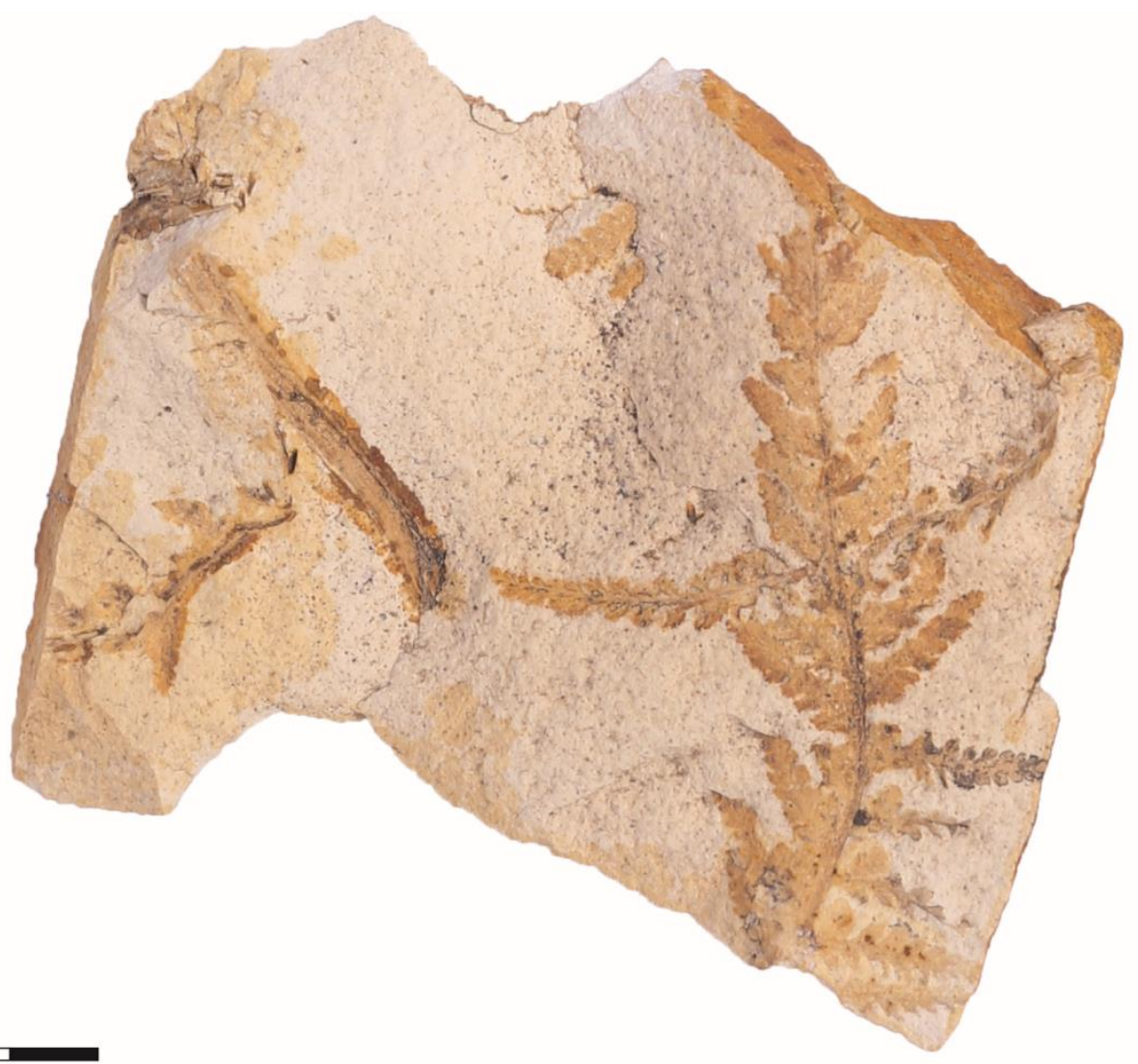

$1 \mathrm{~cm}$

(B)

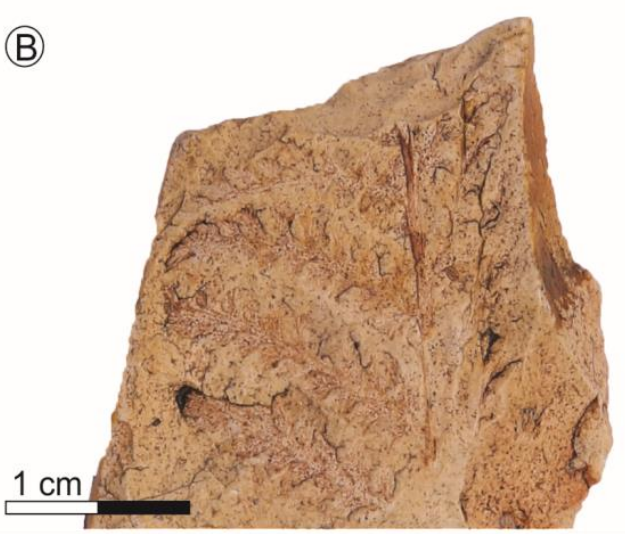

(D)

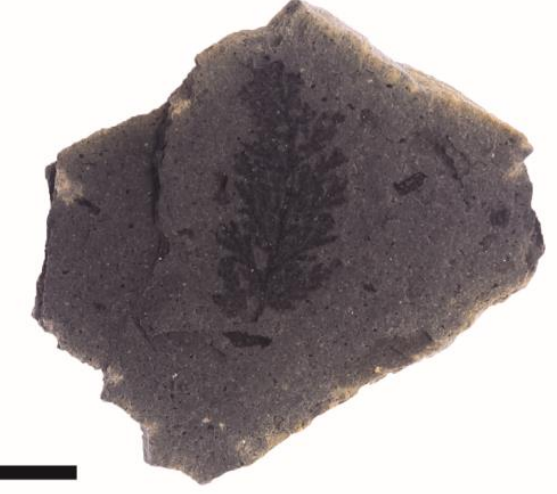

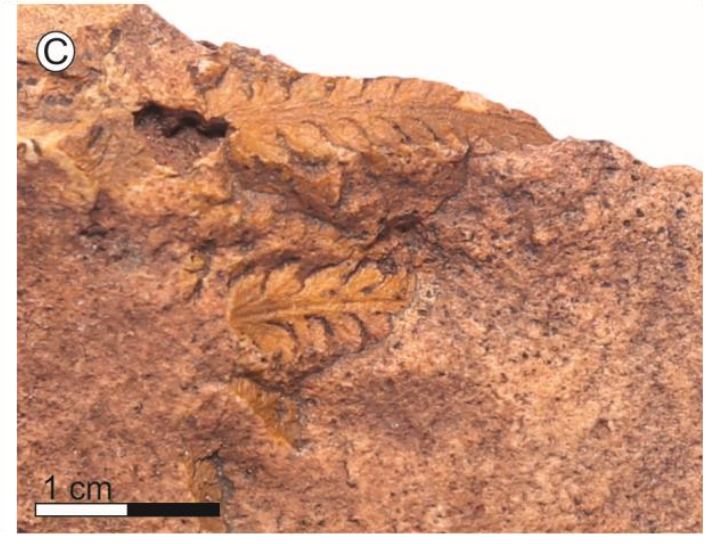

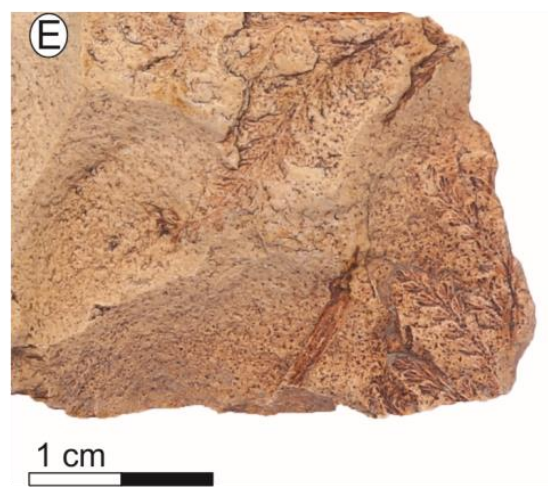

Figura 7.13.Paleoflora de la localidad Laguna Flecha Negra. A. Fragmento de pinna de Slceropteris vincei Herbst. MPM PB 16006. B. Detalle pínnulas, MPM PB 16007. C. Detalle pinnululas, MPM PB 16008. D. Sphenopteris cf. nordenskjöldii MPM PB 15886. E. Sphenopteris cf. nordenskjöldii MPM PB 16007. 
Ana Julia Sagasti - Estudio paleobotánico, paleoecológico y paleoambiental...

Figura. 7.14.C

Estructura reproductiva pinnada indet $A$.

Ejemplar de referencia. MPM PB 16021

Descripción. Eje delgado (0,2 cm de ancho) que porta esporofilos de manera alterna. La estructura completa es de 2,7 cm de largo por 1,1 cm en su parte más ancha. Es aparentemente imparipinnada. En la cara adaxial de los esporofilos se ubican aparentes óvulos invertidos. Estos óvulos son de 0,4 cm de largo por 0,2 cm de ancho. Se observa un óvulo por esporofilo. El estado de preservación no permite identificar posibles cúpulas ni tegumentos que acompañen a estos óvulos. No se preservan caracteres cuticulares ni se observa ningún tipo de ornamentación ni tricomas sobre la superficie de los óvulos y esporofilos.

Estructura reproductiva pinnada indet B.

Figura. 7.14.D

Ejemplar de referencia. MPM PB 15894.

Descripción. Fragmento de eje delgado $(0,1 \mathrm{~cm}$ de ancho) que porta aparentes óvulos pedicelados dispuestos de manera opuesta. Estos aparentes óvulos presentan un pedicelo corto, de 0,1 cm de largo por 0,1 cm de ancho. Son ovalados, de $0,4 \mathrm{~cm}$ de largo por $0,3 \mathrm{~cm}$ de ancho. El estado de preservación no permite distinguir venación, desarrollo de tegumentos ni cúpulas. No se preserva material carbonoso en las muestras que permita analizar cutículas/estructuras epidérmicas. Su apariencia es lisa. No se preserva el ápice de la estructura, lo cual impide identificar si se trata de ejes imparipinnados o no.

Comentarios. La distribución pinnada de estas estructuras reproductivas indica una afinidad con el grupo de las Pteridospermas, lo cual es consistente a su vez por la abundante presencia de frondes del taxón fósil Scleropteris. La ausencia de caracteres cuticulares, la morfología simple de las estructuras y el hecho de encontrar pocos ejemplares, no asociados a frondes estériles impide realizar una determinación sistemática ajustada para los ejemplares. 

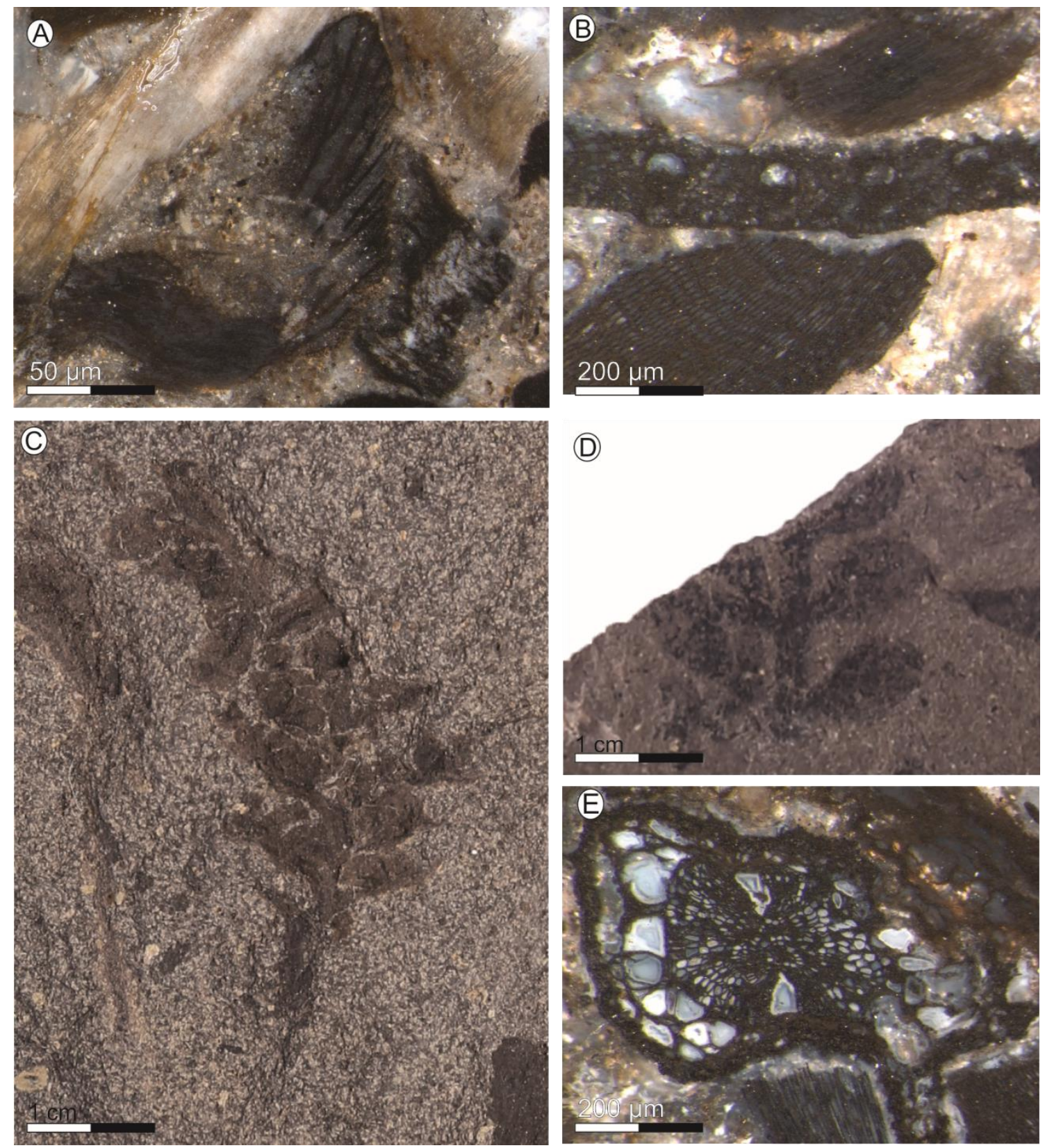

Figura. 7.14 Paleoflora de Laguna Flecha Negra. A. Hoja plurinervia de afinidad incierta. MPM PB 16023. B. CT hoja plurinervia de afinidad incierta MPM PB 16022. C. Estructura reproductiva pinnada indet A. MPM PB 16021. D. Estructura reproductiva pinnada indet B. MPM PB 15894. E. Raíz diarca. MPM PB 16022

\section{Raíz diarca indet.}

Figura. 7.14.E.

Ejemplar de referencia. MPM PB 16022.

Localidad. Laguna Flecha Negra.

Horizonte estratigráfico. Lentes de chert. 
Ana Julia Sagasti - Estudio paleobotánico, paleoecológico y paleoambiental...

Descripción. Fragmento de raíz diarca preservado como permineralización silícea en masa. Se observa en sección transversal, en forma de clepsidra. Diámetro mayor de $0,57 \mathrm{~mm}$, diámetro menor de $0,33 \mathrm{~mm}$. Los polos metaxilemáticos presentan células de sección cuadrangular, de 0,06 mm por $0,05 \mathrm{~mm}$. El protoxilema no se preserva, se puede observar una zona sin células donde deberían ubicarse las células protoxilemáticas. La zona central de la raíz está compuesta por células parenquimáticas de sección rectangular a poligonal, de $17,9 \mu \mathrm{m}$ por $10,2 \mu \mathrm{m}$.

Comentarios. Raíces diarcas pueden encontrarse tanto en helechos como en gimnospermas, elementos que se encuentran representados en la paleoflora de la localidad Laguna Flecha Negra. Este elemento no presenta características distintivas que permitan determinar su afinidad de manera certera, aunque se señala que es consistente con la composición florística estudiada en esta localidad.

\section{Anexo xilotafoflora.}

Los leños permineralizados colectados en el nivel de areniscas gruesas basales de la secuencia aflorante en la localidad Laguna Flecha Negra presentan un estado de preservación de regular a malo. Los ejemplares presentaban abundantes fracturas, lo cual dificultó el preparado de cortes delgados y en algunos casos no se cuenta con los tres cortes estándar para el estudio de maderas. Por otro lado, el estado general de preservación de los materiales, dificulta su análisis en detalle. La tabla 7.3 resume las características que pudieron ser observadas en cada uno de los materiales, señalando las afinidades sistemáticas inferibles a partir de su estudio.

Los materiales colectados en el bosque in situ preservado en el nivel de tobas blancas presentan un estado de preservación de pobre a malo. Se pudieron realizar determinaciones sobre 8 muestras de las 25 colectadas. La tabla 7.4 resume las características que pudieron ser observadas en cada uno de los materiales, señalando las afinidades sistemáticas inferibles a partir de su estudio. 
Ana Julia Sagasti - Estudio paleobotánico, paleoecológico y paleoambiental...

Tabla 7.3. Caracteres anatómicos observados en los leños preservados como permineralizaciones individuales en el nivel de areniscas basales del perfil aflorante en la localidad Laguna Flecha Negra.

\begin{tabular}{|c|c|c|c|c|c|c|c|}
\hline Muestra & $\begin{array}{l}\text { Anillos de } \\
\text { crecimiento }\end{array}$ & $\begin{array}{l}\text { Punteaduras de } \\
\text { las paredes } \\
\text { radiales de las } \\
\text { traqueidas }\end{array}$ & $\begin{array}{l}\text { Parén- } \\
\text { quima } \\
\text { axial }\end{array}$ & $\begin{array}{l}\text { Campos de } \\
\text { cruzamiento }\end{array}$ & Radios & $\begin{array}{l}\text { Afinidad } \\
\text { sistemática }\end{array}$ & Observaciones \\
\hline $\begin{array}{l}\text { MPM PB } \\
15962\end{array}$ & $\begin{array}{l}\text { Presentes, de } \\
\text { transición } \\
\text { abrupta. 1-2 } \\
\text { células leño } \\
\text { tardío. }\end{array}$ & Araucarioides & No & - & $\begin{array}{l}\text { Heterocelulares. } \\
\text { Uniseriados 1-12 (4) }\end{array}$ & Araucariaceae & $\begin{array}{l}\text { Estado de } \\
\text { preservación malo. }\end{array}$ \\
\hline $\begin{array}{l}\text { MPM PB } \\
15896\end{array}$ & - & Araucarioides & No & $\begin{array}{l}\text { Dos a cuatro } \\
\text { punteaduras } \\
\text { cupresoides por } \\
\text { campo. }\end{array}$ & $\begin{array}{l}\text { Heterocelulares. } \\
\text { Uniseriados 1-12 (6) }\end{array}$ & Araucariaceae & $\begin{array}{l}\text { Estado de } \\
\text { preservación pobre }\end{array}$ \\
\hline $\begin{array}{l}\text { MPM } \\
\text { PB15897 }\end{array}$ & $\begin{array}{l}\text { Presentes, de } \\
\text { transición } \\
\text { abrupta. 1-2 } \\
\text { células leño } \\
\text { tardío. }\end{array}$ & Araucarioides & No & - & $\begin{array}{l}\text { Uniseriados. 6-16 } \\
\text { (9) }\end{array}$ & Araucariaceae & $\begin{array}{l}\text { Abundantes cuñas de } \\
\text { resina en las } \\
\text { traqueidas. }\end{array}$ \\
\hline $\begin{array}{l}\text { MPM PB } \\
15898\end{array}$ & - & Araucarioides & - & - & Uniseriados & Araucariaceae? & $\begin{array}{l}\text { Estado de } \\
\text { preservación muy } \\
\text { malo. }\end{array}$ \\
\hline $\begin{array}{l}\text { MPM } \\
\text { PB15899 }\end{array}$ & $\begin{array}{l}\text { Presentes, de } \\
\text { transición } \\
\text { abrupta. } 1 \text { célula } \\
\text { leño tardío }\end{array}$ & - & - & - & Uniseriados 1-8 (3) & - & $\begin{array}{l}\text { Estado de } \\
\text { preservación malo. }\end{array}$ \\
\hline $\begin{array}{l}\text { MPM PB } \\
15900\end{array}$ & - & - & - & - & - & - & $\begin{array}{l}\text { Estado de } \\
\text { preservación muy } \\
\text { malo. }\end{array}$ \\
\hline $\begin{array}{l}\text { MPM PB } \\
15901\end{array}$ & - & Araucarioides & - & - & - & Araucariaceae? & $\begin{array}{l}\text { Estado de } \\
\text { preservación muy } \\
\text { malo. }\end{array}$ \\
\hline
\end{tabular}


Ana Julia Sagasti - Estudio paleobotánico, paleoecológico y paleoambiental...

Tabla 7.3. Continuación.

\begin{tabular}{|c|c|c|c|c|c|c|c|}
\hline $\begin{array}{l}\text { MPM PB } \\
15902\end{array}$ & $\begin{array}{l}\text { Presentes, de } \\
\text { transición } \\
\text { abrupta. } 1-2 \\
\text { células leño } \\
\text { tardío. }\end{array}$ & - & - & - & Uniseriados 1-8 (4) & - & $\begin{array}{l}\text { Estado de } \\
\text { preservación malo, } \\
\text { leño muy deformado. }\end{array}$ \\
\hline $\begin{array}{l}\text { MPM PB } \\
15903\end{array}$ & - & - & - & - & $\begin{array}{l}\text { Uniseriados. 2-34 } \\
\text { (11) }\end{array}$ & - & $\begin{array}{l}\text { Estado de } \\
\text { preservación muy } \\
\text { malo }\end{array}$ \\
\hline $\begin{array}{l}\text { MPM } \\
\text { PB15904 }\end{array}$ & $\begin{array}{l}\text { Presentes, de } \\
\text { transición } \\
\text { abrupta. } 2-3 \text { cs } \\
\text { leño tardío }\end{array}$ & - & $\mathrm{Si}$ & - & $\begin{array}{l}\text { Uniseriados. 2- } \\
34(16)\end{array}$ & - & $\begin{array}{l}\text { Abundantes placas de } \\
\text { resina en el } \\
\text { parénquima axial }\end{array}$ \\
\hline $\begin{array}{l}\text { MPM } \\
\text { PB15905 }\end{array}$ & $\begin{array}{l}\text { Presentes, de } \\
\text { transición } \\
\text { abrupta. 1-2 cs } \\
\text { leño tardío. }\end{array}$ & $\begin{array}{l}\text { Uniseriadas, } \\
\text { raramente } \\
\text { biseriadas. } \\
\text { Comprimidas. De } \\
\text { tipo mixto }\end{array}$ & No & $\begin{array}{l}4 \text { punteaduras } \\
\text { cupresoides por } \\
\text { campo }\end{array}$ & $\begin{array}{l}\text { Homocelulares. } \\
\text { Uniseriados 1-7 (3) } \\
\text { Paredes lisas. }\end{array}$ & & $\begin{array}{l}\text { Abundantes placas de } \\
\text { resina en las } \\
\text { traqueidas }\end{array}$ \\
\hline $\begin{array}{l}\text { MPM } \\
\text { PB15906 }\end{array}$ & - & - & - & - & - & - & $\begin{array}{l}\text { Estado de } \\
\text { preservación muy } \\
\text { malo }\end{array}$ \\
\hline $\begin{array}{l}\text { MPM } \\
\text { PB15907 }\end{array}$ & - & Araucarioides & No & $\begin{array}{l}4 \text { a } 5 \\
\text { punteaduras } \\
\text { cupresoides por } \\
\text { campo, alternas, } \\
\text { contiguas. }\end{array}$ & $\begin{array}{l}\text { Uniseriados. 1-10 } \\
\text { (3) }\end{array}$ & Araucariaceae & $\begin{array}{l}\text { Estado de } \\
\text { preservación pobre. }\end{array}$ \\
\hline $\begin{array}{l}\text { MPM } \\
\text { PB15908 }\end{array}$ & $\begin{array}{l}\text { Presentes, de } \\
\text { transición } \\
\text { abrupta. } 1-2 \\
\text { células leño } \\
\text { tardío. }\end{array}$ & De tipo Xenoxylon & No & $\begin{array}{l}4 \text { a } 6 \\
\text { punteaduras } \\
\text { cupresoides, } \\
\text { alineadas en } \\
\text { dos columnas, } \\
\text { contiguas. }\end{array}$ & $\begin{array}{l}\text { Uniseriados. 1-10 } \\
\text { (4) }\end{array}$ & Araucariaceae & $\begin{array}{l}\text { Estado de } \\
\text { preservación pobre. }\end{array}$ \\
\hline $\begin{array}{l}\text { MPM } \\
\text { PB15909 }\end{array}$ & - & - & - & - & $\begin{array}{l}\text { Uniseriados. 3-36 } \\
\text { (12) }\end{array}$ & - & $\begin{array}{l}\text { Estado de } \\
\text { preservación muy } \\
\text { malo. }\end{array}$ \\
\hline
\end{tabular}


Ana Julia Sagasti - Estudio paleobotánico, paleoecológico y paleoambiental...

Tabla 7.3. Continuación

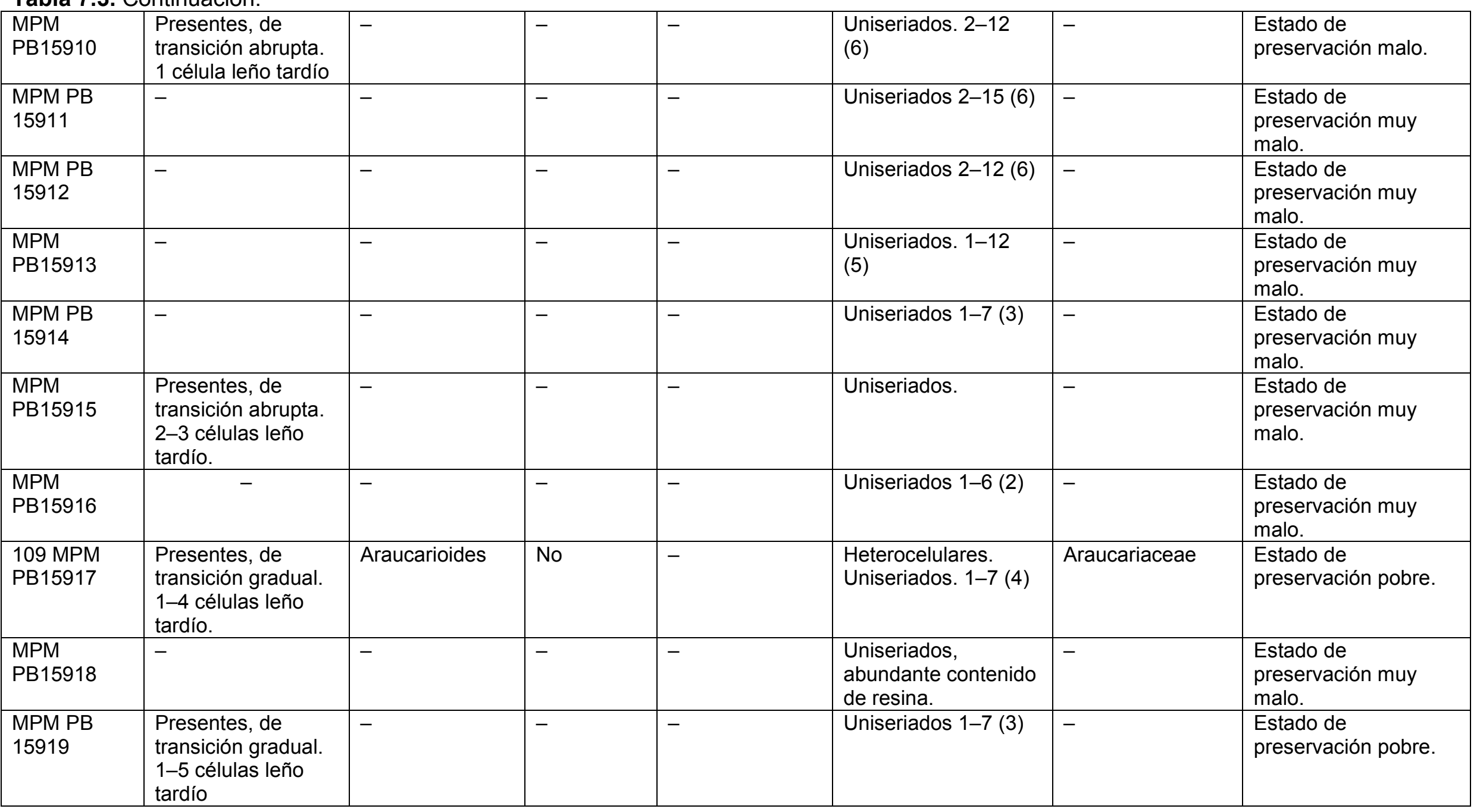


Ana Julia Sagasti - Estudio paleobotánico, paleoecológico y paleoambiental...

Tabla 7.3. Continuación.

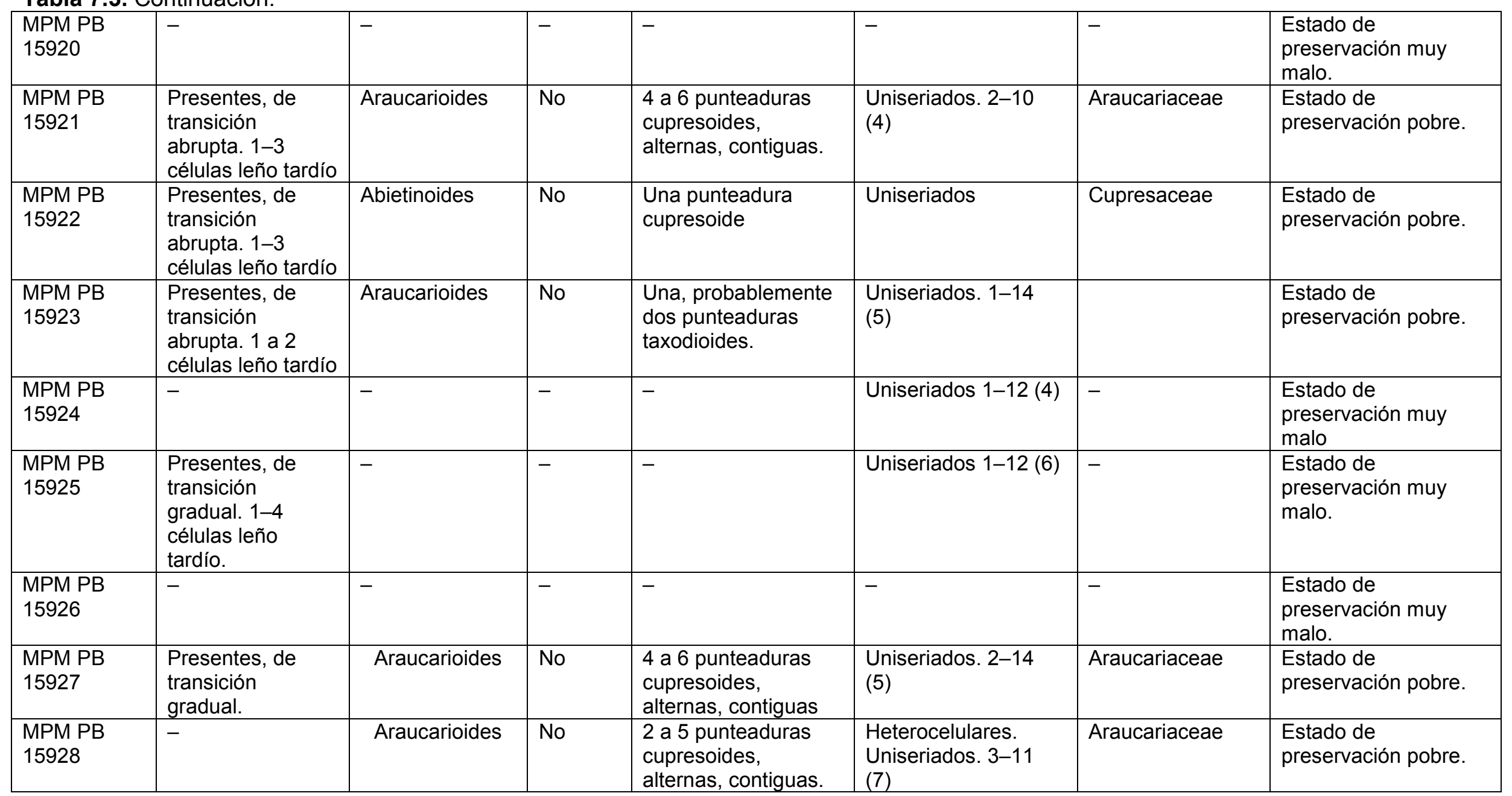


Ana Julia Sagasti - Estudio paleobotánico, paleoecológico y paleoambiental...

Tabla 7.3. Continuación.

\begin{tabular}{|c|c|c|c|c|c|c|c|}
\hline $\begin{array}{l}\text { MPM PB } \\
15929\end{array}$ & - & Araucarioides & No & $\begin{array}{l}2 \text { a } 4 \\
\text { punteaduras } \\
\text { cupresoides, } \\
\text { alternas, } \\
\text { contiguas. }\end{array}$ & $\begin{array}{l}\text { Homocelulares. } \\
\text { Uniseriados. 2-24 } \\
\text { (7) }\end{array}$ & Araucariaceae & $\begin{array}{l}\text { Estado de } \\
\text { preservación malo. }\end{array}$ \\
\hline $\begin{array}{l}\text { MPM PB } \\
15931\end{array}$ & - & $\begin{array}{l}\text { Araucarioides o } \\
\text { tipo xenoxylon }\end{array}$ & - & - & Uniseriados & Araucariaceae & $\begin{array}{l}\text { Estado de } \\
\text { preservación malo, } \\
\text { abundantes depósitos } \\
\text { de resina en el } \\
\text { parénquima radial. }\end{array}$ \\
\hline $\begin{array}{l}\text { MPM PB } \\
15932\end{array}$ & - & - & - & - & $\begin{array}{l}\text { Uniseriados. 1-15 } \\
\text { (6) }\end{array}$ & - & $\begin{array}{l}\text { Estado de } \\
\text { preservación muy } \\
\text { malo. }\end{array}$ \\
\hline $\begin{array}{l}\text { MPM PB } \\
15933\end{array}$ & $\begin{array}{l}\text { Presentes, de } \\
\text { transición } \\
\text { abrupta. 1-2 } \\
\text { células leño tardío }\end{array}$ & - & - & - & Uniseriados & - & $\begin{array}{l}\text { Estado de } \\
\text { preservación muy } \\
\text { malo. }\end{array}$ \\
\hline $\begin{array}{l}\text { MPM PB } \\
15934\end{array}$ & $\begin{array}{l}\text { Presentes, de } \\
\text { transición } \\
\text { gradual. 1-4 } \\
\text { células leño } \\
\text { tardío. }\end{array}$ & - & - & - & - & - & $\begin{array}{l}\text { Estado de } \\
\text { preservación muy } \\
\text { malo. }\end{array}$ \\
\hline
\end{tabular}


Ana Julia Sagasti - Estudio paleobotánico, paleoecológico y paleoambiental...

Tabla 7.4. Caracteres anatómicos observados en los leños preservados como troncos y tocones permineralizados en el tope del nivel de tobas blancas masivas, correspondientes al bosque in situ aflorante en la localidad Laguna Flecha Negra.

\begin{tabular}{|c|c|c|c|c|c|c|c|}
\hline Muestra & $\begin{array}{l}\text { Anillos de } \\
\text { crecimiento }\end{array}$ & $\begin{array}{l}\text { Punteaduras de } \\
\text { las paredes } \\
\text { radiales de las } \\
\text { traqueidas }\end{array}$ & $\begin{array}{l}\text { Parénquim } \\
\text { a axial }\end{array}$ & $\begin{array}{l}\text { Campos de } \\
\text { cruzamiento }\end{array}$ & Radios & $\begin{array}{l}\text { Afinidad } \\
\text { sistemática }\end{array}$ & Observaciones. \\
\hline $\begin{array}{l}\text { MPM PB } \\
15935\end{array}$ & $\begin{array}{l}\text { Presentes, de } \\
\text { transición } \\
\text { abrupta. 1-4 } \\
\text { células leño } \\
\text { tardío. }\end{array}$ & Araucarioides & No & - & $\begin{array}{l}\text { Uniseriados } 2-13 \\
\text { células alto (6). } \\
\text { Paredes lisas. }\end{array}$ & Araucariaceae & $\begin{array}{l}\text { Estado de } \\
\text { preservación pobre. } \\
\text { Anatomía poco clara } \\
\text { en CLR. }\end{array}$ \\
\hline $\begin{array}{l}\text { MPM PB } \\
15936\end{array}$ & $\begin{array}{l}\text { Presentes, de } \\
\text { transición } \\
\text { abrupta. } 1 \text { célula } \\
\text { leño tardío. }\end{array}$ & - & No & - & Uniseriados. & $?$ & $\begin{array}{l}\text { Fuerte deformación, } \\
\text { observable en CT. }\end{array}$ \\
\hline $\begin{array}{l}\text { MPM PB } \\
15937\end{array}$ & - & Araucarioides & - & $\begin{array}{l}\text { Dos } \\
\text { punteaduras } \\
\text { taxodioides por } \\
\text { campo. } \\
\text { Alineadas, } \\
\text { espaciadas. }\end{array}$ & Uniseriados. & Araucariaceae & $\begin{array}{l}\text { Fuerte deformación, } \\
\text { observable tanto en } \\
\text { CT como CLT. }\end{array}$ \\
\hline $\begin{array}{l}\text { MPM PB } \\
15938\end{array}$ & - & - & - & - & - & - & $\begin{array}{l}\text { Preservación muy } \\
\text { mala. No se puede } \\
\text { observar la anatomía }\end{array}$ \\
\hline $\begin{array}{l}\text { MPM PB } \\
15939\end{array}$ & $\begin{array}{l}\text { Presentes, de } \\
\text { transición } \\
\text { abrupta. 1-2 } \\
\text { células leño tardío }\end{array}$ & Araucarioides & No & $\begin{array}{l}\text { Dos } \\
\text { punteaduras } \\
\text { cupresoides por } \\
\text { campo. } \\
\text { Alineadas, } \\
\text { espaciadas. } \\
\end{array}$ & Uniseriados & Araucariaceae & $\begin{array}{l}\text { Preservación pobre, } \\
\text { particularmente en el } \\
\text { CLT }\end{array}$ \\
\hline $\begin{array}{l}\text { MPM PB } \\
15940\end{array}$ & No se observan & Araucarioides & No & $\begin{array}{l}\text { Al menos una } \\
\text { punteadura } \\
\text { ¿taxodioide? }\end{array}$ & Uniseriados & Araucariaceae & $\begin{array}{l}\text { Preservación muy } \\
\text { pobre. Anatomía poco } \\
\text { clara. }\end{array}$ \\
\hline
\end{tabular}


Ana Julia Sagasti - Estudio paleobotánico, paleoecológico y paleoambiental...

Tabla 7.4. Continuación.

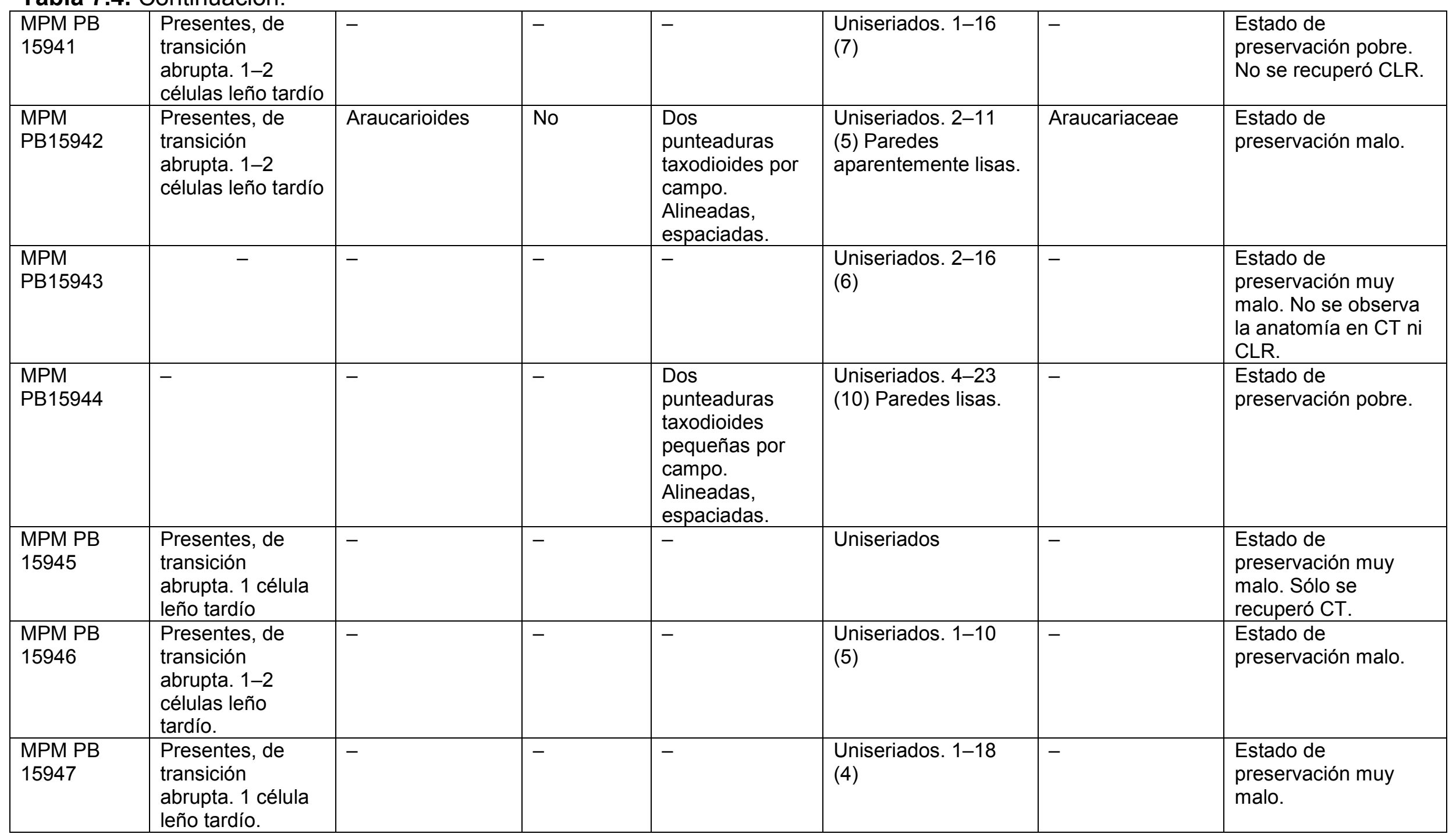


Ana Julia Sagasti - Estudio paleobotánico, paleoecológico y paleoambiental...

Tabla 7.4. Continuación.

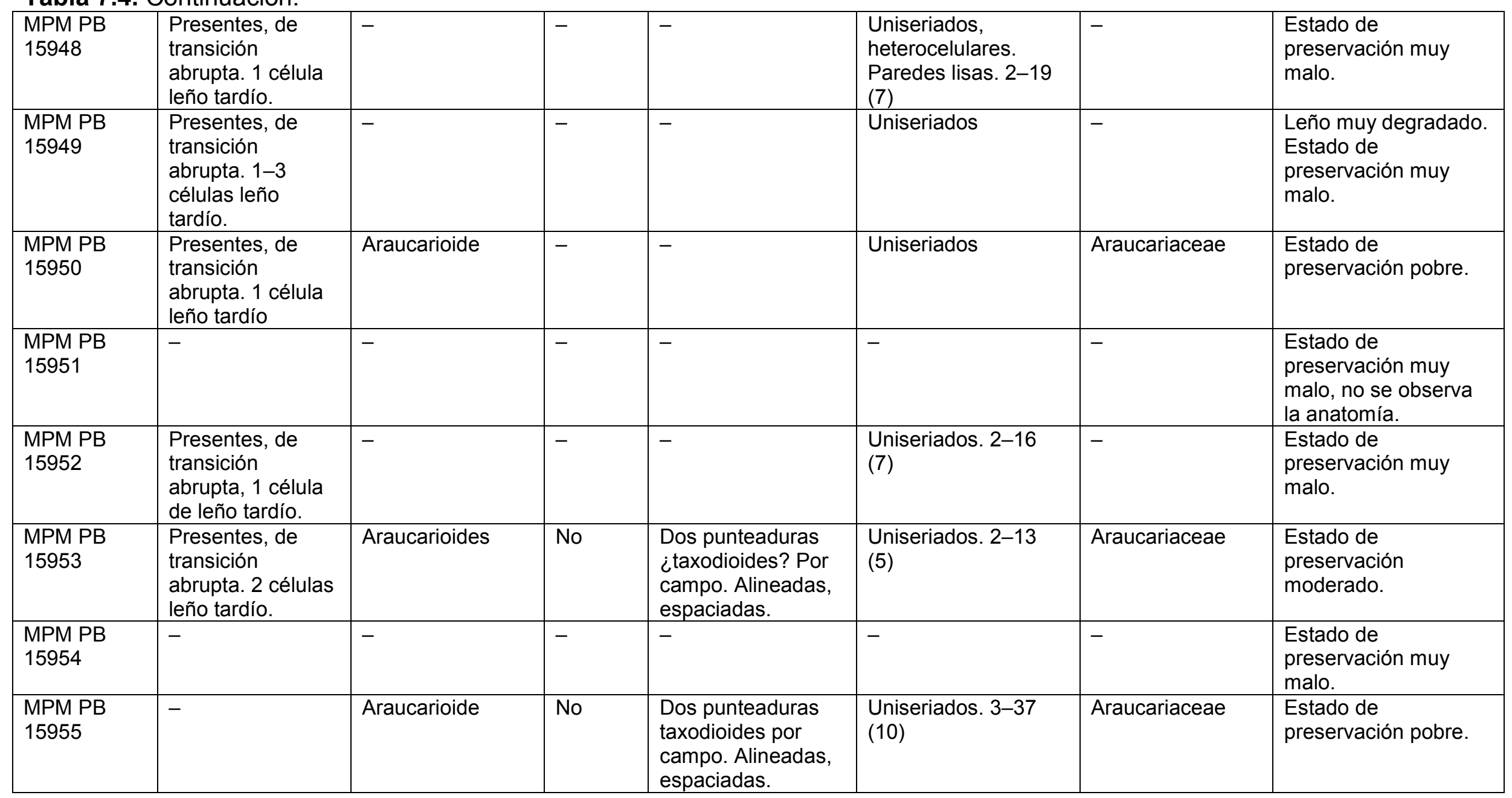


Ana Julia Sagasti - Estudio paleobotánico, paleoecológico y paleoambiental...

Tabla 7.4. Continuación.

\begin{tabular}{|c|c|c|c|c|c|c|c|}
\hline $\begin{array}{l}\text { MPM PB } \\
15956\end{array}$ & - & - & - & - & - & - & $\begin{array}{l}\text { Estado de } \\
\text { preservación muy } \\
\text { malo. }\end{array}$ \\
\hline $\begin{array}{l}\text { MPM PB } \\
15957\end{array}$ & $\begin{array}{l}\text { Presentes, de } \\
\text { transición } \\
\text { abrupta. } 1 \text { célula } \\
\text { leño tardío. }\end{array}$ & Araucarioides & No & $\begin{array}{l}\text { Al menos una, } \\
\text { probablemente } \\
\text { dos, } \\
\text { punteaduras } \\
\text { cupresoides por } \\
\text { campo. }\end{array}$ & $\begin{array}{l}\text { Uniseriados. 1-16 } \\
\text { (5) }\end{array}$ & Araucariaceae & $\begin{array}{l}\text { Estado de } \\
\text { preservación pobre. }\end{array}$ \\
\hline $\begin{array}{l}\text { MPM PB } \\
15958\end{array}$ & - & - & - & - & - & - & $\begin{array}{l}\text { Estado de } \\
\text { preservación muy } \\
\text { malo. }\end{array}$ \\
\hline $\begin{array}{l}\text { MPM } \\
\text { PB15959 }\end{array}$ & $\begin{array}{l}\text { Presentes, de } \\
\text { transición } \\
\text { abrupta. } 1-2 \\
\text { células leño } \\
\text { tardío. }\end{array}$ & - & No & $\begin{array}{l}\text { Al menos una, } \\
\text { probablemente } \\
\text { dos, } \\
\text { punteaduras } \\
\text { taxodioides por } \\
\text { campo. }\end{array}$ & $\begin{array}{l}\text { Uniseriados. } 2-18 \\
\text { (8) } \\
\text { Paredes lisas. }\end{array}$ & & $\begin{array}{l}\text { Estado de } \\
\text { preservación pobre. }\end{array}$ \\
\hline
\end{tabular}


Ana Julia Sagasti - Estudio paleobotánico, paleoecológico y paleoambiental...

\section{Conclusiones.}

En el estudio de detalle de la secuencia aflorante en la localidad Laguna Flecha Negra se pudo identificar que los niveles basales, de areniscas gruesas y pelitas oscuras, son los que contienen restos fosilíferos megascópicos de impresiones-compresiones de expansiones laminares y estructuras reproductivas. Contenido en el horizonte de areniscas gruesas, se presentan dos lentes de chert que preservan un abundante detrito vegetal fragmentario en el que pueden identificarse órganos vegetales de afinidad con las paleoflora estudiada en esta localidad. Dentro del análisis sistemático de la paleoflora de Laguna Flecha Negra se incluye el análisis de leños gimnospérmicos preservados como permineralizaciones individuales en el nivel de areniscas gruesas, y como tocones y troncos preservados en el bosque in situ contenido en el horizonte de tobas blancas. La tabla 7.5 resume la abundancia de los taxones en cada nivel. Los restos fósiles presentan un estado de preservación variable, según el sedimento en el que se encuentran contenidos. El significado tafonómico de estas variaciones será analizado en el capítulo IX.

El análisis sistemático de los restos permitió reconocer la presencia de taxones ampliamente reconocidos para el Jurásico de Argentina, e ilustra la diversidad de las comunidades vegetales establecidas en contextos volcaniclásticos con influencia geotérmica. Los elementos dominantes de esta flora incluyen coníferas micrófilas representadas por taxones fósiles asignables a las familias Araucariaceae, Cupressaceae y Cheirolepidiaceae. Las Cycadeoideales codominan esta comunidad, estando representadas por frondes monopinnadas, mayormente del taxón fósil Otozamites, con menor presencia de Ptilophyllum. Se observa una baja diversidad de helechos, tanto en lo que se refiere a cantidad de taxones, como número de muestras asignables a este grupo. Es destacable, la ausencia de restos asignables a las Equisetaceae, elemento que se observa en otras localidades del Jurásico Medio-Superior (e.g. Channing et al., 2011). Por otro lado, se observa la presencia de frondes de afinidad incierta pertenecientes al género Scleropteris, que sumado a la aparición de estructuras reproductivas pinnadas, podría indicar la presencia de pteridospermas en la comunidad vegetal. 
Ana Julia Sagasti - Estudio paleobotánico, paleoecológico y paleoambiental...

\begin{tabular}{|c|c|c|c|c|}
\hline Especie & $\begin{array}{l}\text { Pelitas } \\
\text { oscuras }\end{array}$ & $\begin{array}{c}\text { Areniscas } \\
\text { gruesas }\end{array}$ & $\begin{array}{l}\text { Lentes } \\
\text { de chert }\end{array}$ & $\begin{array}{l}\text { Tobas } \\
\text { blancas }\end{array}$ \\
\hline Gleicheniaceae indet & & & 1 & \\
\hline Coniopteris hymenophylloides & & 2 & & \\
\hline Korallipteris potrerillensis & & 2 & & \\
\hline Otozamites albosaxatilis & 3 & & & \\
\hline Otozamites sanctae-crucis & 6 & & & \\
\hline Otozamites sueroi & 10 & & & \\
\hline $\begin{array}{l}\text { Cf. Otozamites bumburyanus } \\
\text { var. major }\end{array}$ & 2 & & & \\
\hline Ptilophyllum hislopi & & 2 & & \\
\hline Araucarites cutchensis & 3 & & & \\
\hline Araucarites phillipsi & 10 & & & \\
\hline Araucarites sp. (conos) & 2 & 2 & & \\
\hline Agathoxylon arayaii & & 1 & & \\
\hline Agathoxylon cf. floresii & & 3 & & \\
\hline Agathoxylon jurassicum & & 3 & & \\
\hline Agathoxylon matildense & & 1 & & \\
\hline Araucariaceae indet & & 2 & & 1 \\
\hline Protaxodioxylon sp. & & 1 & & 6 \\
\hline Cupressinoxylon sp. & & 1 & & \\
\hline Protocupressinoxylon sp. & & & & 2 \\
\hline Pararaucaria patagonica & & 3 & & \\
\hline Brachyphyllum lotenaense & 14 & 11 & & \\
\hline Brachyphyllum sp. & 5 & 6 & & \\
\hline Pagiophyllum cf. crassifolium & 9 & & & \\
\hline Elatocladus confertus & 8 & & & \\
\hline Elatocladus cf. planus & 4 & & & \\
\hline Impresiones de ramas foliosas & 4 & 3 & & \\
\hline $\begin{array}{l}\text { Permineralizaciones de ramas } \\
\text { foliosas indet }\end{array}$ & & & 3 & \\
\hline $\begin{array}{l}\text { Leños gimnospérmicos de } \\
\text { afinidad incierta }\end{array}$ & & & & 3 \\
\hline Scleropteris vincei & & 16 & & \\
\hline Sphenopteris cf. nordenskjöldii & 4 & 1 & & \\
\hline $\begin{array}{l}\text { Hojas plurinervias de afinidad } \\
\text { incierta }\end{array}$ & & & 2 & \\
\hline Estructura pinnada A & 1 & & & \\
\hline Estructura pinnada B & 1 & & & \\
\hline Raíz diarca indet & & & 1 & \\
\hline
\end{tabular}

Tabla 7.5. Taxones fósiles identificados en la localidad Laguna Flecha Negra, cantidad de ejemplares registrados en los niveles portadores. 
Ana Julia Sagasti - Estudio paleobotánico, paleoecológico y paleoambiental...

En la localidad Laguna Flecha Negra se colectaron restos de maderas permineralizadas en dos niveles. En la sección basal del perfil aflorante, se observan permineralizaciones individuales de ejes dispersos, de poco diámetro, que podrían representar restos de ramas abscindidas de la comunidad arbórea local. El tope de la secuencia preserva un bosque in situ, en el que se identificaron tocones en posición de vida y fragmentos de los mismos, de carácter autóctono a para-autóctono, con escaso a nulo transporte. Se puede apreciar que la diversidad a nivel de familias es consistiente con aquella observada para taxones de hábito arbóreo preservados como impresiones e impresiones-compresiones. Aquellos ejemplares que no pudieron ser determinados a nivel genérico (ver tablas 7.3 y 7.4 ), muestran una afinidad con la familia Araucariaceae.

La familia Araucariaceae está representada actualmente por tres géneros, con un bajo número de especies; y posee una distribución restringida al Hemisferio Sur (Pujana et al. 2007). El registro fósil para la familia es muy abundante, encontrándose hojas, conos, polen y maderas desde el Triásico (Florin, 1963; Dutra y Stanz, 2003; Romero et al., 2004). La cita de maderas afines a la familia es particularmente abundante durante el Cretácico, período donde se encuentran representadas cerca del $70 \%$ del total de las especies de Sudamérica y Antártida (Pujana et al., 2007).

Las maderas de Araucariaceae se caracterizan por la ausencia de parénquima axial, punteaduras de las paredes radiales de las traqueidas comprimidas, de tipo araucarioide y campos de cruzamiento con numerosas (2 o más) punteaduras dispuestas de manera generalmente comprimida y alterna (Tortorelli, 1956; Rancusi et al. 1987). La presencia de anillos poco marcados y el escaso desarrollo de leño tardío, indicaría una débil estacionalidad climática, generalmente correspondiente a climas templados cálidos. Sin embargo, las maderas de Araucariaceae no desarrollan anillos de crecimiento demasiado marcados debido principalmente a su hábito perennifolio (Falcon Lang, 2000; Pujana et al., 2007). Teniendo esto en cuenta, no es recomendable realizar inferencias paleoclimáticas concluyentes a partir de ésta característica en el género Agathoxylon (Brison et al., 2001). 
Ana Julia Sagasti - Estudio paleobotánico, paleoecológico y paleoambiental...

Se describen por primera vez, restos de maderas permineralizadas para la Formación Chon Aike (Jurásico Medio-Superior, Provincia de Santa Cruz). Los materiales fueron colectados de dos niveles del perfil aflorante en la localidad Laguna Flecha Negra, correspondiendo a ejes de alto orden (probablemente ramas) y tocones en posición de vida.

El estudio anatómico de los restos permitió identificar taxones fósiles asignables al Orden Coniferales. La comunidad arbórea estaba compuesta por miembros de las familias Araucariaceae, Cheirolepidiaceae y Cupressaceae. Se observa una alta diversidad específica, reconociéndose cuatro especies del género Agathoxylon: Agathoxylon arayaii, Agathoxylon cf. floresii, Agathoxylon jurassicum y Agathoxylon matildense, todas ellas características del Jurásico y Cretácico de Gondwana. A su vez, se identificaron 3 ejemplares de afinidad con las Araucariaceae. Dentro de la familia Cheirolepidiaceae se reconoce la presencia de 2 ejemplares de leños asignables al género Protocupressinoxylon. En cuanto a las Cupressaceae, esta familia se encuentra representada en la localidad Laguna Flecha Negra por un ejemplar del género Cupressinoxylon y 7 ejemplares asignables al género Protaxodioxylon.

Los materiales analizados en este capítulo aportan evidencia sobre las comunidades vegetales preservadas en secuencias de la Formación Chon Aike. Hasta el momento, sólo se conocían restos de hojas colectados en los alrededores de la Estancia Bajo Pellegrini (de Barrio et al., 1982). Esta asociación está compuesta únicamente por elementos asignables a las Cycadoideaceae. El análisis de la paleoflora de Laguna Flecha Negra amplía significativamente el registro de paleofloras de esta unidad estratigráfica, evidenciando una mayor diversidad, estando representados componentes de los grandes clados de plantas vasculares que se conocen para el Jurásico de Argentina. 


\section{Interacciones multitróficas en leños degradados.}

\section{Introducción}

Los organismos se interrelacionan de múltiples maneras, generando redes de asociación que regulan la diversidad biológica y las funciones y estructura trófica de los ecosistemas terrestres (Tscharntke y Hawkins, 2008). Plantas, hongos, bacterias y atrópodos se vinculan con distintos grados de dependencia mutua, lo que resulta en interacciones que inciden en el desarrollo de sus respectivos ciclos de vida (Dighton, 2003, 2016; Vega y Blackwell, 2005; Grimaldi y Engel, 2005). Estas asociaciones están representadas por ejemplos en los cuales los distintos componentes bióticos desarrollan microcomunidades con funciones que los conectan entre ellos, de manera más o menos estricta (Johnson y Rasmann, 2015). Un caso común es el rol que cumple la madera como substrato para el crecimiento de hongos, actinobacterias e insectos, en ecosistemas boscosos. Las relaciones que se establecen entre estos organismos pueden clasificarse dentro de un espectro que abarca desde parasitismo a saprotrofismo y aparentes mutualismos (Scott et al., 2008; Hulcr et al., 2011; Rojas-Jimenez y Hernandez, 2015).

Los registros de interacciones bióticas en paleocomunidades proveen información crucial para comprender la estructura trófica y las relaciones entre los distintos grupos de organismos en el pasado (e.g. Brues, 1936; Labandeira, 1998; Kellog y Taylor, 2004; Rößler, 2000; Strullu-Derrien et al., 2012; Slater et al., 2012, 2015; Krings et al., 2016; McLoughlin y Strullu-Derrien, 2016). Sin embargo, la evidencia fósil de interacciones entre diferentes organismos está comparativamente menos representada que aquella sobre individuos aislados. Esto se debe en gran parte al bajo potencial de fosilización de los microorganismos en función de la naturaleza delicada de muchos de sus órganos (e.g. filamentos de hongos y bacterias), la escasez de ambientes sedimentarios propicios para su preservación, y la focalización de las investigaciones paleontológicas en aquellos especímenes mejor preservados. Cabe destacar, que los casos de interacciones múltiples entre microorganismos, artrópodos y plantas, tienen una representación 
particularmente escasa en el registro fósil (e.g. D’Rozario et al., 2011; García Massini et al., 2012b; McLoughlin y Bomfleur, 2016). Sin embargo, en ciertas condiciones (e.g. entrampamiento en ámbar, permineralizaciones), la preservación detallada de estas asociaciones biológicas es posible (e.g. Taylor et al., 2009; Schmidt et al., 2007, 2012; García Massini et al., 2012a, 2016; Harper et al., 2016). Como consecuencia de este sesgo preservacional, se cuenta con escasa información sobre las relaciones entre distintos grupos, lo cual dificulta la comprensión de la evolución de los roles desempeñados en las distintas paleocomunidades.

En este capítulo, se analiza un fragmento de eje leñoso de Agathoxylon sp. colectado en el nivel de areniscas gruesas en la base de la secuencia aflorante en la localidad Laguna Flecha Negra. En él se preservan restos de microorganismos vinculables con hongos y actinobacterias, y evidencias de actividad metabólica de artrópodos xilófagos. Se analizan las afinidades sistemáticas de las estructuras y se postulan hipótesis sobre las funciones e interacciones que habrían relacionado a los componentes bióticos presentes, a partir de la comparación con ejemplos actuales y fósiles.

\section{Resultados}

Madera: se trata de un fragmento de eje de conífera preservado desde el peridermo hasta el xilema secundario (Fig. 8.1.A), cuyas características anatómicas permiten ubicarlo dentro de la familia Araucariaceae. La sección transversal presenta xilema secundario con anillos de crecimiento de tamaño variable, con baja proporción de leño tardío (Fig, 8.1.A). En sección longitudinal tangencial se puede observar radios uniseriados, de 1-12 células de altura (Fig. 8.1.B), éstos pueden estar localmente biseriados de manera esporádica. En sección longitudinal radial se observan paredes radiales de las traqueidas con punteaduras araucarioides (Fig. 8.1.D); campos de cruzamiento pobremente preservados, con dos a cuatro ooporos redondeados con una areola delgada (Fig. 8.1.E). Radios homocelulares, con paredes delgadas, lisas y sin perforar (Fig. 8.1.E). No se reconoce parénquima axial. Estas características permiten 
Ana Julia Sagasti - Estudio paleobotánico, paleoecológico y paleoambiental...

clasificar el leño dentro del taxón fósil Agathoxylon Hartig sensu Philippe y Bamford (2009).

El floema secundario presenta capas tangenciales de células cribosas y parenquimáticas que alternan con capas de tejidos mecánicos (fibras y esclereidas) (Fig. 8.1.A, 8.1.C). Los radios floemáticos son uniseriados (Fig. 8.1.C). Las células cribosas suelen aparecer colapsadas, dando una apariencia sinuosa a los radios (Fig. 8.1.C). En esta zona de la madera, se observan numerosos canales resiníferos traumáticos de margen circular a irregular (230$330 \mu \mathrm{m}$ en sección transversal; Fig. 8.1.C), alongados longitudinalmente (250$1750 \mu \mathrm{m})$ (Fig. 8.2.A). Estos canales se disponen de manera concéntrica, en filas paralelas a irregulares, formando una barrera bastante compacta hacia el exterior (Fig. 8.1.A). Las paredes de los canales traumáticos son multiestratificadas y delimitan una cavidad que suele estar rellena con contenidos opacos de tipo resinoso (Fig. 8.2.A-B). A su vez, es común observar abundantes microorganismos en su interior, incluyendo estructuras relacionables con hongos y actinobacterias (Fig. 8.2.B-C). 

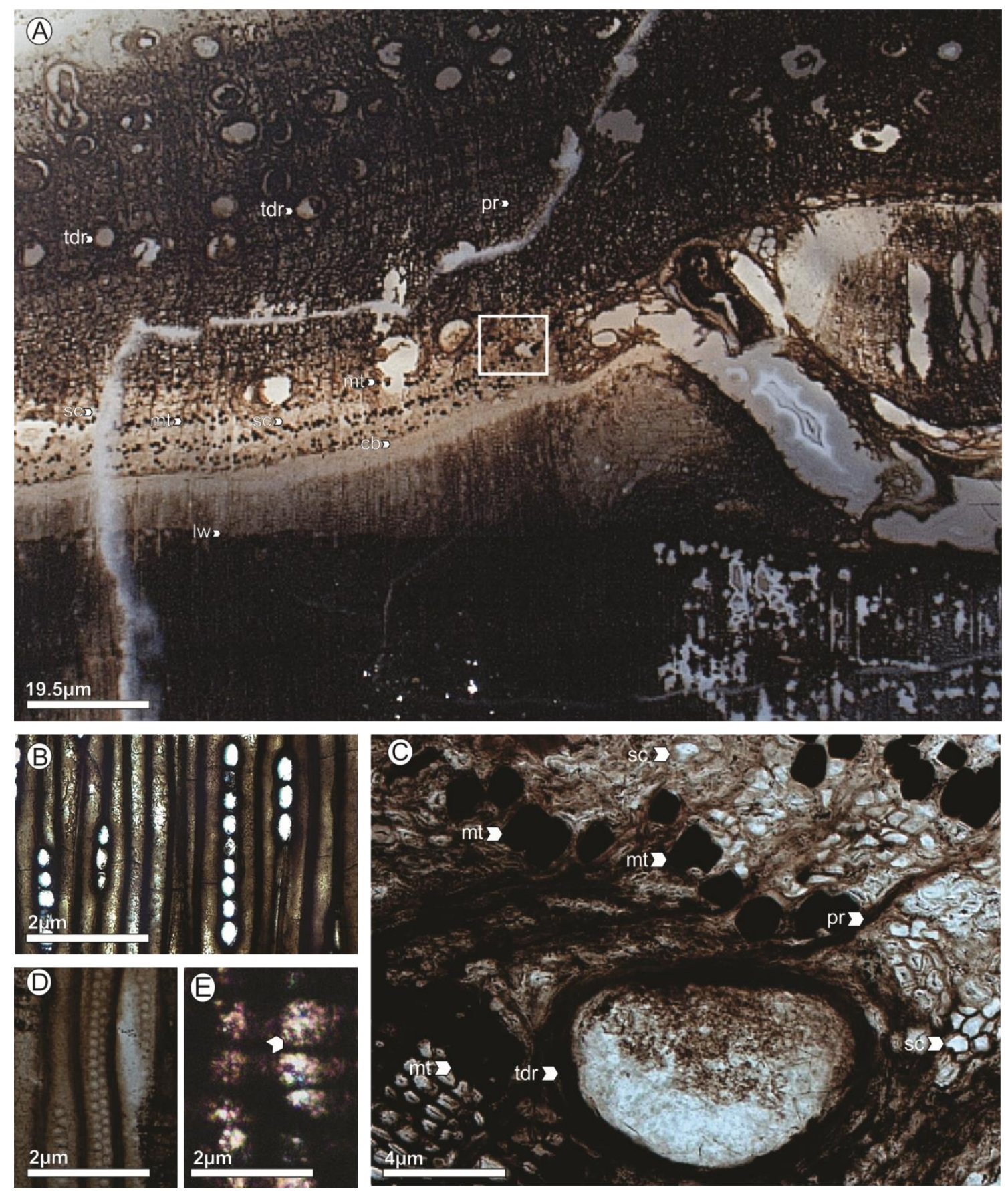

Fig. 8.1. Características anatómicas de un eje de Agathoxylon preservado desde el peridermo hasta el xilema secundario, se observan patrones de degradación por hongos y canales resiníferos traumáticos. A. Vista general de las capas externas mostrando los canales traumáticos en el floema (tdr), radios floemáticos (pr), células cribosas (sc), tejidos mecánicos (mt), leño tardío (Iw) y el patrón de degradación por hongos. B. Radios parenquimáticos uniseriados. C. Detalle del floema secundario (cuadrado blanco en 9.1.A), se observan los tejidos mecánicos (mt), radios floemáticos ( $\mathrm{pr}$ ), células cribosas colapsadas (sc), canal resinífero traumático (tdr). D. Corte longitudinal tangencial mostrando las punteaduras araucarioides en las paredes tangenciales de las traqueidas. E. Campos de cruzamiento con dos a cuatro ooporos redondos, con areola delgada; células radiales lisas y no perforadas. 
En la sección longitudinal tangencial del xilema secundario se observan zonas altamente deformadas, con un tejido amarronado en el que las células individuales no pueden ser reconocidas (Fig. 8.2.D). Algunas traqueidas muestran placas de resina, en zonas que limitan con traqueidas degradadas que presentan microorganismos creciendo en su interior (Fig. 8.2.E).
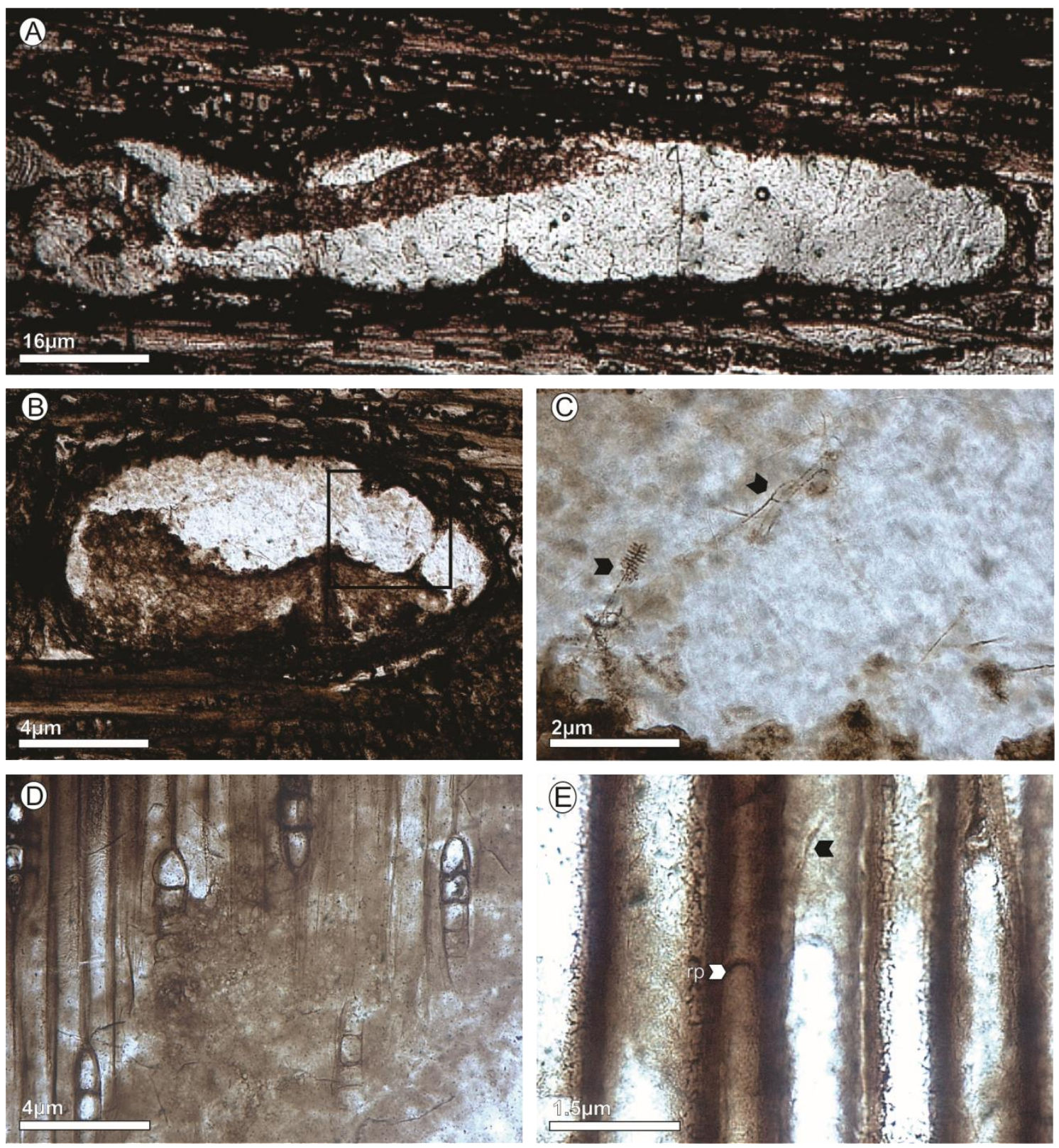

Fig. 8.2. Características anatómicas y patrones de degradación en leños de Agathoxylon sp. A. Canal resinífero traumático en sección longitudinal. B. Detalle del canal resinífero mostrando las múltiples capas de epitelio de la pared y los microorganismos creciendo en el lumen del canal (cuadrado negro). C. Detalle del lumen del canal resinífero mostrando los microorganismos que crecen en su interior (flechas negras) D. Sección longitudinal tangencial mostrando traqueidas y parénquima altamente degradados, formando una masa marrón claro. E. Detalle de traqueida con placas de resina ( $r p$ ) en sección longitudinal. La flecha negra indica la presencia de filamentos de microorganismos. 
El xilema secundario de la madera muestra un patrón de degradación macroscópico con zonas completamente degradadas que dejan espacios libres de células entre el tejido menos alterado estructuralmente (Fig. 8.3.A). La degradación se observa como áreas con células decoloradas, con cierto grado de deformación, y áreas con grupos de células preservadas estructuralmente, que suelen presentar contenidos opacos, de tipo resinoso, en sus lúmenes (Fig. 8.3.B.). A mayor magnificación, se evidencia que los componentes celulósicos de la pared celular (i.e. laminilla media, pared primaria) en las zonas decoloradas del xilema secundario, presentan un deterioro diferencial (Fig. 8.3.C). Otras células presentan todas sus paredes sincrónicamente degradadas (Fig. 8.3.D). En el mismo plano, algunas células presentan los bordes de las capas de la pared alteradas: aserrados o con dentículos que apuntan hacia el lumen celular (Fig. 8.3.E).

El xilema secundario suele presentar células con engrosamientos en las diferentes capas de la pared secundaria (S2 y S3) que pueden distinguirse claramente en sección transversal (Fig. 8.3.F). En algunas traqueidas se observa la capa S2 desprendida de la S3 y esta última plegada hacia el interior del lumen. Esto ocurre en células adyacentes a zonas con elementos axiales parcialmente desintegrados (Fig. 8.3.G). En sección longitudinal, se pueden ver traqueidas con cuñas erosivas elongadas (Fig. 8.3.H). En este mismo corte aparecen radios parenquimáticos completamente degradados, con hifas creciendo en su interior (Fig. 8.3.H). Las células degradadas suelen presentar filamentos (Fig. 8.3.C, G, H) y propágulos esféricos de microorganismos invasores (Fig. 8.4.A). 

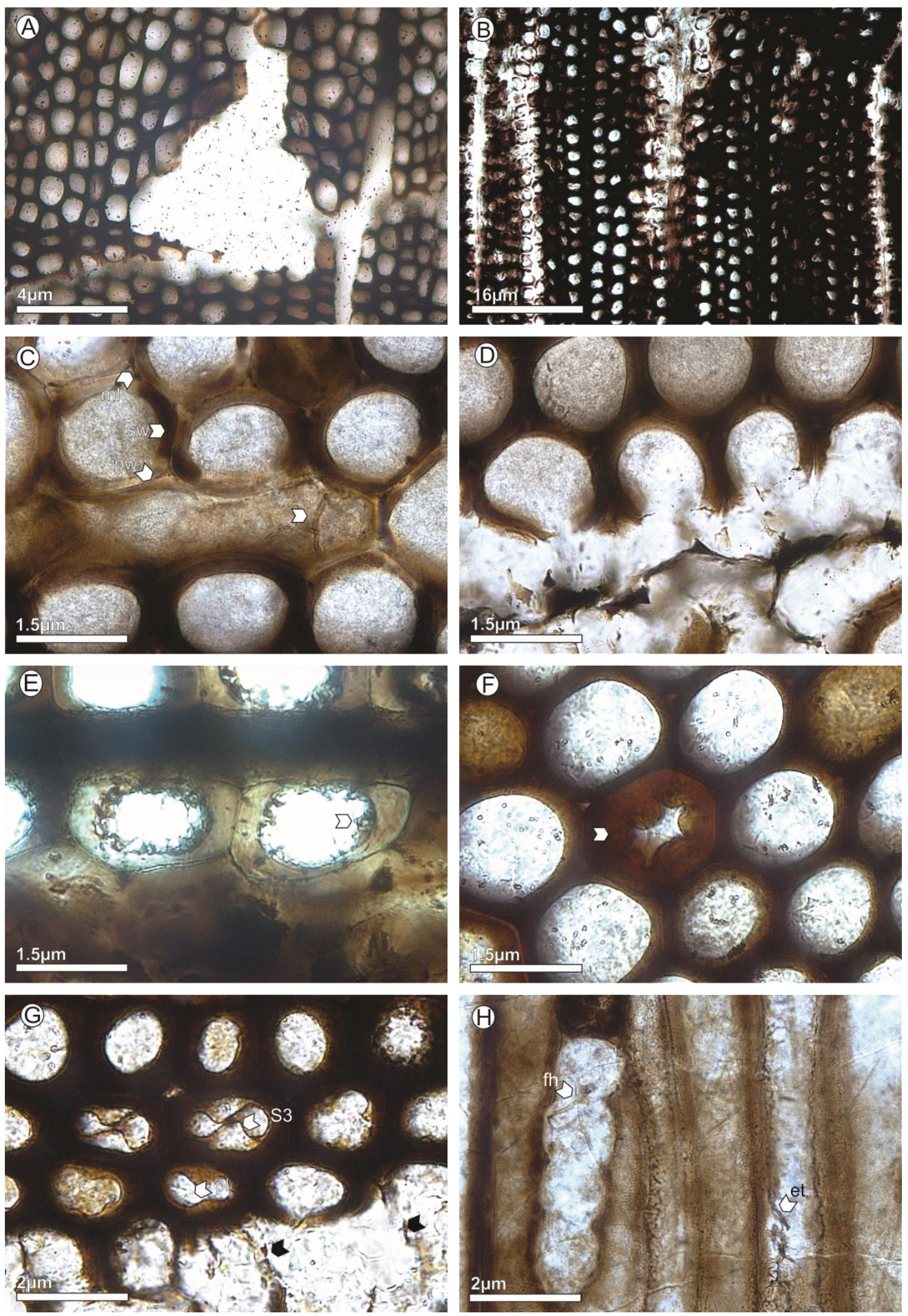

Figura 8.3. Patrones de degradación por microorganismos en restos de Agathoxylon sp. A. Patrón de degradación en el xilema secundario, mostrando espacios libres de células. B. Patrón de compartimentalización evidenciado por la localización de filas de células deslignificadas alternando con filas de células con buen estado de preservación y otras con contenidos resinosos. C. Detalle del xilema secundario mostrando diferencias en la descomposición de las capas de la pared celular; microorganismos dentro de células parenquimáticas (flecha). D. Detalle de las traqueidas con todas las capas celulares decaídas. E. Traqueidas con dentículos en la pared secundaria. F. Traqueidas con 
Ana Julia Sagasti - Estudio paleobotánico, paleoecológico y paleoambiental...

paredes engrosadas (flecha). G. Traqueidas con desprendimiento de la capa S3 y lúmenes perforados. Las flechas negras indican células con todas las capas degradadas sincrónicamente. H. Sección longitudinal mostrando traqueidas con cuñas erosivas (et) y radios parenquimáticos degradados, con hifas fúngicas (fh).

\section{Microorganismos}

Estructuras esféricas. En el interior de los canales resiníferos traumáticos (Fig. 8.2.B), se observan numerosas estructuras aproximádamente esféricas, de tamaño uniforme (15-18 $\mu \mathrm{m}$ de diámetro) (Fig. 8.4.A-B), con una pared interna lisa y una externa ornamentada con verrugas cortas (Fig. 8.4.C). Estas estructuras esféricas presentan un poro recubierto por restos de tejido en forma de tapón, que en algunos individuos aparece desprendido (Fig. 8.4.E-F). En otros casos, presentan una especie de apófisis piramidal con la que se conectan al tejido vegetal (Fig. 8.4.D).

Micelio formado por hifas septadas. Filamentos septados de 2,5-3,5 $\mu \mathrm{m}$ ancho y hasta $100 \mu \mathrm{m}$ de largo, de aspecto espiralado (Fig. 8.4.G). Estas hifas son más comunes en traqueidas altamente degradadas entre la corteza externa y el xilema secundario (Fig. 8.4.H). Los filamentos se ramifican con ángulos variables (Fig. 8.5.A). En los extremos pueden diferenciarse apresorios terminales en forma de dedal (Fig. 8.5.B), o hifas ramificadas, cortas, con septos regulares, que parecen artrosporas (Fig. 8.4.B). También pueden observarse medallones o protuberancias con forma de fíbulas (Fig. 8.5.D flecha). Algunos filamentos aparecen junto a pequeñas esporas dispersas (Fig. 8.5.C). 

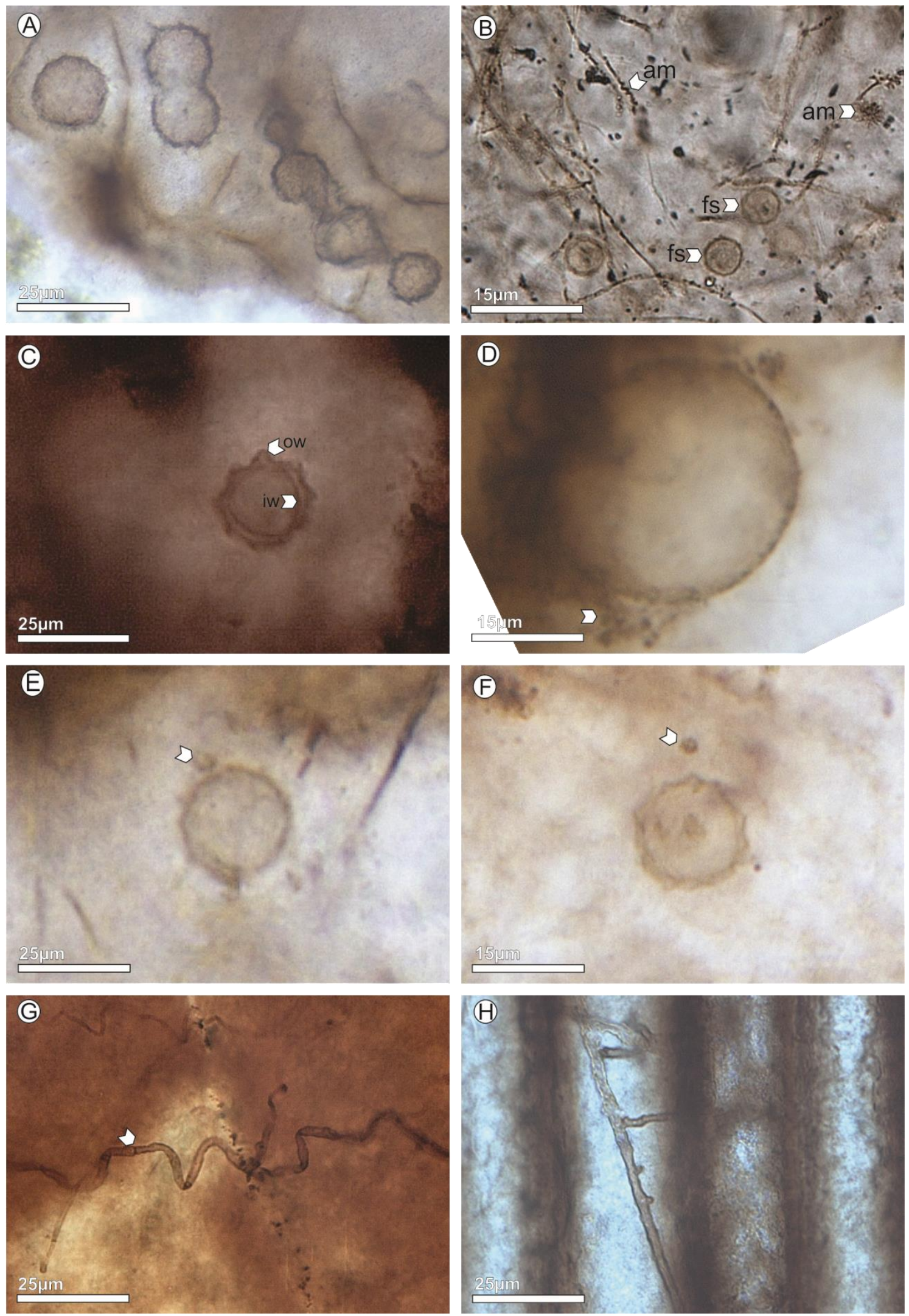

Figura 8.4. Microorganismos en tejidos degradados de Agathoxylon sp. A. Propágulos esféricos en el interior de células degradadas. B. Propágulos esféricos de posibles hongos (fs) y estructuras de posibles actinomicetes $(\mathrm{am})$ en el interior de los canales resiníferos traumáticos. C. Detalle de los propágulos esféricos con una pared interna lisa (iw) y una pared externa ornamentada (ow). D. Detalle de los propágulos esféricos con una secreción externa y posible apófisis piramidal (flecha). E. y F. Detalle de propágulos esféricos con tapón progresivamente desprendido. G. Filamentos fúngicos con septos transversales a oblicuos (flechas). F. Filamentos fúngicos en el interior de traqueidas degradadas. 
Hifas diferenciadas en estructuras reproductivas. Hifas y estructuras reproductivas erectas se distribuyen de manera profusa en los canales resiníferos traumáticos, asociadas con sus bordes, y libres en el lumen (Fig. 8.2.C. Flechas negras). Las hifas consisten de filamentos muy angostos, ramificados, septados, de tamaño constante $(1-1,5 \mu \mathrm{m}$ de diámetro por hasta $105 \mu \mathrm{m}$ de largo), que se distribuyen de manera profusa en el interior de los canales resiníferos traumáticos y se diferencian en un micelio postrado y otro aéreo (Fig. 8.2.C y 8.4.B). Los septos son opacos y están, dispuestos a intervalos irregulares, en posición recta a aproximadamente oblicua (Fig. 8.5.E). Algunas hifas se diferencian en sus extremos en una estructura con aspecto de peine, de la que surgen esporas en posición lateral (Fig. 8.5.E). Estas estructuras portadoras de esporas consisten de una serie de ramas cortas laterales ubicadas en ángulo recto a agudo con respecto al eje principal, de las cuales se originan unas pocas esporas (2-3) dispuestas en línea (Fig. 8.5.E). Las esporas son lisas, esféricas a elipsoidales y son difíciles de distinguir debido a su tamaño dimunuto $(\sim 3 \mu \mathrm{m})$ (Fig. 8.5.E). Otras hifas presentan sus extremos diferenciados en estructuras reproductivas "arrosariadas" de pigmentación y grosor variables (Fig. 8.6.A). Algunas hifas presentan ramas laterales cortas, en forma de basto, que portan en su extremo una espora diminuta (Fig. 8.5.F). Esporas similares pueden encontrarse como unidades dispersas dentro de los canales resiníferos traumáticos (Fig. 8.4.B, 8.5.C). Estas hifas delgadas diminutas pueden encontrarse también en otras zonas de la madera degradada, incluyendo traqueidas del xilema secundario. 

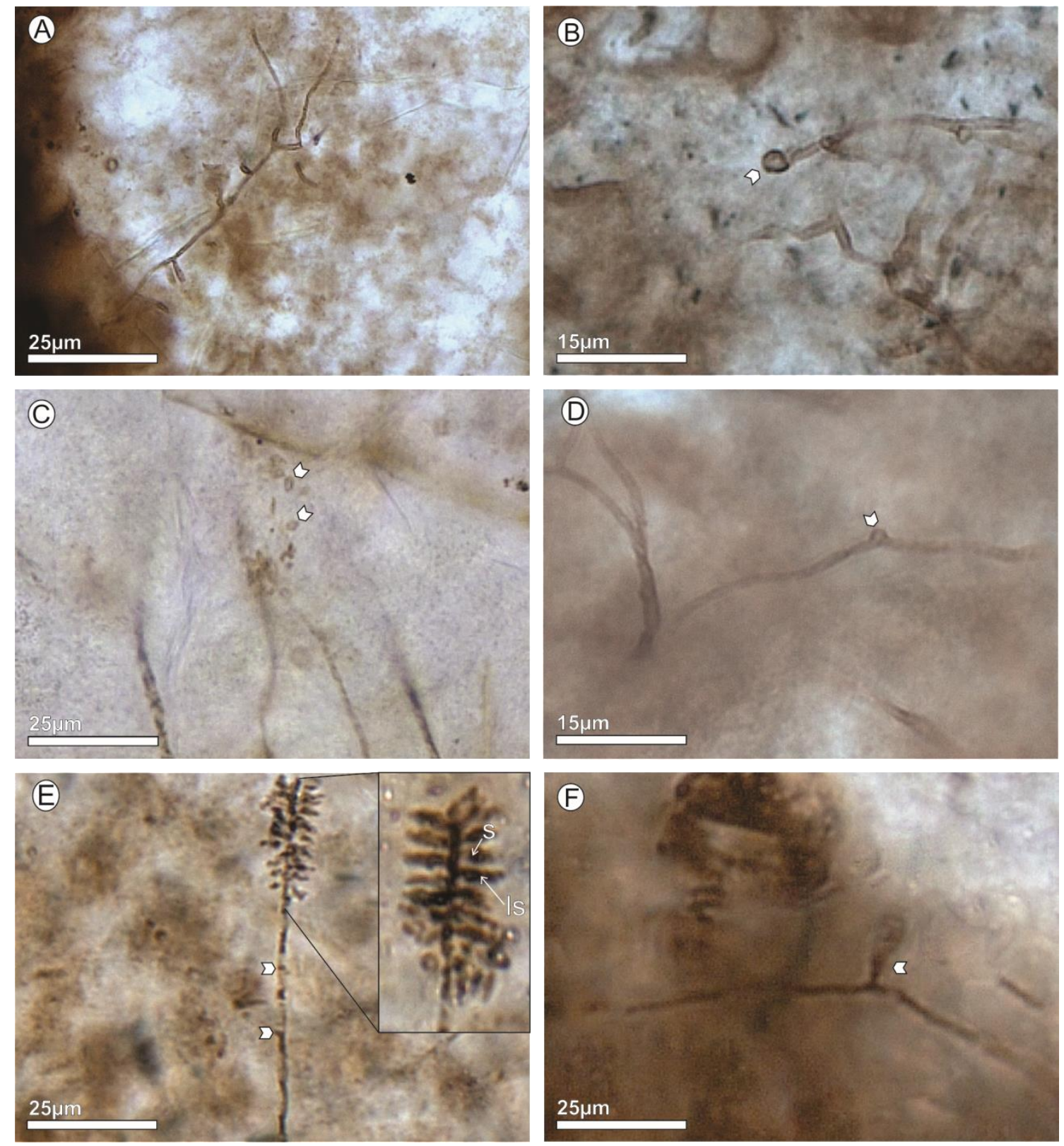

Figura 8.5. Estructuras de microorganismos encontradas en los tejidos degradados de Agathoxylon sp. A. Filamentos de posibles hongos, que ramifican con ángulos variables. B. Apresorio en forma de dedal, en el extremo de filamentos fúngicos (flecha). C. Filamentos asociados a esporas diminutas dispersas. D. Detalle de los filamentos fúngicos con conexiones en fíbula (flecha). E. Filamentos de posibles actinomicetes donde se observan septos pigmentados (flecha) ubicados a intervalos irregulares. Estructuras portadoras de esporas en el extremo distal. F. Filamentos de posibles actinomicetes con ramificaciones laterales cortas, en forma de basto (flecha). 
Ana Julia Sagasti - Estudio paleobotánico, paleoecológico y paleoambiental...

Galerías. En el xilema secundario, se observan cavidades relativamente rectas, más o menos alargadas (en el plano longitudinal), de sección transversal circular a elíptica ( $\sim 3 \mathrm{~mm}$ de diámetro) que se ubican de manera paralela al eje principal de la madera (Fig. 8.6.B). Algunas de estas galerías se agrandan en sus extremos distales (Fig. 8.6.C). Están directamente excavadas en xilema secundario degradado, y suelen estar rellenas con aserrín compuesto de elementos celulares reconocibles, incluyendo traqueidas y parénquima (Fig. 8.6.C). El contenido de las galerías se encuentra laxamente compactado (Fig. 8.6.C). Los bordes de las galerías son irregulares, oscuros y están formados por traqueidas fragmentadas (Fig. 8.6. B-C). Las células adyacentes a las galerías suelen presentar hifas septadas y esporas dispersas (Fig. 8.6.D)
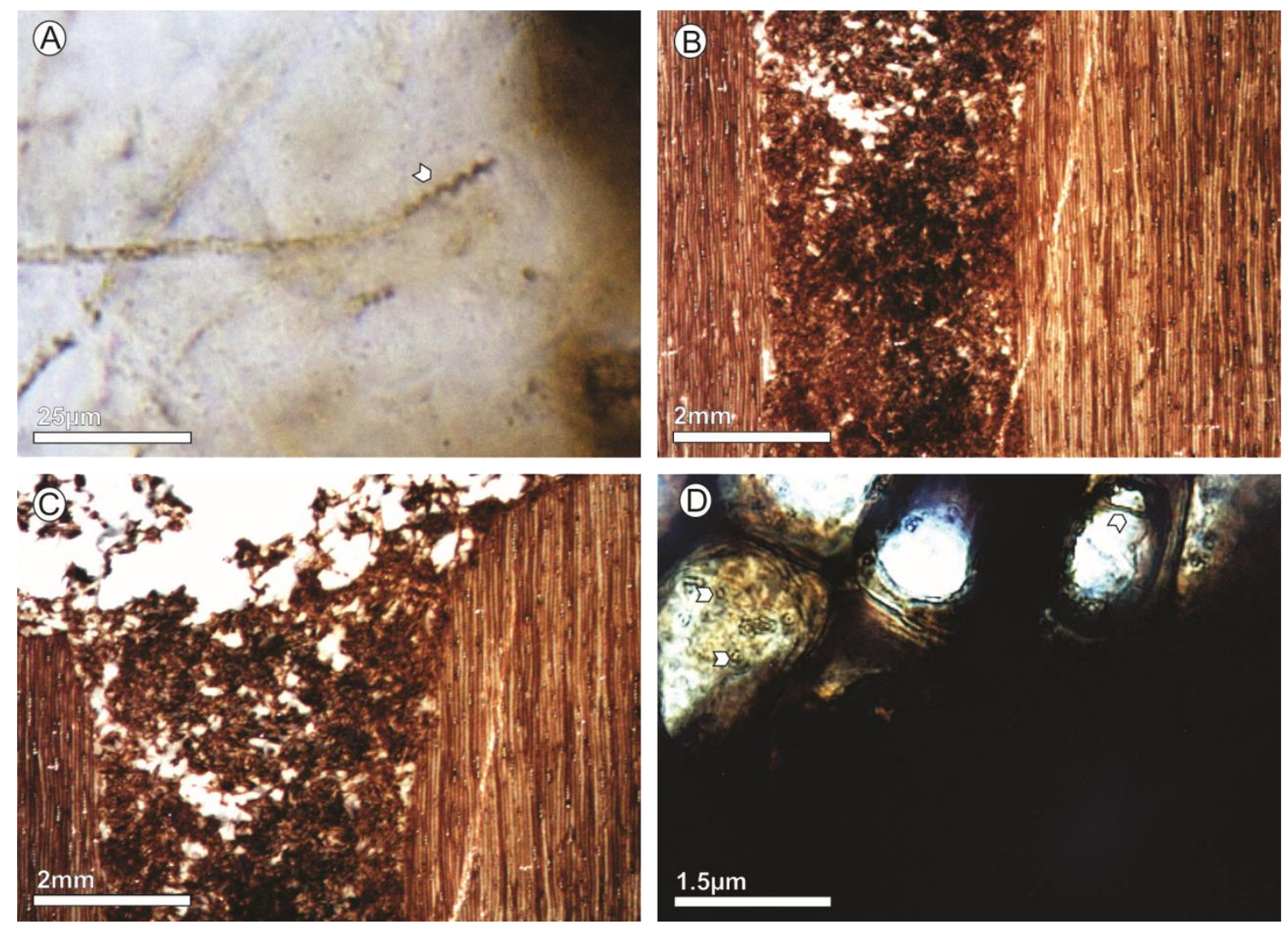

Figura. 8.6. Microorganismos y galerías de artrópodos en madera de Agathoxylon sp. A. Hifas de posibles actinomicetes con sus extremos apicales diferenciados en unidades reproductivas en forma de rosario enroscado, con variable pigmentación. B. Galerías en el xilema secundario, de forma elongada paralela al eje principal del tallo. Aserrín compactado en el lumen de la galería. C. Detalle del extremo distal alargado de la galería, el aserrín se encuentra dispuesto de manera más laxa en esta zona. $\mathbf{F}$. Filamentos fúngicos y esporas en las traqueidas adyacentes a las galerías (flechas). 
Ana Julia Sagasti - Estudio paleobotánico, paleoecológico y paleoambiental...

\section{Discusión}

El estudio de interacciones multitróficas (i.e. donde hay más de dos organismos involucrados) preservadas en el registro geológico es fundamental para comprender la evolución de los organismos y sus relaciones dentro de los ecosistemas terrestres, y cómo ésto ha influenciado el desarrollo de las redes tróficas a través del tiempo (Tscharntke y Hawkins, 2008). Los ejemplos conocidos de fósiles que preservan evidencias de interacciones multitróficas proveen información única sobre el tipo y significado de las relaciones entre distintos grupos de organismos en los paleoecosistemas (Taylor et al., 2015). Los datos aportados por éstos y otros estudios han sido muy útiles como parámetro para interpretar las funciones de los distintos grupos de organismos dentro de los paleoecosistemas y para la reconstrucción de su estructura (Taylor et al., 2009, 2015 y referencias). Los ejemplos conocidos incluyen casos de comensalismo, mutualismo, parasitismo e interacciones saprotróficas entre distintos grupos de artrópodos (ácaros, insectos), hongos (glomeromicetes, ascomicetes, basidiomicetes, quitridiomicetes), plantas (helechos, coníferas, licofitas), protistas (peronosporomicetes) y vertebrados (dinosaurios) (e.g. Müller-Stoll, 1936; Bruer, 1939; Taylor y Taylor, 2000; Taylor y Krings, 2005; Chin, 2007; Krings et al., 2007; Barthel et al., 2010; D'Rozario et al., 2011; Krings et al., 2012; Harper et al., 2012; Slater et al., 2012; StrulluDerrien et al., 2012; Wan et al., 2016; McLoughlin y Bomfleur, 2016; Krings et al., 2016). En particular, las interacciones en maderas fósiles de coníferas conocidas incluyen aquellas con hongos, insectos y ácaros de manera individual o combinada en un mismo hospedador (e.g. Müller-Stoll, 1936; Creber y Ash, 1990; Ibáñez y Zamuner, 1996; Pujana et al., 2009; Harper et al., 2012; García Massini et al., 2012b; Klymiuk et al., 2015). Hasta donde pudo revisarse, no se han registrado casos de interacciones multitróficas que incluyan coníferas, artrópodos xilófagos horadadores de madera y tan diversos microorganismos (Taylor et al., 2015). El caso estudiado en restos del yacimiento Laguna Flecha Negra representa un registro sin precedentes, ya que se observa una micro-comunidad que incluye: un leño de Araucariaceae, evidencias de la actividad de artrópodos xilófagos, y distintos tipos de 
Ana Julia Sagasti - Estudio paleobotánico, paleoecológico y paleoambiental...

microorganismos que se vinculan a través de relaciones de parasitismo, saprotrofismo y potencialmente mutualistas, que se discutirán a continuación.

Las relaciones parasíticas pueden deducirse a partir de ciertas características del leño degradado. Una de ellas, es la evidencia de división celular activa que resulta en cambios anatómicos en distintas capas de la madera (e.g. desarrollo de canales resiníferos traumáticos en la región cortical), los cuales representan un tipo común de respuesta constitutiva de la planta hospedadora ante estreses bióticos o abióticos (Hudgins et al., 2004; Stoffel, 2008). Por otro lado, las capas de xilema y floema muestran otras reacciones de respuesta caracterizadas por cambios químicos (e.g. depositación de compuestos resinosos en el lumen celular) y anatómicos (e.g. proliferación de células esclerenquimáticas, agrandamiento de las paredes primaria y secundaria de las traqueidas) en sus células. Estos cambios estructurales representan barreras defensivas inducibles (Salle et al., 2005). Estas características son respuestas comúnes y bien representadas en plantas frente a la invasión de insectos, hongos y actinomicetes parásitos (Loria et al., 2003, 2006; Schwarze et al., 2004; Bonello et al., 2006; Joshi et al., 2007).

Una característica a destacar es el agrupamiento de células de reacción en la madera en descomposición, esto es comparable a la compartimentalización que se produce en plantas cuando se enfrentan a infecciones fúngicas (Shortle y Cowling, 1978; Shortle, 1979). El desarrollo de tales barreras de defensa es común en coníferas, y actúa como un mecanismo que previene la dispersión del ataque patogénico (Franceschi et al., 2005). De manera similar, la abundancia de canales resiníferos traumáticos en filas irregulares a tangenciales a lo largo de la corteza externa de la madera, es un mecanismo de defensa bastante común en coníferas actuales ante ataques de insectos e incluso frente a estreses abióticos (Nagy et al., 2000; Martin et al., 2002; Hudgins et al., 2004; Bolschweiler et al., 2008). La expresión de barreras constitutivas necesita mucho más tiempo que las barreras inducibles para desarrollarse, estas últimas se despliegan rápidamente cuando el agente de infección ha penetrado en tejidos más internos (Bonello et al., 2006). Sin embargo, estos dos tipos de respuestas suelen retroalimentarse. Esto puede verse por ejemplo, en fibras juveniles que rápidamente depositan capas gruesas de lignina en sus paredes celulares, y proliferan tangencialmente, 
Ana Julia Sagasti - Estudio paleobotánico, paleoecológico y paleoambiental...

formando filas distinguibles que generan una fuerte barrera ante diversos patógenos (Hudgins et al., 2004; Krokene et al., 2008).

La presencia de distintos tipos de estructuras asignables a microorganismos encontradas en el interior de los canales resiníferos traumáticos, permite generar una hipótesis explicativa sobre el desarrollo de éstos. Se observa un micelio profusamente desarrollado con una serie de estructuras reproductivas (e.g. portadoras de esporas). También se encuentran numerosas estructuras de pared gruesa, doble, similares a quistes de resistencia. Estas estructuras pueden compararse con estructuras presentes en hongos y en actinomicetes. El micelio está conformado por hifas de escaso diámetro, delgadas (menos de dos micrones de ancho), ramificadas, y ocasionalmente septadas, que se disponen adheridas a los bordes de los canales resiníferos, proyectándose hacia el interior de la cavidad; las hifas se diferencian en estructuras terminales, erectas, de aspecto pectinado. Dichas estructuras consisten de una serie de ramas laterales, originadas en ángulo recto al eje principal, que portan terminalmente una serie de pocas esporas diminutas, dispuestas linearmente. Esporas esféricas a elipsoidales similares a éstas pueden observarse escindidas de las estructuras portantes, en el interior de los canales resiníferos. A partir de estas características, el micelio y las estructuras portadoras de esporas pueden ser comparadas con aquellas producidas por hongos mitospóricos, tales como Paecilomyces y Radiomyces (e.g. Barnett y Hunter, 1998; Domsch et al., 2007). Si éste fuera el caso, los ápices pectinoides portadores de esporas podrían representar conidióforos erectos con células conidiógenas poliblásticas terminales que portan conidios que se originan de manera simpodial. Otra característica observada, son estructuras que se diferencian en los extremos de hifas erectas y que recuerdan a extremos retorcidos en forma "arrosariada". Estas últimas podrían representar artrosporas terminales en proceso de diferenciación o conidióforos dehiscidos (Webster y Weber, 2007).

Diversos grupos de hongos endófitos se distribuyen en un amplio rango de plantas modernas, y desarrollan distintos roles, incluído el de patógenos que causan efectos negativos, moderados a severos, sobre la salud de sus hospedadores (Carlile et. al., 2001; Sun et al., 2015). Algunos de estos hongos están adaptados para infectar la corteza de las maderas y causar una variedad 
Ana Julia Sagasti - Estudio paleobotánico, paleoecológico y paleoambiental...

de lesiones que resultan en agallas y lesiones ulcerosas, y en el desarrollo de canales resiníferos traumáticos (Christiansen et al., 1999; Franceschi et al., 2005; Sinclair y Lyon, 2005). En particular, algunos ascomicetes y sus estados asexuales (i.e. hongos mitospóricos) que producen úlceras y lesiones similares, pasan al menos parte de su ciclo de vida dentro del área infectada, lo cual genera una extensa área necrotizada en la planta hospedadora (Sinclair y Lyon, 2005). Algunos ascomicetes atacan selectivamente a coníferas, de los cuales Seridium cardinale, Hypoderma podocarpi y Caliciopsis brevipes son de particular importancia, ya que atacan especies que son endémicas de Sudamérica (Butin y Peredo, 1986). Estos hongos producen diversas estructuras vegetativas y reproductivas (e.g. espermogonios, estroma pseudoparenquimático, ascocarpos, etc) dentro de los tejidos de sus hospedadores, que al momento de la maduración penetran a través de la epidermis para esporular (Butin y Peredo, 1986). Además de las reacciones hipertróficas desencadenadas en coníferas debido a la infección fúngica, los hongos patogénicos pueden generar toda una serie de cambios químicos y estructurales de células individuales a partir de su actividad (Schwartze et al., 2004; Bonello et al., 2006). Estos cambios suelen desencadenarse cuando las barreras constitutivas de defensa no han podido detener la infección, lo cual lleva al desarrollo de diversos cambios fisiológicos que afectan células de tejidos más internos (Hammerschmidt et al., 1999). Estos cambios inducibles incluyen la producción de metabolitos secundarios como resina y compuestos fenólicos, que resultan en cambios químicos cuantitativos y/o cualitativos en los tejidos de regiones infectadas (Kleipzig et al., 1995; Raffa y Smalley, 1995; Christiansen et al. 1999).

Alternativamente, estos microorganismos fósiles pueden compararse con algunos actinomicetes, ya que éstos comparten el hábito filamentoso y estructuras productoras de esporas similares con algunos hongos filamentosos, especialmente con los hongos mitospóricos (Domsch et al., 2007; Taylor et al. 2015; Li et al., 2016). Los actinomicetes son bacterias Gram-positivas de amplia distribución en la Tierra, que ocupan el mismo hábito que los hongos y que además, desempeñan roles patogénicos, saprotróficos y mutualistas similares en los ecosistemas terrestres (Gao y Gupta, 2012). Su clasificación se realiza en base a caracteres morfológicos, ultraestructurales, fisiológicos, 
Ana Julia Sagasti - Estudio paleobotánico, paleoecológico y paleoambiental...

ecológicos, moleculares y de cultivo (e.g. Williams, 1970; Hunter-Cevera y Eveleigh, 1990; Zhang et al., 1998; Stackebrandt y Schaumann, 2006; Li et al., 2016). Al igual que con los hongos, esto representa un problema al momento de analizar actinomicetes fósiles, donde sólo pueden evaluarse las características morfológicas, y secundariamente su hábito y hábitat (Taylor et al., 2015). El conflicto se profundiza si tenemos en cuenta que desde su nombre ya se evidencia la similitud con los hongos, tanto en caracteres morfológicos como al hábito y hábitat que ocupan (Taylor et al., 2015; Li et al., 2016). A pesar de ello, se ha logrado identificar fósiles de actinomicetes en sedimentos Fanerozoicos, lo cual nos permite considerar su potencial de preservación como equivalente a aquel de los hongos (e.g. Zalessky, 1915; Waggoner, 1993, 1994; Girard y Adl, 2011). Un criterio considerado útil a la hora de discernir entre fósiles asignables a actinomicetes $u$ hongos, es su tamaño. Los actinomicetes son en general mucho más pequeños y presentan hifas característicamente más delgadas, en el rango de dos o menos micrones de diámetro (e.g. Hunter-Cevera y Eveleigh, 1990; Wilkinson, 2003; Breton, 2010; Taylor et al., 2015; Li et al., 2016). La combinación de caracteres morfológicos (micelio, esporas, esporangios) son también características estables de los actinomicetes (Lechevalier, 1986; Hunter-Cevera y Eveleigh, 1990; Breton, 2010; Li et al., 2016).

Los posibles actinomicetes encontrados en maderas de Laguna Flecha Negra están representados por un tipo dual de micelio (aquel unido a los tejidos de los canales resiníferos traumáticos, que actúan como substrato, y aquel que se proyecta aéreamente hacia el lumen del canal), altamente ramificado, no fragmentado, diferenciado distalmente en estructuras pectinoides con ramas laterales portadoras de un número variable de esporas terminales dispuestas linearmente. Estas estructuras pueden ser interpretadas como esporóforos con ramas laterales cortas, que portan esporas diminutas, en filas cortas, lineares. En el caso de las ramas perpendiculares, en forma de basto, pueden interpretarse como esporangios laterales cortos. En función de estas estructuras, los posibles actinomicetes pueden compararse con distintos miembros de la familia Thermomonosporaceae (e.g. Actinomadura cremea), los cuales producen esporas a partir de esporóforos ramificados o no (McCarthy y Cross, 1984; Kroppensteadtt y Goodfellow, 2006). El esporóforo pectinoide 
Ana Julia Sagasti - Estudio paleobotánico, paleoecológico y paleoambiental...

también puede compararse con estructuras similares presentes en géneros actuales (Dactylosporangium, Microbispora, Planobispora) pertenecientes a otras familias (Streptosporongiaceae, Micromonosporaceae), los cuales forman esporangios lateralmente, que surgen de la hifa principal de manera perpendicular a oblicua, y generan una a múltiples esporas unicelulares en filas cortas (e.g. Williams, 1970; Li et al., 2016). La familia Thermomonosporaceae incluye actinomicetes aeróbicos, quemo-organotróficos que forman un micelio ramificado que actúa como sustrato y porta hifas aéreas que se diferencian en cadenas simples o cortas de artrosporas (Actinomadura, Actinocorallia y Thermomonospora), las cuales son comparables con las hifas terminales en forma de rosario espiralado que se encuentran en el fósil (McCarthy y Cross, 1984; Kroppenstedt y Goodfellow, 2006). La presencia de ramificaciones robustas, en forma de basto, portadoras de esporas es una característica que este material fósil también comparte con Thermomonosporaceae modernos (Shirling y Gottlieb, 1969; Kroppensteadtt y Goodfellow, 2006). La producción de un número variable de esporas a partir de esporóforos y estructuras terminales arrosariadas y enroscadas, también puede compararse con artrosporas (tres a muchas) formadas en espirales cortas de hifas aéreas y con esporóforos umbelados-verticilados presentes en la familia Streptomycetaceae (Shirling y Gottlieb, 1968, 1969; Hunter-Cevera y Eveligh, 1990; Kämpfer, 2006).

El material estudiado en Laguna Flecha Negra es comparable con otros actinomicetes descriptos previamente en depósitos Cretácicos y Cenozoicos, los cuales fueron clasificados dentro del taxón fósil Thermomonosporopsis, el cual se relaciona con la familia actual Thermomonosporaceae (Breton, 2010, 2012; Breton et al., 2013, 2014). Estos restos fueron recuperados en ambar del Mesozoico y Cenozoico, y comparten ciertas características morfológicas tales como la presencia de un micelio dual, ramificado, el desarrollo de estructuras portadoras de esporas, referidas como esporóforos, que forman estructuras hifales terminales complejas y que probablemente habrían producido endosporas (Breton et al., 2013); sin embargo, las posibles endosporas presentes en los fósiles de Laguna Flecha Negra, también asemejan posibles septos. Otras diferencias encontradas incluyen la presencia de esporas unicelulares diminutas terminales, que surgen de manera perpendicular a partir 
Ana Julia Sagasti - Estudio paleobotánico, paleoecológico y paleoambiental...

de un micelio ramificado, portador de esporóforos pectinoides, que se adhiere firmemente al tejido hospedador (micelio de tipo substrato), y otro, no adherido a ningún tejido, presente de manera libre en el lumen de los canales resiníferos traumáticos del hospedador (micelio de tipo aéreo), con extremos de las hifas modificadas en estructuras espiraladas, que podrían representar otro tipo de propágulos de dispersión.

Los actinomicetes cumplen roles simbióticos con plantas, tanto como patógenos como mutualistas (Locci, 1994), mientras que otros (e.g. Streptomyces, Microbispora, Actinoplanes) tienen un rol de endófitos que involuca la capacidad de producir metabolitos bioactivos tales como antibióticos, promotores e inhibidores del crecimiento vegetal y enzimas hidrolíticas que degradan las paredes celulares (e.g. McCarthy y Cross, 1984). En particular, algunos actinomicetes (Streptomyces scabies) crecen inter e intra-celularmente en tejidos vegetales hospedadores y promueven la hipertrofia de los tejidos, incluyendo lesiones necróticas tipo agallas en tubérculos y raíces (Locci, 1994; Loria et al., 2003; Joshi y Loria, 2007; Lerat et al., 2009). Esto sucede en regiones de rápido crecimiento celular, lo cual es consistente con el desarrollo de una efectiva barrera de defensa en las capas más externas de las plantas, tales como los canales traumáticos de las coníferas (Loria et al., 2003; Hudgins et al., 2004). La presencia y el desarrollo de estos posibles actinomicetes en el interior de canales resiníferos traumáticos podría estar indicando un tipo de interacción patogénica. Sin embargo, por lo que pudo estudiarse, no existen ejemplos modernos de actinomicetes que desencadenen el desarrollo de canales traumáticos en coníferas. De manera alternativa, la presencia extendida de posibles actinomicetes en los canales traumáticos en las capas externas del tallo de la madera fósil aquí estudiada podría reflejar dos escenarios adicionales. Estos incluyen la llegada del actinomicete a los canales del hospedador vía un insecto vector, posiblemente un xilófago, o la entrada por un fenómeno de contacto, luego de la muerte o abscisión de la rama que habría caído al substrato, donde estas bacterias son comunes (Goodfellow, 1983). Estas alternativas indicarían un rol saprotrófico para los posibles actinomicetes, contribuyendo al deterioro general del eje. Respecto de esto, algunos actinomicetes tienen un importante rol en la descomposición de tejidos vegetales en la rizósfera y el rizoplano, con actividad 
Ana Julia Sagasti - Estudio paleobotánico, paleoecológico y paleoambiental...

enzimática que promueve la degradación de almidón, pectina, celulosa, hemicelulosa, queratina y lignina (Solans y Vobis, 2003). Algunos miembros de la familia Thermomonosporase son, al igual que muchos otros actinomicetes, saprótrofos terrestres activos, los cuales incluyen un amplio e inespecífico rango de plantas como substrato (Solans y Vobis, 2003).

Por otro lado, se ha asignado un rol de simbiontes mutualistas para algunos actinomicetes que aparecenen asociaciones circunstanciales con artrópodos perforadores de maderas, y que han sido interpretados como productores secundarios de antibióticos contra patógenos presentes en los substratos colonizados por estos insectos (Scott et al., 2008; Hulcr et al., 2011). Un ejemplo de este tipo de asociación mutualista ocurre entre avispas del género Philantus, que hospedan Streptomyces en sus antenas y utilizan los antibióticos secretados por las bacterias para proteger a sus larvas (Kaltenpoth et al., 2004). Las hormigas del tipo Attine, cultivadoras de hongos, mantienen Streptomyces en sus cavidades especiales (i.e. mycangia), quienes producen antibióticos que previenen el crecimiento de hongos indeseados (e.g. Escovopsis) en sus colonias (Currie et al., 1999). El ejemplo más significativo de simbiosis mutualista, es el caso de escarabajos del género Dendroctonus y las actinobacterias del género Streptomyces. Esta asociación se ha registrado tanto en árboles vivos, como en restos de floema muerto, y se ha propuesto que Streptomyces participaría en la degradación de lignocelulosa (Hulcr et al., 2011). Las especies del género Dendroctonus explotan los tejidos subcorticales de especies leñosas (West et al., 2016) y, aunque no penetran profundamente en el xilema secundario, la asociación de Dendroctonus y Streptomyces en la degradación del floema de coníferas modernas podría servir como un análogo del par de simbiontes que infectaron y atacaron estos restos de Araucariaceae en el Jurásico. Éste podría haber sido el mecanismo por el cual ocurrió la colonización inicial del árbol mientras vivía, el desencadenante de la posterior formación de canales resiníferos traumáticos, y el resultado del ingreso de estos microorganismos (Hudgins et al., 2004; Bonello et al., 2006).

Otros microorganismos hallados en el interior de canales resiníferos traumáticos están representados por cuerpos globosos, de pared doble, con una capa externa espinosa a verrucosa y con un poro más o menos circular, que aparecen comúnmente cubiertos por una secreción amorfa. Éstos se 
Ana Julia Sagasti - Estudio paleobotánico, paleoecológico y paleoambiental...

distribuyen de manera libre en el lumen o conectados a los tejidos degradados de los canales traumáticos resiníferos. Teniendo en cuenta su pared gruesa de dos capas, estas estructuras podrían interpretarse como clamidosporas (esporas de resistencia comunes en hongos); sin embargo, aunque las clamidosporas son estructuras morfológicamente simples e incluyen ejemplos actuales comparables con los fósiles aquí descriptos, no suelen desarrollar paredes externas ornamentadas o poros como los que se observan en este material. Ninguna de estas estructuras ha sido hallada en conexión orgánica con hifas parentales y por lo tanto, tampoco puede afirmarse si el poro representa una cicatriz de germinación, como podría observarse en clamidosporas (Riggs y Mims, 2000; Carlile et al., 2001; Kirk et al., 2008). Alternativamente, estos cuerpos globosos pueden compararse con zoosporangios ornamentados de quitridiomicetes actuales (Sparrow, 1960; Karling, 1977). Algunos quitridiomicetes inoperculados forman un número variable de papilas de descarga en su superficie (e.g. Rhizophydium sphaerotheca, Rhizopidium macroporosum; Zopf, 1887; Pires-Zottarelli y Lenk Gomes, 2007), las cuales se asemejan a lo observado en los fósiles de Laguna Flecha Negra. En otros géneros de quitridiomicetes (tanto inoperculados como operculados) que se vuelven quiescentes en determinados períodos, se desarrolla una capa secundaria que protege los contenidos internos y desarrolla gradualmente engrosamientos en forma de papila que llegan a transformarse en poros germinativos (Couch, 1932; Johanson, 1944). Estas estructuras actúan como zoosporangios de resistencia, así la similitud de los fósiles con estas sugiere un rol análogo. Los fósiles comparten con los zoosporangios de resistencia de quitridiomicetes actuales (e.g. Karlingiomyces asterocystis, Diplophyctis asteroidea) tamaño, forma (subesférica), hábito (saprotrófico) y una pared gruesa, opaca y ornamentada (con elementos papilares y clavijas puntiagudas) (Karling, 1949; Jeronimo et al., 2015). Lo que no puede observarse de manera clara en los fósiles, es un sistema rizoidal, a través del cual los zoosporangios de resistencia normalmente se adhieren al substrato. Sin embargo, en algunos de los aparentes zoosporangios fósiles, se observan restos de una estructura piramidal o triangular en la base, comparable con una apófisis que cumple una función de anclaje comparable a la de los sistemas rizoidales (Sparrow, 1960). En los ejemplares que muestran 
Ana Julia Sagasti - Estudio paleobotánico, paleoecológico y paleoambiental...

esta estructura, la pared aparece lisa, lo que lleva a pensar que podrían tratarse de zoosporangios de resistencia inmaduros en un estadio de desarrollo previo al engrosamiento de la pared, absorción de la apófisis y acumulación de reservas (Sparrow, 1960).

Es bien conocido el rol parasítico que cumplen algunos quitridiomicetes actuales, incluyendo como hospedador una amplia variedad de algas y algunas plantas vasculares (Karling, 1954, 1964, 1977; Sparrow, 1960; Barr, 2001). Además de ser parásitos, algunos quitridiomicetes son saprótrofos, adhiriéndose a substratos orgánicos, especialmente órganos en proceso de degradación, indistintamente de su origen filogenético (Gleason et al., 2008, 2010 y sus referencias). La aparición de quitridiomicetes fósiles como endosimbiontes en los canales traumáticos de coníferas podría indicar un rol relacionado con el desarrollo de estas estructuras de reacción. Sin embargo, y aunque numerosos quitridiomicetes se conocen como saprótrofos de tejidos leñosos de coníferas (Sparrow, 1960), no se han encontrado referencias que los señalen como promotores del desarrollo de canales resiníferos traumáticos. De hecho, múltiples aspectos sobre las interacciones planta-quitridiomicetes, tales como las reacciones del hospedador y el substrato de preferencia del saprótrofo, así como su especificidad, son muy poco conocidos (Gleason et al., 2008). Es más probable pensar que estos posibles quitridiomicetes habrían arrivado a las zonas de reacción como consecuencia de lo que puede denominarse intersección de nicho (Gleason et al., 2008). Esto es, los quitridiomicetes habrían sido habitantes comunes de los suelos inundados que se desarrollaron en los alrededores del sistema geotérmico, el contacto con su hospedador se habría producido una vez que éste entró en contacto con el terreno inundado. La presencia de quitridiomicetes podría haber promovido la edibilidad del sustrato leñoso, generando de manera indirecta, condiciones más favorables para el consumo por parte de animales (e.g. atrópodos xilófagos) (ver Kagami et al., 2007). Este rol para los quítridos se sostiene en su capacidad como degradadores de celulosa, presente en especies saprotróficas que habitan en humedales (Haskins, 1939; Whiffen, 1941). La abundancia de estructuras de resistencia, en vez de zoosporangios normales, podría indicar un deterioro de las condiciones microambientales, lo cual es esperable en un ambiente geotérmico donde hay una rápida variación lateral de las condiciones 
Ana Julia Sagasti - Estudio paleobotánico, paleoecológico y paleoambiental...

ambientales, que habrían generado una gradual desaparición de las condiciones óptimas para la multiplicación de los microorganismos (Sparrow, 1960; Gleason et al., 2010; Guido et al., 2010).

Las características macro y microscópicas de degradación de la madera y sus células, coincide con las generadas por hongos degradadores de madera actuales (Schmidt, 2006). La presencia de células xilemáticas parcial a totalmente deslignificadas, y células con todos sus componentes de la pared (celulosa y lignina) degradados sincrónicamente, es consistente con el patrón de pudrición blanca (Schwarze, 2007). El eje de conífera presenta xilema secundario con dos tipos de deterioro caracterizados por la descomposición preferencial de la celulosa y lignina. Se observan células que muestran la lamela media y la pared primaria con una coloración blanquecina y diferencialmente decaída y la separación de la pared como resultado de la pérdida de estructura celular. Otras células presentan sólo partes de sus paredes preservadas, sin ninguna capa degradada de manera específica. Éstas pueden presentar muescas radiales dirigidas desde el lumen hacia afuera y canales erosivos en sección longitudinal, lo cual es consistente con la degradación sincrónica de todos los componentes de la pared. Estos patrones se conocen en maderas modernas como patrones de pudrición blanca selectivo y simultáneo (Schmidt, 2006). Las áreas de la madera con una degradación más intensa muestran zonas completamente libres de células o células rotas, decoloradas y degradadas, lo cual también indica una degradación simultánea de la celulosa y la lignina, y una deslignificación selectiva consistente con el patrón de degradación de "podredumbre blanca moteada" (Blanchette et al., 1985; Blanchette, 1991). Estos patrones de degradación pueden observarse en secciones de la madera donde también aparecen hifas, y en secciones que alternan con células que evidencian reacción del hospedador, tales como engrosamiento de las paredes y depósitos de resina en sus lúmenes. Este patrón puede compararse con el resultado de la compartimentalización producida por coníferas hospedadoras enfrentadas a infecciones de hongos patógenos (Shortle, 1979; Shortle y Cowling, 1978). La estrategia de codegradación de la lignina diferencialmente y de ésta y los componentes de la pared ricos en celulosa por el mismo hongo, al mismo tiempo y en la misma pieza de madera es característica del proceso de degradación que generan 
Ana Julia Sagasti - Estudio paleobotánico, paleoecológico y paleoambiental...

algunos basidiomicetes en ecosistemas modernos (Blanchette et al., 1985). La afinidad con hongos basidiomicetes del agente causante de este patrón de degradación puede inferirse a su vez, en base a la asociación directa de las áreas del xilema secundario degradadas, con hifas septadas con engrosamientos tipo fíbulas (Oberwinkler, 1978; Schwarze, 2007).

En ecosistemas modernos, la descomposición de maderas es llevada adelante por una serie de basidiomicetes y ascomicetes, los cuales han desarrollado un set más o menos específico de enzimas adaptadas a degradar los diferentes componentes de la pared celular (Schmidt, 2006). La capacidad de remover lignina de materiales vegetales se encuentra principalmente en Basidiomycota (Peláez et al., 1995; Schwarze et al., 2004). Se conocen varios ejemplos de maderas degradadas en el registro fósil, las cuales evidencian la importancia de los hongos en el mantenimiento del equilibrio ecológico por medio del reciclado de materiales orgánicos en ecosistemas terrestres a través del tiempo (e.g. Pujana et al., 2009; Harper et al., 2017). Además de su participación en el ciclo del carbono, los hongos cumplen un rol igualmente importante en el mantenimiento de las estructuras tróficas y sus dinámicas en los ecosistemas modernos. Los hongos que habitan substratos leñosos se han especializado en el consumo de componentes recalcitrantes e indigeribles para otros organismos, tales como los insectos xilófagos (Grimaldi y Engel, 2005), Al hacer esto, no sólo detoxifican el substrato preferido por insectos, sino que lo hacen más atractivo al liberar los componentes de manera más masticable y digerible (Martin, 1979; Kukor y Martin, 1986).

Los hongos que se encuentran en áreas altamente degradadas, de coloración amarronada, donde se observan traqueidas y parénquima axial altamente deteriorado, se caracterizan por la producción de un extenso micelio que consiste de hifas septadas y ramificadas que presentan artrosporas, apresorios y conexiones en fíbula, estructuras que son producidas por basidiomicetes (Oberwinkler, 1979; Webster y Weber, 2007). Dentro de este orden, la familia Polyporaceae está integrada por hongos saprótrofos, comunes en ramas o troncos caídos, así como algunos parásitos y productores de enfermedades moderadas a severas en coníferas y angiospermas, muchos de ellos productores de podredumbre blanca en bosques (Stalpers, 1984; Wright, 1970). Los basidiomicetes hallados en Laguna Flecha Negra probablemente 
Ana Julia Sagasti - Estudio paleobotánico, paleoecológico y paleoambiental...

desarrollaron un habito saprotrófico, ya que son más abundantes en traqueidas altamente degradadas ubicadas en las capas más externas del xilema secundario de la madera infectada. También pueden observarse en traqueidas deterioradas en zonas del xilema secundario con evidencias de reacción del hospedador (e.g. células con los lúmenes rellenos por sustancias opacas, zonas de proliferación de esclereidas y células con engrosamiento de sus paredes), lo cual por su parte podría señalarlos como potenciales parásitos. El deterioro de las maderas modernas es un proceso continuo que puede ser producido por el mismo o diferentes hongos, que se suceden en el tiempo afectando a la planta hospedadora tanto como parásitos como saprótrofos (Dighton, 2003). Por otro lado, los mecanismos de defensa inducibles suelen ser inespecíficos, pudiendo ser activados por diferentes hongos, causando síntomas similares que afecten subsecuentes hongos colonizantes, indistintamente del momento de arrivo y su localización dentro de la planta hospedadora (Krokene et al., 1999).

Algunas estructuras encontradas en este tallo, incluyendo las galerías perforadas en el xilema secundario, son productos comunes de diferentes artrópodos que habitan y se alimentan de maderas, particularmente insectos (mariposas, avispas, escarabajos y otros) en ecosistemas terrestres (Grimaldi y Engel, 2005). Las galerías encontradas en el xilema secundario presentan una sección transversal circular a algo achatada, tienen bordes irregulares, y están rellenas con aserrín variablemente compactado que incluye restos de tejido entre los que pueden identificarse células vegetales. Corren verticalmente, siguiendo el eje principal de la madera. Son de tamaño relativamente grande y fueron perforados en áreas descompuestas por hongos. Todas estas características los relacionan con el tipo de galerías producidas por distintos escarabajos xilófagos, particularmente perforadores de cabeza redonda o plana (Grimaldi y Engel, 2005). En función de su morfología, pueden compararse con las galerías generadas por larvas de Cerambycidae (excavadores de cabeza redonda), las cuales habitan debajo de la corteza y dentro del leño (Grimaldi y Engel, 2005). Los túneles que producen las larvas de cerambícidos son de sección casi circular, en respuesta a la morfología cilíndrica de las larvas. A medida que excavan, van compactando el aserrín de manera continua dentro del túnel (Buss y Foltz, 2003). Estas galerías fósiles también pueden 
Ana Julia Sagasti - Estudio paleobotánico, paleoecológico y paleoambiental...

compararse con las generadas por larvas de Buprestidae (excavadores de cabeza chata), que habitan por debajo de la corteza o en la albura. Sus galerías son más achatadas en sección transversal. Los adultos generan galerías amplias y sinuosas, con aserrín fuertemente compactado, por debajo de la corteza de los tallos (Furniss y Carolin, 1977). A medida que las larvas mudan hacia estadios de mayor tamaño, suelen perforar más profundamente hacia la albura y el duramen, generando galerías ovoides rellenas con aserrín (Furniss y Carolin, 1977; Sutherland, 2006). Sus galerías suelen ser sinuosas, rellenas de aserrín compactado, y pueden asociarse con árboles estresados, heridos, enfermos o muertos (Buss y Foltz, 2003).

Teniendo en cuenta las características de las galerías encontradas en los materiales de Laguna Flecha Negra, lo más probable es que el insecto perforador se trate de un coleóptero. La rama colectada no preserva evidencia de un agujero de salida, lo cual sería fundamental para realizar una delimitación más precisa. La compactación del aserrín dentro de los túneles es consistente con la actividad de las larvas tanto de Cerambycidae como Buprestidae. No se encontraron cámaras de nidificación, y la compactación del aserrín no muestra meniscos claros, como los que pueden observarse en otros ejemplos del Mesozoico de Patagonia (e.g. Genise, 1995). Genise (1995) describe galerías del icnogénero Xylonichnus en maderas de coníferas del Cretácico de la provincia de Chubut. Éstas difieren de las estudiadas aquí en que están excavadas en madera sin signos de degradación y se componen de una red de túneles interconectados. Este autor asigna las galerías a miembros de la familia Buprestidae, en función de la sección achatada de las galerías. Otras galerías comparables (con aserrín compactado, bordes irregulares y distribución similar) se han encontrado en coníferas del Jurásico y Cretácico de Patagonia, y han sido interpretadas como productos de la excavación de cerambícidos (Genise y Hazeldine, 1995; García Massini et al., 2012b). Por otro lado, los géneros xilófagos de Buprestidae aparecen en el Jurásico medio, pero fueron bastante raros hasta mediados del Cretácico (Alexeev, 1999). Esta evidencia soporta la hipótesis de que los productores de galerías en los materiales de Laguna Flecha Negra tendrían más probablemente una afinidad cercana con escarabajos perforadores de la familia Cerambycidae. En cuanto a las actividades comportamentales que pueden inferirse a partir de las galerías, 
Ana Julia Sagasti - Estudio paleobotánico, paleoecológico y paleoambiental...

estas icnitas presentan evidencia de alimentación por la presencia de aserrín compuesto de traqueidas fragmentadas y bordes irregulares en las paredes de la galería, lo cual permite clasificarlas dentro del grupo etológico fodinichnia (Seilacher, 1953). Otras categorías que permiten acomodar el rango de comportamientos inferibles a partir de los cambios estructurales realizados sobre el substrato afectado por insectos y otros organismos, incluyen alimentación, refugio y reproducción (Scott et al., 1992). No se observan signos de reacción en los bordes de las galerías, pero teniendo en cuenta que éstas han sido excavadas en el xilema secundario, donde la mayoría de las células están muertas, la ausencia de reacción del hospedador no permite realizar una interpretación inequívoca sobre el momento en el cual los artrópodos habrían afectado a la madera.

Los insectos perforadores atacan generalmente árboles que ya se encuentran sufriendo estrés biótico o físico (Bonello et al., 2006). Dependiendo del momento, intensidad, modo y el sitio específico de infección, estos diferentes estreses pueden eventualmente debilitar al hospedador, predisponiendo al árbol a subsecuentes ataques. Un ejemplo de esto se observa en coníferas afectadas por hongos patogénicos, que experimentan un ataque masivo por parte de escarabajos excavadores de corteza (e.g. Dendroctonus) (Owen et al., 2005). Las larvas de Buprestidae y Cerambycidae que excavan galerías en albura y duramen pueden producir daños en órganos leñosos de árboles heridos o recientemente caídos, mientras que los adultos promueven la descomposición general de las maderas al introducir levaduras, bacterias y hongos xilófagos en los tejidos (Furniss y Carolin, 1977; Yee et al., 2005). Por otro lado, algunos artrópodos excavadores se alimentan de hongos que crecen dentro de las galerías o en la zona cambial del hospedador; esto puede verse en la mayoría de los escarabajos xilófagos, y algunos hymenóperos y lepidópteros (Grimaldi y Engel, 2005). Se conocen una serie de ejemplos que sustentan que los artrópodos xilófagos realizan sus actividades de alimentación y nidificación preferencialmente en maderas degradadas por hongos, particularmente los escarabajos (e.g. Furniss y Carolin, 1977; Owen et al., 2005; Yee et al., 2006). La asociación de escarabajos xilófagos con maderas degradadas por hongos ha sido registrada previamente en el Jurásico de Patagonia por García Massini et al. (2012b), quienes argumentan que este 
Ana Julia Sagasti - Estudio paleobotánico, paleoecológico y paleoambiental...

sería un fenómeno mucho más ampliamente desarrollado de lo que el registro fósil muestra hasta el momento. El material estudiado en Laguna Flecha Negra aporta evidencia que sustenta la asociación preferencial de escarabajos xilófagos con maderas degradadas por hongos como una fuente de alimentación en el Mesozoico. Este tipo de asociación habría influenciado en el desarrollo de la cohorte de microorganismos hallados en leños de Laguna Flecha Negra, beneficiado a los escarabajos que encuentran los nutrientes de manera más asimilable, y a los hongos que encuentran en los xilófagos, un medio de dispersión de sus diferentes estructuras.

En resumen, la evidencia de actividad xilófaga encontrada en el leño de Agathoxylon sp. muestra características consistentes con la actividad biótica de larvas de coleópteros de la familia Cerambycidae. Los márgenes de los túneles presentan restos de hongos que podrían haber ingresado con el insecto horadador y habrían actuado como promotores de la degradación de los componentes lignificados de la madera, descomponiendo las paredes celulares a nutrientes más palatables para el insecto. Otros microorganismos, tales como los actinomicetes, podrían haber tenido un rol de simbionte, promoviendo la degradación de la lignocelulosa, y siendo transportados hacia los tejidos leñosos utilizando al insecto como vector. Alternativamente, la aparición de estas estructuras comparables con actinomicetes, en el interior de canales resiníferos traumáticos, podría indicar un rol patogénico para este componente de la asociación. El resto de las estructuras fúngicas parecen haber promovido el deterioro general del leño, produciendo patrones de pudrición blanca y pudrición blanca moteada, contribuyendo al proceso general de descomposición. El conjunto de organismos que componen esta asociación pertenecen a grupos taxonómicos muy diversos, mostrando evidencia de una compleja red de herbívoros y descomponedores de tejidos leñosos, que conformaron una diversa micro-comunidad en el Jurásico de Patagonia. 
Ana Julia Sagasti - Estudio paleobotánico, paleoecológico y paleoambiental...

\section{Conclusiones}

Debido al bajo potencial de preservación de las estructuras delicadas de los microorganismos, la evidencia fósil de interacciones multitróficas está pobremente representada en el registro geológico. En este sentido, los sistemas geotérmicos fosilizados como los que se observan en el Macizo del Deseado, representan una importante fuente de información para el estudio de las interacciones entre plantas y microorganismos en el pasado.

La madera permineralizada hallada en la localidad Laguna Flecha Negra representa el primer ejemplo, hasta el momento, de interacciones multitróficas que incluyen actinomicetes. Además de éstos, se observan estructuras fúngicas, galerías de artrópodos y un diverso set de patrones de degradación consistentes con pudrición fúngica, hospedados en un eje de Araucariaceae.

La presencia de cambios anatómicos, tales como los canales resiníferos traumáticos, la depositación de componentes resinosos en lúmenes celulares, engrosamiento de las paredes de traqueidas y proliferación de esclereidas, representarían respuestas de la planta a los patógenos. Estas barreras de defensa son comunes en coníferas actuales y actúan como mecanismos preventivos para detener posteriores ataques en árboles debilitados. La presencia de estos mecanismos de defensa permite concluír que al menos parte de las interacciones se dieron mientras el hospedador aún vivía.

La descomposición del eje se dio principalmente por la acción de hongos degradadores de maderas, cuya asociación con el eje podría haber sido pasiva o activa vía la dispersión forética de un insecto xilófago, probablemente un escarabajo. La asociación de hifas con conexiones en fíbula, aparentes zoosporangios y posibles actinomicetes con los tejidos degradados, sugiere un rol saprotrófico para los restantes microorganismos fúngicos y no-fúngicos de hábito comparable. Finalmente, la presencia de galerías con trazas de xilema digerido es consistente con la actividad de un artrópodo xilófago que habría sido parte de esta micro-comunidad, actuando como vector para parte de los microorganismos, tal como se ve en ecosistemas boscosos modernos (e.g. Takasuka et al., 2013).

Esta asociación fósil descripta sugiere que al menos desde el Jurásico Medio, algunas coníferas habrían desarrollado mecanismos de defensa 
Ana Julia Sagasti - Estudio paleobotánico, paleoecológico y paleoambiental...

constitutivos e inducibles que sirvieron como barreras de defensa contra diversas pestes y patógenos, contribuyendo a la estabilidad de los ecosistemas forestales dominados por coníferas, a través del tiempo.

Este registro del Jurásico de Patagonia ayuda a completar espacios desconocidos de las interacciones multitróficas en el registro geológico y constituye un punto de referencia para comprender el desarrollo de los mecanismos de procesamiento de biomasa vegetal por medio de distintos grupos de micro organismos, durante el Mesozoico Medio. 


\section{Tafonomía}

\section{Introducción.}

La Tafonomía es la disciplina que se encarga del estudio de los procesos que afectan a los restos de un organismo durante los procesos de fosilización (Brenchley y Harper 1998). El proceso de enterramiento de un resto puede llevar, por un lado, a la pérdida de información (e.g. debido a la preservación selectiva de distintos órganos), pero a su vez se gana otro tipo de información, ya que los distintos tipos de preservación de los fósiles son indicativos de los ambientes depositacionales en los cuales se acumularon estos restos. Tradicionalmente, la tafonomía incluye dos aspectos: la bioestratinomia y la diagénesis de los fósiles. La bioestratinomia incluye la historia sedimentaria de los restos orgánicos potencialmente preservables. Esto incluye abrasión, fragmentación, desarticulación, reorientación y selección, los resultados de estos procesos son fácilmente evidenciables en el registro fósil (Speyer y Brett, 1988). La diagénesis de los fósiles comprende aquellos procesos que comienzan luego de la muerte o absición. Éstos incluyen necrólisis y diagénesis temprana (e.g. reemplazo, recristalización) (Speyer y Brett, 1988). El término tafonomía fue establecido por Efremov (1940) para referirse a la historia de los restos fosilizados, incluyendo la relación en vida con el substrato, condiciones en las que murió, la sedimentología presepultamiento de los restos, enterramiento, necrólisis y cambios químicos tempranos durante el sepultamiento. En este contexto, la historia tafonómica está fuertemente correlacionada con las condiciones ambientales y el ambiente sedimentario y, por lo tanto, se refleja en los distintos atributos tafonómicos (Speyer y Brett, 1988)

Las plantas son organismos modulares compuestos de varias partes (ramas, raíces, hojas, semillas, etc) que tienden a la dispersión selectiva durante la vida (e.g. absición foliar, producción de diásporas) y posmortem (e.g. fragmentación de los órganos por ruptura y/o transporte). La comprensión de los procesos de dispersión que afectan a las distintas partes es fundamental para interpretar las asociaciones paleoflorísticas (Brenchley y Harper 1998). 
Ana Julia Sagasti - Estudio paleobotánico, paleoecológico y paleoambiental...

En general, las plantas fósiles se preservan en cuencas sedimentarias, esto es, zonas donde la acumulación de sedimento supera a la erosión. En la gran mayoría de los casos, la acumulación de restos vegetales se da en ambientes húmedos, donde el agua transporta y deposita el sedimento (Channing y Edwards, 2013). El potencial de preservación de las plantas es afectado negativamente por procesos de oxidación en la superficie y subsuperficie de la zona vadosa, pero aumenta dramáticamente en presencia de cuerpos de agua superficiales, líneas freáticas altas o con el rápido enterramiento por debajo de la zona vadosa (Gastaldo y Demko, 2011). Estos sesgos tafonómicos positivos se encuentran más frecuentemente en ambientes con climas húmedos que en áridos o semiáridos, y en zonas donde las tasas de sedimentación son altas (Channing y Edwards, 2013).

La fosilización instantánea, o $\mathrm{T}^{0}$, es un término utilizado para describir una vegetación fósil que se ha preservado esencialmente con la misma conformación que tenían en vida, y que ha sufrido poco a ningún filtro tafonómico posterior a la muerte de los vegetales (Channing y Edwards, 2013). Para que este tipo de fosilización ocurra, se requiere un evento geológicamente instantáneo de enterramiento. Los principales contextos sedimentarios que favorecen el origen de este tipo de fosilización incluyen la caída de cenizas volcánicas, el inundamiento de planicies costeras por eventos de rápido aumento del nivel relativo del mar, y, en menor escala, la rápida sedimentación asociada a ambientes fluviales tales como barras de canal, lóbulos de explayamiento y lóbulos distributivos (DiMichele y Falcon-Lang, 2011).

Los sistemas geotérmicos han atraído un importante interés desde un punto de vista geológico, ya que pueden indicar la presencia de recursos energéticos en profundidad, tienen una relación espacial cercana con procesos de mineralización epitermal de metales preciosos (oro y plata), y sus manifestaciones en superficie como hot springs sirven como análogos de las condiciones ambientales extremas que habrían originado la vida temprana en la Tierra y posiblemente en otros planetas (e.g. Sillitoe, 1993; Guido y Campbell, 2011). Desde un punto de vista paleontológico, el estudio de sistemas depositacionales geotérmicos es de interés ya que las planicies de inundación (=wetlands) asociadas a estos sistemas presentan condiciones ambientales que promueven la permineralización de asociaciones vegetales en 
Ana Julia Sagasti - Estudio paleobotánico, paleoecológico y paleoambiental...

posición de vida y la preservación de rasgos anatómicos de alto detalle (e.g. Anderson y Trewin, 2003; Channing et al., 2007; Guido et al., 2010; Channing y Edwards, 2013; García Massini et al., 2016; Sagasti et al., 2016).

En este capítulo se discutirán los distintos tipos preservacionales encontrados en el yacimiento Laguna Flecha Negra y su significado paleoambiental en un marco sedimentario volcaniclástico asociado a facies distales de sistemas geotérmicos.

\section{Tipos de fosilización.}

Los tipos de fosilización observados en la localidad Laguna Flecha Negra fueron clasificados siguiendo el criterio de Archangelsky (1970), Willis y McElwain (2002) y Taylor et al. (2009). Se identificaron los siguientes tipos de fosilización:

Impresiones: son copias bidimensionales de un resto vegetal, donde se preserva una huella en la roca, sin preservación de materia orgánica. Puede quedar de una coloración diferente a la roca que la contiene, como consecuencia de la presencia de óxidos. Este tipo de preservación se observó en hojas y estructuras reproductivas en el nivel de areniscas gruesas basales, en las pelitas oscuras, y unos pocos ejemplares asociados al bosque in situ aflorante al tope de las tobas blancas.

Moldes: este tipo de fosilización preserva copias de órganos tridimensionales, como tallos, ramas y estructuras reproductivas, en los que puede apreciarse el volumen del órgano vegetal y a los que no se asocia materia órganica. Cuando el resto cae al substrato, el sedimento que se deposita a su alrededor forma una cavidad a su alrededor, generando un molde negativo tridimensional del órgano o fragmento. Posteriormente, si se produce la completa desintegración de la materia vegetal, esta cavidad puede ser rellenada secundariamente, formando un molde positivo. Se han registrado escasos restos preservados como moldes en Laguna Flecha Negra, pueden verse moldes negativos de ramas de alto órden y un ejemplar de Brachyphyllum lotenaense preservado como un molde positivo con excelente registro de la morfología del ejemplar. 
Ana Julia Sagasti - Estudio paleobotánico, paleoecológico y paleoambiental...

Impresiones-Compresiones: se trata de fragmentos vegetales compactados por la pila sedimentaria, produciendo la eliminación de agua de la materia orgánica, obliterando la estructura interna y preservando una lámina de carbón en el sedimento que se denomina compresión. Estas compresiones suelen acompañar improntas de hojas, por lo que se denominan impresionescompresiones. Se observan fundamentalmente en el nivel de pelitas oscuras. En el registro fósil, las compresiones pueden preservar un importante detalle de las estructuras epidérmicas de los órganos, permitiendo estudiar tricomas, estomas y anatomía interna de las capas superficiales. También es común que se asocien con restos de cúticulas. Estos caracteres no se han observado en los restos colectados en Laguna Flecha Negra, existiendo únicamente una película carbonosa amorfa.

Carbonizaciones: son restos fósiles en los que toda la materia orgánica se ha convertido en carbón. A diferencia de las compresiones, preservan el volumen del resto original, evidenciando un proceso de fosilización que ocurre mucho más rápidamente que en las compresiones, ya que no se llega a producir la compactación del resto. En la secuencia estudiada en Laguna Flecha Negra se observan escasos restos preservados como carbonizaciones, y ellos se encuentran en sedimentitas formadas por lluvias de cenizas que habrían quemado las ramas y generando este tipo de preservación.

Permineralizaciones individuales: en este tipo de fósil se preservan órganos individuales en los que se produce la imbibición de soluciones minerales en los tejidos vegetales a nivel de los espacios intra e intercelulares. Se produce durante la diagénesis temprana, durante el sepultamiento del resto o poco después de ello. Este tipo de fosilización preserva el detalle celular de los tejidos, permitiendo estudiar la anatomía del órgano. Se han colectado restos de raíces, ramas, troncos y tocones preservados como permineralizaciones individuales silíceas en la localidad Laguna Flecha Negra.

Chert: Se trata de una permineralización silícea en masa. En este caso, las soluciones minerales circulan siguiendo la topografía de la región entrampando en su camino restos de detrito vegetal, plantas en posición de vida, microorganismos y artrópodos que habitaban el substrato. En Laguna Flecha 
Ana Julia Sagasti - Estudio paleobotánico, paleoecológico y paleoambiental...

Negra se preservan dos lentes de chert interdigitados con areniscas gruesas, en la zona noroeste de la localidad.

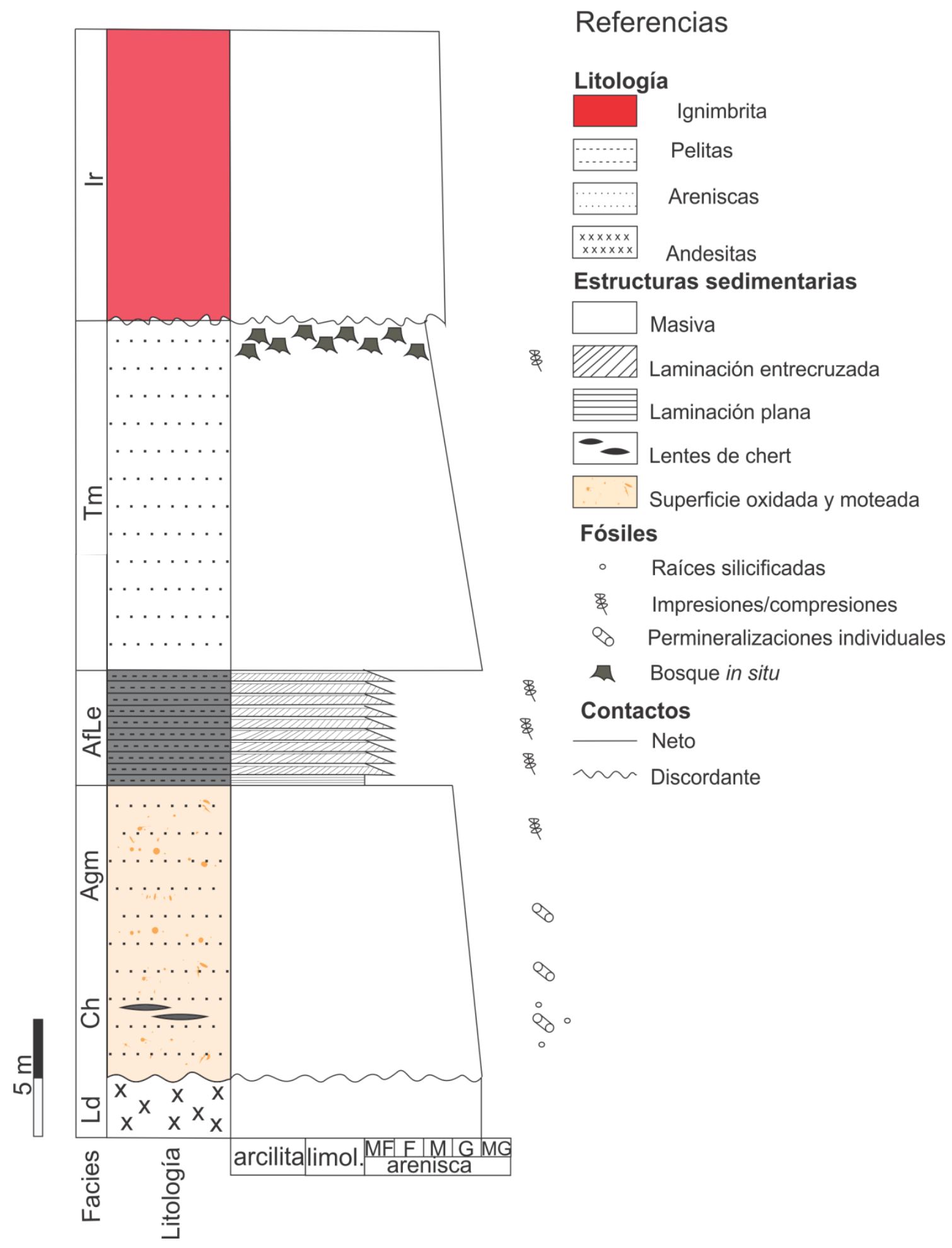

Figura 9.1. Perfil esquemático de la secuencia jurásica aflorante en la localidad Laguna Flecha Negra. 
Ana Julia Sagasti - Estudio paleobotánico, paleoecológico y paleoambiental...

\section{Estilos preservacionales}

En el capítulo VI se describió el perfil de la secuencia aflorante en la localidad Laguna Flecha Negra, definiendo las facies sedimentarias observadas en el campo. En este capítulo se tratarán los estilos preservacionales de fósiles hallados en los distintos niveles portadores.

En las tafofloras contenidas en la secuencia aflorante en la localidad Laguna Flecha Negra, se identificaron 11 estilos preservacionales: (1) Permineralizaciones individuales de raíces, (2) moldes de maderas, (3) impresiones de maderas (4) carbonizaciones de madera, (5) permineralizaciones silíceas en masa, (6) permineralizaciones individuales de tallos, (7) impresiones de hojas, ramas foliosas y estructuras reproductivas, (8) impresiones - compresiones (9) troncos y tocones silicificados verticales, (10) troncos silicificados horizontales y oblicuos y (11) briznas vegetales.

(1). Permineralizaciones individuales de raíces (Fig. 9.2.A). Son restos autóctonos de raíces de tamaño medio, que se encuentran perpendiculares, oblicuas o paralelas al plano de estratificación, sin ramificaciones observables. Su diámetro varía de 0,5 a $10 \mathrm{~cm}$ y la longitud observada alcanza los $60 \mathrm{~cm}$. Se observan en pequeñas concentraciones, distribuidas de manera relativamente agrupada. Están preservadas como permineralizaciones individuales dentro del nivel de areniscas gruesas, a pocos centímetros de la zona de emplazamiento de cherts.

(2). Moldes de tallos (Fig. 9.2.C). Se trata de moldes negativos de tallos, de unos $30 \mathrm{~cm}$ de largo por $10 \mathrm{~cm}$ de ancho, presentan una superficie estriada que suele estar cubierta por una pátina de óxido en su superficie. Se ubican casi paralelos al plano de estratificación. Se han encontrado escasos restos con este tipo de preservación, de manera aislada, asociados con impresiones de maderas.

(3). Impresiones de tallos (Fig. 9.2.B). Se trata de improntas bidimensionales de maderas con su superficie estriada. Son restos fragmentarios, siendo los de mayor tamaño de $25 \mathrm{~cm}$ de largo por $30 \mathrm{~cm}$ de ancho. Pueden o no presentar una pátina de óxido en la superficie. Se encuentran en pequeñas concentraciones, posicionados paralelamente al plano de estratificación. 
Ana Julia Sagasti - Estudio paleobotánico, paleoecológico y paleoambiental...

(4). Carbonizaciones de madera (Fig. 9.2.D). Pequeños fragmentos de madera completamente carbonizada. De $10 \mathrm{~cm}$ de largo por $15 \mathrm{~cm}$ de ancho, los de mayores dimensiones. Se encuentran en pequeñas concentraciones, distribuidas al azar. Se orientan paralelamente al plano de estratificación.

(5). Permineralizaciones silíceas en masa (=chert) (Fig. 9.2.E-F). Se trata de dos lentes de chert, de unos $20 \mathrm{~cm}$ de espesor, por hasta tres metros de largo aflorante. Consiste de una matriz silícea que contiene abundante detrito vegetal parautóctono, evidenciado por la orientación de los restos, que sigue el plano de estratificación. Dentro de la matriz pueden observarse restos fragmentarios de tejido vegetal identificable. El grado de fragmentación es variable, incluyendo pequeños restos de madera, fragmentos de hojas, renovales, raíces, tallos y detrito vegetal. Se encuentran interdigitados con areniscas gruesas, formando lentes que siguen el plano de estratificación.

(6). Permineralizaciones individuales de tallos (Fig. 9.2.G). Se trata de fragmentos de ejes silicificados, de $20 \mathrm{~cm}$ a $50 \mathrm{~cm}$ de diámetro, probablemente ramas. Se encuentran en concentraciones altas, dispuestos de manera paralela al plano de estratificación. La determinación de los ejemplares se detalla en el Capítulo VII. La preservación es de pobre a buena, pudiéndose estudiar la anatomía de los ejemplares. En algunos casos, se observan patrones de degradación de la madera y evidencias de interacciones con microorganismos (ver Capítulo VIII).

(7). Impresiones de hojas, ramas foliosas y estructuras reproductivas (Fig. 9.3. A). Improntas de órganos planos o tridimensionales, autóctonos o parautóctonos, con distinto grado de fragmentación. Ramas foliosas a veces ramificadas. Pueden presentar una pátina de óxido, pero nunca se asocian con materia orgánica carbonizada. Se ubican de manera paralela al plano de estratificación, en importantes acumulaciones dentro de los niveles portadores. No se observa una superposición significativa de los órganos, pudiéndose extraer de manera relativamente aislada. La determinación de los ejemplares se detalla en el Capítulo VII. Se han identificado Coniferales (Araucariaceae, Cheirolepidiaceae e Incertae sedis), Polypodiopsidas (Dicksoniaceae e Incertae sedis), Cycadoideales y frondes de afinidades inciertas. 

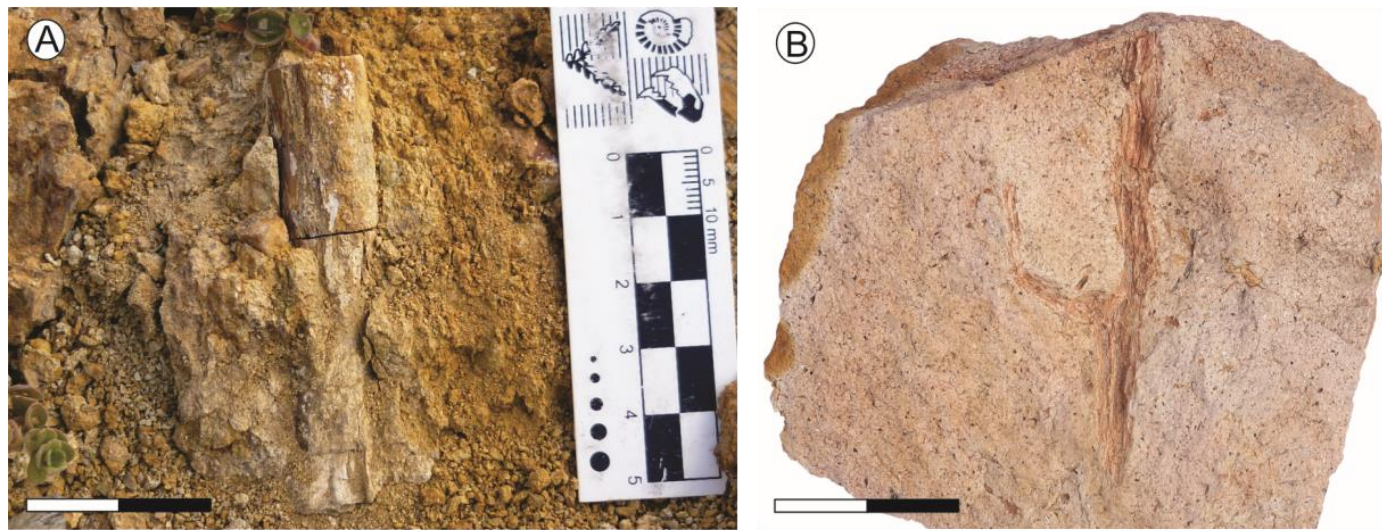

(C)
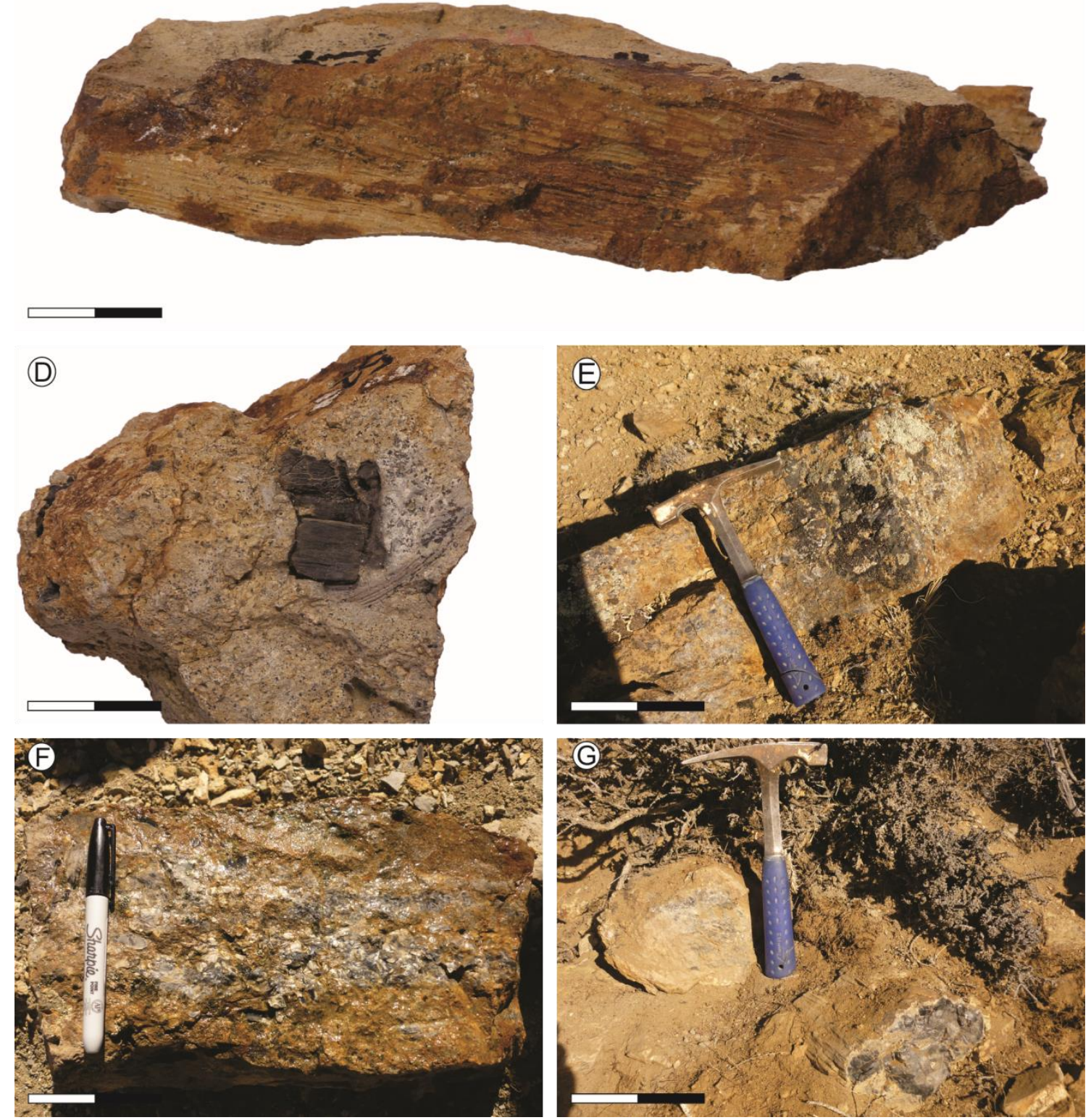

Figura 9.2. Estilos preservacionales encontrados en la secuencia aflorante en Laguna Flecha Negra. A. Permineralizaciones individuales de raíces. MPM PB 15896. Escala: $2 \mathrm{~cm}$. B. Impresiones de maderas. MPM PB 16028. Escala: $4 \mathrm{~cm}$.C. Moldes de maderas. MPM PB 15897. Escala: $1 \mathrm{~cm}$. D. Carbonizaciones de maderas. MPM PB 15898. Escala: $1 \mathrm{~cm}$. E, F. Permineralizaciones silíceas en masa. Escala: $15 \mathrm{~cm}$. G. Permineralizaciones individuales de tallos. Escala: $15 \mathrm{~cm}$. 
Ana Julia Sagasti - Estudio paleobotánico, paleoecológico y paleoambiental...

(8). Impresiones-compresiones (Fig. 9.3.B). Se trata de improntas de hojas monopinnadas y estructuras reproductivas que preservan una capa carbonosa asociada en su superficie. Se encuentran en concentraciones abundantes en el nivel portador, aunque no se produce una superposición significativa de los ejemplares, pudiéndose extraer de manera relativamente aislada. Se ubican de manera paralela al plano de estratificación. La determinación de los ejemplares se detalla en el Capítulo VII. Se han identificado Cycadoideales, Coniferales y estructuras reproductivas pinnadas indeterminadas.

(9). Troncos y tocones silicificados verticales (Fig. 9.3.C). Se trata de troncos y bases (tocones) de árboles autóctonos, pertenecientes al Orden Coniferales. Los tocones están en conexión con raíces, aunque esto no pudo observarse en todos los ejemplares, por estar contenidos en la roca. Su diámetro varía ente $50 \mathrm{~cm}$ y $1,5 \mathrm{~m}$. Están orientados de manera perpendicular a ligeramente oblicua con respecto al plano de estratificación. Su concentración es mediana, a alta, junto a los troncos de la siguiente categoría. La estructura interna de los troncos se encuentra con una preservación de pobre a muy mala.

(10). Troncos silicificados horizontales y oblicuos (Fig. 9.3.D). Se trata de troncos de Coniferales autóctonos y parautóctonos. En el primer caso, son árboles caídos y que no sufrieron transporte, evidenciado por la presencia de sus bases. Los segundos son fragmentos de tronco, sin base preservada, que han sufrido un mínimo transporte dentro del mismo subambiente sedimentarios. No presentan ramificaciones en conexión orgánica, aunque algunos ejemplares presentan trazas de salidas de ramas. Tanto estos ejemplares, como los de la categoría anterior, se encuentran en el tope del nivel de tobas masivas, parcialmente cubiertos por sedimento. Su diámetro varía de $0,3 \mathrm{~m}$ a $1,5 \mathrm{~m}$, son restos relativamente fragmentarios, que nunca superan los $2 \mathrm{~m}$ de longitud. La permineralización es de sílice amorfa y la estructura interna tiene una preservación de pobre a muy mala. Los troncos y tocones están distribuidos en concentraciones altas, junto a los troncos de la categoría anterior, paralelos al plano de estratificación, con rumbos muy diversos.

(11) Briznas vegetales (Fig. 9.3.E). Fragmentos muy pequeños de hojas y ramas, que no permiten realizar una determinación sistemática. El tipo de 
Ana Julia Sagasti - Estudio paleobotánico, paleoecológico y paleoambiental...

fosilización al que corresponden es compresiones. Se encuentran de manera abundante, asociados a las impresiones - compresiones, dispuestos de manera paralela al plano de estratificación.
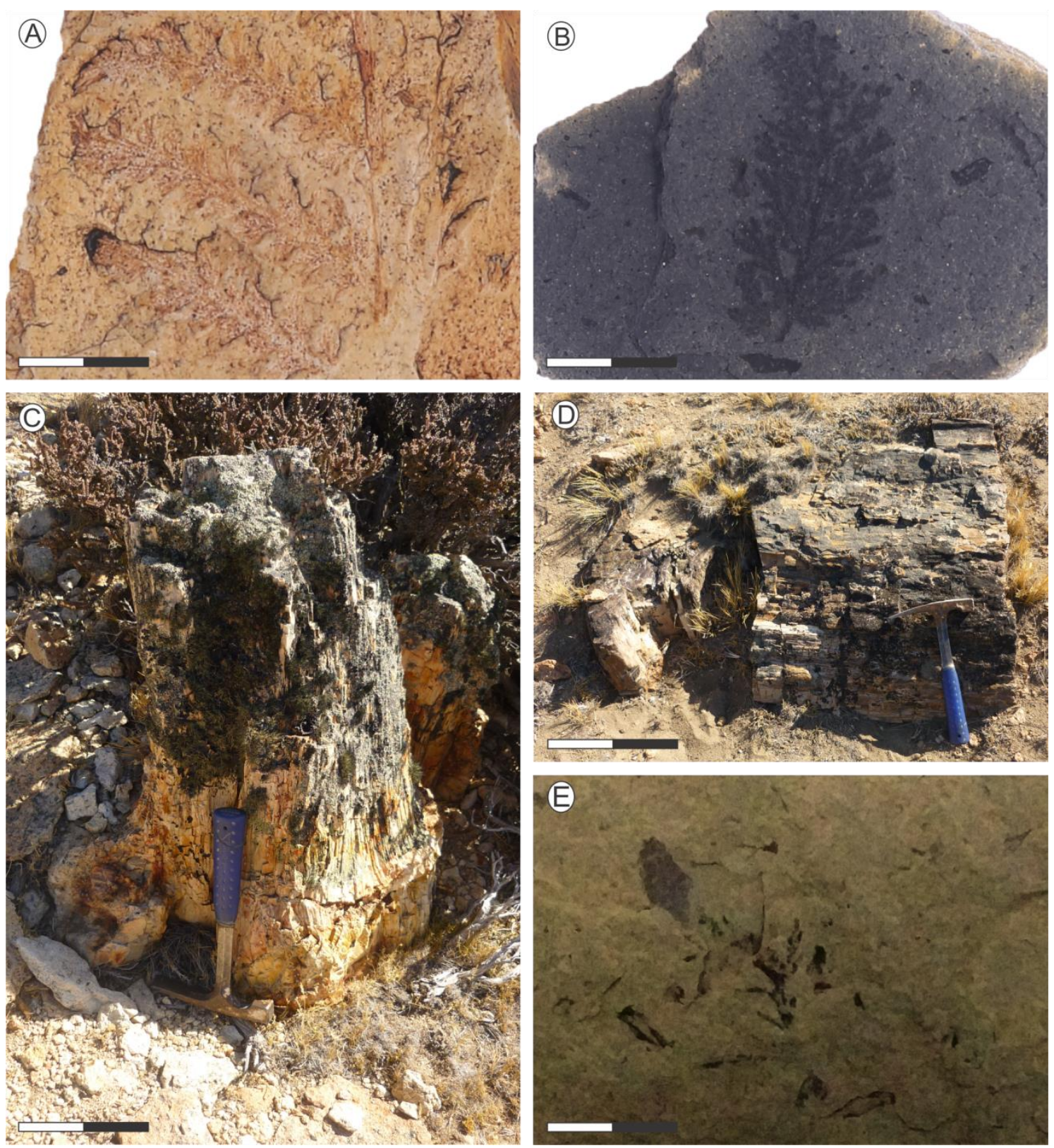

Figura 9.3.Estilos preservacionales encontrados en la secuencia aflorante en Laguna Flecha Negra. A. Impresiones de hojas, ramas foliosas y estructuras reproductivas. En la figura se ejemplifica el estilo preservacional con la impronta de una fronde estéril. $\mathbf{B}$. Impresiones-compresiones. FNSW24. Escala: $0,5 \mathrm{~cm}$. MPM PB 15885. Escala: 0,5 $\mathrm{cm}$, C. Troncos y tocones silicificados verticales. Tronco 056 . Escala: $20 \mathrm{~cm}$. D. Troncos silicificados horizontales y oblicuos. Tronco 003. Escala: $30 \mathrm{~cm}$. E. Briznas vegetales. MPM PB 15898. Escala: 0,5 cm. 
Ana Julia Sagasti - Estudio paleobotánico, paleoecológico y paleoambiental...

\section{Definición de las tafofacies.}

El concepto de tafofacies describe los distintos tipos de preservación entre niveles en un perfil sedimentario y los diferentes tipos de preservación y modos de aparición de diferentes taxones fósiles dentro de un mismo nivel (Speyer y Brett, 1986; Speyer y Brett, 1988). Estas diferencias, permiten reconocer patrones de distribución temporal y espacial de los restos en un yacimiento, integran información sobre la distribución de las especies, y permiten testear la asociación proceso-producto de los restos (Speyer y Brett, 1988). Debido a que las propiedades tafonómicas son el producto de las condiciones ambientales específicas (Brett y Baird, 1986), las tafofacies se generan por un mosaico interdigitado de condiciones ambientales. En este sentido, los modelos de tafofacies describen la distribución de condiciones tafonómicas que se corresponden con fenómenos ambientales determinables de manera deductiva y empírica (Speyer y Brett, 1988).

Para definir y nombrar a las tafofacies se utilizó el código de litofacies establecido en el Capítulo VI, agregándole un código alfabético que representa el estilo preservacional (Miall, 1996; Colombi y Parrish, 2008). Finalmente se analizan las asociaciones de tafofacies presentes en cada nivel de la secuencia estudiada en Laguna Flecha Negra.

Las tafofloras estudiadas comprenden 12 tafofacies: (1) Agm(Rp) areniscas gruesas blancuzcas con permineralizaciones individuales de raíces, (2) $\operatorname{Agm}(\mathrm{Mm})$ areniscas gruesas blancuzcas con moldes de maderas; (3) Agm(Im) areniscas gruesas blancuzcas con impresiones de maderas; Agm $(\mathrm{Cm})$ areniscas gruesas blancuzcas con maderas carbonizadas; (5) Ch lentes de chert con detrito vegetal con distintos grados de fragmentación; (6) Agm(Pt) areniscas gruesas blancuzcas con permineralizaciones individuales de tallos; (7) Agm(I) areniscas gruesas blancuzcas con impresiones de hojas, ramas foliosas y estructuras reproductivas; (8) AfLe(IC) areniscas finas y limolitas oscuras con impresiones-compresiones de hojas, ramas foliosas y estructuras reproductivas; (9) AfLe(B) areniscas finas y limolitas oscuras con impresiones compresiones de briznas vegetales; (10) Tm(Tv) tobas blancas masivas con troncos y tocones silicificados en posición vertical; (11) Tm(Th) tobas blancas, masivas con troncos silicificados en posición oblicua a horizontal; (12) $\operatorname{Tm}(\mathrm{I})$ 
Ana Julia Sagasti - Estudio paleobotánico, paleoecológico y paleoambiental...

tobas blancas masivas con improntas de ramas de alto órden y escasas expansiones laminares fragmentarias.

(1). Tafofacies Agm(Rp): areniscas gruesas, blancuzcas, masivas, con rasgos de oxidación por exposición subaérea. Clastos volcánicos angulosos y cristales de feldespato erosionados. Geometría general tabular. Presencia de permineralizaciones individuales de raíces de posición perpendicular, oblicua o paralela al plano de estratificación.

(2). Tafofacies Agm(Mm): areniscas gruesas, blancuzcas, masivas, con rasgos de oxidación por exposición subaérea. Clastos volcánicos angulosos y cristales de feldespato erosionados. Geometría general tabular. Presencia de moldes de maderas con estrías en su superficie y rasgos de oxidación en algunos ejemplares. Se ubican en posición paralela al plano de estratificación.

(3) Tafofacies Agm(Im): areniscas gruesas, blancuzcas, masivas, con rasgos de oxidación por exposición subaérea. Clastos volcánicos angulosos y cristales de feldespato erosionados. Geometría general tabular. Presencia de impresiones de maderas con estrías en su superficie y rasgos de oxidación en algunos ejemplares. Se ubican en posición paralela al plano de estratificación.

(4) Tafofacies $\operatorname{Agm}(\mathrm{Cm})$ : areniscas gruesas, blancuzcas, masivas, con rasgos de oxidación por exposición subaérea. Clastos volcánicos angulosos y cristales de feldespato erosionados. Geometría general tabular. Presencia de maderas completamente carbonizadas, ubicadas de manera paralela al plano de estratificación.

(5) Tafofacies Ch: lentes de chert de 20 centímetros de espesor por hasta 3 metros de largo aflorante. Abundante contenido de detritos vegetales distribuídos de manera laminar a azarosa, paralelos al plano de estratificación. La matriz silícea porta los restos vegetales de carácter fragmentario, algunos de ellos preservan la anatomía con alto grado de detalle y la morfología del resto casi intacta, evidenciando poco a nulo transporte de los restos.

(6) Tafofacies Agm(Pt): areniscas gruesas, blancuzcas, masivas, con rasgos de oxidación por exposición subaérea. Clastos volcánicos angulosos y cristales de feldespato erosionados. Geometría general tabular. Presencia de permineralizaciones individuales de tallos de Coníferas, orientados de manera paralela al plano de estratificación. Los restos no se encuentran compactados, 
Ana Julia Sagasti - Estudio paleobotánico, paleoecológico y paleoambiental...

evidenciando el carácter autóctono y rápido sepultamiento de los órganos. La matriz es silícea y el estado de preservación es de pobre a bueno, permitiendo realizar determinaciones sistemáticas de los ejemplares (ver Capítulo VII).

(7)Tafofacies Agm(I): areniscas gruesas, blancuzcas, masivas, con rasgos de oxidación por exposición subaérea. Clastos volcánicos angulosos y cristales de feldespato erosionados. Geometría general tabular. Sedimentitas muy bien cementadas. Restos de improntas de hojas, ramas foliosas y estructuras reproductivas con un estado de preservación de bueno a muy bueno. Se ubican de manera paralela al plano de estratificación.

(8) Tafofacies AfLe(IC): areniscas finas y limolitas oscuras, de geometría tabular, con estructura interna granodecreciente de arena fina a limo, laminación entrecruzada que se hace paralela hacia el tope. Superficies de estratificación con clastos volcánicos fuertemente meteorizados, partículas de ceniza y escamas de mica. Abundantes restos de hojas, ramas foliosas y estructuras reproductivas preservadas como impresiones-compresiones. Impresiones-compresiones con capa carbonosa amorfa sin rasgos anatómicos ni cutículas asociadas. Se ubican de manera paralela al plano de estratificación.

(9) Tafofacies AfLe(B): areniscas finas y limolitas oscuras, de geometría tabular, con estructura interna granodecreciente de arena fina a limo, laminación entrecruzada que se hace paralela hacia el tope. Superficies de estratificación con clastos volcánicos fuertemente meteorizados, partículas de ceniza y escamas de mica. Abundantes restos de briznas vegetales con alto grado de fragmentación, que no permiten identificar órganos ni realizar asignaciones sistemáticas de los restos. Se preservan como impresionescompresiones y se ubican de manera paralela al plano de estratificación.

(10) Tafofacies Tm(Tv): Tobas blancas, gruesas a finas, que rematan en horizontes delgados con abundancia de lapilli. Geometría tabular. Estructura interna masiva en rasgos generales, con organización granodecreciente de las partículas. Tope de la secuencia con troncos y tocones silicificados de posición vertical, perpendiculares a oblicuos con respecto al plano de estratificación.

(11) Tafofacies $\mathrm{Tm}(\mathrm{Th})$ : Tobas blancas, gruesas a finas, que rematan en horizontes delgados con abundancia de lapilli. Geometría tabular. Estructura interna masiva en rasgos generales, con organización granodecreciente de las 
Ana Julia Sagasti - Estudio paleobotánico, paleoecológico y paleoambiental...

partículas. Tope de la secuencia con troncos silicificados horizontales y oblicuos con respecto al plano de estratificación.

(12) Tafofacies $\operatorname{Tm}(\mathrm{I})$ : Tobas blancas, gruesas a finas, que rematan en horizontes delgados con abundancia de lapilli. Geometría tabular. Estructura interna masiva en rasgos generales, con organización granodecreciente de las partículas. Escasos restos de improntas de ramas delgadas, de último orden, algunos portando expansiones laminares escasas y fragmentarias. Se ubican de manera paralela al plano de estratificación, normalmente asociadas a la base de tocones silicificados de posición vertical.

\section{Asociaciones de tafofacies.}

En el sector noroeste de la localidad Laguna Flecha Negra se observa, por encima del domo andesítico Bajo Pobre, un nivel de areniscas gruesas en el cual se pueden reconocer las tafofacies $\operatorname{Agm}(\operatorname{Rp}), \operatorname{Agm}(\mathrm{Mm}), \operatorname{Agm}(\operatorname{Im})$, $\operatorname{Agm}(\mathrm{Cm}), \mathrm{Ch}, \operatorname{Agm}(\mathrm{Pt})$ y en menor medida, $\operatorname{Agm}(\mathrm{I})$. En la zona sudoeste de la localidad se observa un mayor desarrollo de la tafofacies $\operatorname{Agm}(I)$ que en esta región se ubica de manera aislada, y no aparece asociada a las tafofacies mencionadas previamente. Por encima, y abarcando la zona centro y sudoeste de la localidad, se encuentra la asociación de tafofacies AfLe(IC) y AfLe(B), allí se encuentran los restos vegetales que mejor preservan la morfología de los órganos preservados. Sobre este nivel se desarrolla de manera verticalmente extensa la litofacies de tobas masivas, que recién en su tope presenta una asociación de tafofacies que incluye $\operatorname{Tm}(\mathrm{Tv}), \operatorname{Tm}(\mathrm{Th})$ y $\operatorname{Tm}(\mathrm{I})$. Culmina la secuencia con la Ignimbrita Flecha Negra, que no porta restos fósiles de ningún tipo.

\section{Comparación con los modelos sedimentarios de ambientes geotérmicos del Macizo del Deseado.}

Guido y Campbell (2011) reconocen un total de 23 localidades con afloramientos de tipo hot-spring en el Macizo del Deseado (Fig. 9.4), la mayoría de ellas, ubicadas en la región oeste del Macizo. A partir del análisis de detalle 
Ana Julia Sagasti - Estudio paleobotánico, paleoecológico y paleoambiental...

en cinco de las localidades, estos autores construyen dos modelos generalizados de facies. Los depósitos de hot-springs del Macizo del Deseado fueron reconocidos en función de la asociación vertical y lateral de facies, las morfologías depositacionales distintivas, y las micro- y/o macro-texturas preservadas (Guido y Campbell, 2011). Los autores reconocen hot-springs conformados por travertinos (e.g. El Macanudo, Cerro Negro), sinters silíceos (e.g. San Agustín), o sinter silíceo con áreas que presentan travertinos dentro del mismo sistema geotérmico (Claudia). Dada la composición silícea del chert aflorante en el yacimiento fosilífero de la localidad Laguna Flecha Negra, se realizan comparaciones con el modelo de sinter silíceo.

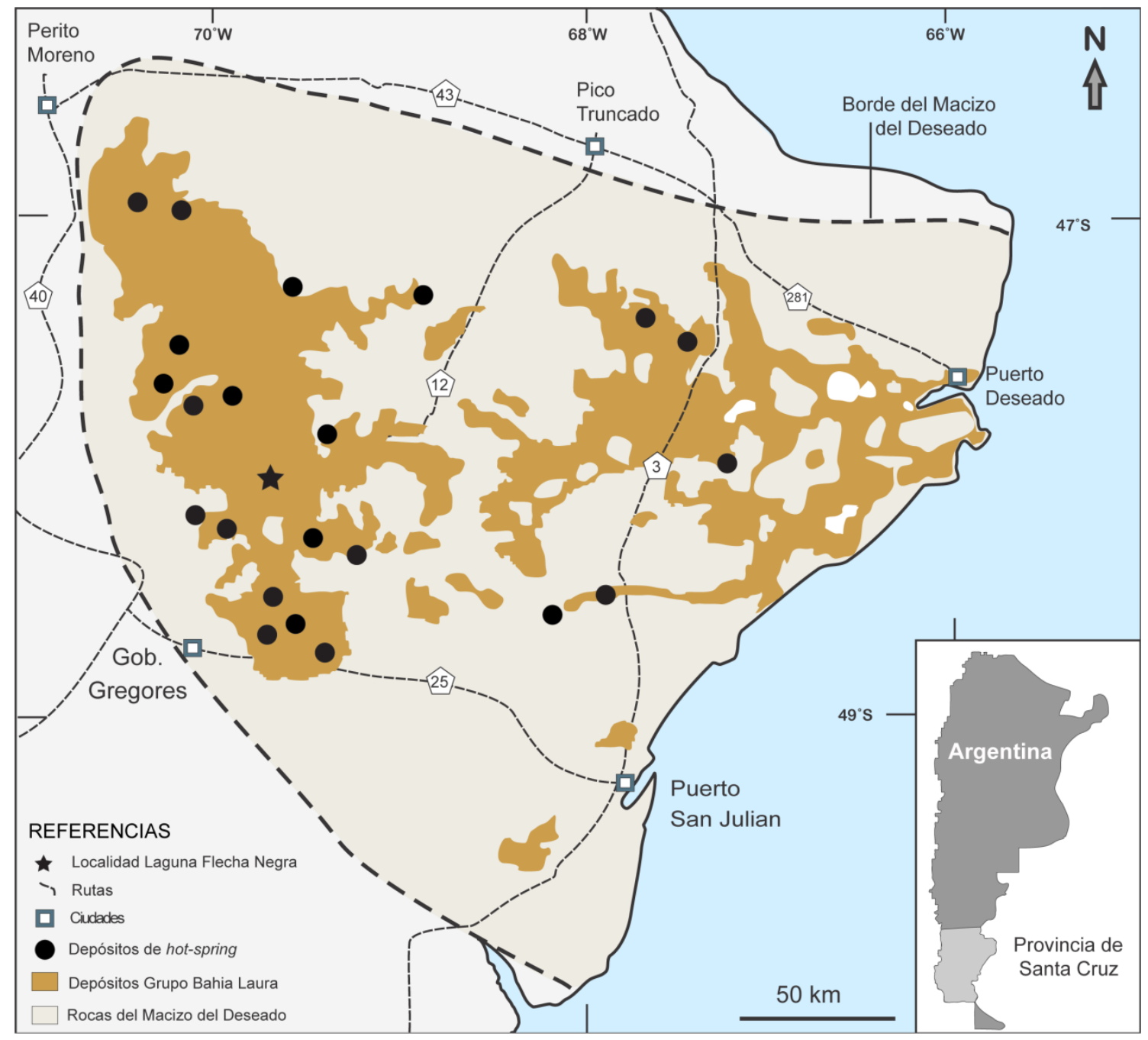

Figura 9.4. Localidades del Macizo del Deseado con afloramientos de tipo hotspring. La estrella señala la ubicación de la localidad Laguna Flecha Negra. Modificado de Sagasti et al. (2016). 
Ana Julia Sagasti - Estudio paleobotánico, paleoecológico y paleoambiental...

Las facies observadas en ambientes de hot-spring actuales están controladas por diversos factores, tales como la composición y $\mathrm{pH}$ de los fluidos, temperatura de precipitación, topografía, estacionalidad, disponibilidad de agua, suministro de $\mathrm{CO}_{2}$, composición de la comunidad biológica, relación con fallas activas, etc (e.g. Walter, 1976; Gibert et al., 2009; Guido et al., 2010; Guido y Campbell, 2011). El análisis de sistemas modernos con emanaciones termales silíceas subaéreas, abanicos de desborde y pantanos con influencia geotérmica ha permitido subdividir estos sistemas en tres áreas principales en una transecta de descarga que incluye: zonas proximales a la emanación (vent) donde predominan las altas temperaturas $\left(>59^{\circ} \mathrm{C}\right)$, abanicos o terrazas de desborde (mid-slope apron) con temperaturas moderadas ( 59 a $\left.35^{\circ} \mathrm{C}\right)$, y abanicos distales (distal-slope aprons) de baja temperatura $\left(<35^{\circ} \mathrm{C}\right)$ (Fig. 10.5) (e.g. Walter, 1976; Channing et al., 2004). La composición de los fluidos y los procesos de mineralización a lo largo de la transecta generan asociaciones texturales y biológicas recurrentes que permiten la comparación con sistemas fósiles. La tabla 9.1 resume las asociaciones de facies descriptas por Guido y Campbell (2011) para los sistemas geotérmicos fósiles del Macizo del Deseado.

DEPÓSITOS DE SINTER

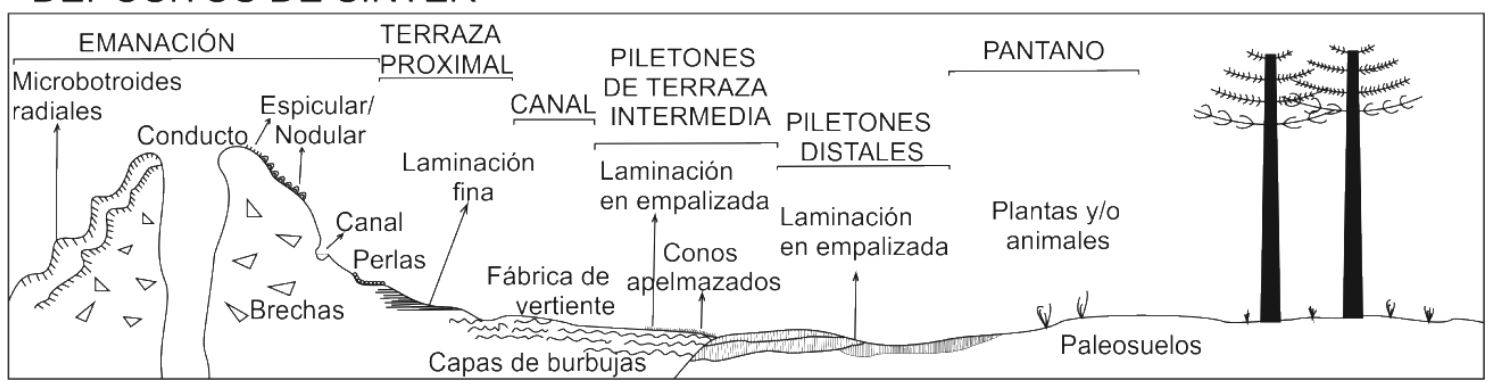

Figura 9.5. Modelo de depositación y asociaciones de facies en sistemas geotermales silíceos. Modificado de Guido y Campbell (2011). 
Ana Julia Sagasti - Estudio paleobotánico, paleoecológico y paleoambiental...

\begin{tabular}{|c|c|c|c|c|}
\hline $\begin{array}{l}\text { Asociaciones } \\
\text { de facies }\end{array}$ & \multicolumn{2}{|l|}{ Facies } & Texturas & Asociación de estromatolitos \\
\hline \multirow{11}{*}{ Proximal } & \multirow{6}{*}{\multicolumn{2}{|c|}{ Emanación (vent) }} & Conducto & \\
\hline & & & Brechas/panal de abejas & \\
\hline & & & Canales & \\
\hline & & & Espicular/ nodular/ botroidal & Biofilms superficiales \\
\hline & & & "Perlitas" (beads) & \\
\hline & & & Microbotroides radiales & \\
\hline & \multicolumn{2}{|c|}{ Terraza proximal (proximal slope) } & Laminación fina & Biofilms superficiales \\
\hline & \multirow[t]{3}{*}{ Subácuea } & $\begin{array}{l}\text { Conos en forma de } \\
\text { volcán }\end{array}$ & Estratificación inclinada alrededor del conducto & $\begin{array}{l}\text { "Coliflores" alrededor de los conductos basales } \\
\text { (en travertinos) }\end{array}$ \\
\hline & & Conos concéntricos & Laminación crenulada concéntrica & Fábrica microbial primaria (en travertinos) \\
\hline & & Tubos & Habitáculos larvales cilíndricos, concéntricos & "Coliflores" encrustados en tubos \\
\hline & \multicolumn{2}{|c|}{ Montículos/terrazas } & Macrobotroides concéntricos / estratificados & Microbios incorporados en las estructuras. \\
\hline \multirow{6}{*}{ Medio } & \multirow{3}{*}{\multicolumn{2}{|c|}{ Canal }} & Capas de burbujas & Fábrica microbial primaria \\
\hline & & & Textura fragmentaria empaquetada & $\begin{array}{l}\text { Tapetes de zona basal de corrientes cálidas } \\
\text { (transportados) }\end{array}$ \\
\hline & & & Fábrica de vertiente & Fábrica microbial primaria \\
\hline & \multirow{3}{*}{\multicolumn{2}{|c|}{ Piletones de terraza intermedia }} & Laminación en empalizada gruesa & Fábrica microbial primaria (en travertinos) \\
\hline & & & $\begin{array}{l}\text { Fábrica interconectada (network) / conos } \\
\text { apelmazados }\end{array}$ & Fábrica microbial primaria \\
\hline & & & Textura esponjosa & En travertinos. \\
\hline \multirow{7}{*}{ Distal } & \multirow{3}{*}{\multicolumn{2}{|c|}{ Abanicos distales }} & Terrazas / laminación en empalizada delgada & Fábrica microbial primaria \\
\hline & & & Estratificación ondulosa de baja amplitud & $\begin{array}{l}\text { Estructuras sedimentarias físicas + microbiales } \\
\text { (en travertinos) }\end{array}$ \\
\hline & & & Esferulitas / oncoides & Fábrica microbial primaria (en travertinos) \\
\hline & \multirow{4}{*}{\multicolumn{2}{|c|}{ Pantano }} & Fenestriforme & $\begin{array}{l}\text { Generalmente formada en sedimentos } \\
\text { microbianos (En travertinos) }\end{array}$ \\
\hline & & & Moteado/ peloidal & Fábrica microbial primaria \\
\hline & & & Plantas y/o animales & En algunas zonas, pátinas de microbialita \\
\hline & & & Paleosuelos & $\begin{array}{l}\text { Fragmentos meteorizados, algunos } \\
\text { microbianos. }\end{array}$ \\
\hline
\end{tabular}

Tabla 9.1. Asociaciones de facies reconocidas en cinco localidades de tipo hot-spring en el Macizo del Deseado (La Marciana, San Agustín, Claudia, Cerro Negro, El Macanudo). Se señala aquellas que sólo se observaron en yacimientos formados por travertinos y no se registran en sinters silíceos. Modificado de Guido y Campbell (2011). 
Ana Julia Sagasti - Estudio paleobotánico, paleoecológico y paleoambiental...

En ambientes modernos con actividad geotérmica se observan tres rutas para la incorporación de material vegetal en depósitos de sinter (Channing y Edwards, 2013):

Órganos vegetales alóctonos y para-autóctonos se desprenden de la vegetación local (tanto dentro del sistema de hot-springs como de sus márgenes), éstos se transportan hacia el ambiente de silicificación e incluyen ramas de alto orden y foliosas, hojas de angiospermas y gimnospermas, estructuras reproductivas y polen. Este tipo de órganos pueden ocurrir en todas las zonas del sistema geotérmico y su preservación varía en función del subambiente en el cual son depositados. En los abanicos de desborde (aprons), donde dominan los procesos de desecación y oxidación, la fosilización se reduce a moldes externos y permineralización de órganos degradados y tejidos colapsados, mientras que en zonas húmedas de temperaturas más bajas, la preservación anatómica puede observarse con mejor detalle. El contexto preservacional para estas facies se expresa por micro- y macro-fábricas de matriz silícea, tipo chert (Channing y Edwards, 2013).

La preservación de comunidades vegetales autóctonas, "normales" de zonas húmedas o áridas, ocurre por progradación de los abanicos de desborde y márgenes periféricos de las zonas geotérmicas pantanosas (wetlands) hacia áreas que previamente no estaban afectadas por fluidos geotérmicos (Channing y Edwards, 2013). Este proceso genera una secuencia sedimentaria distintiva que es observable en el registro fósil. En la base de la secuencia vertical pueden observarse sedimentos clásticos con evidencia de eventos de inundación por aguas termales, que se observan como silicificación pervasiva. Estos horizontes pueden estar asociados a paleosuelos, interpretados a partir de la presencia de horizontes de raíces bien preservadas, y en algunos casos, renovales in situ. También pueden preservarse tallos o troncos caídos bien preservados, detrito vegetal bien degradado, ramas y hojas o estructuras reproductivas abcindidas de la vegetación afectada por la incipiente inundación (Channing y Edwards, 2013).

El tercer tipo de aporte de material vegetal se observa tras largos períodos de inundación en el ambiente, al desarrollarse pantanos geotérmicos 
Ana Julia Sagasti - Estudio paleobotánico, paleoecológico y paleoambiental...

(wetlands), los cuales son colonizados por plantas que habitan las zonas distales, donde la temperatura permite el desarrollo de comunidades vegetales. En este subambiente, las comunidades herbáceas de pequeño porte reemplazan al componente arbóreo y la diversidad de especies declina. Es común observar permineralizaciones de tallos, raíces o rizomas en posición de vida (Channing y Edwards, 2013).

\section{Interpretación del yacimiento Laguna Flecha Negra.}

El estudio vertical y lateral de las asociaciones de litofacies y tafofacies aflorantes en la localidad Laguna Flecha Negra permite realizar una reconstrucción paleoambiental en el marco de los modelos de facies para sistemas geotermales elaborados por Guido y Campbell (2011). Como se ha señalado previamente, los depósitos de permineralizaciones en masa estudiados son de carácter silíceo, lenticular y se encuentran aislados en el sector noroeste de la localidad, interdigitando con areniscas gruesas, masivas. En primer lugar, cabe destacar que no se observan características distintivas de los subambientes proximal y medio, tal y como fueran definidos por Guido y Campbell (2011). La geometría y textura de los lentes de chert permiten ubicarnos dentro de los sectores distales del modelo de sínter silíceo, más precisamente, en la zona de pantanos con influencia geotérmica, o wetlands.

Dentro de los lentes de chert se puede observar abundante detrito vegetal con diverso grado de fragmentación (Fig. 9.6.A). Se reconocen ramas foliosas de gimnospermas con una preservación de muy buena (Fig. 9.6.B) a regular (Fig. 9.6.C). Parte de los restos preserva su anatomía con alto grado de definición, pudiendo observarse células parenquimáticas sin colapsar (Fig. 9.6.B). También se observan pecíolos con anatomía de gleicheniaceae, en excelente grado de preservación, observándose sus detalles anatómicos y sin signos de compactación (Fig. 9.6.D). Otros elementos reconocibles incluyen pínnulas pteridofíticas fragmentadas (Fig. 9.7.A), raíces diarcas con alto grado de detalle (Fig. 9.7.B), fragmentos de ramas foliosas gimnospérmicas con parénquima en empalizada (Fig. 9.7.C), fragmentos de hojas cicadofíticas (Fig. 9.7.D), tallos eustélicos con médula amplia e incipiente desarrollo de leño (Fig. 
Ana Julia Sagasti - Estudio paleobotánico, paleoecológico y paleoambiental...

9.7.E) y abundantes restos de maderas, en los que se puede reconocer su carácter picnoxílico (Fig. 9.7.F). La composición del detrito vegetal preservado en el chert presenta una alta afinidad con la flora de impresiones-compresiones estudiada en la localidad, señalando su carácter autóctono o para-autóctono. En este sentido, se puede señalar que los materiales aquí preservados provienen de un aporte del primer y segundo tipo según lo definido por Channing y Edwards (2013).

Las areniscas gruesas con las que interdigita este chert preservan, en la zona noroeste del yacimiento, una asociación de restos de maderas de afinidad incierta, preservados como moldes, impresiones y carbonizaciones. En esta misma región, se pueden reconocer permineralizaciones individuales de troncos y ramas de gimnospermas, así como también raíces permineralizadas en posición de vida. La presencia de clastos volcánicos angulosos indica el aporte de carácter volcaniclástico de los sedimentos portadores. Se interpreta que el nivel se habría formado por depositación de cenizas volcánicas provenientes de un edificio volcánico relativamente cercano o en las etapas iniciales de su actividad (evidenciado por la granulometría de la sedimentita). La actividad hidrotermal asociada con este evento volcánico habría favorecido el desarrollo de fluidos altamente cargados de minerales que se habrían desplazado siguiendo la topografía, registrándose en la localidad como lentes de chert que interdigitan con las areniscas.

La interpretación de estos cherts como posiciones distales del sistema geotérmico se sustenta a su vez por la ausencia de esta tafofacies en el sector sudoeste de la localidad. Allí, las areniscas aparecen con un mayor grado de cementación, preservando una flora de impresiones con un buen estado de preservación, pero sin evidencia de influencia de los fluidos geotérmicos.

Suprayacentemente a este nivel, la secuencia adquiere un carácter netamente volcaniclástico. En los sectores central y sudoeste de la localidad, la asociación de tafofacies $A f L e(I C)$ y $A f L e(B)$, se desarrolla en un conjunto de estratos de 10-35 cm de espesor, que conforman un nivel con una potencia máxima de 5 metros. Este es el nivel de menor granulometría de la secuencia, evidenciando un carácter más tardío dentro del episodio volcánico. A su vez, es el nivel con mayor cantidad de materia orgánica en la secuencia. Los estratos preservan tanto una flora autóctona a para-autóctona de restos vegetales bien 
Ana Julia Sagasti - Estudio paleobotánico, paleoecológico y paleoambiental...

preservados como abundantes briznas vegetales de carácter fragmentario. La presencia de laminación entrecruzada a paralela, sumado al abundante detrito vegetal (representado por las briznas) y la granulometría fina de las sedimentitas podría indicar la formación de estos cuerpos de roca en un ambiente subácueo.

Concordantemente a este nivel, se registra un nuevo episodio eruptivo de gran desarrollo vertical. Las tobas estudiadas son de carácter mayormente estéril, registrando una comunidad vegetal arbórea hacia el tope de la secuencia. Allí se puede observar la asociación de tafofacies Tm(Tv), Tm(Th) y $\mathrm{Tm}(\mathrm{I})$, en la que se encuentra un bosque de coníferas de carácter autóctono a para-autóctono. Los parámetros ambientales indicados por esta paleocomunidad se analizan en detalle en el Capítulo $X$.

Finalmente, y como se señaló en el Capítulo VI, se observa el paso hacia una etapa de flujo dentro del evento volcánico, la cual está representada por la Ignimbrita Flecha Negra, que culmina la secuencia dentro del marco de la localidad Laguna Flecha Negra. 

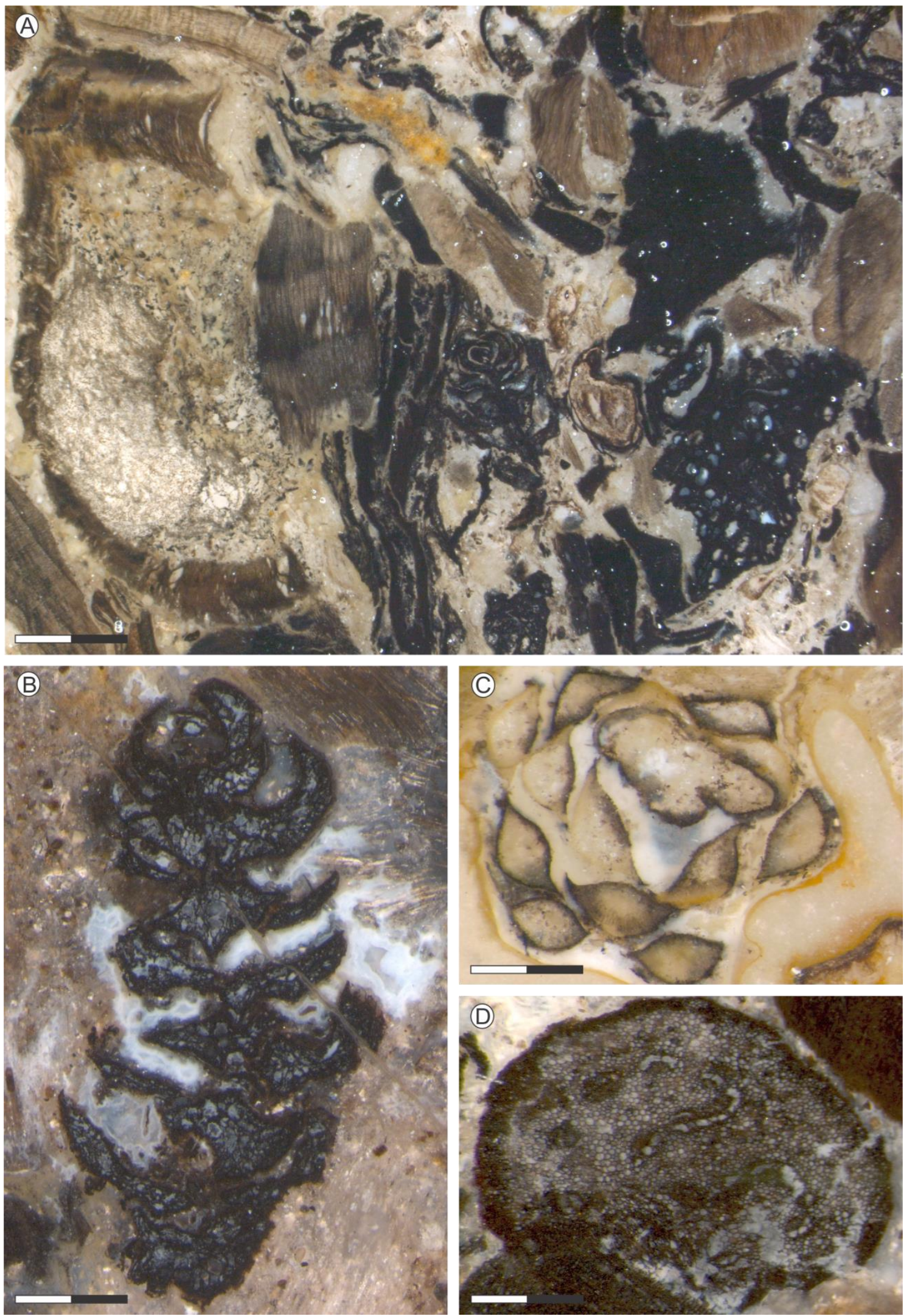

Figura 9.6. Elementos vegetales reconocidos dentro de los lentes de chert. A. Detrito vegetal fragmentario. B. Corte longitudinal de rama foliosa de Conífera con excelente nivel de preservación. Se puede observar la presencia de células parenquimáticas no colapsadas. C. Corte transversal de rama foliosa de Conífera con estado de preservación moderado. Se observa la filotaxis espiralada de las hojas. D. Corte transversal de pecíolo de gleicheniaceae con muy buen nivel de preservación. No se observan signos de compactación, las células parenquimáticas no se encuentran degradadas y la traza peciolar mantiene la morfología característica de la familia. 

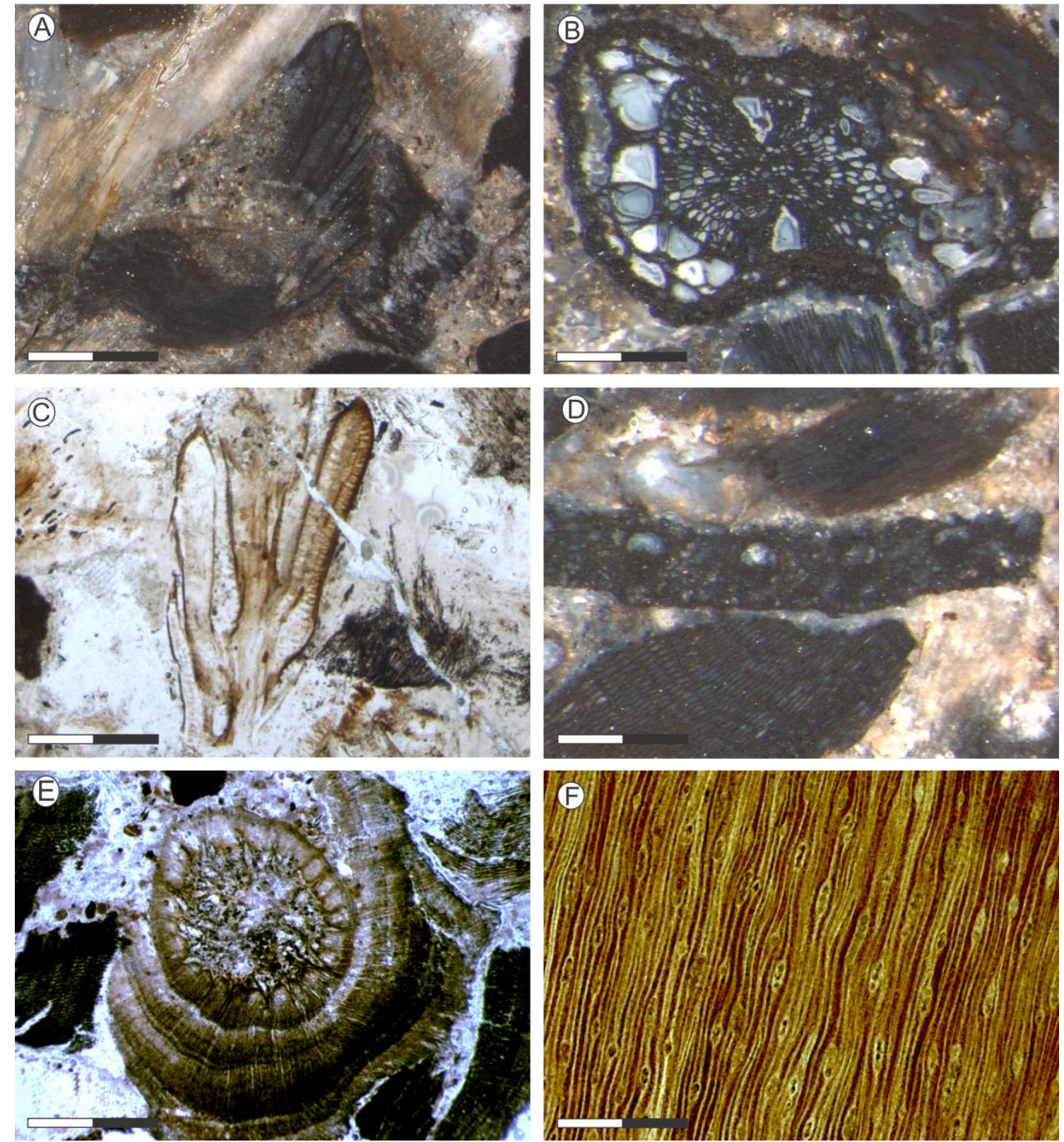

Figura 9.7.Elementos vegetales reconocidos dentro de los lentes de chert. A. Pínnula pteridofítica fragmentaria. B. Raíz diarca en excelente estado de preservación. C. Corte longitudinal de fragmento de rama foliosa de Conífera, con parénquima en empalizada preservado. D. Corte transversal de hoja cicadofítica en la que se observan múltiples trazas vasculares. E. Corte transversal de eje eustélico con médula amplia e incipiente desarrollo de leño. El estado de preservación es regular, preservando sólo parte del cilindro vascular secundario. F. Corte longitudinal tangencial de fragmento de leño picnoxílico con signos de deformación. 


\section{Reconstrucción ecológica de las paleocomunidades}

\section{Introducción}

En este capítulo se realiza una reconstrucción ecológica de las paleocomunidades estudiadas en la localidad Laguna Flecha Negra. A partir de la evaluación integral de los elementos florísticos identificados en el capítulo VII, junto con su distribución espacial horizontal y vertical establecida en el capítulo IX, se evalúa la composición de las paleocomunidades preservadas en el yacimiento. Se analiza el primer bosque in situ para la Formación Chon Aike. El bosque se reconstruye sobre la base de información cuantitativa (distribución de los árboles en el afloramiento, densidad, clases de diámetro y altura, dominancia y estimación de altura). Por último, se compara la diversidad sistemática de la paleoflora observada en esta localidad, con aquella registrada en otros yacimientos Jurásicos de la Argentina, para evaluar las variaciones temporales y espaciales de las comunidades vegetales conocidas.

\section{Las paleocomunidades del Jurásico}

El supercontinente Gondwana llegó a ocupar más del $70 \%$ del área continental de la Tierra en el momento de su máximo desarrollo (Scotese et al., 1999). A lo largo de su historia, se registraron diversos tipos de regiones climáticas: templada, selva tropical ecuatorial húmeda, desiertos subtropicales áridos, bosques templados y capas polares. Se ha propueto que los cambios climáticos experimentados en el supercontinente se deben a dos componentes principales: i) cambios seculares debidos al desplazamiento latitudinal del continente, y ii) cambios climáticos globales debidos a las transiciones entre condiciones de Casa Cálida y Casa fría (Hot House to Ice House) (Scotese et al., 1999).

Entre el Triásico y el Jurásico inferior se produce un recambio florístico que modifica la composición y distribución de la vegetación global. Las Cordaitales, Gigantopteridales y Glossopteridales dejaron de dominar las floras 
Ana Julia Sagasti - Estudio paleobotánico, paleoecológico y paleoambiental...

mundiales, desarrollándose en su lugar, Cycadales, Bennettitales, Gingkoales y Coniferales (Willis y McElwain, 2002). En la Argentina, este recambio florístico se caracteriza por la desaparición de las Peltaspermales y Corystospermales (Iglesias et al., 2011). Es a partir de este momento, que las floras comienzan a tener un componente significativo de la vegetación con formas reconocibles en comunidades vegetales actuales (Willis y McElwain, 2002).

La composición de los ecosistemas terrestres en Gondwana durante el intervalo Jurásico-Cretácico temprano se encuentra pobremente resuelta, y suele considerarse que las floras eran relativamente uniformes (Philippe et al., 2004). Este hecho es extraño si tenemos en cuenta el tamaño del continente Gondwana, que se extendía desde el ecuador hasta el polo sur. La tendencia general durante este intervalo muestra que los continentes que conformaron Gondwana, se desplazaron hacia el norte, tanto desde posiciones subtropicales hacia ecuatoriales (África, Arabia, India y Sudamérica), como desde zonas templadas hacia subtropicales (Australia) (Scotese et al., 1999).

A las variaciones debidas al desplazamiento de las masas continentales, se le suman los cambios en el clima global. Scotese et al. (1999) postulan cuatro cambios entre condiciones de Casa Fría y Casa Cálida durante los 500 millones de años en los que Gondwana y sus fragmentos han existido (Fig.10.1). Las condiciones de Casa Fría se definen como aquellos períodos de la historia geológica en los que ambas regiones polares se encuentran permanentemente cubiertas por hielo. Las variaciones en el tamaño de las capas polares, se producen debido a las oscilaciones en la órbita terrestre (ciclos de Milankovitch) y los cambios en los patrones de circulación oceánica termo-halina (Broecker y van Donk, 1970). La temperatura global promedio en tiempos de Casa Fría, se ubica entre los 12 y $14^{\circ} \mathrm{C}$ (Worsley et al., 1994). En contraposición, los períodos de Casa Cálida no cuentan con cobertura de hielo permanente en los polos, y las estaciones con producción de nieve y hielo son escasas o están ausentes (Scotese et al., 1999). La temperatura global promedio se registra en el rango entre 18 y $22^{\circ} \mathrm{C}$, con extremos que pueden alcanzar los $30^{\circ} \mathrm{C}$ en el ecuador y $14^{\circ} \mathrm{C}$ en los polos (Worsley et al., 1994). 
Ana Julia Sagasti - Estudio paleobotánico, paleoecológico y paleoambiental...

En el intervalo Pérmico Medio Jurásico Medio, se registra un ciclo de Casa Cálida. La extinción masiva acaecida en la transición permotriásica, ocurre en este contexto de Casa Cálida, y se ha sugerido como causa principal un masivo calentamiento global desencadenado por la erupción de las Siberian Traps (Erwin, 1998, 1999; Bowring et al., 1998). Las reconstrucciones paleoclimáticas del Jurásico Medio, señalan la ausencia de cinturones tropicales húmedos (Scotese et al., 1999). Esto se ha atribuído a procesos de circulación atmosférica megamonzónicos (Parrish, 1993).

A partir del Jurásico Medio y hasta el Cretácico inferior, se observa un período de Casa Fría. La apertura de los océanos y la fragmentación del supercontinente Gondwana produjeron cambios en la circulación atmosférica. Sin embargo, esta etapa de Casa Fría no se presenta tan severa como las previas; no se desarrollaron capas de hielo polares ni glaciares continentales, y se postula que gran parte de las masas de hielos fueron estacionales (Scotese et al., 1999).

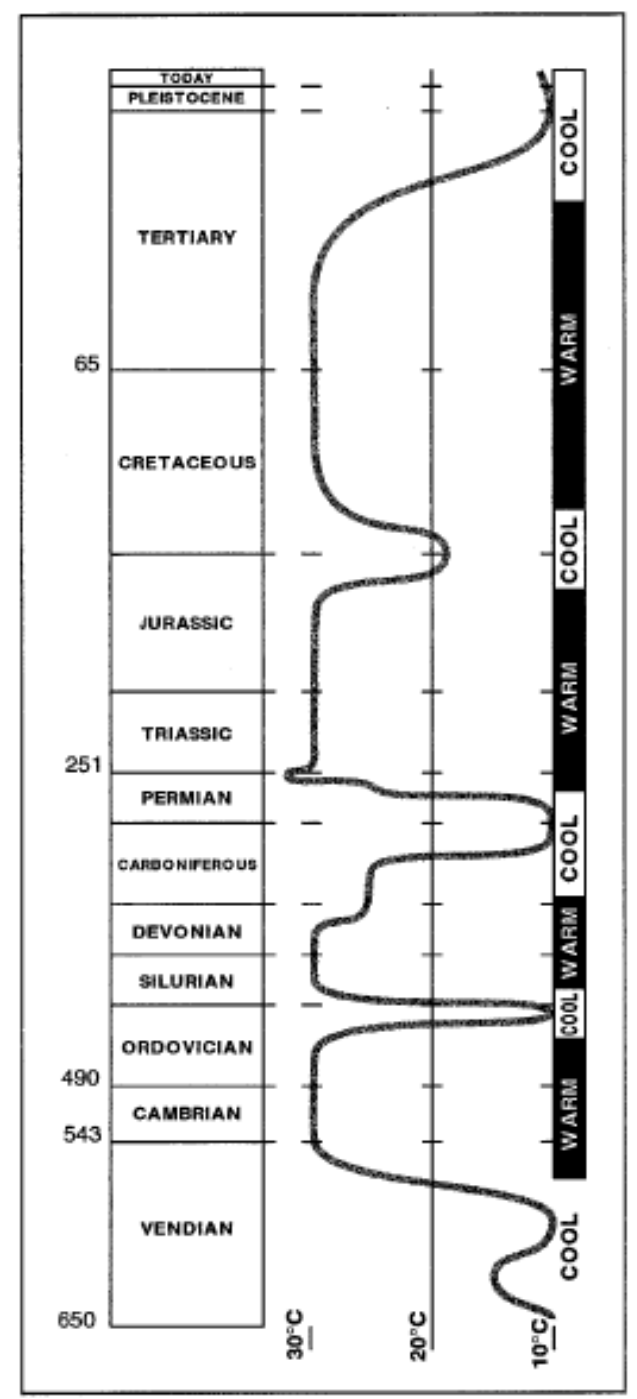

Figura 10.1. Cambios climáticos globales. Tomado de Scotese et al. (1999).

Para comprender la distribución de las asociaciones florísticas, Phillippe et al. (2004) realizaron un análisis biogeográfico de las comunidades arbóreas del Mesozoico Medio, a través del estudio de restos de maderas fosilizadas. 
Estos autores usan como base las cinco zonas climáticas definidas por Rees et al. (2000): verano húmedo, desierto, invierno húmedo, templado cálido y templado frío (Fig. 10.2). Rees et al. (2000) plantean que la mayor productividad y diversidad de las plantas jurásicas se encontraban concentradas en latitudes medias, donde los bosques estaban dominados por comunidades vegetales mixtas compuestas de helechos, cycadofitas, esfenofitas, pteridospermas y coníferas. La vegetación en latitudes bajas presentaba un carácter xeromórfico, con parcelas arboladas integradas por coníferas micrófilas y cycadofitas. En zonas polares se registran coníferas macrófilas y gingkofitas, aparentemente deciduas. La vegetación tropical húmeda se considera altamente restringida y de escaso desarrollo (Rees et al., 2000). El estudio de Philippe et al. (2004) demostró que las maderas coniferofíticas con afinidad a las Araucariaceae eran elementos cosmopolitas, mientras que otros taxones presentaban un mayor grado de provincialismo.

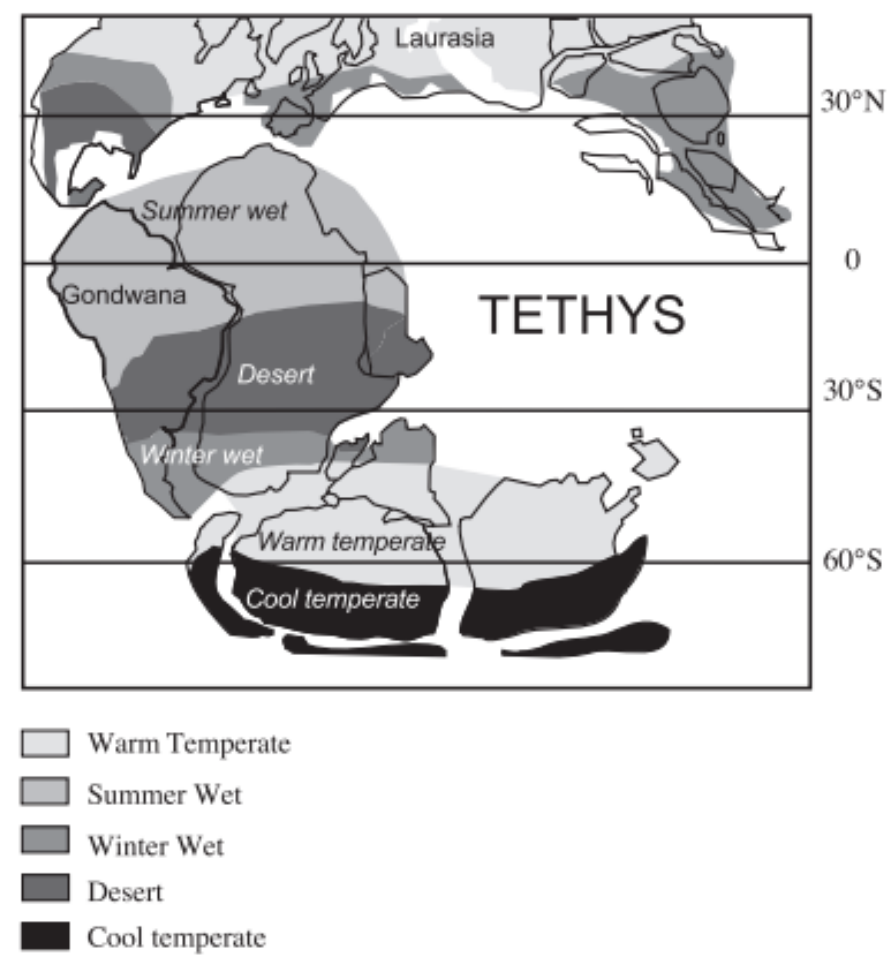

Figura 10.2. Zonas paleoclimáticas definidas para el Jurásico, según Rees et al. (2000). 
Ana Julia Sagasti - Estudio paleobotánico, paleoecológico y paleoambiental...

La mayoría de las localidades del sur de Gondwana corresponden al Bioma Templado Cálido. Las floras de Argentina y la Península Antártica son la excepción, y han sido asignadas al Bioma Subtropical Estacional Seco (Iglesias et al., 2011). La diversidad observada en especies de la familia Dipteridaceae indica un clima Subtropical Seco con estacionalidad para el Jurásico Temprano de la Argentina. Los análisis de asociaciones de leños apoyan esta interpretación (Cantrill, 1995; Rees et al., 2000; Philippe et al., 2004, Iglesias et al., 2011).

Las floras del Jurásico Temprano de la Argentina estaban dominadas por helechos, Cycadoideales y Coniferales, que sumado a la baja biodiversidad, presentaban una uniformidad espacial en los distintos yacimientos de esta época (Iglesias et al., 2011). Quattrocchio et al. (2007) señalan que estas paleocomunidades presentaban una composición florística similar desde la provincia de Mendoza hasta la Península Antártica. Por su parte, Del Fueyo et al. (2007), observan una composición de las paleocomunidades gondwánicas muy similar a aquellas conocidas para el Hemisferio Norte.

A partir del Jurásico Medio (180 Ma), la intensificación en la actividad magmática en Patagonia generó amplias áreas con actividad volcánica, lo que afectó la distribución y características de las comunidades vegetales (Iglesias et al., 2011). Estos cambios ambientales llevaron a que las floras de Patagonia comiencen a divergir de las Laurásicas. Las comunidades boscosas incluyen coníferas de las familias Araucariaceae, Cheirolepidiaceae, Podocarpaceae y algunas Taxodiaceae (Quattrocchio et al., 2007). En áreas abiertas, se desarrollaron comunidades representadas por pequeños árboles y arbustos de Cycadales y Cycadoideales, con pteridospermas como elementos subordinados (Iglesias et al., 2011). La diversidad de los grupos de helechos también declina en este momento, representadas fundamentalmente por Osmundaceae, Gleicheniaceae y Equisetaceae (Del Fueyo et al., 2007). Se ha señalado que la disminución en las especies de Dipteridaceae indicaría estaciones más secas y el prevalecimiento de condiciones de menor humedad que se incrementan luego del Jurásico temprano (Cantrill, 1995). Los análisis de las paleocomunidades desarrolladas en el Jurásico Medio-Superior de Patagonia coinciden en que la familia Araucariaceae habría representado un 
Ana Julia Sagasti - Estudio paleobotánico, paleoecológico y paleoambiental...

componente dominante de las asociaciones, como representante principal de los bosques in situ estudiados en la región (Philippe et al., 2004; Falaschi y Zamuner, 2005; Falaschi, 2009; Iglesias et al., 2011).

\section{Análisis estructural de las paleocomunidades}

El análisis de las paleocomunidades vegetales incluye tres aspectos principales: 1. Composición taxonómica, 2. Estructura horizontal (distribución de los árboles y densidad), y 3. Distribución vertical (clases de alturas).

\section{Composición taxonómica}

La tabla 10.1 muestra el tipo de vegetación, la composición taxonómica y los elementos dominantes y subordinados de cada una de las paleocomunidades definidas.

Los bosques de la Formación Chon Aike están claramente dominados por las Coníferas, particularmente aquellas de la familia Araucariaceae. Como formas subordinadas, se encuentran Cycadoideales, Cheirolepidiaceae, Taxodiaceae y Podocarpaceae.

El estrato arbóreo de los bosques estudiados muestra una gran diversidad del género Agathoxylon, identificándose las especies Agathoxylon cf. floresii, Agathoxylon matildense, Agathoxylon jurassicum y Agathoxylon arayaii. Sin embargo, ninguna de ellas se encontró preservada como tocones en posición de vida en el nivel de tobas blancas. El bosque en posición de vida se encuentra dominado por el género Protaxodioxylon, que en algunas zonas mapeadas se encontró asociado con improntas de ramas estériles de escaso diámetro. Como componente subordinado del bosque in situ se pueden reconocer materiales asignables al género Protocupressinoxylon.

En la paleocomunidad 1, se observa un sesgo preservacional lateral. La zona noroeste de la localidad, que presenta influencia de fluidos hidrotermales y areniscas gruesas porosas, preserva permineralizaciones individuales de Agathoxylon spp., y elementos de afinidad con las Coniferales en los lentes de chert (e.g. ramas foliosas, ejes eustélicos, leños picnoxílicos y homoxilados). 
En la región sudoeste, la paleocomunidad 1 se registra en la tafofacies $\operatorname{Agm}(\mathrm{I})$ representada por improntas de Brachyphyllum sp., Brachyphyllum lotenaense, Pararaucaria patagonica y Araucarites sp. (conos) como representantes del estrato arbóreo, de clara afinidad con las coníferas de las familias Araucariaceae y Cheirolepidiaceae. El sotobosque herbáceo-arbustivo se encuentra representado por frondes de las especies Scleropteris vincei, Sphenopteris cf. nordenskjöldii, Coniopteris hymenophylloides y Korallipteris potrerillensis cuya afinidad es con los helechos y las pteridospermas. La distribución horizontal de los distintos órganos es consistente con los sesgos preservacionales que favorecen el registro de las distintas partes de las plantas. La concentración de restos de leños se da en zonas con sedimentos de mayor porosidad y con influencia de fluidos cargados de minerales, mientras que los órganos laminares y las estructuras reproductivas como improntas, se acumulan en sedimentitas sin influencia geotérmica y de menor porosidad.

La abundancia de restos de Cycadoideaceae preservados como improntas e impresiones-compresiones en la tafofacies AfLe(IC), en contraste con la ausencia de leños afines a este grupo, sugiere un hábito arbustivo para este componente de la vegetación, hábito que se ha señalado para estos componentes en el Triásico de la Argentina (Artabe et al., 2001). Por otro lado, la presencia de la tafofacies $\mathrm{AfLe}(\mathrm{B})$ en esta región del yacimiento se ha interpretado como indicativo de condiciones de exposición subácuea. Esta asociación de tafofacies, y las características de las sedimentitas (particularmente su granulometría fina), es indicativa de ambientes sedimentarios que podrían haber contribuído a la no preservación de restos de leños de esta familia. 


\begin{tabular}{|c|c|c|c|c|}
\hline Tafocenosis & Tafofacies & $\begin{array}{l}\text { Tipo } \\
\text { vegetación }\end{array}$ & Elementos dominantes & Elementos subordinados \\
\hline Paleocomunidad 1 & $\begin{array}{l}\operatorname{Agm}(\mathrm{Rp}) \\
\operatorname{Agm}(\mathrm{Mm}) \\
\operatorname{Agm}(\mathrm{Im}) \\
\operatorname{Agm}(\mathrm{Cm}) \\
\mathrm{Ch} \\
\operatorname{Agm}(\mathrm{Pt}) \\
\operatorname{Agm}(\mathrm{I})\end{array}$ & Arbórea & $\begin{array}{l}\text { Estrato arbóreo dominado por Coníferas: } \\
\text { Agathoxylon cf. floresi, Agathoxylon } \\
\text { jurassicum, Brachyphyllum sp., } \\
\text { Brachyphyllum lotenaense. } \\
\text { Sotobosque herbáceo-arbustivo de } \\
\text { afinidad incierta: Scleropteris vincei. }\end{array}$ & $\begin{array}{l}\text { Agathoxylon matildense, Cupress } \\
\text { Protaxodioxylon, Agathoxylon arayaii, Par } \\
\text { patagonica, Ptilophyllum acutifolium, Arauca } \\
\text { (conos), gleicheniaceae indet. (fragmentos en } \\
\text { ramas foliosas de afinidad incierta. } \\
\text { Sotobosque de helechos/pterido } \\
\text { Sphenopteris cf. nordenskjöldii, Co } \\
\text { hymenophylloides, Korallipteris potrerillensis. }\end{array}$ \\
\hline Paleocomunidad 2 & $\begin{array}{l}\text { AfLe(IC), } \\
\text { AfLe(B) }\end{array}$ & Arbórea-arbustiva & $\begin{array}{l}\text { Estrato arbóreo dominado por Coníferas: } \\
\text { Araucarites phillipsi, Brachyphyllum sp., } \\
\text { Elatocladus confertus, Brachyphyllum } \\
\text { lotenaense, Pagiophyllum cf. crassifolium } \\
\text { Estrato arbustivo de Bennettitales: } \\
\text { Otozamites albosaxatilis, Otozamites } \\
\text { sanctae-crucis, Otozamites sueroi }\end{array}$ & $\begin{array}{l}\text { Elementos subordinados del estrato } \\
\text { Araucarites sp. (conos), Araucarites cu } \\
\text { Ramas foliosas, Elatocladus cf. planus, } \\
\text { Elementos subordinados del estrato arbus } \\
\text { Otozamites bumburyanus var. major } \\
\text { Sotobosque de helechos y pterido } \\
\text { Sphenopteris cf. nordenskjöldii, } \\
\text { reproductiva pinnada indet. A y B, }\end{array}$ \\
\hline Paleocomunidad 3 & $\begin{array}{l}\operatorname{Tm}(\mathrm{Tv}) \\
\operatorname{Tm}(\mathrm{Th}) \\
\operatorname{Tm}(\mathrm{I})\end{array}$ & Arbórea & $\begin{array}{l}\text { Estrato arbóreo dominado por Coníferas } \\
\text { de la familia Cupressaceae (s.l.): } \\
\text { Protaxodioxylon }\end{array}$ & Protocupressinoxylon \\
\hline
\end{tabular}

Tabla 10.1. Tipo de vegetación, nivel en que se registran, taxones dominantes y taxones subordinados de las paleocomunidades. 
Ana Julia Sagasti - Estudio paleobotánico, paleoecológico y paleoambiental...

\section{Estructura horizontal}

Se mapeó la sección superior del nivel de tobas blancas, en el que se identifica un bosque preservado in situ. Este bosque está constituido por árboles en posición de vida y fragmentos caídos con o sin conexión a los tocones, siendo todos ellos autóctonos a para-autóctonos (Fig. 10.3). Se consideraron todos los árboles y tocones muestreados (un total de 185). Los cálculos de densidad se realizaron con el programa de software QGIS (V.2.18.11). Como primer paso, se calculó la densidad mínima, utilizando la función de envolvente convexa, que considera el polígono total que incluye los puntos muestreados y la cantidad de árboles presentes (Fig. 10.4). Luego se obtuvo el valor máximo de densidad considerando el polígono mínimo que incluye todos los árboles muestreados (Fig. 10.5). La densidad promedio se calculó utilizando los dos valores. La tabla 10.2 resume los datos obtenidos. 

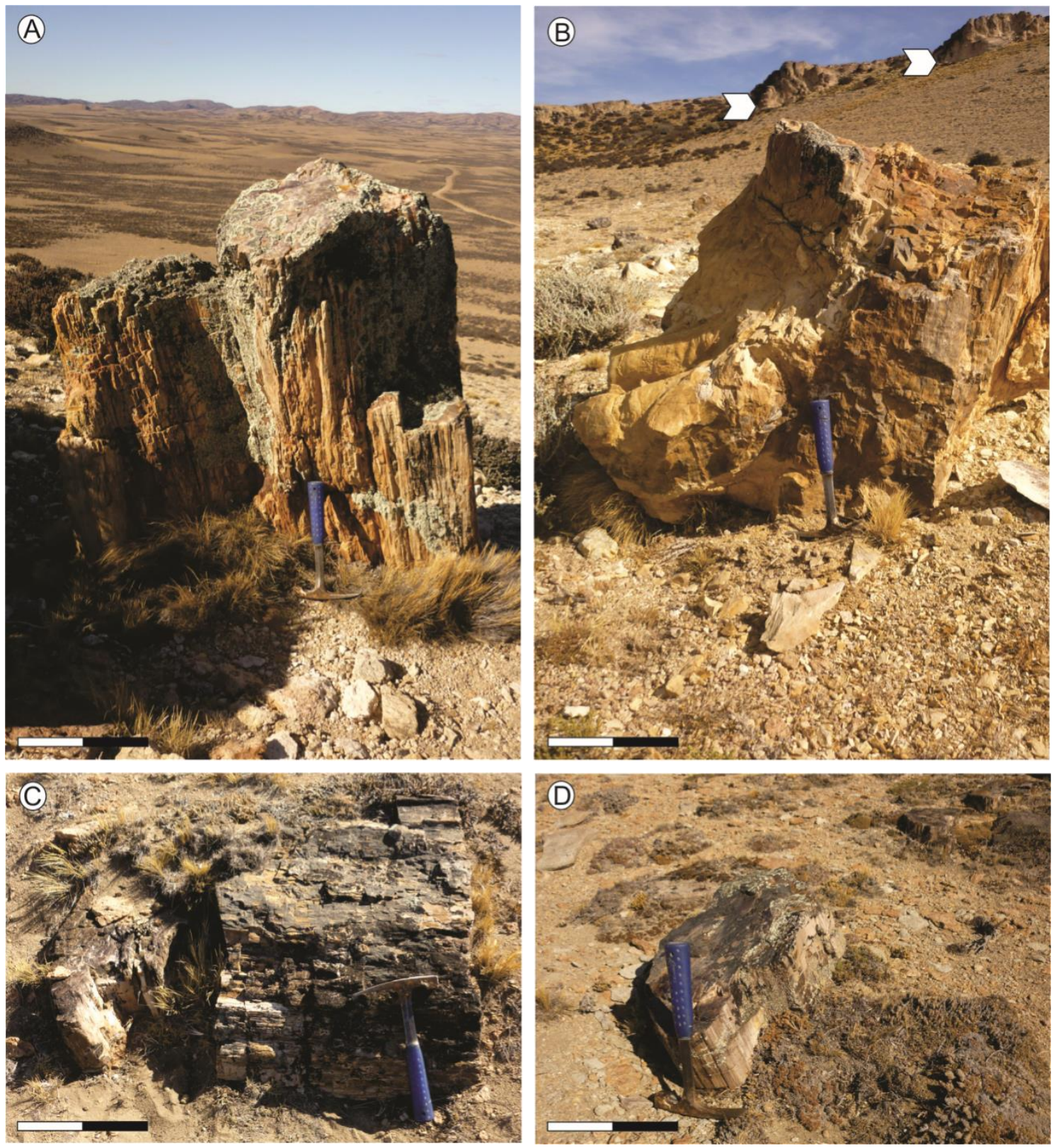

Figura. 10.3. Tocones y troncos del bosque Laguna Flecha Negra. A. Tronco 029. Escala: $40 \mathrm{~cm}$. B. Tronco 023. Escala: $50 \mathrm{~cm}$. Las flechas blancas señalan el contacto de la Ignimbrita Flecha Negra con el nivel de tobas blancas. C. Tronco 003. Base en posición de vida y fragmento del tronco caído. Escala: 30 cm. D. Tronco 053. Escala: $30 \mathrm{~cm}$. 
Ana Julia Sagasti - Estudio paleobotánico, paleoecológico y paleoambiental...

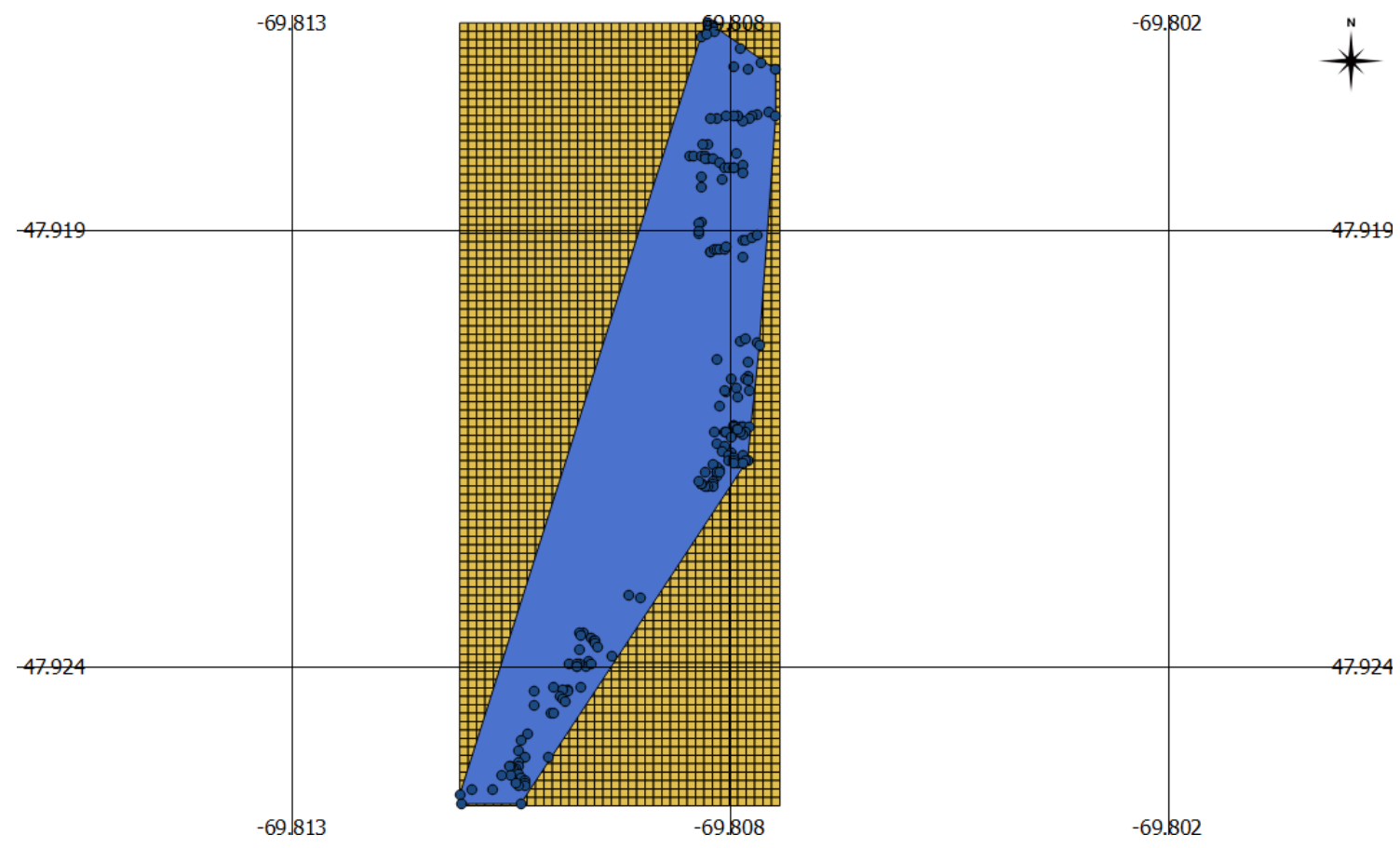

Figura 10.3. Mapeo del bosque in situ con poligonal convexa. El área incluída en la poligonal es de $170000 \mathrm{~m}^{2}$.

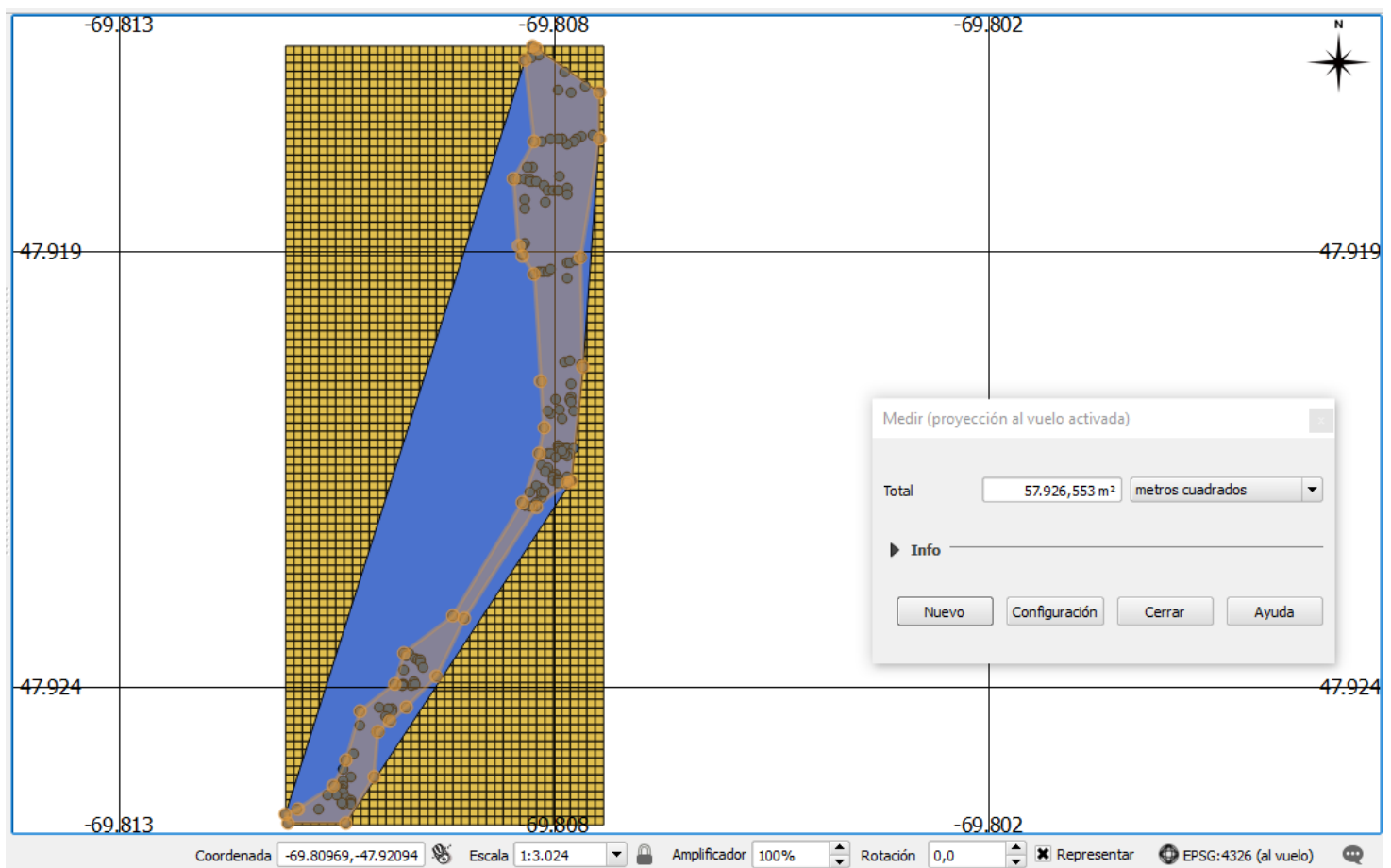

Figura 10.4. Mapeo del bosque in situ con polígono mínimo. El área incluída es de $57926 \mathrm{~m}^{2}$. 
Ana Julia Sagasti - Estudio paleobotánico, paleoecológico y paleoambiental...

\begin{tabular}{|l|l|}
\hline Parámetros & Bosque in situ \\
\hline Tamaño de la muestra & 185 \\
\hline Área de la poligonal convexa & $170000 \mathrm{~m}^{2}$ \\
\hline Densidad mínima & 10,88 árboles/ha \\
\hline Área del polígono mínimo & $57926 \mathrm{~m}^{2}$ \\
\hline Densidad máxima & 31,94 árboles/ha \\
\hline Densidad promedio & 21,41 árboles/ha \\
\hline
\end{tabular}

Tabla 10.2. Análisis de densidad por poligonal convexa y polígonos mínimos del bosque estudiado en la Formación Chon Aike.

El término "bosque" significa "sitio poblado de árboles" (Fossa-Mancini, 1941). Debido a esto, podemos llamar "bosque fósil" sólo a un conjunto, relativamente numeroso, de restos, improntas o vestigios de árboles que, por su posición y por sus relaciones con los estratos que los contienen, denotan claramente que han quedado en el lugar donde, en tiempos remotos, nacieron y crecieron (Fossa-Mancini, 1941). La prueba segura de la existencia de un bosque fósil la hallamos en los restos, o vestigios, de raíces implantadas en gran número en estratos que representan los suelos que estaban poblados por árboles, millones de años atrás (Fossa-Mancini, op cit). Es notable la asociación frecuente de bosques silicificados con acumulaciones de cenizas volcánicas, generalmente transformadas en tobas de consistencia regular (Fossa-Mancini, 1941).

El bosque estudiado en la localidad Laguna Flecha Negra, aflora en la sección superior del nivel de tobas blancas, el cual se encuentra cubierto por la ignimbrita Flecha Negra, en relación de discordancia. El análisis de polígonos mínimos señala la densidad máxima observada en campo. El análisis de la poligonal convexa realizado toma como área muestreada secciones que en el campo se encuentran cubiertas por la mencionada ignimbrita. Esto resulta en un área total significativamente mayor a la que ocupan los árboles en el yacimiento. Según los límites que establece la poligonal convexa, el área que podría haber ocupado el bosque es hasta tres veces mayor que la observada, 
Ana Julia Sagasti - Estudio paleobotánico, paleoecológico y paleoambiental...

existiendo la posibilidad de que parte de la paleocomunidad se encuentre cubierta por los depósitos piroclásticos de flujo.

\section{Distribución vertical}

Se calcularon las alturas crítica $\left(\mathrm{H}_{\text {crit }}\right)$ y estimada $\left(\mathrm{H}_{\mathrm{est}}\right)$ de los ejemplares, mediante las fórmulas propuestas por Niklas (1993, 1994a, b): $H_{\text {crit }}=97,78 x D^{0.689} ; \log _{10}$ Hest= $1.59+0,39\left(\log _{10} D\right)-0,18\left(\log _{10} D\right)^{2} a$ este resultado se le aplicó un exponencial de 10 para expresar el resultado de la altura estimada en metros. D es el diámetro en metros para cada ejemplar. La tabla 11.3 detalla los cálculos de altura crítica y estimada para cada árbol muestreado. En la tabla 11.4 se resumen los parámetros analizados.

Tabla 10.3. Diámetros, altura estimada y altura crítica de los árboles del bosque de la localidad Laguna Flecha Negra.

\begin{tabular}{|c|c|c|c|}
\hline Tronco & Diámetro (m) & Altura estimada & Altura crítica \\
\hline 1 & 0,7 & 33,52 & 76,41 \\
\hline 2 & 0,62 & 31,72 & 70,28 \\
\hline 3 & 0,7 & 33,52 & 76,41 \\
\hline 4 & 0,75 & 34,55 & 80,13 \\
\hline 5 & 0,55 & 29,96 & 64,71 \\
\hline 6 & ? & - & - \\
\hline 7 & 0,48 & 28,02 & 58,92 \\
\hline 8 & 0,75 & 34,55 & 80,13 \\
\hline 9 & 0,66 & 32,64 & 73,38 \\
\hline 10 & 0,4 & 25,49 & 51,97 \\
\hline 11 & 0,5 & 28,59 & 60,60 \\
\hline 12 & 0,2 & 16,96 & 32,23 \\
\hline 13 & 0,43 & 26,48 & 54,62 \\
\hline 14 & 0,43 & 26,48 & 54,62 \\
\hline 15 & 0,45 & 27,11 & 56,36 \\
\hline 16 & 0,6 & 31,23 & 68,71 \\
\hline 17 & 0,5 & 28,59 & 60,60 \\
\hline 18 & 0,7 & 33,52 & 76,41 \\
\hline 19 & 0,64 & 32,18 & 71,84 \\
\hline 20 & ? & - & - \\
\hline 21 & 0,46 & 27,42 & 57,22 \\
\hline 22 & 0,66 & 32,64 & 73,38 \\
\hline 23 & 1,12 & 40,62 & 105,63 \\
\hline 24 & 0,5 & 28,59 & 60,60 \\
\hline
\end{tabular}


Ana Julia Sagasti - Estudio paleobotánico, paleoecológico y paleoambiental...

\begin{tabular}{|c|c|c|c|}
\hline 25 & 0,85 & 36,44 & 87,35 \\
\hline 26 & 1,2 & 41,66 & 110,78 \\
\hline 27 & 1,4 & 43,97 & 123,19 \\
\hline 28 & 0,85 & 36,44 & 87,35 \\
\hline 29 & 1,5 & 44,99 & 129,19 \\
\hline 30 & 1,5 & 44,99 & 129,19 \\
\hline 31 & 1,2 & 41,66 & 110,78 \\
\hline 32 & 1,07 & 39,93 & 102,36 \\
\hline 33 & 1,6 & 45,93 & 135,06 \\
\hline 34 & 1,55 & 45,47 & 132,14 \\
\hline 35 & 1,3 & 42,86 & 117,06 \\
\hline 36 & 1,2 & 41,66 & 110,78 \\
\hline 37 & 0,95 & 38,13 & 94,31 \\
\hline 38 & 0,96 & 38,29 & 94,99 \\
\hline 39 & 0,76 & 34,75 & 80,87 \\
\hline 40 & 1,2 & 41,66 & 110,78 \\
\hline 41 & 0,75 & 34,55 & 80,13 \\
\hline 42 & 0,7 & 33,52 & 76,41 \\
\hline $42^{\prime}$ & 0,55 & 29,96 & 64,71 \\
\hline 43 & 0,47 & 27,72 & 58,07 \\
\hline 44 & 0,9 & 37,31 & 90,86 \\
\hline 45 & 0,5 & 28,59 & 60,60 \\
\hline 46 & 0,45 & 27,11 & 56,36 \\
\hline 47 & 0,7 & 33,52 & 76,41 \\
\hline 48 & 0,5 & 28,59 & 60,60 \\
\hline 49 & 0,7 & 33,52 & 76,41 \\
\hline 50 & 0,6 & 31,23 & 68,71 \\
\hline 51 & 0,6 & 31,23 & 68,71 \\
\hline 52 & 0,4 & 25,49 & 51,97 \\
\hline 53 & 0,48 & 28,02 & 58,92 \\
\hline 54 & 0,44 & 26,80 & 55,49 \\
\hline 55 & 0,4 & 25,49 & 51,97 \\
\hline 56 & 0,8 & 35,52 & 83,78 \\
\hline 57 & 0,4 & 25,49 & 51,97 \\
\hline 58 & 0,3 & 21,72 & 42,62 \\
\hline 59 & 0,45 & 27,11 & 56,36 \\
\hline 60 & 0,7 & 33,52 & 76,41 \\
\hline 61 & 0,38 & 24,79 & 50,16 \\
\hline 62 & 0,47 & 27,72 & 58,07 \\
\hline 63 & 0,76 & 34,75 & 80,87 \\
\hline 64 & 0,4 & 25,49 & 51,97 \\
\hline 65 & 0,25 & 19,50 & 37,59 \\
\hline 66 & 0,7 & 33,52 & 76,41 \\
\hline 67 & 0,3 & 21,72 & 42,62 \\
\hline 68 & 0,4 & 25,49 & 51,97 \\
\hline 69 & 0,3 & 21,72 & 42,62 \\
\hline 70 & 0,3 & 21,72 & 42,62 \\
\hline 71 & 0,32 & 22,54 & 44,56 \\
\hline 72 & 0,25 & 19,50 & 37,59 \\
\hline 73 & 0,55 & 29,96 & 64,71 \\
\hline
\end{tabular}


Ana Julia Sagasti - Estudio paleobotánico, paleoecológico y paleoambiental...

\begin{tabular}{|c|c|c|c|}
\hline 74 & 0,45 & 27,11 & 56,36 \\
\hline 75 & 0,3 & 21,72 & 42,62 \\
\hline 76 & 0,27 & 20,42 & 39,64 \\
\hline 77 & 0,55 & 29,96 & 64,71 \\
\hline 78 & 0,3 & 21,72 & 42,62 \\
\hline 79 & 0,56 & 30,23 & 65,52 \\
\hline 80 & 0,3 & 21,72 & 42,62 \\
\hline 81 & 0,55 & 29,96 & 64,71 \\
\hline 82 & 0,36 & 24,07 & 48,33 \\
\hline 83 & 0,53 & 29,43 & 63,08 \\
\hline 84 & 0,68 & 33,08 & 74,90 \\
\hline 85 & 0,85 & 36,44 & 87,35 \\
\hline 86 & 0,85 & 36,44 & 87,35 \\
\hline 87 & 0,5 & 28,59 & 60,60 \\
\hline 88 & 0,43 & 26,48 & 54,62 \\
\hline 89 & 0,47 & 27,72 & 58,07 \\
\hline 90 & 0,7 & 33,52 & 76,41 \\
\hline 91 & 0,65 & 32,41 & 72,61 \\
\hline 92 & 0,45 & 27,11 & 56,36 \\
\hline 93 & 0,4 & 25,49 & 51,97 \\
\hline 94 & 0,32 & 22,54 & 44,56 \\
\hline 95 & 0,37 & 24,44 & 49,25 \\
\hline 96 & 0,6 & 31,23 & 68,71 \\
\hline 97 & 0,3 & 21,72 & 42,62 \\
\hline 98 & 0,28 & 20,86 & 40,64 \\
\hline 99 & 0,3 & 21,72 & 42,62 \\
\hline 100 & 0,2 & 16,96 & 32,23 \\
\hline 101 & 0,31 & 22,13 & 43,60 \\
\hline 102 & 0,4 & 25,49 & 51,97 \\
\hline 103 & 0,6 & 31,23 & 68,71 \\
\hline 104 & 0,73 & 34,15 & 78,65 \\
\hline 105 & 0,43 & 26,48 & 54,62 \\
\hline 106 & 0,47 & 27,72 & 58,07 \\
\hline 107 & 0,44 & 26,80 & 55,49 \\
\hline 108 & 0,54 & 29,70 & 63,90 \\
\hline 109 & 0,42 & 26,15 & 53,74 \\
\hline 110 & 0,57 & 30,48 & 66,33 \\
\hline 111 & 0,77 & 34,95 & 81,60 \\
\hline 112 & 0,38 & 24,79 & 50,16 \\
\hline 113 & 0,77 & 34,95 & 81,60 \\
\hline 114 & 0,72 & 33,94 & 77,91 \\
\hline 115 & 0,4 & 25,49 & 51,97 \\
\hline 116 & 0,49 & 28,31 & 59,76 \\
\hline 117 & 0,28 & 20,86 & 40,64 \\
\hline 118 & 0,62 & 31,72 & 70,28 \\
\hline 119 & 0,29 & 21,30 & 41,64 \\
\hline 120 & 0,45 & 27,11 & 56,36 \\
\hline 121 & 0,5 & 28,59 & 60,60 \\
\hline 122 & 0,36 & 24,07 & 48,33 \\
\hline 123 & 0,7 & 33,52 & 76,41 \\
\hline
\end{tabular}


Ana Julia Sagasti - Estudio paleobotánico, paleoecológico y paleoambiental...

\begin{tabular}{|c|c|c|c|}
\hline 124 & 0,58 & 30,74 & 67,13 \\
\hline 125 & 0,38 & 24,79 & 50,16 \\
\hline 126 & 0,3 & 21,72 & 42,62 \\
\hline 127 & 0,9 & 37,31 & 90,86 \\
\hline 128 & 0,6 & 31,23 & 68,71 \\
\hline 129 & 0,55 & 29,96 & 64,71 \\
\hline 130 & 0,38 & 24,79 & 50,16 \\
\hline 131 & 0,24 & 19,02 & 36,55 \\
\hline 132 & 0,4 & 25,49 & 51,97 \\
\hline 133 & 0,6 & 31,23 & 68,71 \\
\hline 134 & 0,36 & 24,07 & 48,33 \\
\hline 135 & 0,58 & 30,74 & 67,13 \\
\hline 136 & 0,35 & 23,70 & 47,40 \\
\hline 137 & 0,35 & 23,70 & 47,40 \\
\hline 138 & 0,7 & 33,52 & 76,41 \\
\hline 139 & 0,45 & 27,11 & 56,36 \\
\hline 140 & 0,8 & 35,52 & 83,78 \\
\hline 141 & 0,71 & 33,73 & 77,16 \\
\hline 142 & 0,55 & 29,96 & 64,71 \\
\hline 143 & 0,52 & 29,16 & 62,26 \\
\hline 144 & 1 & 38,90 & 97,70 \\
\hline 145 & 0,4 & 25,49 & 51,97 \\
\hline 146 & 0,43 & 26,48 & 54,62 \\
\hline 147 & 0,4 & 25,49 & 51,97 \\
\hline 148 & 0,83 & 36,08 & 85,93 \\
\hline 149 & 0,56 & 30,23 & 65,52 \\
\hline 150 & 0,6 & 31,23 & 68,71 \\
\hline 151 & 0,45 & 27,11 & 56,36 \\
\hline 152 & 1,2 & 41,66 & 110,78 \\
\hline 153 & 0,4 & 25,49 & 51,97 \\
\hline 154 & 0,45 & 27,11 & 56,36 \\
\hline 155 & 0,51 & 28,88 & 61,43 \\
\hline 156 & 0,5 & 28,59 & 60,60 \\
\hline 157 & 0,4 & 25,49 & 51,97 \\
\hline 158 & 0,9 & 37,31 & 90,86 \\
\hline 159 & 0,4 & 25,49 & 51,97 \\
\hline 160 & 0,65 & 32,41 & 72,61 \\
\hline 161 & 0,6 & 31,23 & 68,71 \\
\hline 162 & 0,68 & 33,08 & 74,90 \\
\hline 163 & 0,31 & 22,13 & 43,60 \\
\hline 164 & 0,6 & 31,23 & 68,71 \\
\hline 165 & 0,85 & 36,44 & 87,35 \\
\hline 166 & 0,3 & 21,72 & 42,62 \\
\hline 167 & 0,4 & 25,49 & 51,97 \\
\hline 168 & 0,48 & 28,02 & 58,92 \\
\hline 169 & 0,43 & 26,48 & 54,62 \\
\hline 170 & 0,42 & 26,15 & 53,74 \\
\hline 171 & 0,9 & 37,31 & 90,86 \\
\hline 172 & 0,8 & 35,52 & 83,78 \\
\hline 173 & 1,57 & 45,66 & 133,31 \\
\hline
\end{tabular}


Ana Julia Sagasti - Estudio paleobotánico, paleoecológico y paleoambiental...

\begin{tabular}{|r|r|r|r|}
\hline 174 & 0,64 & 32,18 & 71,84 \\
\hline 175 & 0,5 & 28,59 & 60,60 \\
\hline 176 & 0,4 & 25,49 & 51,97 \\
\hline 177 & 0,38 & 24,79 & 50,16 \\
\hline 178 & 0,26 & 19,96 & 38,62 \\
\hline 179 & 0,26 & 19,96 & 38,62 \\
\hline 180 & 0,63 & 31,95 & 71,06 \\
\hline 181 & 2,16 & 50,15 & 166,09 \\
\hline 182 & 0,65 & 32,41 & 72,61 \\
\hline 183 & 1,45 & 44,49 & 126,21 \\
\hline 184 & 1,7 & 46,81 & 140,82 \\
\hline
\end{tabular}

\begin{tabular}{|l|c|}
\hline Parámetros & Bosque in situ \\
\hline Diámetro mínimo & $0,2 \mathrm{~m}$ \\
\hline Diámetro máximo & 2,16 \\
\hline Diámetro promedio & $\mathbf{0 , 6 1} \mathbf{~ m}$ \\
\hline Altura crítica mínima & $32,23 \mathrm{~m}$ \\
\hline Altura crítica máxima & $166,09 \mathrm{~m}$ \\
\hline Altura crítica promedio & $\mathbf{7 5 , 7 3} \mathbf{~}$ \\
\hline Altura estimada mínima & $16,96 \mathrm{~m}$ \\
\hline Altura estimada máxima & $50,15 \mathrm{~m}$ \\
\hline Altura estimada promedio & $\mathbf{3 0 , 1 2} \mathbf{~ m}$ \\
\hline
\end{tabular}

Tabla 10.4. Resumen de los valores de diámetro, altura crítica y estimada.

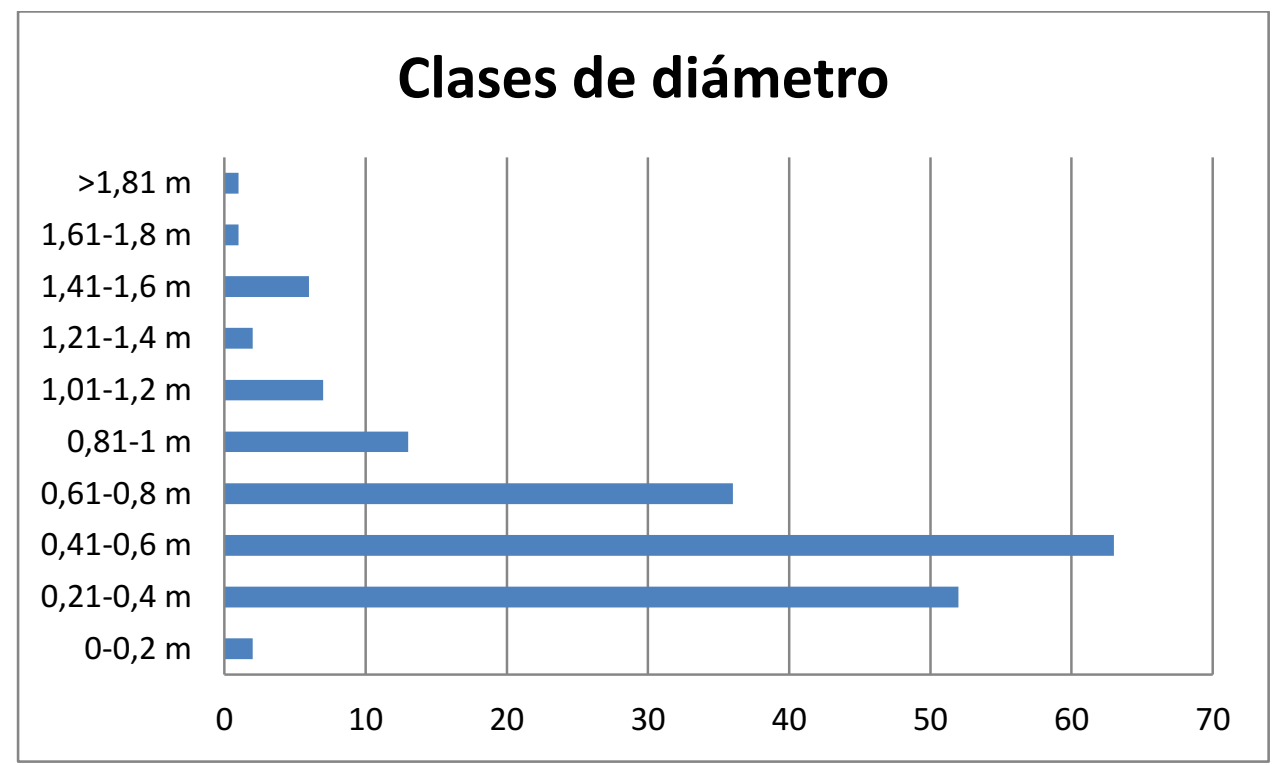


Figura 10.5. Pirámide poblacional por clases de altura (intervalo 0,2 m).

La pirámide poblacional para tipos de diámetros muestra una distribución de los individuos de la paleopoblación, de carácter mixto. La mayor abundancia de clases de diámetro, se observa entre los 0,2 y 0,6 metros. Sólo el 1,09\% de los ejemplares, presentan diámetros menores a $0,2 \mathrm{~m}$; el $28,41 \%$ entre 2,21 y $0,4 \mathrm{~m}$; el $34,43 \%$ entre 0,41 y $0,6 \mathrm{~m}$; el $19,67 \%$ entre 0,81 y $1 \mathrm{~m}$, y el restante $16,4 \%$ presenta diámetros mayores a $1 \mathrm{~m}$, alcanzando un máximo de 2,16 m. Se puede observar una abundancia de especímenes viejos (mayores a 0,4 m), y una menor representatividad de árboles jóvenes (menores a 0,4 $\mathrm{m}$ ), que representan apenas el $29,5 \%$ de la paleopoblación.

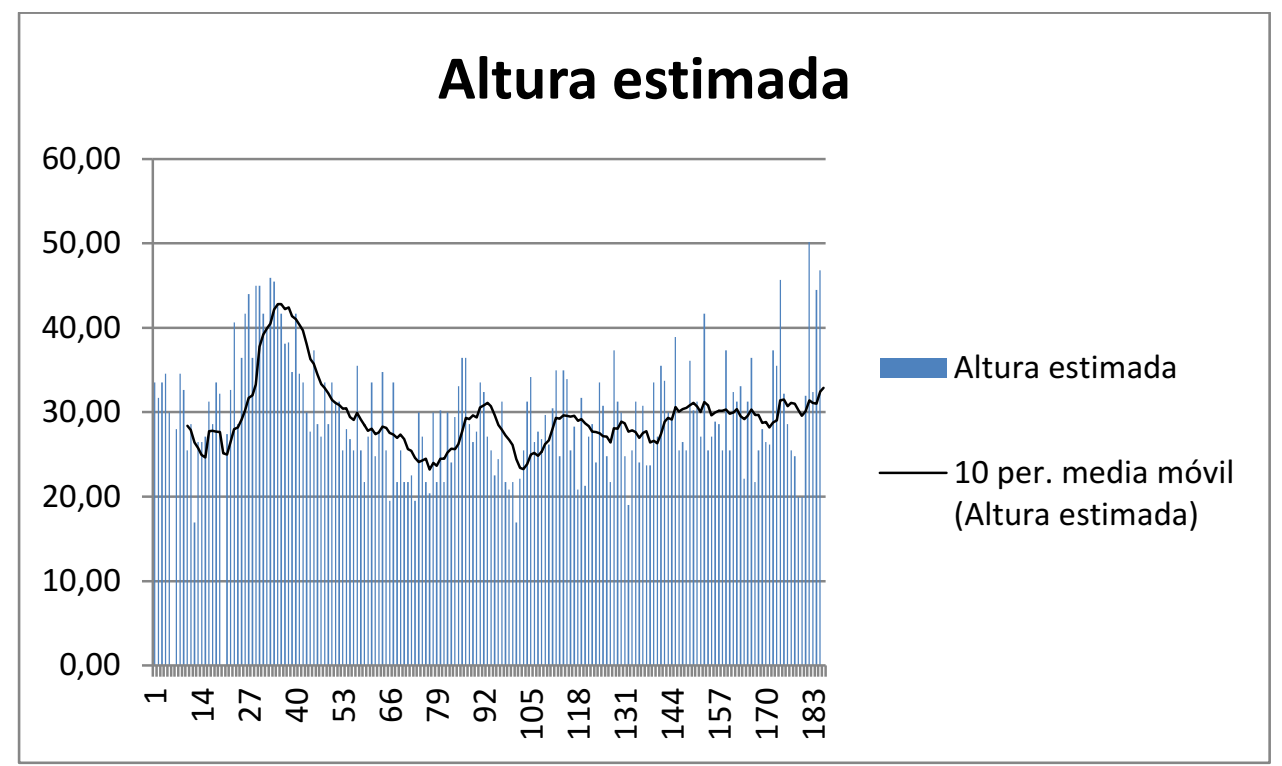

Figura 10.6. Gráfico detallado de alturas estimadas para los árboles de la localidad Laguna Flecha Negra. 
Ana Julia Sagasti - Estudio paleobotánico, paleoecológico y paleoambiental...

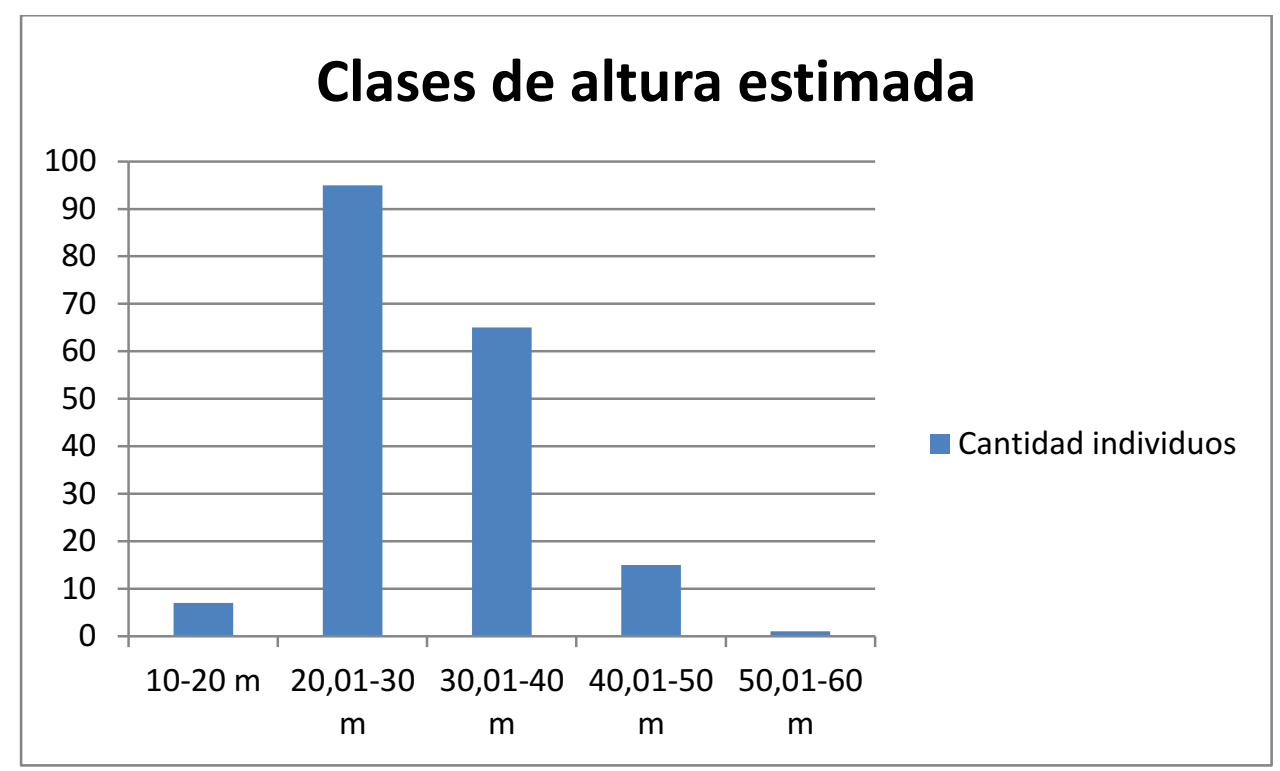

Figura 10.7. Clases de altura (estimada) para los árboles del bosque de Laguna Flecha Negra. Intervalo: $10 \mathrm{~m}$.

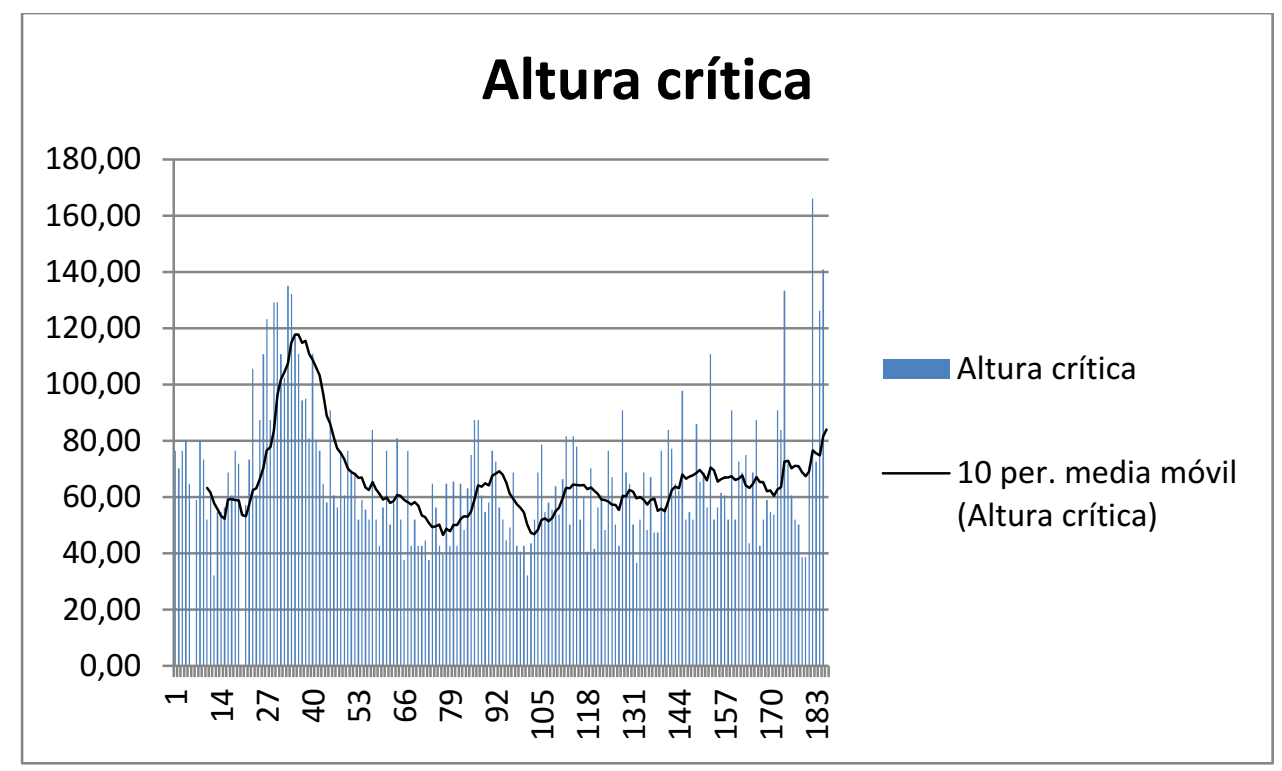

Figura 10.8. Gráfico detallado de las alturas críticas calculadas para los árboles de Laguna Flecha Negra. 


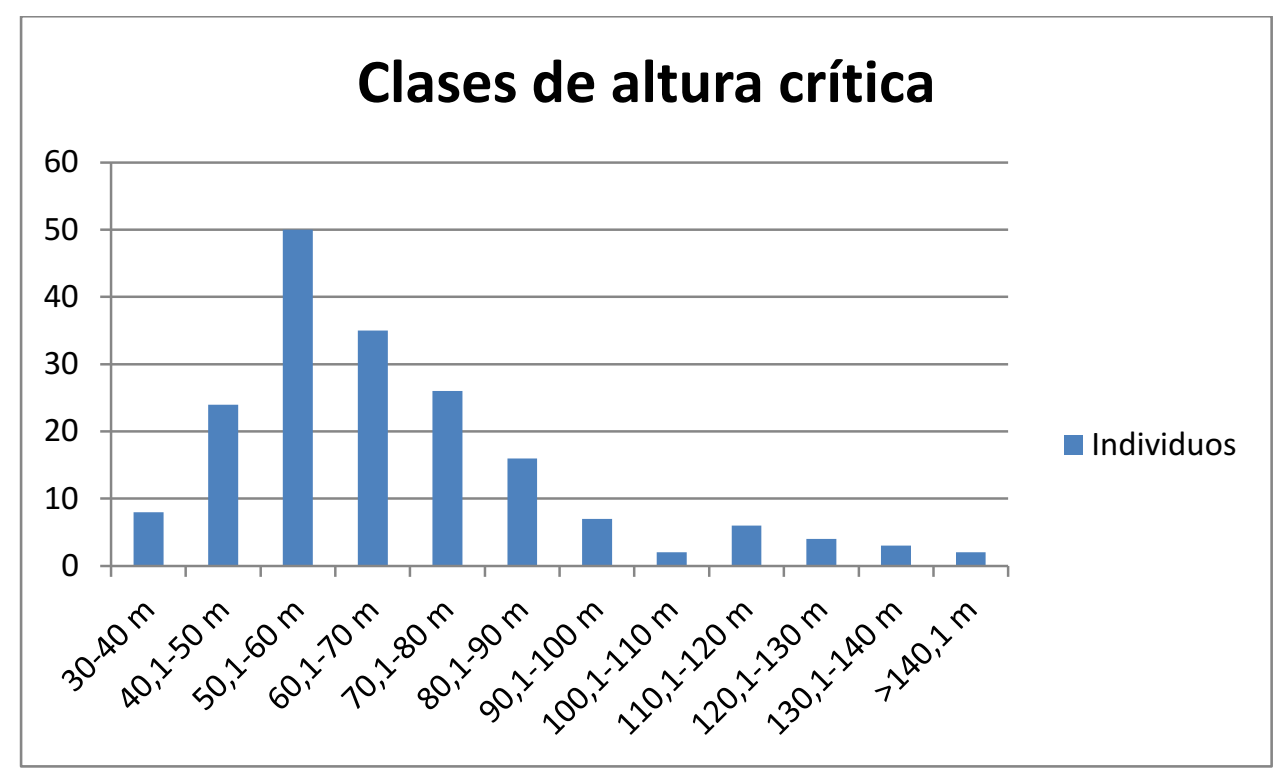

Figura 10.9. Clases de altura (crítica) para los árboles de Laguna Flecha Negra. Intervalo: $10 \mathrm{~m}$.

La altura a la cual habrían crecido las plantas fósiles, tiene importancia evolutiva ya que se correlaciona con el potencial de dispersión a larga distancia de las diásporas, la capacidad de generar sombra sobre otras plantas y con la estratificación ecológica de las comunidades del pasado (Niklas 1994a). Conocer la altura a la cual crecían las especies fósiles nos aporta una medida indirecta de la habilidad para colonizar nuevos sitios, competir con otras plantas por espacio y luz, y una medida indirecta de los microhabitats disponibles para otras plantas y animales (Taylor y Taylor, 1993; Niklas 1994a).

Los histogramas de alturas estimadas, muestran curvas normales con picos entre 20 y 40 metros, y colas en valores menores y mayores. El $52 \%$ de los individuos, presentan alturas entre los 20 y $30 \mathrm{~m}$, el $35,5 \%$ entre 30 y $40 \mathrm{~m}$, sólo el 3,8\% presenta alturas menores a $20 \mathrm{~m}$, y el $8,7 \%$, entre 40 y $60 \mathrm{~m}$.

Los histogramas de alturas críticas, también muestran una distribución normal con dos colas, en la que el pico de diámetros se ubica entre los 50 y 90 metros. Este tipo de análisis fue elaborado por Niklas et al. (1993) para predecir la altura máxima a la que se produce el colapso de los tejidos que sostienen un árbol. Por definición, este valor nunca es alcanzado, pero nos permite evaluar el desarrollo teórico que podría alcanzar un individuo en condiciones óptimas de crecimiento y sin factores externos que lo afecten, por fuera de la fuerza gravitatoria. 


\section{Diversidad de las asociaciones florísticas del Jurásico en Argentina.}

Se evaluaron los cambios en la diversidad de las paleofloras de los yacimientos Jurásicos y sus variaciones en las distintas épocas. La figura 10.10 resume los resultados de este análisis.

En la provincia del Neuquén, la mayor diversidad de especies se registra en yacimientos asignables al Jurásico Inferior. Esta región geográfica presenta la mayor diversidad de especies para esta época, seguida por la Provincia de Chubut que presenta una diversidad levemente inferior pero de riqueza comparable. Las paleocomunidades del Neuquén comienzan a declinar hacia el Jurásico Medio, y no se hayan restos en el Jurásico Superior. En Chubut, la riqueza de especies alcanza su pico durante el Jurásico Inferior y declina progresivamente a lo largo de todo el período, alcanzando su mínima diversidad en el Jurásico Superior. Las provincias de San Juan y Mendoza, registran floras poco diversas, todas asignables al Jurásico Inferior. En contraposición, la provincia de Santa Cruz, presenta registros poco diversos en el Jurásico Inferior, seguido de un aumento progresivo en la riqueza de especies a lo largo de todo el Jurásico, alcanzando su máxima diversidad hacia el final de este período.

En este recambio florístico, se produce el incremento progresivo en especies de Coníferas y Cycadoideales (hojas, ramas foliosas y estructuras reproductivas); los helechos, Cycas y Pteridospermas constituyen elementos subordinados de las paleocomunidades de la Argentina. 
Ana Julia Sagasti - Estudio paleobotánico, paleoecológico y paleoambiental...

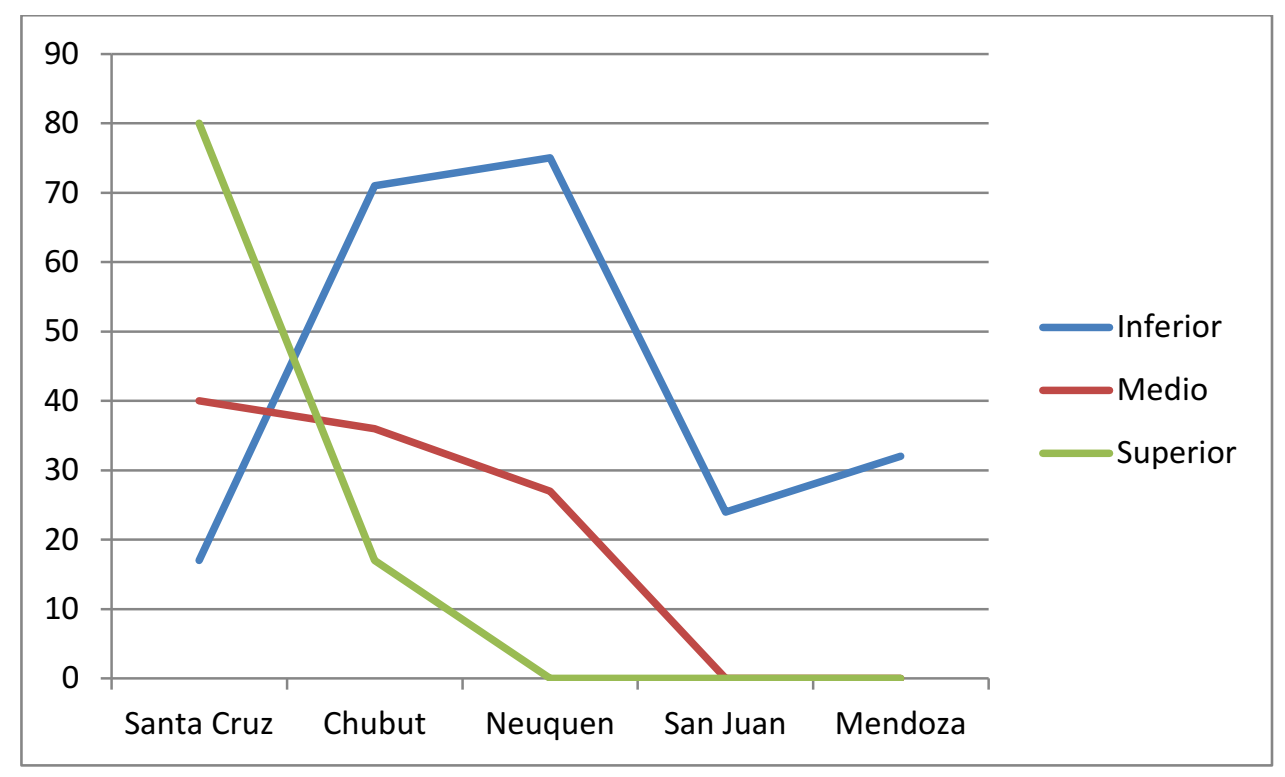

Figura 10.10. Curvas de diversidad de especies Jurásicas en yacimientos de las provincias de Santa Cruz, Chubut, Neuquén, San Juan y Mendoza.

\begin{tabular}{|l|l|l|l|l|l|}
\hline Especies & Mendoza & $\begin{array}{l}\text { San } \\
\text { Juan }\end{array}$ & Neuquen & Chubut & \begin{tabular}{l} 
Cruzta \\
\hline Todites_williamsoni
\end{tabular} \\
\hline Archangelskya_furcata & 0 & 0 & 0 & 0 & 1 \\
\hline Cladophlebis_denticulada & 0 & 0 & 0 & 1 & 0 \\
\hline Cladophlebis_cf._antárctica & 0 & 0 & 0 & 1 & 0 \\
\hline Cladophlebis_patagónica & 0 & 0 & 0 & 1 & 1 \\
\hline Cladophlebis_sp. & 0 & 0 & 0 & 0 & 1 \\
\hline Millerocaulis_zamunerae & 0 & 0 & 0 & 0 & 1 \\
\hline Gleichenites_juliensis & 0 & 0 & 0 & 0 & 1 \\
\hline Gleichenites_taquetrensis & 0 & 0 & 0 & 0 & 1 \\
\hline Clathropteris_obovata & 0 & 0 & 0 & 1 & 0 \\
\hline Sagenopteris_rhoifolia & 0 & 0 & 0 & 1 & 0 \\
\hline Ticoa_magallánica & 0 & 0 & 0 & 1 & 0 \\
\hline Otozamites_sanctae-crucis & 0 & 0 & 0 & 0 & 1 \\
\hline Cycadites_sp & 0 & 0 & 0 & 0 & 1 \\
\hline Pseudoctenis_eathiensis & 0 & 0 & 0 & 0 & 1 \\
\hline Dictyozamites_cazaubonii & 0 & 0 & 0 & 0 & 1 \\
\hline Dictyozamites_crassinervis & 0 & 0 & 0 & 0 & 1 \\
\hline Dictyozamites_falcatus & 0 & 0 & 0 & 0 & 1 \\
\hline Dictyozamites_inmamurae & 0 & 0 & 0 & 1 \\
\hline
\end{tabular}


Ana Julia Sagasti - Estudio paleobotánico, paleoecológico y paleoambiental...

\begin{tabular}{|c|c|c|c|c|c|}
\hline Dictyozamites_ishikawaensis & 0 & 0 & 0 & 0 & 1 \\
\hline Dictyozamites_latifolium & 0 & 0 & 0 & 0 & 1 \\
\hline Pterophyllum_barrealense & 0 & 0 & 0 & 0 & 1 \\
\hline Zamites_pusillus & 0 & 0 & 0 & 1 & 0 \\
\hline Zamites_cf._gigas & 0 & 0 & 0 & 1 & 0 \\
\hline Zamites_sp. & 0 & 0 & 0 & 0 & 1 \\
\hline Williamsonia_cf._gigas & 0 & 0 & 0 & 1 & 0 \\
\hline Ptilophyllum_antarcticum & 0 & 0 & 0 & 0 & 1 \\
\hline Cycadolepis_involuta & 0 & 0 & 0 & 0 & 1 \\
\hline Brachyphyllum_feistmanteli & 0 & 0 & 0 & 0 & 1 \\
\hline Araucarites_chilensis & 0 & 0 & 0 & 0 & 1 \\
\hline Araucarites_sp. & 0 & 0 & 0 & 1 & 1 \\
\hline Thaumathopteris_sp. & 0 & 0 & 0 & 1 & 0 \\
\hline Hausmannia_de-ferrariissii & 0 & 0 & 0 & 0 & 1 \\
\hline Athrotaxis_ungeri & 0 & 0 & 0 & 0 & 1 \\
\hline Cladophlebis_patagónica & 0 & 0 & 0 & 0 & 1 \\
\hline Sphenopteris_delicatula & 0 & 0 & 0 & 0 & 1 \\
\hline Sphenopteris_sanjulianensis & 0 & 0 & 0 & 0 & 1 \\
\hline Sphenopteris_nordenskjöldii & 0 & 0 & 0 & 1 & 0 \\
\hline Ruffordia_goepperti & 0 & 0 & 0 & 0 & 1 \\
\hline Osmundites & 0 & 0 & 0 & 0 & 1 \\
\hline Equisetum_thermale & 0 & 0 & 0 & 0 & 1 \\
\hline Equisetites_sp. & 0 & 0 & 0 & 1 & 1 \\
\hline Cladophlebis_cf._copiosa & 0 & 0 & 0 & 0 & 1 \\
\hline Scleropteris furcata & 0 & 0 & 0 & 1 & 0 \\
\hline Scleropteris_sp._A & 0 & 0 & 0 & 0 & 1 \\
\hline Scleropteris_cf._vincei & 0 & 0 & 0 & 0 & 1 \\
\hline Sphenopteris_cf._delicatula & 0 & 0 & 0 & 0 & 1 \\
\hline Otozamites_cf._barthianus & 0 & 0 & 0 & 0 & 1 \\
\hline Otozamites_bunburyanus_var._major & 0 & 0 & 0 & 0 & 1 \\
\hline Zamites_antarcticus & 0 & 0 & 0 & 0 & 1 \\
\hline Pachypteris crassa & 0 & 0 & 0 & 0 & 1 \\
\hline Elatocladus_confertus & 0 & 0 & 0 & 1 & 0 \\
\hline
\end{tabular}


Ana Julia Sagasti - Estudio paleobotánico, paleoecológico y paleoambiental...

\begin{tabular}{|c|c|c|c|c|c|}
\hline Elatocladus_casamiquelensis & 0 & 0 & 0 & 1 & 0 \\
\hline Brachyphyllum_sp. & 0 & 0 & 0 & 0 & 1 \\
\hline Pagiophyllum_feistmantelli & 0 & 0 & 0 & 1 & 0 \\
\hline Pagiophyllum_sp. & 0 & 0 & 0 & 0 & 1 \\
\hline Prototaxoxylon intertrappeum & 0 & 0 & 0 & 0 & 1 \\
\hline Prototaxoxylon uniseriale & 0 & 0 & 0 & 0 & 1 \\
\hline Prototaxoxylon acevedoae & 0 & 0 & 0 & 0 & 1 \\
\hline Podocarpoxylon feruglioi & 0 & 0 & 0 & 0 & 1 \\
\hline Podocarpoxylon austroamericanum & 0 & 0 & 0 & 0 & 1 \\
\hline Circoporoxylon sanjuliense & 0 & 0 & 0 & 0 & 1 \\
\hline Circoporopitys argentinum & 0 & 0 & 0 & 0 & 1 \\
\hline Circoporopitys shanense & 0 & 0 & 0 & 0 & 1 \\
\hline Planoxylon feriziense & 0 & 0 & 0 & 0 & 1 \\
\hline Herbstiloxylon patagonicum & 0 & 0 & 0 & 0 & 1 \\
\hline Ginkgomyeloxylon tanzanii & 0 & 0 & 0 & 0 & 1 \\
\hline Podocarpus palissyafolia & 0 & 0 & 0 & 0 & 1 \\
\hline Araucarites mirabilis & 0 & 0 & 0 & 0 & 1 \\
\hline Agathoxylon matildense & 0 & 0 & 0 & 0 & 1 \\
\hline Korallipteris_potrerillensis & 0 & 0 & 0 & 0 & 1 \\
\hline Coniopteris_hymenophylloides & 0 & 0 & 0 & 0 & 1 \\
\hline Otozamites_sueroi & 0 & 0 & 0 & 0 & 1 \\
\hline Otozamites_sanctae-crucis & 0 & 0 & 0 & 0 & 1 \\
\hline Otozamites_albosaxatilis & 0 & 0 & 0 & 0 & 1 \\
\hline Cf._Otozamites_bumburyanus_var._major & 0 & 0 & 0 & 0 & 1 \\
\hline Ptilophyllum_hislopi & 0 & 0 & 0 & 0 & 1 \\
\hline Araucarites_cutchensis & 0 & 0 & 0 & 0 & 1 \\
\hline Araucarites_phillipsi & 0 & 0 & 0 & 0 & 1 \\
\hline Araucarites_sp._(conos) & 0 & 0 & 0 & 0 & 1 \\
\hline Brachyphyllum_sp._ & 0 & 0 & 0 & 0 & 1 \\
\hline Pagiophyllum_cf._crassifolium & 0 & 0 & 0 & 0 & 1 \\
\hline Brachyphyllum_lotenaense & 0 & 0 & 0 & 0 & 1 \\
\hline Agathoxylon arayaii & 0 & 0 & 0 & 0 & 1 \\
\hline Agathoxylon cf floresii & 0 & 0 & 0 & 0 & 1 \\
\hline
\end{tabular}


Ana Julia Sagasti - Estudio paleobotánico, paleoecológico y paleoambiental...

\begin{tabular}{|c|c|c|c|c|c|}
\hline Agathoxylon jurassicum & 0 & 0 & 0 & 0 & 1 \\
\hline Cupressinoxylon sp & 0 & 0 & 0 & 0 & 1 \\
\hline Protaxodioxylon sp & 0 & 0 & 0 & 0 & 1 \\
\hline Protocupressinoxylon sp & 0 & 0 & 0 & 0 & 1 \\
\hline Pararaucaria_patagonica & 0 & 0 & 0 & 0 & 1 \\
\hline Scleropteris_vincei & 0 & 0 & 0 & 0 & 1 \\
\hline Sphenopteriscf._nordenskjöldii & 0 & 0 & 0 & 0 & 1 \\
\hline Elatocladus_cf._planus & 0 & 0 & 0 & 0 & 1 \\
\hline Elatocladus_confertus & 0 & 0 & 0 & 0 & 1 \\
\hline Carpolitthus_sp & 0 & 0 & 0 & 1 & 0 \\
\hline Taxites_sp. & 0 & 0 & 1 & 0 & 0 \\
\hline Cycadites_sp. & 0 & 0 & 1 & 0 & 0 \\
\hline Gleichenites_taquetrensis & 0 & 0 & 0 & 1 & 0 \\
\hline Gleichenites_juliensis & 0 & 0 & 0 & 0 & 1 \\
\hline Osmundites_patagónica & 0 & 0 & 0 & 0 & 1 \\
\hline Todites_williamsoni & 0 & 0 & 1 & 0 & 1 \\
\hline Cladophlebis_australis & 0 & 0 & 0 & 0 & 1 \\
\hline Cladophlebis_denticulada & 0 & 0 & 1 & 1 & 0 \\
\hline Cladophlebis_indica & 0 & 0 & 0 & 0 & 1 \\
\hline Cladophlebis_patagónica & 0 & 0 & 0 & 1 & 1 \\
\hline Cladophlebis_antárctica & 0 & 0 & 0 & 1 & 1 \\
\hline Cladophlebis_copiosa & 0 & 0 & 0 & 0 & 1 \\
\hline Cladophlebis_cf._kurtzi & 0 & 0 & 0 & 1 & 0 \\
\hline Cladophlebis_grahami & 0 & 0 & 0 & 1 & 0 \\
\hline Cladophlebis_sp. & 0 & 0 & 1 & 0 & 0 \\
\hline Clathropteris_obovata & 0 & 0 & 0 & 1 & 0 \\
\hline Scleropteris_sp._a & 0 & 0 & 0 & 0 & 1 \\
\hline Scleropteris_vincei & 0 & 0 & 0 & 0 & 1 \\
\hline Scleropteris_furcata & 0 & 0 & 0 & 1 & 0 \\
\hline Scleropteris_cf_furcata & 0 & 0 & 0 & 1 & 0 \\
\hline Sphenopteris_bagualensis & 0 & 0 & 1 & 0 & 0 \\
\hline Sphenopteris_delicatula & 0 & 0 & 0 & 0 & 1 \\
\hline Sphenopteris_goeppertti & 0 & 0 & 0 & 0 & 1 \\
\hline
\end{tabular}


Ana Julia Sagasti - Estudio paleobotánico, paleoecológico y paleoambiental...

\begin{tabular}{|c|c|c|c|c|c|}
\hline Sphenopteris_hallei & 0 & 0 & 0 & 1 & 0 \\
\hline Sphenopteris_patagónica & 0 & 0 & 0 & 1 & 1 \\
\hline Sphenopteris_picunleufuensis & 0 & 0 & 1 & 0 & 0 \\
\hline Sphenopteris_permira & 0 & 0 & 1 & 0 & 0 \\
\hline Sphenopteris_sanjulianensis & 0 & 0 & 0 & 0 & 1 \\
\hline Sphenopteris_nordenskjoldii & 0 & 0 & 0 & 1 & 0 \\
\hline Sphenopteris_sp. & 0 & 0 & 1 & 1 & 0 \\
\hline Thaumatopteris_sp. & 0 & 0 & 0 & 1 & 0 \\
\hline Ptilophyllum_antarcticum & 0 & 0 & 0 & 0 & 1 \\
\hline Ptilophyllum_patagónica & 0 & 0 & 0 & 0 & 1 \\
\hline Ptilophyllum_sp. & 0 & 0 & 1 & 0 & 0 \\
\hline Elatocladus_casamiquelensis & 0 & 0 & 0 & 1 & 0 \\
\hline Elatocladus_confertus & 0 & 0 & 0 & 1 & 1 \\
\hline Elatocladus_heterophylla & 0 & 0 & 1 & 0 & 1 \\
\hline Elatocladus_longifolium & 0 & 0 & 1 & 0 & 0 \\
\hline Sagenopteris_nilssoniana & 0 & 0 & 1 & 1 & 0 \\
\hline Sagenopteris_rhoifolia & 0 & 0 & 0 & 1 & 0 \\
\hline Otozamites_barthianus & 0 & 0 & 0 & 0 & 1 \\
\hline Otozamites_bunburyanus_var._major & 0 & 0 & 0 & 0 & 1 \\
\hline Otozamites_linearis & 0 & 0 & 1 & 0 & 0 \\
\hline Otozamites_santaecrucis & 0 & 0 & 0 & 1 & 1 \\
\hline Otozamites_simonatoi & 0 & 0 & 1 & 0 & 0 \\
\hline Otozamites_traversoi & 0 & 0 & 1 & 0 & 0 \\
\hline Otozamites_waltonii & 0 & 0 & 0 & 0 & 1 \\
\hline Dictyozamites_sp. & 0 & 0 & 1 & 0 & 0 \\
\hline Williamsonia_cf_gigas & 0 & 0 & 0 & 1 & 0 \\
\hline Williamsonia_sp. & 0 & 0 & 1 & 0 & 0 \\
\hline Equisetites_sp. & 0 & 0 & 0 & 1 & 1 \\
\hline Sagenopteris_phillipsi & 0 & 0 & 0 & 0 & 1 \\
\hline Sagenopteris_sp. & 0 & 0 & 1 & 0 & 0 \\
\hline Conipteris_hymenophylloides & 0 & 0 & 0 & 0 & 1 \\
\hline Brachyphyllum_feistmantellii & 0 & 0 & 0 & 1 & 1 \\
\hline Brachyphyllum_lotenaense & 0 & 0 & 1 & 0 & 0 \\
\hline
\end{tabular}


Ana Julia Sagasti - Estudio paleobotánico, paleoecológico y paleoambiental...

\begin{tabular}{|c|c|c|c|c|c|}
\hline Brachypyllum_neuquinum & 0 & 0 & 1 & 0 & 0 \\
\hline Brachyphyllum_ramosum & 0 & 0 & 1 & 0 & 0 \\
\hline Brachyphyllym_sp. & 0 & 0 & 1 & 0 & 1 \\
\hline Tomaxellia_crassa & 0 & 0 & 1 & 0 & 0 \\
\hline Scleropteris furcata & 0 & 0 & 0 & 1 & 0 \\
\hline Scleropteris_lotenaensis & 0 & 0 & 1 & 0 & 0 \\
\hline Araucarites_cutchensis & 0 & 0 & 0 & 1 & 1 \\
\hline Araucarites_mirabilis & 0 & 0 & 0 & 0 & 1 \\
\hline Araucarites_sanctae-crucis & 0 & 0 & 0 & 0 & 1 \\
\hline Araucarites_sp. & 0 & 0 & 1 & 0 & 1 \\
\hline Equisetites_minimus & 0 & 0 & 0 & 0 & 1 \\
\hline Equisetites_approximatus & 0 & 0 & 0 & 1 & 0 \\
\hline Pagiophyllum_divaricatum & 0 & 0 & 0 & 1 & 0 \\
\hline Pagiophyllum_feistmantelii & 0 & 0 & 0 & 1 & 1 \\
\hline Arthrotaxis_ungeri & 0 & 0 & 0 & 0 & 1 \\
\hline ?Palissya_confertus & 0 & 0 & 0 & 1 & 0 \\
\hline ?Palissya_jabalpurensis & 0 & 0 & 0 & 1 & 0 \\
\hline Zamites_cf_gigas & 0 & 0 & 0 & 1 & 0 \\
\hline Zamites_antarcticus & 0 & 0 & 0 & 0 & 1 \\
\hline Feruglioa_sp. & 0 & 0 & 0 & 1 & 0 \\
\hline Hausmannia_(Protorhipis)_de_ferrarisii & 0 & 0 & 0 & 0 & 1 \\
\hline Podocarpus_palissyafolia & 0 & 0 & 0 & 0 & 1 \\
\hline Masculostrobus_altoensis & 0 & 0 & 0 & 0 & 1 \\
\hline Pararaucaria_patagonica & 0 & 0 & 0 & 0 & 1 \\
\hline Dictyophyllum_sp. & 0 & 0 & 1 & 0 & 0 \\
\hline Matonidium_goepertii & 0 & 0 & 0 & 0 & 1 \\
\hline Neocalamites_carrerei & 1 & 0 & 1 & 0 & 0 \\
\hline Equisetites_frenguelli & 0 & 0 & 1 & 0 & 0 \\
\hline Equisetites_patagónica & 0 & 0 & 0 & 0 & 1 \\
\hline Equisetites_sp. & 1 & 1 & 1 & 1 & 0 \\
\hline Rienitsia_colliveri & 1 & 0 & 0 & 0 & 0 \\
\hline Marattia_münsteri & 1 & 0 & 1 & 0 & 0 \\
\hline Gleichenites_cf._sanmartini & 0 & 0 & 1 & 0 & 0 \\
\hline
\end{tabular}


Ana Julia Sagasti - Estudio paleobotánico, paleoecológico y paleoambiental...

\begin{tabular}{|c|c|c|c|c|c|}
\hline Cladophlebis_antárctica & 1 & 0 & 0 & 0 & 0 \\
\hline Cladophlebis_denticulata & 0 & 0 & 1 & 0 & 0 \\
\hline Cladophlebis_grahami & 0 & 0 & 1 & 0 & 0 \\
\hline Cladophlebis_mendozaensis & 1 & 0 & 1 & 0 & 0 \\
\hline Cladophlebis_cf._mesozoica & 1 & 0 & 0 & 0 & 0 \\
\hline Cladophlebis_pintadensis & 0 & 0 & 1 & 0 & 0 \\
\hline Cladophlebis_(Todites?)_ugartei & 1 & 0 & 0 & 0 & 0 \\
\hline Cladophlebis_oblonga & 1 & 0 & 1 & 0 & 1 \\
\hline Cladophlebis_sp._cf._C._kurtzi & 0 & 1 & 0 & 0 & 0 \\
\hline Cladophlebis_sp._cf._C._haiburensis & 0 & 0 & 1 & 0 & 0 \\
\hline Cladophlebis_sp._cf._C._indica & 0 & 0 & 1 & 0 & 0 \\
\hline Cladophlebis_haiburnensis & 0 & 0 & 1 & 0 & 0 \\
\hline Cladophlebis_indica & 0 & 0 & 1 & 0 & 0 \\
\hline Cladophlebis_sp. & 0 & 0 & 1 & 1 & 0 \\
\hline Todites_williamsoni & 0 & 0 & 1 & 0 & 0 \\
\hline Dejerseya_lobata & 1 & 0 & 0 & 0 & 0 \\
\hline Sphenopteris_sp. & 0 & 0 & 1 & 0 & 0 \\
\hline Sphenopteris_(Coniopteris?)_permira & 0 & 0 & 1 & 0 & 0 \\
\hline Sphenopteris_bagualensis & 0 & 0 & 1 & 0 & 0 \\
\hline Pachypteris_sanjuanina & 0 & 1 & 0 & 0 & 0 \\
\hline Sagenopteris_rhoifolia & 1 & 0 & 1 & 1 & 1 \\
\hline Sagenopteris_nilssoniana & 0 & 0 & 1 & 0 & 0 \\
\hline Sagenopteris_sp. & 0 & 0 & 1 & 1 & 0 \\
\hline Desmiophyllum_sp. & 0 & 0 & 0 & 1 & 0 \\
\hline Dictyophyllum_apertum & 0 & 0 & 1 & 0 & 0 \\
\hline Dictyophyllum_atuelense & 1 & 0 & 0 & 0 & 0 \\
\hline Dictyophyllum_rothii & 1 & 0 & 1 & 0 & 0 \\
\hline Dictyophyllum_sp. & 0 & 0 & 1 & 0 & 0 \\
\hline Clathropteris_kurtzi & 0 & 0 & 1 & 0 & 0 \\
\hline Clathropteris_ingens & 0 & 0 & 1 & 0 & 0 \\
\hline Clathropteris_obovata & 0 & 0 & 1 & 1 & 0 \\
\hline Clathropteris_sp. & 0 & 0 & 0 & 0 & 1 \\
\hline Thaumatopteris_rocablanquensis & 0 & 0 & 0 & 0 & 1 \\
\hline
\end{tabular}


Ana Julia Sagasti - Estudio paleobotánico, paleoecológico y paleoambiental...

\begin{tabular}{|c|c|c|c|c|c|}
\hline Thaumatopteris_eximia & 0 & 0 & 1 & 0 & 0 \\
\hline Thaumatopteris_sp. & 0 & 0 & 1 & 1 & 0 \\
\hline Coniopteris_meschiana & 0 & 0 & 0 & 1 & 0 \\
\hline Coniopteris_leucopetraea & 0 & 0 & 0 & 0 & 1 \\
\hline Goeppertella_macroloba & 0 & 0 & 0 & 1 & 0 \\
\hline Goeppertella_neuqueniana & 0 & 0 & 1 & 0 & 0 \\
\hline Goeppertella_diazii & 0 & 0 & 1 & 0 & 0 \\
\hline Goeppertella_frenguelliana & 0 & 0 & 0 & 1 & 0 \\
\hline Goeppertella_herbstii & 0 & 0 & 0 & 0 & 1 \\
\hline Archangelskya_protoloxsoma & 1 & 0 & 1 & 0 & 0 \\
\hline Archangelskya_furcata & 1 & 0 & 0 & 0 & 0 \\
\hline Alethopteris_?_sp. & 0 & 0 & 0 & 1 & 0 \\
\hline Scleropteris_vincei & 1 & 0 & 1 & 1 & 1 \\
\hline Scleropteris_sp. & 0 & 0 & 1 & 0 & 0 \\
\hline Ptilophyllum_acutifolium & 1 & 0 & 1 & 0 & 0 \\
\hline Ptilophyllum_cutchense & 0 & 0 & 1 & 1 & 0 \\
\hline Ptilophyllum_sp._cf._P._cutchense & 0 & 0 & 1 & 0 & 0 \\
\hline Ptilophyllum_hislopi & 0 & 0 & 1 & 0 & 0 \\
\hline Ptilophyllum_sp. & 0 & 0 & 1 & 0 & 0 \\
\hline Desmiophyllum_sp. & 0 & 0 & 1 & 0 & 0 \\
\hline Otozamites_albosaxatilis & 1 & 0 & 1 & 1 & 0 \\
\hline Otozamites_barthianus & 0 & 0 & 1 & 0 & 0 \\
\hline Otozamites_bechei & 1 & 0 & 1 & 0 & 0 \\
\hline Otozamites_bengalensis & 0 & 0 & 1 & 0 & 0 \\
\hline Otozamites_ameghinoi & 0 & 0 & 1 & 0 & 0 \\
\hline Otozamites_bunburyanus_var._mayor & 1 & 0 & 1 & 0 & 0 \\
\hline Otozamites_simonatoi & 1 & 0 & 1 & 0 & 0 \\
\hline Otozamites_linearis & 0 & 0 & 1 & 0 & 0 \\
\hline Otozamites_hislopi & 1 & 0 & 1 & 1 & 0 \\
\hline Otozamites_cf._hislopi & 0 & 0 & 1 & 0 & 0 \\
\hline Otozamites_obtusus & 0 & 0 & 1 & 0 & 0 \\
\hline Otozamites_groeberi & 0 & 0 & 1 & 0 & 0 \\
\hline Otozamites_oldhami & 0 & 0 & 1 & 1 & 0 \\
\hline
\end{tabular}


Ana Julia Sagasti - Estudio paleobotánico, paleoecológico y paleoambiental...

\begin{tabular}{|c|c|c|c|c|c|}
\hline Otozamites_sueroi & 0 & 0 & 0 & 1 & 0 \\
\hline Otozamites_chubutensis & 0 & 0 & 0 & 1 & 0 \\
\hline Otozamites_volkheimeri & 0 & 1 & 0 & 0 & 0 \\
\hline Pterophyllum_prínceps & 1 & 0 & 0 & 0 & 0 \\
\hline Dictyozamites_falcatus & 0 & 0 & 0 & 1 & 0 \\
\hline Dictyozamites_hallei & 0 & 0 & 0 & 1 & 0 \\
\hline Dictyozamites_sp. & 0 & 0 & 1 & 0 & 0 \\
\hline Williamsonia_sp. & 1 & 0 & 1 & 0 & 0 \\
\hline Cycadolepis_sp. & 0 & 0 & 0 & 0 & 1 \\
\hline Strobilites_sp. & 0 & 0 & 0 & 0 & 1 \\
\hline Araucarites_phillipsi & 0 & 0 & 1 & 0 & 0 \\
\hline Araucarites_sp._ & 0 & 0 & 1 & 0 & 0 \\
\hline Brachyphyllum_sp. & 0 & 0 & 1 & 1 & 0 \\
\hline ?_Brachyphyllum_sp. & 0 & 0 & 1 & 0 & 0 \\
\hline Brachyphyllum_neuquinum & 0 & 0 & 1 & 0 & 0 \\
\hline Brachyphyllum_menendezii & 0 & 1 & 0 & 0 & 0 \\
\hline Pagiophyllum_sp. & 1 & 1 & 1 & 1 & 0 \\
\hline Podozamites_elongatus & 0 & 0 & 1 & 0 & 0 \\
\hline Taeniopteris_sp. & 1 & 0 & 1 & 0 & 0 \\
\hline Elatocladus_heterophylla & 0 & 0 & 1 & 0 & 0 \\
\hline Elatocladus_confertus & 1 & 0 & 1 & 1 & 0 \\
\hline Elatocladus_planus & 0 & 0 & 1 & 0 & 1 \\
\hline Nilssonia_taenipteroides & 0 & 0 & 1 & 0 & 0 \\
\hline Kurtziana_cacheutensis & 0 & 0 & 1 & 0 & 0 \\
\hline Kurtziana_brandmayrii & 1 & 0 & 1 & 0 & 0 \\
\hline Rhizomopteris_sp. & 0 & 0 & 0 & 0 & 1 \\
\hline Spiropteris_sp. & 0 & 0 & 0 & 0 & 1 \\
\hline Ctenis_patagónica & 0 & 0 & 0 & 1 & 0 \\
\hline Cycadites_sp. & 0 & 0 & 1 & 0 & 0 \\
\hline Taxites_sp. & 0 & 0 & 1 & 0 & 0 \\
\hline Tomaxellia_crassa & 0 & 0 & 1 & 0 & 0 \\
\hline Ginkgoites_cf._digitata & 0 & 0 & 0 & 1 & 0 \\
\hline Baieroxylon rocablanquense & 0 & 0 & 0 & 0 & 1 \\
\hline
\end{tabular}


Ana Julia Sagasti - Estudio paleobotánico, paleoecológico y paleoambiental...

\begin{tabular}{|c|c|c|c|c|c|}
\hline Baieroxylon sp. cf. B. chilensis & 0 & 0 & 0 & 0 & 1 \\
\hline Prototaxoxylon pintadense & 0 & 0 & 1 & 0 & 1 \\
\hline Agathoxylon protoaraucana & 0 & 0 & 0 & 0 & 1 \\
\hline Dictyophylum (Dictyophylum) sp. & 1 & 0 & 0 & 0 & 0 \\
\hline Goeppertella sp. & 1 & 0 & 0 & 0 & 0 \\
\hline Agathoxylon liguaensis & 1 & 0 & 0 & 0 & 0 \\
\hline Podocarpoxylon atuelensis & 1 & 0 & 0 & 0 & 0 \\
\hline Austrohamia minuta & 0 & 0 & 0 & 1 & 0 \\
\hline Brachyoxylon currumilii & 0 & 0 & 0 & 1 & 0 \\
\hline Pararaucaria delfueyoi & 0 & 0 & 0 & 1 & 0 \\
\hline Clathropteris meniscioides & 0 & 0 & 0 & 1 & 0 \\
\hline Marattiopsis patagonica & 0 & 0 & 0 & 1 & 0 \\
\hline Equisetum dimorphum & 0 & 0 & 0 & 1 & 0 \\
\hline Agathoxylon termieri & 0 & 0 & 1 & 0 & 0 \\
\hline Equisetum sp. A & 0 & 0 & 0 & 1 & 0 \\
\hline Equisetum sp. B & 0 & 0 & 0 & 1 & 0 \\
\hline Equisetum sp. C & 0 & 0 & 0 & 1 & 0 \\
\hline Equisetum sp. D & 0 & 0 & 0 & 1 & 0 \\
\hline Dictyophyllum (Clathropteroides) obovata & 0 & 0 & 0 & 1 & 0 \\
\hline Dictyophyllum (Clathropteroides) sp. & 0 & 0 & 0 & 1 & 0 \\
\hline Goeppertella sp. A & 0 & 0 & 0 & 1 & 0 \\
\hline Goeppertella sp. B & 0 & 0 & 0 & 1 & 0 \\
\hline Goepertella sp. C & 0 & 0 & 0 & 1 & 0 \\
\hline Todites sp. & 0 & 0 & 0 & 1 & 0 \\
\hline Osmundopsis sp. & 0 & 0 & 0 & 1 & 0 \\
\hline Microphyllopteris sp. & 0 & 0 & 0 & 1 & 0 \\
\hline Cladophlebis denticulada & 0 & 0 & 0 & 1 & 0 \\
\hline Cladophlebis sp. A & 0 & 0 & 0 & 1 & 0 \\
\hline Cladophlebis sp. B & 0 & 0 & 0 & 1 & 0 \\
\hline Sphenopteris sp. A & 0 & 0 & 0 & 1 & 0 \\
\hline Sphenopteris sp. B. & 0 & 0 & 0 & 1 & 0 \\
\hline Sphenopteris nordenskjöldii & 0 & 0 & 0 & 1 & 0 \\
\hline Weltrichia sp. & 0 & 0 & 0 & 1 & 0 \\
\hline
\end{tabular}


Ana Julia Sagasti - Estudio paleobotánico, paleoecológico y paleoambiental...

\begin{tabular}{|l|l|l|l|l|l|}
\hline Zamites cf. gigas & 0 & 0 & 0 & 1 & 0 \\
\hline Zamites pusillus & 0 & 0 & 0 & 1 & 0 \\
\hline Sagenopteris nilssoniana & 0 & 0 & 0 & 1 & 0 \\
\hline Caytonanthus sp. & 0 & 0 & 0 & 1 & 0 \\
\hline Elatides sp. & 0 & 0 & 0 & 1 & 0 \\
\hline Araucaria cf. cutchensis & 0 & 0 & 0 & 1 & 0 \\
\hline Araucaria sp. A & 0 & 0 & 0 & 1 & 0 \\
\hline Araucaria sp. B & 0 & 0 & 0 & 1 & 0 \\
\hline Araucaria sp. C & 0 & 0 & 0 & 1 & 0 \\
\hline Araucarites sp. & 0 & 0 & 0 & 1 & 0 \\
\hline Pararaucaria sp. & 0 & 0 & 0 & 1 & 0 \\
\hline Masculostrobus sp. A & 0 & 0 & 0 & 1 & 0 \\
\hline Masculostrobus sp. B & 0 & 0 & 0 & 1 & 0 \\
\hline Elatocladus confertus & 0 & 0 & 0 & 1 & 0 \\
\hline Elatocladus casamiquelensis & 0 & 0 & 0 & 1 & 0 \\
\hline Brachyphyllum cf. lotenaense & 0 & 0 & 0 & 1 & 0 \\
\hline Pachypteris indica & 0 & 0 & 0 & 1 & 0 \\
\hline Pachypteris sp. & 0 & 0 & 0 & 1 & 0 \\
\hline Tabla 10.6. Matiz presencialausen & & 0 & 0 & & 1 \\
\hline
\end{tabular}

Tabla 10.6. Matriz presencia/ausencia de taxones por provincia por época. Matriz construida a partir de las referencias citadas en el capítulo IV y la determinación sistemática realizada en el capítulo VII.

\section{Conclusiones paleoecológicas.}

Teniendo en cuenta las condiciones paleoambientales analizadas en capítulos anteriores, y el análisis ecológico del presente capítulo, se pueden interpretar tres tipos diferentes de paleocomunidades desarrolladas en el área de la localidad Laguna Flecha Negra: vegetación arbórea dominada por Araucariaceae, con Cycadoideales, Cheirolepidiaceae como elementos subordinados, y un sotobosque integrado por helechos y pteridospermas de los géneros Scleropteris, Sphenopteris, Coniopteris y Korallipteris (paleocomunidad 1); vegetación arbóreo-arbustiva dominada por Cycadoideales y Coniferales, con helechos como elementos subordinados (paleocomunidad 2); y vegetación arbórea de Cupressaceae (s.l.) con 
Ana Julia Sagasti - Estudio paleobotánico, paleoecológico y paleoambiental...

Cheirolepidiaceae como elementos subordinados (paleocomunidad 3). La tafoflora estudiada en el yacimiento Laguna Flecha Negra presenta una composición taxónomica de sus paleocomunidades comparable con los estudios de Quattrocchio et al. (2007), Del Fueyo et al. (2007) e Iglesias et al. (2011).

La configuración de la pirámide poblacional de clases de diámetro sugiere el establecimiento de un bosque relativamente maduro, donde el $70,5 \%$ de los individuos representan árboles adultos (de diámetros mayores a 0,4 m) y un posterior establecimiento de árboles jóvenes. El análisis de alturas estimadas y críticas, avala esta interpretación. La ubicación de este bosque en la sección superior del nivel de tobas masivas, sugiere el establecimiento de una paleocomunidad arbórea en un período de relativa calma en la actividad volcánica de la región. Que ve trunco su desarrollo, por un nuevo episodio volcánico, de carácter piroclástico de flujo, que cubre la secuencia estudiada.

El análisis de los cambios en la diversidad específica para los afloramientos Jurásicos de la Argentina, muestra un pico en el Jurásico inferior, concentrado en las provincias de Neuquén y Chubut. El Jurásico medio muestra una diversidad moderada para las tafofloras de impresiones, que se observa en todos los depocentros de la época. Para el Jurásico Superior, se conocen registros en las provincias de Chubut y Santa Cruz, los cuales presentan una diversidad de alta a moderada, con su mayor desarrollo concentrado en la provincia de Santa Cruz.

Los cambios en los elencos paleoflorísticos a lo largo del Jurásico de la Argentina, muestran un incremento progresivo en las especies de coníferas y Cycadoideales, con menor representatividad de especies de helechos, Cycadales y Pteridospermas. Esto es congruente con los análisis paleobiogeográficos realizados por Rees et al. (2000), Philippe et al. (2004) e Iglesias et al. (2011), que identifican en los yacimientos de Patagonia, características del Bioma Subtropical Estacional Seco, con una vegetación de carácter xeromórfico, con parcelas arboladas integradas por coníferas micrófilas y cycadofitas; y una abundancia de maderas de Araucariaceae como elemento dominante y cosmopolita para el período Jurásico, en el supercontinente de Gondwana. 


\section{Conclusiones Generales}

En la localidad Laguna Flecha Negra se observa una secuencia volcaniclástica atribuible a la Formación Chon Aike (Jurásico Medio-Superior). Se registra una serie de episodios eruptivos de caída y de flujo que llevaron a la preservación de la comunidad vegetal que habitaba en la región. La comparación de estos depósitos con el análisis de facies elaborado por Guido (2004), permite identificar una secuencia volcaniclástica que se deposita sobre un domo andesítico de la Formación Bajo Pobre, que puede ser clasificado como subfacies lávicas. En los cuerpos de roca correspondientes a la Formación Chon Aike predominan los depósitos de caída. En la sección basal de la secuencia estudiada, se observan depósitos generados por flujos hidrotermales, que se hayan restringidos a la zona noroeste de la localidad. La secuencia culmina con depósitos de flujo piroclástico, representados por la Ignimbrita Flecha Negra.

En el estudio de detalle de la secuencia aflorante en la localidad Laguna Flecha Negra se pudo identificar que los niveles basales, de areniscas gruesas y pelitas oscuras, son los que contienen restos fosilíferos megascópicos de impresiones e impresiones-compresiones de expansiones laminares y estructuras reproductivas. Los restos fósiles presentan un estado de preservación variable, según el sedimento en el que se encuentran contenidos.

El análisis sistemático de los restos de improntas permitió reconocer la presencia de taxones ampliamente reconocidos para el Jurásico de Argentina. Es la primera vez que se cita para la formación Chon Aike las especies Korallipteris potrerillensis, Coniopteris hymenophylloides, Otozamites sueroi, Otozamites sanctae-crucis, Otozamites albosaxatilis, cf. Otozamites bumburyanus var. major, Prilophyllum acutifolium, Araucarites cutchensis, Araucarites phillipsi, Araucarites sp. (conos), Brachyphyllum sp., Pagiophyllum cf. crassifolium, Brachyphyllum lotenaense, Pararaucaria patagónica, Scleropteris vincei, Sphenopteris cf. nordenskjöldii, Elatocladus cf. planus, Elatocladus confertus y estructuras pinnadas de afinidad con las pteridospermas. 
Ana Julia Sagasti - Estudio paleobotánico, paleoecológico y paleoambiental...

Se describen por primera vez, restos de maderas permineralizadas para la Formación Chon Aike. El estudio anatómico de los restos permitió identificar taxones fósiles asignalbes al Orden Coniferales. La comunidad arbórea estaba dominada por la familia Araucariaceae, incluyendo especies de Agathoxylon y restos de dudosa asignación genérica; y por componentes de las Cupressaceae en sentido amplio y estricto: Protaxodioxylon sp. y Cupressinoxylon sp. . Como elemento subordinado, se identifican restos asignables al género Protocupressinoxylon correspondiente a la familia Cheirolepidiaceae. Se observa una alta diversidad específica, reconociéndose cuatro especies del género Agathoxylon: Agathoxylon matildense, Agathoxylon cf floresii, Agathoxylon jurassicum y Agathoxylon arayaii, todas ellas características del Jurásico y Cretácico de Gondwana.

Se estudió un resto de madera permineralizada que presenta evidencias de interacciones multitróficas que incluyen actinomicetes, estructuras fúngicas, galerías de artrópodos y un diverso set de patrones de degradación consistentes con pudrición fúngica, hospedados en un eje de Araucariaceae. La presencia de cambios anatómicos, tales como los canales resiníferos traumáticos, la depositación de componentes resinosos en lúmenes celulares, engrosamiento de las paredes de traqueidas y proliferación de esclereidas, representarían respuestas de la planta a los patógenos. Estos cambios estructurales y anatómicos sugieren que, al menos desde el Jurásico Medio, algunas coníferas habrían desarrollado mecanismos de defensa constitutivos e inducibles, que sirvieron como barreras de defensa contra diversas pestes y patógenos. La presencia de estos mecanismos de defensa permite concluír que al menos parte de las interacciones se dieron mientras el hospedador aún vivía. La descomposición del eje se dio principalmente por la acción de hongos degradadores de maderas, cuya asociación con el eje podría haber sido pasiva o activa vía la dispersión forética de un insecto xilófago. La asociación de hifas con conexiones en fíbula, aparentes zoosporangios y posibles actinomicetes, con los tejidos degradados, sugiere un rol saprotrófico para los restantes microorganismos fúngicos y no-fúngicos de hábito comparable. La presencia de galerías con restos de aserrín compuesto por traqueidas fragmentadas, es consistente con la actividad de un artrópodo xilófago que podría haber actuado 
Ana Julia Sagasti - Estudio paleobotánico, paleoecológico y paleoambiental...

como vector para parte de los microorganismos; rol que se observa en ecosistemas boscosos modernos.

El estudio vertical y lateral de las asociaciones de litofacies y tafofacies aflorantes en la localidad Laguna Flecha Negra permite realizar una reconstrucción paleoambiental en el marco de los modelos de facies para sistemas geotérmicos elaborados por Guido y Campbell (2011). Los depósitos de permineralizaciones en masa estudiados son de carácter silíceo, lenticular y se encuentran aislados en el sector noroeste de la localidad, interdigitando con areniscas gruesas, masivas. La geometría y textura de los lentes de chert permiten comparar los depósitos estudiados con sectores distales del modelo de sínter silíceo, más precisamente, la zona de pantanos con influencia geotérmica, o wetlands. Los materiales preservados en los lentes de chert provienen de una fuente alóctona a para-autóctona de órganos que se desprenden de la vegetación local, y restos de la vegetación autóctona que quedan entrampados por progradación de los fluídos geotérmicos. Suprayacentemente a este nivel, la secuencia adquiere un carácter netamente volcaniclástico. En los sectores central y sudoeste de la localidad, la asociación de tafofacies AfLe(IC) y AfLe(B), se desarrolla en un conjunto de estratos de 10-35 cm de espesor, que conforman un nivel con una potencia máxima de 5 metros. Los estratos preservan tanto una flora autóctona a para-autóctona de restos vegetales bien preservados como abundantes briznas vegetales de carácter fragmentario. La presencia de laminación entrecruzada a paralela, sumado al abundante detrito vegetal (representado por las briznas) y la granulometría fina de las sedimentitas podría indicar la formación de estos cuerpos de roca en un ambiente subácueo. Concordantemente a este nivel, se registra un nuevo episodio eruptivo de gran desarrollo vertical. Las tobas estudiadas son de carácter mayormente estéril, registrando una comunidad vegetal arbórea hacia el tope de la secuencia. Allí se puede observar la asociación de tafofacies $\operatorname{Tm}(\mathrm{Tv}), \operatorname{Tm}(\mathrm{Th})$ y $\operatorname{Tm}(\mathrm{I})$, en la que se encuentra un bosque de coníferas de carácter autóctono a para-autóctono.

Se interpretaron tres tipos diferentes de paleocomunidades desarrolladas en el área de la localidad Laguna Flecha Negra: vegetación arbórea dominada por Araucariaceae, con Cycadoideales, Cheirolepidiaceae, como elementos subordinados y un sotobosque integrado por helechos y 
Ana Julia Sagasti - Estudio paleobotánico, paleoecológico y paleoambiental...

pteridospermas de los géneros Scleropteris, Sphenopteris, Coniopteris y Korallipteris (paleocomunidad 1); vegetación arbórea-arbustiva dominada por Cycadoideales y Coniferales, con helechos como elementos subordinados (paleocomunidad 2); y vegetación arbórea de Cupressaceae (s.l.) con Cheirolepidiaceae como elementos subordinados (paleocomunidad 3 ).

La configuración de la pirámide poblacional de clases de diámetro sugiere el establecimiento de un bosque relativamente maduro, donde el $70,5 \%$ de los individuos representan árboles adultos (de diámetros mayores a 0,4 m) y un posterior establecimiento de árboles jóvenes. El análisis de alturas estimadas y críticas, avala esta interpretación. La ubicación de este bosque en la sección superior del nivel de tobas masivas, sugiere el establecimiento de una paleocomunidad arbórea en un período de relativa calma en la actividad volcánica de la región. Que ve trunco su desarrollo, por un nuevo episodio volcánico, de carácter piroclástico de flujo, que cubre la secuencia estudiada.

El análisis de los cambios en la diversidad específica para los afloramientos Jurásicos de la Argentina, muestra un pico en el Jurásico Inferior, concentrado en las provincias de Neuquén y Chubut. El Jurásico Medio muestra una diversidad moderada para las paleofloras, que se observa en todos los depocentros de la época. Para el Jurásico Superior, se conocen registros en las Provincias de Chubut y Santa Cruz, los cuales presentan una diversidad de alta a moderada, con su mayor desarrollo concentrado en la Provincia de Santa Cruz.

Los cambios en los elencos paleoflorísticos a lo largo del Jurásico de la Argentina, muestran un incremento progresivo en las especies de Coníferas y Cycadoideales, con menor representatividad de especies de helechos, Cycadales y Pteridospermas. Esto es congruente con los análisis paleobiogeográficos realizados por Rees et al. (2000) y Philippe et al. (2004), que observan en latitudes bajas, una vegetación de carácter xeromórfico, con parcelas arboladas integradas por coníferas micrófilas y cycadofitas; y una abundancia de maderas de Araucariaceae como elemento dominante y cosmopolita para el período Jurásico, en el supercontinente de Gondwana. 


\section{Bibliografía citada}

Adams, A.S., Jordan, M,S., Adams, S.M., Suen, G., Goodwin, L.A., Davenport, K.W., Currie, C.R. and Raffa, K.,F. 2011. Cellulose-degrading bacteria associated with the invasive woodwasp Sirex noctilio. The ISME Journal 1-9.

Aleexev, A.V. 1999. A survey of Mesozoic Buprestids (Coleoptera) from Eurasian deposits.Proceedings of the First International Palaeoentomological Conference, Moscow 1998.AMBA projects, Bratislava. Pp: 5-9.

Álvarez, P.P., Benoit, S.V.y Ottone, E.G. 1994. Las Formaciones Rancho de Lata, Los Patillos y otras unidades mesozoicas de la Cordillera Principal de San Juan. Revista de la Asociación Geológica Argentina. 49: 123-142.

Ameghino, F. 1906. Les formations sédimentaires du Crétacé supérieur et du Tertiare de Patagonie avec un paralléle entre leurs faunes mammalogiques et celles de l'ancien continent. Anales Museo Nacional Buenos Aires, 15 (3) 8 : 1-568.

Anderson, L.I. y Trewin, N.H. 2003. An early Devonian arthropod fauna from the Windyfield cherts, Aberdeenshire, Scotland. Palaeontology 46: 467-509.

Arber, E.A.N., 1917. The earlier Mesozoic floras of New Zealand. New Zealand Geological Survey. Palaeontological Bulletin 6, 1-80.

Archangelski, S. 1967. Estudio de la Formación Baqueró, Cretácico inferior de Santa Cruz, Argentina. Revista del Museo de La Plata (nueva serie), Paleontología 5: 63-171.

Archangelsky, S. 1968. On the genus Tomaxellia (Coniferae) from the Lower Cretaceous of Patagonia (Argentina) and its male and female cones. Botanical Journal of the Linnean Society 61: 153-165.

Archangelsky, S. 1970. Fundamentos de Paleobotánica. Facultad de Ciencias Naturales y Museo, Universidad Nacional de la Plata, Serie técnica y Didáctica 10, $347 \mathrm{pp}$

Archangelsky S. y Archangelsky A. 2002. Paleobotánica y palinología del Mesozoico. Geología y Recursos Naturales de Santa Cruz. Relatorio del XV Congreso Geológico Argentino. El Calafate, II-3: 407-420.

Archangelsky, S. y De La Sota, R.E. 1962. Estudio anatómico de un estípite petrificado de Osmundites, procedente del Gran Bajo de San Julián, provincia de Santa Cruz. Ameghiniana 2: 153-164.

Arrondo, O.G. 1972. Estudio Geológico y Paleontológico en la zona de la Estancia La Juanita y Alrededores, Provincia de Santa Cruz, Argentina. Revista del Museo de La Plata, Nueva Serie, Paleontología 43: 1-194.

Arrondo, O.G. y Petriella, B. 1980. Alicurá, una nueva localidad plantífera liásica de la provincia de Neuquén, Argentina. Ameghiniana 17: 200-215.

Arrondo, O.G., Spalletti, L., Morel, E.M., Ganuza, D. 1991. The sedimentological and paleobotanical characteristics of an Upper Triassic-Lower Liassic basin in northwestern Patagonia (Argentina). En: H. Ulbrich y A.C. Rocha-Campos (Eds.), $7^{\text {th }}$ Gondwana Symposium Proceedings, Instituto de Geociencias, Universidade de Sao Paulo (Sao Paulo), 741: 517-532.

Artabe, A.E. 1982. Presencia de Podozamites elongatus (Morris) Feistmantel (Coniferales, Podozamitaceae) en la tafoflora de Alicurá (Provincia de Neuquén, Argentina). Ameghiniana 19: 361-365.

Artabe, A.E., Morel, E. y Zamuner, A.B. 1994. Estudio paleobotánico y tafonómico de la Formación Paso Flores (Triásico superior), en el Cañadón de Pancho, provincia de Neuquén, Argentina. Ameghiniana 31: 153-160.

Artabe, A., Morel, E.M., y Spalletti, L.A. 2001. Paleoecología de las Floras triásicas argentinas. En: Artabe, A.E., Morel, E.M. y Zamuner, A.B. (Eds), El Sistema Triásico en la Argentina pp. 199-225. La Plata, Argentina: Fundación Museo de La Plata.

Artabe, A.E., Ganuza, D.G., Spalletti, L.A., Zúñiga, A., Morel, E.M. 2005. Revisión de la paleoflora del cerro La Brea (Jurásico temprano), provincia de Mendoza, Argentina. Ameghiniana 42: 429-442. 
Ana Julia Sagasti - Estudio paleobotánico, paleoecológico y paleoambiental...

Baldoni, A.M. 1977. Estudio paleobotánico del Jurásico-Cretácico inferior de la Patagonia. Tesis inédita. Facultad de Ciencias Naturales y Museo, La Plata.

Baldoni A. M. 1978. Plantas fósiles jurásicas del subsuelo de Plaza Huincul Provincia de Neuquén. Boletín de la Asociación Latinoamericana de Paleobotánica y Palinología 5: $1-12$.

Baldoni, A.M. 1980. Plantas fósiles Jurásicas de una nueva localidad en la Provincia de Neuquén. Ameghiniana 17: 255-272.

Baldoni, A.M. 1980. Nota sobre una nueva especie de Elatocladus (?) (Coniferae) de la Formación Springhill, límite Jurásico-Cretácico, Provincia de Santa Cruz. Ameghiniana 17 (4): 373-378.

Baldoni, A.M. 1981. Tafofloras jurásicas y eocretácicas de América del Sur. En Volkheimer, W. y Musaccio, E.A. (Eds) Cuencas sedimentarias del Jurásico y Cretácico de América del Sur (Buenos Aires) 2: 359-391.

Baldoni, A.M. y Olivero, E. 1983. Plantas fósiles de la Formación Lago La Plata procedentes de Arroyo Canogas, provincia de Chubut, Argentina. Ameghiniana 20: 34-40.

Bamford, M.K. y Philippe, M. 2001. Gondwanan Jurassic-Early Cretaceous homoxylous woods: a nomenclatural revision of the genera with taxonomical notes. Review of Paleobotany and Palynology 113: 287-297.

Barnett, H.L., Hunter, B.B., 1998. Illustrated Genera of Imperfect Fungi, fourth ed. APS, St. Paul.

Barr, D. J. S., 2001. 5. Chytridiomycota. In McLaughlin, D. J., E. G. McLaughlin \& P. A. Lemke (eds), The Mycota, Vol. VII, Part A. Springer-Verlag, New York, NY, pp. 93-112.

Barthel, M., Krings, M., Roessler, R., 2010. Die schwarzenn Psaronien von Manebachihre epiphyten, parasiten und pilze. Semana 25, 41-60.

Bhardwaj, D.C. 1953. Jurassic woods from the Rajmahal Hills, Bihar. The Paleobotanist. 2: $59-70$.

Blanchette, R.A., Otjen, L., Effland, M.J., Eslyn, W.E. 1985. Changes in structural and chemical components of wood delignified by fungi. Wood Science and Technology 19: 35-46.

Blanchette, R.A. 1991. Delignification by wood-decay fungi.Annual Review of Phytopathology 29: 381-398.

Bodnar, J. 2017. Proposal to conserve the name Protocupressinoxylon with a conserved type against Protobrachyoxylon (fossil plants). Taxon 66: 1480-1481.

Bodnar, J., Escapa, I., Cúneo, N.R. y Gnaedinger, S. 2013. First record of conifer Wood from the Cañadón Asfalto Formation (Early-Middle Jurassic), Chubut Province, Argentina. Ameghiniana. 50: 227-239.

Bollschweiler, M., Stoffel, M., Schneuwly, D.M., Bourqui, K. 2008.Tree Physiology 28: 255263.

Bonello P, Blodgett JT. 2003. Pinus nigra-Sphaeropsis sapinea as a model pathosystem to investigate local and systemic effects of fungal infection of pines. Physiol Mol Plant $P$ 2003;63:249-61.

Bonello, P., Gordon, T.R., Herms, D.A., Wood, D.L., Erbilgin, N. 2006. Nature and ecological implications of pathogen-induced systemic resistance in conifer: a novel hypothesis. Physiological and Molecular Plant Pathology 68: 95-104.

Bonetti, M.I.R. 1963. Flórula mesojurásica de la zona de Taquetrén (Cañadón del Zaino) Chubut. Revista del Museo Argentino de Ciencias Naturales Bernardino Rivadavia I: 23-43.

Bose , M. N. , and H. K. Maheshwari . 1973. Some detached seedscales belonging to Araucariaceae from the Mesozoic rocks of India. Geophytology $3: 205-214$.

Boureau, E. 1956. Anatomie Végétale. Tome 2. Presses Universitaires de France, París, pp. 333-503.

Bowring, S.A., Erwin, D.H., Jin, Y.G., Martin, M.W., Davidek, K. y Wang, W. 1998. U/Pb geochronology and tempo of the end-Permian mass extinction.Science 280: 10391045. 
Ana Julia Sagasti - Estudio paleobotánico, paleoecológico y paleoambiental...

Breton, G., 2010, Les Actinomycetales de l'ambre sparnacien des Corbières (Aude, France): taphonomie et diversité: Annales de la Société Géologique du Nord, Lille 17 (2è sér.), 3-22.

Breton, G., 2012, L'ambre des Corbières (Aude-France): SESA, Carcassonne, 96 pp, [ISBN 978-2-9531120-3].

Breton, G., Bilotte, M., Eychenne, G., 2013, L'ambre campanien du Mas d'Azil (Ariège, France): gisement, microinclusions, taphonomie. Annales de Paléontologie, http://dx.doi.org/10.1016/j. annpal.2013.06.001

Breton, G., Serrano-Sánchez, M.L., Vega, F. 2014.Filamentous micro-organisms, inorganic inclusions and pseudo-fossils in the Miocene amber from Totolapa (Chiapas, Mexico) : taphonomy and systematics. Boletín de la Sociedad Geológica Mexicana 66: 199-214.

Brett, C.E. y Baird, G.C. 1986. Comparative taphonomy: a key to paleoenvironmental interpretation based on fossil preservation. Palaios 1: 207-227.

Brison, A.L., Philippe, M. y Thevenard, F. 2001. Are Mesozoic wood growth rings climateinduced ? Paleobiology 27: 531-538.

Broecker, W.S. y van Donk, J. 1970. Insolation changes, ice volumes, and the $\mathrm{O}^{18}$ record in deep sea cores. Reviews Geophysics Space Physics8: 169-197.

Brongniart, A. 1849. Tableau des genres de végétaux fossiles considérés sous le point de vue de leur classification botanique et de leur distribution géologique: Dictionnaire universel histoire naturel 13: 1-127.

Brues, C.T. 1936. Evidences of insect activity preserved in fossil Wood. Journal of Paleontology10: 637-643.

Buss, E.A. and Foltz, J.L. 2003.Insect borers of trees and shrubs.Institute of Food and Agrigricultural Sciences Cooperative Extension Service.17.http://edis.ifas.ufl.edu/IR00004256/00001.

Butin, H., Peredo, H.L., 1986. Hongos parásitos en coníferas de América del Sur con especial referencia a Chile. Biblioteca Mycologica 101, 1-100.

Calder, M.G. 1953. A coniferous petrified forest in Patagonia.Bulletin of the British Museum (Natural History) Geology.2: 97-138.

Cantino, P.D., Doyle, J.A., Graham, S.W., Judd, W.S., Olmstead, R.G., Soltis, D.E., Soltis, P.S. y Donoghue, M.J. 2007. Towards a phylogenetic nomenclature of Tracheophyta. Taxon 56: 822-846.

Cantino, P.D., de Queiroz, K. 2010. International code of phylogenetic nomenclature [Internet]. Versión disponible en: http://www.ohio.edu/phylocode/.

Cantrill, D.J., 1998. Early Cretaceous fern foliage from President Head, Snow Island, Antarctica. Alcheringa 22, 241-258.

Carlile, M.J., Watkinson, S.C. and Gooday, G.W. 2001.The Fungi (2 ${ }^{\text {nd }}$. Ed.). Academic, San Diego, Calif.; London.

Cazaubón, A.J. 1947. Una nueva flórula jurásica en el Cordón de Esquel, en el Chubut meridional. Revista de la Sociedad Geológica Argentina 2: 41-58.

Channing, A., Edwards, D., Strutevant, S. 2004. A geothermally influenced wetland containing unconsolidated geochemical sediments. Canadian Journal of Earth Sciences. 41: 809827.

Channing, A., Zamuner, A.B. y Zuñiga, A. 2007. A new Middle-Late Jurassic flora and hot spring chert deposit from the Deseado Massif, Santa Cruz Province, Argentina. Geological Magazine 144: 401-411.

Channing, A., Zamuner, A., Edwards, D. y Guido, D. 2011. Equisetum thermal sp. Nov. (Equisetales) from the Jurassic San Agustín hot spring deposit, Patagonia: anatomy, paleoecology, and inferred paleoecophysiology. American Journal of Botany 98: 680697.

Channing, A. y Edwards, D. 2013. Wetland megabias: ecological and ecophysiological filtering dominates the fossil record of hot spring floras. Paleontology 1-34. doi: 10.1111/pala.12043 
Ana Julia Sagasti - Estudio paleobotánico, paleoecológico y paleoambiental...

Chin, K., 2007. The paleobiological implications of herbivorous dinosaur coprolites from the Upper Cretaceous Two Medicine Formation of Montana: why eat wood? Palaios 22, 554-566.

Choo, T.Y.S., Escapa, I.H. y Bomfleur, B. 2016. Monotypic colonies of Clathropteris meniscioides (Dipteridaceae) from the Early Jurassic of central Patagonia, Argentina: implications for taxonomy and palaeoecology. Palaeontographica, Abt. B: Palaeobotany-Palaeophytology. 294: 85-109.

Christiansen E, Franceschi VR, Nagy N, Krekling T, Berryman AA, Krokene P, et al. 1999. Traumatic resin duct formation in Norway spruce after wounding or infection with a bark beetle associated blue-stain fungus Ceratocystis polonica. In: Lieutier F, Mattson WJ, Wagner MR, editors. Physiology and genetics of tree-phytophage interactions. Versailles, France: INRA Editions. p. 77-89.

Cleal. C.J. and Rees, P.M. 2003. The middle Jurassic flora from Stonesfield, Oxfordshire, UK.Palaeontology 46: 739-801.

Colombi, C.E. y Parrish, J.T. 2008. Late Triassic environmental evolution in southwestern Pangea: plant taphonomy of the Ischigualasto Formation. Palaios 23: 778-795.

Comité Argentino de Estratigrafía, 1992. Código argentino de estratigrafía. Asociación Geológica Argentina, Serie B, Didáctica y Complementaria, 20: 1-64. Buenos Aires.

Cortés, J.M. y Baldoni, A.M. 1984. Plantas fósiles jurásicas al sur del Río Chubut medio. $9^{\circ}$ Congreso Geológico Argentino (San Carlos de Bariloche), Actas 2: 432-443.

Couch, J. N. 1932. The Development of the Sexual Organs in Leptolegnia caudata. American Journal of Botany, 19(7), 584. doi:10.2307/2436251

Crabtree, D.R., 1988. Mid-Cretaceous ferns in situ from the Albino Member of the Mowry Shale, Southwestern Montana. Palaeontographica B 209, 1-27.

Creber, G.T. y Ash, S.R. 1990. Evidence of widespread fungal attack on Upper Triassic trees in southwestern U.S.A. Review of Palaeobotany and Palynology 63: 189-195.

Cronquist, A., Takhtajan, A. y Zimmerman, W. 1966. On the higher taxa of Embryobionta. Taxon 15: 129-134.

Crowson, R.A. 1962. Observations on the beetle family Cupedidae, with descriptions of two new fossil forms and a key to recent genera.Annals and Magazine of Natural History 13: 147-157.

Currie, C.R., Scott, J.A., Summerbell, R.C. \& Malloch, D. 1999. Fungus-growing ants use antibiotic-producing bacteria to control garden parasites. Nature, 398: 701-704.

Darwin, C. 1938. Crónica de los viajes de inspección de los barcos de su majestad "Adventure" y "Beagle". Vol III: Diario y Observaciones, 1832-1835.Traducción por Juan Mateos (2000). Ed. elaleph.com. 624pp.

de Barrio, R. E.; Arrondo, O. G.; Artabe, A. E. y Petriella, B. 1982. Estudio geológico y paleontológica de los alrededores de la Estancia Bajo Pellegrini, Provincia de Santa Cruz. Revista de la Asociación Geológica Argentina 37 (3): 285-299.

de Barrio, R., Panza, J. L. y Nullo, F., 1999. Jurásico y Cretácico del Macizo del Deseado, provincia de Santa Cruz. En: Caminos R. (Ed.): Geología Argentina. Instituto de Geología y Recursos Minerales, 29 (17): 511-527.

De Giusto, J. M., Di Persia, C. A. y Pezzi, E. 1980. Nesocratón del Deseado. En: Leanza, A. F. (Ed.): $2^{\circ}$ Simposio de Geología Regional Argentina, 2:1389-1430. Academia Nacional de Ciencias, Córdoba.

Delhaes, G. 1913. Sobre la presencia del Rético en la costa Patagónica. Dirección General Minería, Geología e Hidrología, Boletín 1 Serie B (Geología): 5-10.

Del Fueyo, G.M., Villar de Seoane, L., Archangelsky, A., Guler, V., Llorens, M., Archangelsky, S., Gamerro, J.C., Musacchio, E.A., Passalia, M.G., Barreda, V.D. 2007. Biodiversidad de las paleofloras de Patagonia austral durante el Cretácico Inferior. En: Asociación Paleontológica Argentina, ed. Ameghiniana 50 aniversario. Buenos Aires: Asociación Paleontológica Argentina, Publicación Especial, 101-122.

Dighton, J. 2003. Fungi in Ecosystem Processes. Marcel Dekker, New York. [Mycology Series No. 17.]Pp. ix +432 . 
Ana Julia Sagasti - Estudio paleobotánico, paleoecológico y paleoambiental...

Dighton, J. 2016. Fungi in Ecosystem Processes, Second Edition. CRC Press, New York. Mycology Series No. 31.382pp.ISBN 9781482249057.

DiMichele, W.A. y Falcon-Lang, H.J. 2011. Pennsylvanian " fossil forest " in growth position ( $\mathrm{T}^{\circ}$ assemblages) : origin, taphonomic bias and palaeoecologial insights. Journal of the Geological Society, 168: 585-605.

DOMSCH, K.H., GAMS, W., and ANDERSON, T.-H., 2007, Compendium of Soil Fungi: IHWVerlag, Eching, Germany, $672 \mathrm{p}$.

Dutra, T.L. y Stranz, A. 2003. História das Araucariaceae: a contribuicao dos fósseis para o entendimento das adaptacoes modernas da familia no hemisfério sul, como vistas a seu manejo e conservacao. En Ronchi, L.H. y Coelho, O.G.W. (Ed.) Tecnología, diagnóstico e planejamento ambiental. Editora Unisinos, 293-651.

D'Rozario, A., Labandeira, C., Guo, W-Y., Yao, Y-F., Li, C-S. 2011. Spatiotemporal extensión of the Euramerican Psaronius component community to the Late Permian of Cathaysia: In situ coprolites in a $P$. housuoensis stem from Yunnan Province, southwest China. Palaeogeography, PAlaeoclimatology, Palaeoecology. 306: 127-133.

Dworkin, M., Falkow, S., Rosenberg, E., Schleifer, K-H., Stachebrandt E. (Eds.). 2006. The Prokaryotes: A Handbook on the Biology of Bacteria. Third Edition.Springer.Singapur. 1185pp.

Echavarría, L. E., Schalamuk, I. B. A., Etcheverry, R. O., 2005. Geologic and tectonic setting of Deseado Massif epithermal deposits, Argentina, based on El Dorado-Monserrat. Journal of South American Earth Sciences 19: 415-432.

Echeveste, H., Fernández, R., Llambías, E., Tessone, M., Schalamuk, I., Bellieni, G., Piccirillo, E., De Min, A. 1999. Ignimbritas tardías de alto grado en la Formación Chon Aike (Jurásico), Macizo del Deseado, Santa Cruz. XIV Congreso Geológico Argentino, Actas // 182-185.

Echeveste, H., Fernández, R., Bellieni, G., Tessone, M., Llambías, E., Schalamuk, I., Piccirillo, E., De Min, A. 2001. Relaciones entre las Formaciones Bajo Pobre y Chon Aike (Jurásico medio a superior) en el área de Estancia El Fénix-Cerro Huemul, zona centro-occidental del Macizo del Deseado, provincia de Santa Cruz. Revista de la Asociación Geológica Argentina 56: 548-558.

Eckhold, W. 1921. Die Hoftüpfel bei rezenten und fossilen Koniferen. Hoschschulverlag, Breslau. 4 pp.

Efremov, J.A. 1940. Taphonomy: a new branch of paleontology. Pan.Am Geol. 74: 81-93.

Elgorriaga, A., Escapa, I.H., Bomfleur, B., Cúneo, R., Ottone, E.G. 2015. Reconstruction and phylogenetic significance of a new Equisetum Linnaeus species from the Lower Jurassic of Cerro Bayo (Chubut Province, Argentina).

Endlicher, S. 1937. Genera plantarum secundum ordines naturals disposita. Vindobonae.232 pp.

Engler, A. 1897. Coniferales. En: Engler, A. y Prantl, K. (eds), Die Natürlichen Pflanzenfamilien. II.-IV:144-149.

Erwin, D. 1998. Biosphere perturbations: from the Neoproterozoic-Cambrian radiation to the end-Permian crisis. Journal of African Earth Sciences 27: 66-67.

Escapa, I.H. 2008. Tesis. La Tafoflora de la Formación Cañadón Asfalto, Jurásico MedioSuperior de Chubut. Taxonomía, bioestratigrafía y paleofitogeografía. Universidad Nacional de Comahue. 250pp.

Escapa, I., Cúneo, R., Axsmith, B. 2008. A new genus of the Cupressaceae (sensu lato) from the Jurassic of Patagonia: Implications for conifer megasporangiate cone homologies. Review of Palaeobotany and Palynology. 151: 110-122.

Escapa, I.H., Rothwell, G.W., Stockey, R.A., Cúneo, N.R. 2012. Seed cone anatomy of Cheirolepidiaceae (Coniferales): reinterpreting Pararaucaria patagonica Wieland. American Journal of Botany 99: 1058-1068.

Escapa, I.H., Cúneo, N.R., Rothwell, G., Stockey, R.A. 2013. Pararaucaria delfueyoi sp. nov. from the Late Jurassic Cañadón Calcáreo Formation, Chubut, Argentina: Insights into the evolution of the Cheirolepidiaceae. Int. J. Plant. Sci. 174: 458-470. 
Ana Julia Sagasti - Estudio paleobotánico, paleoecológico y paleoambiental...

Escapa, I.H., Bomfleur, B., Cúneo, N.R. y Scasso, R. 2014. A new marattiaceour fern from the Lower Jurassic of Patagonia (Argentina): the renaissance of Marattiopsis. Journal of systematic Palaeontology. http://dx.doi.org/10.1080/14772019.2014.936974

Falaschi, P. 2009. Sistemática, paleoecología e indicaciones paleoclimáticas de la tafoflora Monumento Natural Bosques Petrificados, Jurásico Medio, Patagonia, República Argentina. Tesis doctoral inédita.469 pp.

Falaschi, P., Zamuner, A.B. y Foix, N. 2009. Una nueva equisetal fértil de la Formación La Matilde, Jurásico Medio, Argentina. Ameghiniana 46: 263-272.

Falaschi, P., Grosfeld, J., Zamuner, A.B., Foix, N., Rivera, S.M. 2011. Growth architecture and silhouette of Jurassic conifers from La Matilde Formation, Patagonia, Argentina. Palaeogegraphy, Palaeoclimatology, Palaeoecology. 302: 122-141.

Falcon Lang, H. 2000. The relationship between leaf longevity and growth ring markedness in modern conifer woods and its implications for palaeoclimatic studies. Paleogeogr., Paleoclimatol., Palaeoecol. 160: 317-328.

Féraud, G., Alric, V., Fornari, M., Bertrand, H. y Haller, M. $1999 .{ }^{40} \mathrm{Ar} /{ }^{39} \mathrm{Ar}$ dating of the Jurassic volcanic province of Patagonia: migrating magmatism related to Gondwana break-up and subduction. Earth and Planetary Science Letters 172: 83-96.

Ferello, E. 1947. Los depósitos plantíferos de Piedra del Águila (Neuquén) y sus relaciones. Boletín de Informaciones Petroleras 248-261.

Feruglio, E. 1933. Fossili Liassici della Valle del Rio Genua (Patagonia). Annali del R. Museo geológico di Bologna. IX: 1-64.

Feruglio, E. 1949. Descripción geológica de la Patagonia. Dirección Nacional de Yacimientos Petrolíferos Fiscales, Buenos Aires, Tomo 1: 118-141.

Feruglio, E. 1951. Su alcune piante del Gondwana inferiore della Patagonia. Publ. Inst, Geol. Univ. Torino 1: 1-34, 4 láms.

Florin, R. 1958 . On Jurassic taxads and conifers from northwestern Europe and eastern Greenland . Acta Horti Bergiani $17: 257-402$.

Florin, R. 1963. The distribution of conifer and taxad genera in time and space. Acta Horti Bergiani 20: 121-312.

Font Quer, P. 1982. Diccionario de Botánica. 8ª reimpresión. Ed. Labor. S.A., Barcelona, 1244 pp.

Font Quer, P. 2000. Diccionario de Botánica. Ed. Península. Barcelona, 1280 pp.

Fossa-Mancini, E. 1941. Los Bosques Petrificados de la Argentina. Según E.S. Riggs y G. R. Wieland. Notas del Museo de La Plata, Geología. 12: 59-92.

Franceschi, V.R., Krokene, P., Christiansen, E., Krekling, T. 2005. Anatomical and chemical defenses of conifer bark against bark beetles and other pests. New Phytol 167:353-75.

Frenguelli, J. 1933. Situación estratigráfica y edad de la "Zona con Araucarias" al Sur del curso inferior del Río Deseado. Boletín de Informaciones Petroleras 112: 843-900.

Frenguelli, J. 1937. La Flórula Jurásica de Paso Flores. Revista del Museo de La Plata (Nueva Serie) Paleontología I: 67-108.

Frenguelli, J. 1941. Las camptopterideas del lias de Piedra Pintada en el Neuquen (Patagonia). Notas del Museo de La PlataVI, Paleontología 27: 27-57.

Frenguelli, J. 1947. El género Cladophlebis y sus representantes en la Argentina. An. Mus. La Plata. n. s. 2.

Frenguelli, J.1948. Estratigrafía y edad del llamado Rético en la Argentina. GAEA 8: 159-309. Buenos Aires.

Frenguelli, J. 1949. Los estratos con "Estheria" en el Chubut (Patagonia). Revista de la Asociación Geológica Argentina 4: 11-24.

Friis, E.M., Crane, P.R. and Pedersen, K.R. 2011.Early Flowers and Angiosperm Evolution.Cambridge University Press. Cambridge, UK. 596pp.

Furniss, R.L. and Carolin, V.M. 1977. Western forest insects. Misc. Publ. 1339. Washington, DC: U.S. Department of Agriculture, Forest Service. 654p.

Ganuza, D., Morel, E., Spalleti, L.A. y Arrondo, O.G. 1992. Las plantas fósiles triásicas en pelitas lacustres del Cañadón de Pancho (Formación Paso Flores) Provincia de 
Ana Julia Sagasti - Estudio paleobotánico, paleoecológico y paleoambiental...

Neuquén. VIII Simposio Argentino de Paleobotánica y Palinología. Asociación Paleontológica Argentina. Publicación Especial N²: 55-58. Buenos Aires.

Gao, B. y Gupta, R.S. 2012. Phylogenetic framework and molecular signatures for the main clades of the phylum Actinobacteria.Microbiol.Mol.Biol.Rev. 76: 66-112.

García Massini, J.L., Channing, A., Guido, D.M. and Zamuner, A.B. 2012a. First report of fungi and fungus-like organisms from Mesozoic got springs. PALAIOS 27: 55-62.

García Massini, J.L., Falaschi, P., Zamuner, A.B. 2012b. Fungal-arthropod-plant interactions from the Jurassic petrified forest Monumento Natural Bosques Petrificados, Patagonia, Argentina. PAlaeogeography, Palaeoclimatology, Palaeoecology 329-330 (2012): 3746.

García Massini, J.L., Escapa, I.H., Guido, D.M. and Channing, A. 2016.First glimpse of the silicified hot spring biota from a new Jurassic chert deposit in the Deseado Massif, Patagonia, Argentina.Ameghiniana 53: 205-230.

Gastaldo, R.A. y Demko, T.M. 2011. The relationship between continental landscape evolution and the plant-fossil record: long term hydrologic control on preservation. 249-285. En: Allison, P.A. y Bottjer, D.J. (Eds). Taphonomy: process and bias through time. Springer, Heidelberg, 599 pp.

Gee, C.T. 1989. Revision of the late Jurassic/early Cretaceous flora from Hope Bay, Antarctica.Palaeontographica Abt. B. 213: 149-214.

Genise, J.F. 1995. Upper Cretaceous trace fossils in permineralized plant remains from Patagonia, Argentina. Ichnos 3: 287-299.

Genise, J.F. y Hazeldine, P.L., 1995. A new insect trace fossil in Jurassic wood from Patagonia, Argentina.lchnos, 4: 1- 5.

Gibert, R.O., Taberner, C., Sáez, A., Giralt, S., Alonso, R.N., Edwards, R.L., Pueyo, J.J. 2009. Igneous origin of $\mathrm{CO}_{2}$ in ancient and recent hot-spring waters and travertines from the northern Argentinean Andes. Journal of Sedimentary Research 79: 554-567.

Girard, V., Adl, S.M., 2011, Amber microfossils: On the validity of the species concept: Comptes Rendus Palevol, 10, 189-200.

Gleason F. H., Kagami M., Lefevre E., Sime-Ngando T. (2008). The ecology of chytrids in aquatic ecosystems: roles in food web dynamics. Fungal Biol. Rev. 22, 172510.1016/j.fbr.2008.02.001

Gleason, F. H., C. N. Daynes \& P. A. McGee, 2010. Some zoosporic fungi can grow and survive within a wide $\mathrm{pH}$ range. Fungal Ecology 3: 31-37.

Gnaedinger, S. 2004. Tesis: La Paleoxiloflora Jurásica de la Formación La Matilde en el Gran Bajo de San Julián, Provincia de Santa Cruz, Argentina. Realizada en : Facultad de Ciencias Exactas, Físicas y Naturales. Universidad Nacional de Córdoba.

Gnaedinger, S. 2006. Maderas de la Formación Piedra Pintada (Jurásico Temprano), provincia de Neuquén, Argentina. Rev. Mus. Argentino. Cienc. Nat., n.s. 8: 171-177.

Gnaedinger, S. 2007a. Planoxylon Stopes, Protelicoxylon Philippe y Herbstiloxylon nov. gen. (Coniferales) de la Formación La Matilde (Jurásico Medio), provincia de Santa Cruz, Argentina. Ameghiniana. 44: 321-335.

Gnaedinger, S. 2007b. Podocarpaceae Woods (Coniferales) from middle Jurassic La Matilde formation, Santa Cruz province, Argentina. Review of Palaeobotany \& Palynology. 147: 77-93.

Gnaedinger, S. 2012. Ginkgoalean Woods from the Jurassic of Argentina: Taxonomic considerations and palaeogeographical distribution. Geobios. 45: 187-198.

Gnaedinger, S. y Herbst, R. 2006. El género Protaxoxylon Kräusel y Dolianiti (Taxales) de la Formación La Matilde (Jurásico Medio), Gran Bajo de San Julián, Santa Cruz, Argentina. Ameghiniana 43:123-138.

Gnaedinger, S. y Herbst, R. 2009. Primer registro de maderas gimnospérmicas de la Formación Roca Blanca (Jurásico Inferior), provincia de Santa Cruz, Argentina. Ameghiniana. 46: 59-71.

Gnaedinger, S., García Massini, J.L., Bechis, F., Zavattieri, A.M. 2015. Coniferous woods and wood-decaying fungi from the El Flerno Formation (Lower Jurassic), Neuquen Basin, Mendoza Province, Argentina. Ameghiniana. 52: 447-467. 
Ana Julia Sagasti - Estudio paleobotánico, paleoecológico y paleoambiental...

Gothan, W., 1908. Die fossile Holzer von der Seymour und Snow-Hill Inseln.

Wiss. Ergeb.Schwed. Sudpolar Exped. 1901-19033, 1 -33.

Gothan, W., 1925. Sobre restos de plantas fo'siles procedentes de laPatagonia. Bol. Acad. Nat. Cs. 28, 197-212.

Goodfellow, M. 1983. Ecology of Actinomycetes.Ann. Rev. Microbiol. 37: 189-216.

Google Earth Pro, 2017. http://earth.google.es/

Göeppert, H.R., 1836. Die fossilen Farrenkra"uter (Systema filicum fossilium). Nova Acta Leopoldina 17, 1-486.

Göeppert, H.R. 1850. Monographie der fossilen Coniferen. Verhandelinger van de Hollandsche Maatschppij der Wetenschappen te Harlem. Vol 12. 359 pp.

GOODFELLOW, M., 1983, Ecology of Actinomycetes: Annual Review of Microbiology, v. 37, p. 189-216, doi: 10.1146/annurev.mi.37.100183.001201.

Guido, D.M. 2004. Subdivisión litofacial e interpretación del volcanismo jurásico (Grupo Bahía Laura) en el este del Macizo del Deseado, provincia de Santa Cruz. Revista de la Asociación Geológica Argentina 59: 727-742.

Guido, D.M. \& Schalamuk, I. 2003. Genesis and exploration potential of epithermal deposits from the Deseado Massif, Argentinean Patagonia. En: Eliopoulos, D., et al. (Ed.), Mineral Exploration and Sustainable Development. Holanda, I. Balkema, Rotterdam, pp. 489-492.

Guido, D., Escayola, M., de Barrio, R., Schalamuk, I., Franz, G., 2006. La Formación BajoPobre (Jurásico) en el este del Macizo del Deseado, Patagonia: Vinculación con el GrupoBahía Laura. Revista de la Asociación Geológica Argentina 61 (2): 187-196.

Guido, D.M., Channing, A., Campbell, K.A., Zamuner, A. 2010. Jurassic geothermal landscapes and fossil ecosystems at San Agustín, Patagonia, Argentina. Journal of the Geological Society, London 167: 11-20.

Guido, D.M. y Campbell, K.A. 2011.Jurassic hot spring deposits of the Deseado Massif (Patagonia, Argentina): Characteristics and control son regional distribution. Journal of Volcanology and Geothermal Research 203: 35-47.

Greguss, P. 1955. Identification of Gymnosperms on the basis of xylotomy. Akadémiai Kiadó, Budapest, $263 \mathrm{pp}$.

Grimaldi, D. and Engel, M.S. 2005. Evolution of the Insects. Cambridge University Press. Cambridge, UK. 755pp.

Groeber, P., Stipanicic, P.N. y Mingramm, A. 1953. Mesozoico. En: Geografía de la República Argentina, II. Primera Parte. Sociedad Argentina de Estudios Geográficos, 541pp.

Halle, T.G. 1913. The Mesozoic flora of Graham Land.Wissenschaftliche Ergebnisse der Schwedischen Südpolar Expedition 1901-1903, 3(14), 123pp.

Hammer, Ø., Harper, D.A.T. y Ryan, P.D. 2001. PAST: PAleontological Statistics software package for education and data analysis. Palaeontología Electronica 4: 9pp.

Hammerschmidt R, Nicholson RL. 1999. A survey of plant defense responses to pathogens. In: Agrawal AA, Tuzun S, Bent E, editors. Induced plant defenses against pathogens and herbivores. St. Paul, MN: APS Press; 1999. p. 55-71

Harper, C.J., Bomfleur, B., Decombiex, A., Taylor, E.L., Taylor, T.N., Kring, M., 2012.Tylosis formation and fungal interactions in an Early Jurassic conifer from northern Victoria Land, Antarctica.Rev.Palaeobot.Palynol. 175, 25-31.

Harper, C.J., Taylor, T.N., Krings, M., Taylor, E.L. 2016.Structurally preserved fungi from Antarctica: diversity and interactions in late Palaeozoic and Mesozoic polar forest ecosystems.Antarctic Science 28: 153-173.

Harper, C.J., Decombeix, A-L., Taylor, E.L., Taylor, T.N., Krings, M. 2017. Fungal decay in Permian Glossopteridalean stem and root wood from Antarctica. IAWA Journal 38: 2948.

Harris, T. M. 1961. The Yorkshire Jurassic Flora. I. Thallophyta-Pteridophyta . British Museum (Natural History), London . 212 p.

Haskins, R. H., 1939. Cellulose as a substratum for saprophytic chytrids. American Journal of Botany 26: 635-639. 
Ana Julia Sagasti - Estudio paleobotánico, paleoecológico y paleoambiental...

Hass, H. \& Rowe, N.P. 1999. Thin sections and wafering. In: JONES, T.P. \& ROWE, N.P. (Eds.), Fossil plants and spores: modern techniques, 76-81. Geological Society, London.

Harrington, H. 1962. Paleogeographic Development of South America.American Association of Petroleum Geologists.Bulletin 46 (10): 1733-1814.

Harris, T.M. 1969. The Yorkshire Jurassic Flora . III. Bennettitales. British Museum (Natural History), Oxford Alden Press. London. Vi+186pp, 7 pls.

Harris, T.M. 1979. The Yorshire Jurassic Flora. V. Coniferales. British Museum (Natural History),Oxford Alden Press. London. 166 pp.

Hartig, T. 1848. Beiträge zur Geschichte der Pflanzen und zur Kenntnis der nordeutschen Braunkholen-Flora. Bot. Zeitung (Berlin) 6: 122-128; 137-141; 166-172; 185-190.

Herbst, R. 1962. Gleichenites juliensis n. sp. del Jurásico medio de Santa Cruz, Patagonia. Ameghiniana 2: 187-191.

Herbst, R. 1964a. La flora liásica de C. Meschio, Provincia de Chubut, Patagonia. Ameghiniana 3: 227-234.

Herbst, R. 1964b. La flora liásica de la zona del río Atuel, Mendoza, Argentina. Revista de la Asociación Geológica Argentina 19: 108-131.

Herbst, R. 1965. La flora fósil de la Formación Roca Blanca, provincia de Santa Cruz, Patagonia. Con consideraciones geológicas y estratigráficas. Opera Lilloana 12: 7101.

Herbst R. 1966a. Revisión de la Flora Liásica de Piedra Pintada, Provincia de Neuquén, Argentina. Revista del Museo de La Plata (Nueva Serie) Tomo V: 27-53.

Herbst, R. 1966b. Nuevos elementos florísticos de la Formación Piedra del Águila, Neuquén, Argentina. Acta Geológica Lilloana 8: 249-254.

Herbst, R. 1966c. La Flora Liásica del Grupo Pampa de Agnia, Chubut, Patagonia. Ameghiniana 4: 337-349.

Herbst, R. 1972. Gleichenites potrerillensis n. sp. del Triásico medio de Mendoza (Argentina), con comentarios sobre las Gleicheniaceae fosiles de Argentina. Ameghiniana 9: 1722.

Herbst, R. 1980. Flórula fósil de la Formación Los Patos (Sinemuriano) del Río Los Patos, provincia de San Juan, República Argentina. $2^{\circ}$ Congreso Argentino de Paleontología y Bioestratigrafía y $1^{\circ}$ Congreso Latinoamericano de Paleontología (Buenos Aires) Actas 1: 175-189.

Herbst, R. y Anzotegui, L.M. 1968. Nuevas plantas de la flora del Jurásico Medio (Matildense) de Taquetrén, Prov. De Chubut. Ameghiniana 5: 183-190.

Herbst, R. y Gnaedinger, S. 2002. Kurtziana Frenguelli (Pteridospermae? Incertae sedis) y Alicurana nov. gen. (Cycadopsida) del Triásico y Jurásico Temprano de Argentina y Chile. Ameghiniana 39: 331-341.

Herbst, R. y Zalazar, E.B. 1998. Revisión de la Flora Matildense del Gran Bajo de San Julián, provincia de Santa Cruz, Argentina. Facena 14 : 7-23.

Hudgins, J.W., Christiansen. E., Franceschi, V.R. 2004. Induction of anatomically based defense responses in stems of diverse conifers by methyl jasmonate: a phylogenetic perspective. Tree Physiology 24: 251-264.

Hunter-Cevera JC, Eveleigh DE (1990). Actinomycetes.In D.L. Dindal (ed.) Soil Biology Guide.John Wiley and Sons. New York. 3348p.

Hulcr, J., Adams, A.S., Raffa, K., Hofstetter, R.W., Klepzig, K.D. y Currie, C.R. 2011. Presence and Diversity of Streptomyces in Dendroctonous and sympatric bark beetle galleries across North America. Microb.Ecol.DOI 10.1007/s00248-010-9797-0.

Ibáñez, C.G., Zamuner, A.B. 1996. Hyphomycetes (Deuteromycetes) in cones of Araucaria mirabilis (Spegazzini) Windhausen, Middle Jurassic of Patagonia, Argentina.Mycotaxon 59: 137-143.

Iglesias, A., Artabe, A.E., y Morel, E.M. 2011. The evolution of Patagonian climate and vegetation from the Mesozoic to the present. Biological Journal of the Linnean Society, 103: 409-422. 
Ana Julia Sagasti - Estudio paleobotánico, paleoecológico y paleoambiental...

Johnson, S.N. and Rasmann, S. 2015. Root-feeding insects and their interactions with organisms in the rhizosphere.Annual Review of Entomology 60: 517-535.

Joshi, M.V. \& Loria, R. 2007 Streptomyces turgidiscabies possesses a functional cytokinin biosynthetic pathway and produces leafy galls. Mol Plant Microbe Interact 20: 751-758.

Jovic, S., Jovic, N., Guido, D., Schalamuk, I., 2008. Caracterización de cuerpos intrusivos de laFormación Cerro León en el área del anticlinal El Tranquilo, Macizo del Deseado, SantaCruz. $7^{\circ}$ Congreso Geológico Argentino, Actas, Tomo 1; 851-852.

Kagami, M., von Elert, E., Ibelings, B.W., de Bruin, A., Van Donk, E. 2007.The parasitic chytrid, Zygorhizidium, facilitates the growth of the cladoceran zooplankter, Daphnia, in cultures of the inedible alga, Asterionella. Proc. Biol Sci. 274: 1561-1566.

Kämpfer, P. 2006. The Family Strotomycetaceae, Part I: Taxonomy. In: Dworkin, M., Falkow, S., Rosenberg, E., Schleifer, K-H., Stackebrandt, E. (Eds.).The Prokaryotes: A handbook on the Biology of Bacteria. Vol. 3.Springer. 1185pp.

Karling, J. S. 1949. New Monocentric Eucarpic Operculate Chytrids from Maryland. Mycologia, 41(5), 505. doi:10.2307/3755070

KARLING, J.S., 1977, Chytridiomycetarum Iconographia. An Illustrated and Brief Descriptive Guide to the Chytridiomycetous Genera with a Supplement of the Hyphochytriomycetes: J. Cramer, Vaduz, Liechtenstein, $414 \mathrm{p}$.

Katenpoth, M., Göttler, W., Herzner, G. and Strohm, E. 2004. Symbiotic bacteria protect wasp larvae from fungal infestation. Current Biology, 15: 475-479.

Kirk, P.M., Cannon, P.F., Minter, D.W., 2008. Dictionary of the Fungi, tenth ed. CABI Europe, UK.

Klepzig KD, Kruger EL, Smalley EB, Raffa KF. 1995. Effects of biotic and abiotic stress on induced accumulation of terpenes and phenolics in red pines inoculated with bark beetle-vectored fungus. J Chem Ecol 21: 601-26

KLYMIUK, A.A., HARPER, C.J., MOORE, D.S., TAYLOR, E.L., TAYLOR, T.N. and KRINGS, M. 2013. Reinvestigating carboniferous "Actinomycetes": authigenic formation of biomimetic carbonates provides insight into early diagenesis of permineralized plants. Palaios 28: 80-92.

Klymiuk, A.A., Stockey, R.A., and Rothwell, G.W. 2015.Plant-arthropod interactions in Acanthostrobus edenensis (Cupressaceae), a new conifer from the upper Cretaceous of Vancouver Island, British Columbia.Int. J. Plant. Sci. 176: 378-392.

Krings, M., Taylor, T.N., Hass, H., Kerp, H., Dotzler, N., Hermsen, E.J., 2007.Fungal endophytes in a 400-million-yr-old land plant: infection pathways, spatial distribution, and host responses. New Phytol. 174, 648-657.

Kroppenstedt, R.M. and Goodfellow, M. 2006. The family Termomonosporaceae: Actinocorallia, Actinomadura, Spirillospora and Thermomonospora. In: Dworkin, M., Falkow, S., Rosenberg, E., Schleifer, K-H., Stackebrandt, E. (Eds.): The Prokaryotes: A handbook on the Biology of Bacteria. Vol. 3.Springer. 1185pp.

Kellog, D.W. and Taylor, E.L. 2004.Evidence of oribatide mite detritivory in Antarctica during the late Paleozoic and Mesozoic.J. Paleont.78: 1146-1153.

Krings, M., Taylor, T.N., Dotzler, N., 2012. Fungal endophytes as a driving force in land plant evolution: evidence from the fossil record. In: Southworth, D. (ed.), Biocomplexity of Plant-Fungal Interactions, pp. 5-27. Ames IA, John Wiley \& Sons, Inc.

Krings, M., Harper, C.J. White, J.F., Barthel, M., Heinrichs, J., Taylor, E.L. y Taylor, T.N. 2016. Fungi in a Psaronius root mantle from the Rotliegend (Asselian, Lower Permian/Cisuralian) of Thuringia, Germany. Review of Palaeobotany \& Palynology.doi:10.1016/j.revpalbo.2016.12.004.

Krokene, P., Nagy, N.E., Krekling, T. 2008. Traumatic resin ducts and polyphenolic parenchyma cells in Conifers. In: Schaller, A. (Ed.) Induced Plant Resistance to Herbivory Chapter 7. Springer Science.DOI: 10.1007/978-1-4020-8182-8 7

Kukor, J.J., Martin, M.M., 1986. Cellulose digestion in Monochamis marmorator Kby. (Coleoptera: Cerambycidae): Role of acquired enzymes. Journal of Chemical Ecology 12, 1057-1070. 
Ana Julia Sagasti - Estudio paleobotánico, paleoecológico y paleoambiental...

Kurtz, F. 1902. Contributions a la Paleophytogie de l'Argentine. VII. Sur l'existence d'une flore Rajmahalinne dans le Gouvernment du Neuquen (Piedra Pintada entre Limay et Collón-Curá). Rev. Mus. La Plata 10.

Kenrick, P. y Crane, P.R. 1997. The origin and early diversification of land plants. SmithsonianInstitution Press, Washington D.C., $441 \mathrm{pp}$.

Kraus, G., 1870. Bois fossiles de coniferes. In: Schimper, W.P.(Ed.), Traite de Paleontologie vegetale, tome 2. Baillere,Strasbourg, pp. 363-385.

Labandeira, C.C., 1998. The role of insects in Late Jurassic to Middle Cretaceous ecosystems. In: Lucas, S.G., Kirkland, J.I., Estep, J.W., (eds.). Lower and Middle Cretaceous Terrestrial Ecosystems. Bulletin of the New Mexico Museum of Natural History and Science, 14, 105-124.

Lagarreta, L., Gulisano, C.A. y Uliana, M.A. 1993. Las secuencias sedimentarias jurásicocretácicas. $12^{\circ}$ Congreso Geológico Argentino y $2^{\circ}$ Congreso de Exploración de Hidrocarburos (Mendoza). Ramos, V.A. (Ed.): Geología y Recursos Naturales de Mendoza. Relatorio 1: 87-114. Buenos Aires.

Lanés, S., Gnaedinger, S.C., Zavattieri. A.M. y Lezama, L. 2013. Sedimentary paleoenvironment and fossil plants of the El Freno Formation (Early Jurassic) in Las Leñas Valley, Neuquén Basin. Revista de la Asociación Geológica Argentina. 70: 465476.

LEANZA, A.F., 1958. Geología Regional. En:La Argentina, Suma de Geografía, Tomo I, Capítulo III:217-349, Editorial Peuser, BuenosAires.

LECHEVALIER, M.P. 1989. Actinomycetes with multilocular sporangia, 2405-2417 in HOLT, J.G. (Editor in chief) Bergey's manual of systematic bacteriology. Volume 4.Williams \& Wilkins, Baltimore, U.S.A.

Lerat, S.; Simao-Beaunoir, A. M.; Beaulieu, C. (2009)."Genetic and physiological determinants of Streptomyces scabies pathogenicity". Molecular Plant Pathology 10 (5): 579-85

Lesta, P. y Ferello, R. 1972. Región extraandina de Chubut y norte de Santa Cruz. En: Leanza, A. F. (Ed.): Geología Regional Argentina. Academia Nacional de Ciencias, Córdoba. 601-653.

Li, Q., Chen, X., Jiang, Y., Jiang, C. 2016. Morphological identification of Actinobacteria.In: Dhanasekaran, D. y Jiang, Y. (Eds). Actinobacteria: Basics and Biotechnological Applications. INTECH.http://dx.doi.org/10.5772/61461

Locci, R. 1994. Actinomycetes as plant pathogens.European Journal of Plant Pathology 100: 179-200.

Lomholdt, O. 1982. On the origin of the bees (Hymenoptera: Apidae, Sphecidae). Ent. Scand. 13: 185-190.

Loria R, Coombs J, Yoshida M, Kers J \& Bukhalid R (2003) A paucity of bacterial root diseases: Streptomyces succeeds where others fail. Physiol Mol Plant Pathol 62: 6572.

Loria R, Kers J \& Joshi, M. 2006 Evolution of plant pathogenicity in Streptomyces.Annu Rev Phytopathol 44: 469-487.

Mansfeld, F. 1948. Los bosques petrificados y los principals yacimientos de troncos fósiles en Santa Cruz. Argentina Austral 201: 4-15.

Martin, M.M., 1979. Biochemical implications of insect mycophagy.Biological Reviews 54, 121.

Martin, D., Tholl, D., Gershenzon, J., Bohlmann, J. 2002. Methyl jasmonate induces traumatic resin ducts, terpenoid resin biosynthesis, and terpenoid accumulation in developing xylem of Norway spruce stems. Plant Physiology 129: 1003-1018..

McCarthy, A., and T. Cross. 1984. A taxonomic study of Thermomonospora and other monosporic actinomycetes. J. Gen. Microbiol. 130:5-25.

McLoughlin, S., Bomfleur, B. 2016.Biotic interactions in an exceptionally well preserved osmundaceous fern rhizome from the Early Jurassic of Sweden.Palaeogeography, Palaeoclimatology, Palaeoecology 464: 86-96.

McLoughlin, S. \& Strullu-Derrien, C., 2016. Biota and palaeoenvironment of a high middlelatitude Late Triassic peat-forming ecosystem from Hopen, Svalbard Archipelago. In 
Ana Julia Sagasti - Estudio paleobotánico, paleoecológico y paleoambiental...

Kear, B. P., Lindgren, J., Hurum, J. H., Milàn, J. \& Vajda, V., eds, Mesozoic Biotas of Scandinavia and its Arctic Territories. Geological Society of London Special Publications 434: 87-112.

McNeill, J., Barrie, F.R., Buck, W.R., Demoulin, V., Greuter, W., Hawsworth, D.L., Herendeen, P.S., Knapp, S., Marhold, K., Prado, J., Prud'Homme Van Reine, W.F., Smith, G.F., Wiersema, J.H., y Turland, N.J. 2011. Código Internacional de Nomenclatura para algas, hongos y plantas (Código de Melbourne). Edición en español: Greuter, W. y Rankin Rodriguez, R. Editorial CSIC. Madrid, 2012. 213 pp.

Menéndez C. A. 1956. Flórula jurásica del Bajo de los Baguales. Acta Geológica Lilloana I, 315-338.

Menéndez C. A. 1960. Cono masculino de una conífera fósil del bosque petrificado de Santa Cruz. Ameghiniana 1(2): 11-17).

Miall, A.D. 2006. The geology of fluvial deposits. Sedimentary facies, basin analysis and petroleum geology. Springer, $4^{\circ}$ edición, 582pp.

Millay, M.A. y Taylor, T.N. 1990. New fern stems from the Triassic of Antarctica. Review of Paleobotany and Palynology 62: 41-64.

Miller, C.N. 1977. Mesozoic conifers.Botanical Review 43: 217-280.

Morel, E.M., Spalletti, L..A., Arrondo, O.G. y Ganuza, D.G. 1992. Los estratos plantíferos de la Formación Paso Flores. Triásico Superior de Las Lomas y Cañadón de Ranquel Huao. Provincia del Neuquen. Argentina. Revista del Museo de La Plata (Nueva Serie) Paleontología.58: 199-221.

Morel, E.M., Ganuza, D.G., Artabe, A.E., Spalletti, L.A. 2013.Revisión de la paleoflora de la Formación Nestares (Jurásico temprano), provincias del Neuquén y Río Negro, Argentina. Ameghiniana 50:493-508.

Morris, J. 1840. Memoir to illustrate a Geological Map of Cutch (Grant, C.W.). Transactions of the Geological Society, London 5: 289-329.

Müller-Stoll, W.R., 1936 . Pilzzerstörungen an einem jurassischen Koniferenholz.Paläontologische Zeitschrift 18, 202-212.

Müller-Stoll, W.R. 1951. En: Freund, H. (Ed.): Mikroskopie des zerzetzen und fossilierten Holzes. Handbuch Mikroskopie Technik, 5: 727-816.

Nagy, N.E., Franceschi, V.R., Solheim, H., Krekling, T., Christiansen, E. 2000. Wound-induced traumatic resin duct development in stems of Norway spruce (Pinaceae): anatomy and cytochemical traits. American Journal of Botany 87: 302-313.

Niklas, K.J. 1993. The scaling of plant height: a comparison among major plant clades and anatomical grades.Annals of Botany 72: 165-172.

Niklas, K.J. 1994a. Predicting the height of fossil plant remains: an allometric approach to an old problem. American Journal of Botany. 81: 1235-1242.

Niklas, K.J. 1994b. The allometry of safety-factors for plant height.Americal Journal of Botany 81: 345-351.

Nishida, M. y Nishida, H. 1987. Petrified Woods from the Upper Cretaceous of Quiriquina Island, near Concepción, Chile. En: M. Nishida (Ed.) Contribution to the botany in the Andes II. Academic Scientific Book. 5-11. Tokyo.

Orlando, H.A. 1946. Las coniferales y cicadales del Lías de Piedra Pintada, Neuquén. Tesis inédita. Univ. Nac. La Plata (Inst. Museo) nº 98.

Orlando, H.A. 1946. Equisetites frenguellii n. sp. del Lías de Piedra Pintada, Neuquén. Not. Mus. La Plata, 11, Paleont. 91.

Owen DR, Wood DL, Parmeter JR. 2005.Association between Dendroctonus valens and black stain root disease on ponderosa pine in the Sierra Nevada of California. Can Entomol 137:367-75.

Pankhurst, R. J. y Rapela, C. R. 1995. Production of Jurassic rhyolite by anatexis of the lower crust of Patagonia. Earth and Planetary Science Letters 134: 23-36. 
Ana Julia Sagasti - Estudio paleobotánico, paleoecológico y paleoambiental...

Pankhurst, R., Leat, P., Sruoga, P., Rapela, C., Marquez, M., Storey, B., Riley, T., 1998. TheChon Aike province of Patagonia and related rocks in West Antartica: a silicic largeigneous province. Journal of Volcanology and Geothermal Research 81: 113-136.

Pankhurst, R. J., Riley, T. R., Fanning, C. M. and Kelley, S. P. 2000. Episodic Silicic Volcanism in Patagonia and the Antarctic Peninsula: Chronology of Magmatism Associated with the Break-up of Gondwana. Journal of Petrology 45 (5): 605-625.

Panza, J.L., Haller, M.J., 2002. El volcanismo jurásico. In: Haller, M.J. (Ed). Geología yrecursos Naturales de Santa Cruz. Relatorio del XV Congreso Geológico Argentino: 89-102.

Panza, J. L. y Marín, G. (1998). Hoja Geológica 4969-I Gobernador Gregores. Escala 1:250.000, Provincia de Santa Cruz. SEGEMAR. Boletín 211.77p

Parrish, J.T. 1993. Climate of the supercontinent Pangea.Journal of Geology. 101: 215-233.

Peláez, F., Martínez, M.J., Martínez, A.T. 1995. Screening of 68 species of basidiomicetes for enzymes involved in lignin degradation.Mycological Research 99: 37-42.

Person, C.P. y Delevoryas, T. 1982.The Middle Jurassic flora of Oaxaca, Mexico.Palaeontographica Abt. B. 180: 82-119.

Petriella, B. y Arrondo, O.G. 1982. El género Kurtziana Frenguelli: su morfología y vinculaciones. Ameghiniana 19: 209-215.

Petriella, B. y Arrondo, O.G. 1984. La tafoflora liásica de la Estancia La Juanita, Provincia de Santa Cruz, Argentina. Ameghiniana 21: 35-41.

Philippe, M. 1993. Nomenclature générique des trachéidoxyles fossiles mésozoïques á champs araucarioïdes. Taxon 42: 74-80.

Philippe, M. 1995. Bois fossils du Jurassique de Franche-Comté (NE-France). Paleontographica, Abt. B 236, 45-103.

Philippe M., Bamford M., McLoughlin S., Alves L. S. R., Falcon-Lang H. J., Gnaedinger S., Ottone E. G., Pole M, Rajanikanth A., Shoemaker R. E., Torres T., Zamuner A. 2004. Biogeographic analysis of Jurassic-Early Cretaceous wood assemblages from Gondwana.Review of Palaeobotany and Palynology 129: 141-173.

Philippe, M. Bamford, M.K. 2008. A key to morphogenera used for Mesozoic conifer-like woods. Review of Palaeobatony and Palynology 148: 184-207.

Piper, J. 2010.Software-based stacking techniques to enhance depth of field and dynamic range in digital photomicrography. In: Hewitson, T.D., Darby, I.A. (Eds.), Histology Protocols. Methods in Molecular Biology 611.DOI 10.1007/978-1-60327-345-9_16.

Pires-Zottarelli, C.L.A. y Gomes, A.L. 2007.Contribuição para o conhecimēnto de Chytridiomycota da "Reserva Biológica de Paranapiacaba", Santo André, SP, Brasil. Biota Neotropica 7:309-329.

Pujana, R.R., Umazano, A.M. y Bellosi, E.S. 2007 Maderas fósiles afines a Araucariaceae de la Formación Bajo Barreal, Cretácico Tardío de Patagonia central (Argentina). Rev. Mus. Argentino Cienc. Nat., n.s. 9: 161-167.

Pujana, R.R., García Massini, J.L., Rodríguez Brizuela, R., Burrieza, H.P. 2009. Evidence of fungal activity in silicified gymnosperm wood from the Eocene of southern Patagonia (Argentina).Geobios 42: 639-647.

QGIS Development Team. 2017. QGIS 2.18.11. Lyon 2017. QGIS Geographic Information System. Open Source Geospatial Foundation Project. http://www.qgis.org/.

Quattrocchio M. E., Martínez M. A. y Volkheimer W. 2007. Las floras jurásicas de la Argentina. Asociación Paleontológica Argentina. Publicación Especial 11 Ameghiniana 50 aniversario: 87-100. Buenos Aires, 25-11-2007.

Raffa, X.F. y Smalley, E.B. 1995. Interaction of pre-attack and induced monoterpene concentrations in host conifer defense against bark beetle-fungal complexes. Oecologia 102: 285-295.

Ramos, V. A. 1999. Las provincias geológicas del territorio argentino. En: Caminos R. (Ed.) Geología Argentina. Instituto de Geología y Recursos Minerales, 29 (17): 41- 96.

Ramos, V. A., 2002. Evolución Tectónica. En: M. Haller (ed): Geología y Recursos Naturalesde Santa Cruz. Relatorio del XV Congreso Geológico Argentino. El Calafate, I-23: 235-387. 
Ana Julia Sagasti - Estudio paleobotánico, paleoecológico y paleoambiental...

Rancusi, M.H., Nishida, M. y Nishida, H. 1987. Xylotomy of important Chilean Woods. En Nishida, M (Ed.): Contributions to the Botany in the Andes II. Pp 66-153. Academa Scientific Book Inc., Tokyo.

Rapela, C. W., Pankhurst, R., 1996. Monzonite suites: the innermost Cordilleran plutonism ofPatagonia. Transactions of the Royal Society of Edinburgh 87: 193-203.

Reading, H.G. y Levell, B.K. 1996. Controls on the sedimentary rock record. En H.G. Reading (Ed.) Sedimentary environments: processes, facies and stratigraphy. Blackwell Science: 5-36.

Rees, P. McA., Ziegler, A.M. y Valdes, P.J. 2000. Jurassic phytogeography and climates: new data and model comparisons. En: Huber, B.T., Macleod, K.G. y Wing, S.L.. (Eds) Warm climates in Earth History.Cambridge University Press.Cambridge, U.K. 495 pp.

Rees, P.M. y Cleal, C.J. 2004. Lower Jurassic floras from Hope Bay and Botany Bay, Antarctica. Special papers in Palaeontology 72: 5-90.

Reijenstein, C. 1967. Estratigrafía y tectónica de la zona norte del río Atuel entre los arroyos Blanco y Malo (Provincia de Mendoza). Universidad de Buenos Aires, Facultad de Ciencias Exactas y Naturales, Trabajo Final de Licenciatura, Buenos Aires, 67p. (inédito).

Retallack, G.J., 1981. Middle Triassic megafossil plant remains from Long Gully, near Otematata, north Otago, New Zealand. Journal of the Royal Society of New Zealand 11, 167-200.

Reveal, J.L. 2007. Indices Nominum Supragenericorum Plantarum Vascularium.http://www.plantsystematics.org/reveal/pbio/fam/allspgfile.html

Riccardi A. C. y Damborenea S. E. (Eds.). 1993. Léxico Estratigráfico de la Argentina. Vol. IX. Jurásico. Asociación Geológica Argentina, Serie B (Didáctica y Complementaria) 21. 477pp. Buenos Aires.

Riccardi, A.C., Westermann, G.E.G. y Damborenea, S.E. 1990. Middle Jurassic of South America and Antarctic Peninsula.Newsletter on Stratigraphy 21(2): 105-128.

Richardson, N.J. y Underhill, J.R. 2002. Controls on the structural architecture and sedimentary character of syn-rift sequences, North Falkland Basin, South Atlantic.Marine and Petroleum Geology 19: 417-443.

Richter, H.G., Grosser, D., Heinz, I. y Gasson, P.E. (Eds) 2004. IAWA list of microscopic features for softwood identification.IAWA Journal 25: 1-70.

Riggs and Mims 2000. Ultrastructure of Chlamydospore Development in the Plant Pathogenic Fungus Thielaviopsis basicola Mycologia 92(1):123.

Riley, T. R., Leat, P. T., Pankhurst, R. J. and Harris, C. 2001. Origins of Large Volume Rhyolitic Volcanism in the Antarctic Peninsula and Patagonia by Crustal Melting.

Rößler R. 2000. The late Palaeozoic tree fern Psaronius-an ecosystem unto itself.Rev.Palaeobot.Palynol. 108: 55-74.

Rojas-Jimenez, K. y Hernández, M. 2015. Isolation of Fungi and Bacteria associated with the guts of tropical Wood-feeding Coleoptera and determination of their lignocellulolytic activities. International Journal of Microbiology.http://dx.doi.org/10.1155/2015/285018.

Romero, E.J. Panti, C., Zamaloa, M.C. y Césari, S.N. 2004. Araucarian fossil records from South America and western Antarctica. XI Reuniao de Paleobotanicos e Palinólogos, Gramado, RS, Brasil 127.

Ruiz, R., Páez, G. N., Guido, D. M., Schalamuk., I. B., 2008. Ambiente Volcánico yMineralizaciones del Área Cerro 1ro de Abril, Sector Sudoccidental del Macizo delDeseado, Santa Cruz, Argentina. XVII Congreso Geológico Argentino. Actas (II): 897-898. Jujuy, Argentina.

Sagasti, A.J., García Massini, J., Escapa, I.H., Guido, D.M. y Channing, A. 2016. Millerocaulis zamunerae sp. nov. (Osmundaceae) from Jurassic, geothermally influenced, wetland environments of Patagonia, Argentina. Alcheringa: An Australasian Journal of Palaeontology, DOI: 10.1080/03115518.2016.1210851.

Sahni, B., 1920. Petrified plant remains from the Queensland Mesozoicand Tertiary formations. Queensl. Geol. Surv. Publ. 267, 7 - 38. 
Ana Julia Sagasti - Estudio paleobotánico, paleoecológico y paleoambiental...

Salle A, Monclus R, Yart A, Lieutier F. 2005. Effect of phenolic compounds on the in vitro growth of two fungi associated with Ips typographus. Forest Pathol 35:298-304.

Scasso, R.A. y Limarino, C.O. 1997. Petrología y diagénesis de rocas clásticas. Asociación Argentina de Sedimentología, Publicación Especial Nro. 1. Capital Federal, Argentina. 258pp.

Schalamuk, I., Zubia, M., Gennini, A. \& Fernandez, R.R. 1997. Jurassic epithermal Au-Ag deposits of Patagonia, Argentina. Ore Geology Reviews, 12, 173-186.

Schalamuk, I., Guido, D., De Barrio, R. \& Fernandez, R. 1999a. Hot spring structures from El Macanudo-El Mirasol area, Deseado Massif, Argentina. In: Stanley, C.J., et al. (eds) Mineral Deposits: Processes to Processing, 1. Balkema, Rotterdam, 577-580.

Schalamuk, I.B., De Barrio, R.E., Zubia, M.A., Gennini, A. \& Echeveste, H. 1999b. Provincia Auroargentı'fera del Deseado. In: Zappettini, E.O. (ed.) Recursos Minerales de la Repu'blica Argentina, 35. Instituto de Geologı'a y Recursos Minerales SEGEMAR, Buenos Aires, 1177-1188.

Schmidt, O., 2006. Wood and tree fungi.Biology, damage, protection, and use, first ed.Springer, Heilderberg.

Schmidt , A. R. , H. D o rfelt , and V. Perrichot . 2007 .Carnivorous fungi from Cretaceous amber. Science 318, p . 1743 [3]

Schmidt, A.R., Jancke, S, Lindquist, E.E., Ragazzi, E., Roghi, G., Nascimbene, P.C., Schmidt, K., Wappler, T., and Grimaldi, D.A. 2012.Arthropods in amber from the Triassic Period.Proceedings of the National Academy of Sciences, USA. 109: 14796-14801.

Scotese, C.R., Boucout, A.J. y McKerrow, W.S. 1999. Gondwanan palaeogeography and palaeoclimatology.Journal of African Earth Sciences 28: 99-114.Sillitoe, R.H. 1993. Epithermal models: genetic types, geometric controls and shallow features. En: Kirkham, R.V., et al. (Ed.) Mineral Deposit Modeling: Geological Association of Canada, Special Volume 40, pp. 403-417.

Scott, A.C., Stephenson, J. and Chaloner, W.G. 1992. Interaction and coevolution of plants and arthropods during the Palaeozoic and Mesozoic. Phil. Trans. R. Soc. Lond. B 335: 129-165.

Scott JJ, Oh DC, Yuceer, MC, Klepzig KD, Clardy J, Currie CR. 2008.Bacterial protection of beetle-fungus mutualism. Science 322:63

Scott N. Johnson' and Sergio Rasmann. 2015. Root-Feeding Insects and Their Interactions with Organisms in the Rhizosphere Annual Review of Entomology Vol. 60: 517-535.

Seilacher, A. 1953. Studien zur Palichnologie I. Uber die Methoden der Palichnologie, Nues Jahrbuch für Geologie und Paläontologie Abhandlungen 96 : 421-452.

Seipke, R.F., Kaltenpoth, M., Hutchings, M.I. 2012. Streptomyces as symbionts: an emerging and widespread theme? Microbiology Reviews 36: 862-276.

Selmeier, A. 1992. Araukarienholz unter dem Mikroskop. En: W. Jung, A. Selmeier y U. Dernbach, Ulrich Derrnbach's Araucaria: Die Versteinerten Araukarien vom Cerro Cuadrado, Argentinien. D'Oro Verlag, Lorsch, pp. 118-144.

Seward, A.C., 1927. On the Cretaceous plant-bearing rocks of Western Greenland. Philosophical Transactions of the Royal Society of London. Series B 215, 57-174.

Sillitoe, R.H. 1993. Epithermal models: genetic types, geometric controls and shallow features. En: Kirkham, R.V. et al. (Eds.): Mineral Deposit Modeling. Geological Association of Canada, Special Volume 40: 403-417.

Sinclair, W.A, Lyon, H.H. 2005. Diseases of Trees and Shrubs.Cornell University Press, Ithaca, NY.

Slater, G.J., Harmon, L.J. y Alfaro, M.E. 2012. Integrating fossils with molecular phylogenies improves inference of trait evolution. Evolution, 66: 3931-3944.

Smith, A.R., Pryer, K.M., Schuettpelz, E., Korall, P., Schneider, H. y Wolf, P.G. 2006. A classification for extant ferns. Taxon 55: 705-731.

Smith, A.R., Pryer, K.M., Schuettpeltz, P.K., Schneider, H. and Wolf, P.G. 2008. Fern Classification.En: Biology and Evolution of Ferns and Lycophytes. Ed. Ranker, T.A. y Haufler, C.H. Cambridge University Press.480 pp. 
Ana Julia Sagasti - Estudio paleobotánico, paleoecológico y paleoambiental...

Spalletti, L.A., Franzese, J.R. 2007. Mesozoic paleogeography and paleoenvironmental evolution of Patagonia (southern South America). En: Gasparini, Z., Leonardo, S., Coria, R. (Eds). Patagonian Mesozoic reptiles. Bloomington: Indiana University Press, Chapter 2: 29-49.

Spalletti, L.A., Morel, E.M., Franzese, J.R., Artabe, A.E., Ganuza, D.G., Zúñiga, A. 2007. Contribución al conocimiento sedimentológico y paleobotánico de la Formación El Freno (Jurásico Temprano) en el valle superior del río Atuel, Mendoza, Argentina. Ameghiniana 44: 367-386.

Spalletti, L., Franzese, J., Morel, E., D’elia, L., Zúñiga, A. y Fanning, C.M. 2010. Consideraciones acerca de la sedimentología, paleobotánica y geocronología de la Formación Piedra del Águila (Jurásico Inferior, Neuquén). Revista de la Asociación Geológica Argentina 66: 305-315.

Sparrow, F. K., 1960.Aquatic Phycomycetes, 2nd edn. The University of Michigan Press, Ann Arbor.

Spegazzini, C. 1924. Coniferales fósiles patagónicos. Anales de la Sociedad Científica Argentina 98: 125-139.

Sternberg, G.K. 1820-1838, Versuch einer geognostisch-botanischen Darstellung der Flora der Vorwelt: Leipsig und Prague, v. 2, pts. 7-8, p.81-220.

Stewart, W.R. Y Rothwell, G.W. 1993. Paleobotany and the evolution of plants. Cambridge University Press, Cambridge, $521 \mathrm{pp}$.

Stackebrandt, E. and Schumman, P. 2006. Introduction to the Taxonomy of Actinobacteria. In: Dworkin, M., Falkow, S., Rosenberg, E., Schleifer, K-H., Stachenbrandt, E. (Eds.) The Prokaryotes: a handbook on the Biology of Bacteria. Vol 3. 1185pp. Springer

Sternberg, G.K. 1820-1838, Versuch einer geognostisch-botanischen Darstellung der Florader Vorwelt: Leipsig und Prague, v. 2, pts. 7-8, p.81-220.

Stipanicic, P. 1957. El Sistema Triásico en la Argentina. Actas $20^{\circ}$ Congreso Geológico Internacional, 2: 73-112, México.

Stipanicic, P.N. y Bonetti, M.I.R. 1970. Posiciones estratigráficas y edades de las principales floras jurásicas argentinas. II. Floras doggerianas y málmicas. Ameghiniana 7: 101108.

Stipanicic, P.N. y Menéndez, C.A. 1949. Contribución al conocimiento de la flora fósil de Barreal. I. Dipteridaceae. Bol. Inf. Petrol. Bs. As. 291: 3-32.

Stipanicic, P. y Reig, A. 1956. Breve noticia sobre el hallazgo de anuros en el denominado "Complejo Porfírico de la Patagonia Extraandina", con consideraciones acerca de la composición geológica del mismo. Revista Asociación Geológica Argentina, 10: 215 233.

Stipanicic, P. y Reig, A. 1956. El "Complejo Porfírico de la Patagonia Extraandina" y su fauna de anuros. Acta Geológica Lilloana, 1: 185-297.

Stockey, R. A. 1977. Reproductive biology of the Cerro Cuadrado (Jurassic) fossil conifers: Pararaucaria patagonica. American Journal of Botany 64: 733-744.

Stockey, R.A. 1982. The Araucariaceae: an evolutionary perspective. Rev. Palaeobot. Palynol. 37: 133-154.

Stoffel, M. 2008. Dating past geomorphic processes with tangential rows of traumatic resin ducts. Dendrochronologia 26: 53-60.

Sun, S., Zeng, X., Zhang, D. \& Guo, S. 2015. Diverse fungi associated with partial irregular heartwood of Dalbergia odorifera. Scientific Reports 5: 8464. DOI: 10.1038/srep08464.

Sutherland, C.A. 2006. Wood boring beetles. O \& T Guide, New Mexico State University 10: $1-5$.

Strullu-Derrien.C., McLoughlin, S., Philippe, M., Mørk, A., Strullu, D.G. 2012.Arthropod interactions with bennettitalean roots in a Triassic permineralized peat from Hopen, Svalbard Archipielago (Arctic).Palaeogeography, Palaeoclimatology, Palaeoecology (2012), doi: 10.1016/j.palaeo.2012.06.006.

Shirling, E.B. y Gottlieb, D. 1968. Cooperative description of type cultures of Streptomyces III. Addiotional Species descriptions from first and second studies. International Journal of Systematic Bacteriology 18: 279-392. 
Ana Julia Sagasti - Estudio paleobotánico, paleoecológico y paleoambiental...

Shirling, E.B. y Gottlieb, D. 1969. Cooperative description of type cultures of Streptomyces IV. Species descriptions from the second, third and fourth studies.International Journal of Systematic Bacteriology 19: 391-512.

Shortle, W.C. 1979. Mechanisms of compartmentalization of decay in living trees.Phytopathology 69: 1147-1151.

Shortle, W.C., Cowling, E.B. 1978. Development of discoloration, decay and microorganisms following wounding of sweetgum and yellow-poplar trees.Ecology and Epidemiology 68:609-616.

Schwarze FWMR, Mattheck C, Engels J, 2004. Fungal strategies of wood decay in trees.Second Edition.Springer, Heidelberg, New York.185pp.

Schwartze, F.W.M.R. 2007.Wood decay under the microscope.Fungal Biology Reviews 21: 133-170.

Solans, M. y Vobis, G. 2003. Actinomycetes saprofíticos asociados a la rizósfera y rizoplano de Discaria trinervis. Ecología Austral 13: 97-107.

Speyer, S.E. y Brett, C.E. 1986. Trilobite taphonomy and Middle Devonian taphofacies.Palaios 1: 312-327.

Speyer, S.E. y Brett, C.E. 1988. Taphofacies models for epeiric sea environments: middle Paleozoic examples.Palaeogeography, Palaeoclimatology, Palaeoecology 63: 225262.

Steart, D.C., Spencer, A.R.T., Garwood, R.J., Hilton, J., Munt, M.C., Needham, J., y Kenrick, P. 2014. X-ray synchrotron microtomography of a silicified Jurassic Cheirolepidiaceae (Conifer) cone: histology and morphology of Pararaucaria collinsonae sp. nov. PeerJ 2:e624; DOI 10.7717/peerj.624

Stockey, R.A. y Rothwell, G.W. 2013. Pararaucaria carrii sp. nov., Anatomically preserved evidence for the Conifer Family Cheirolepidiaceae in the Northern Hemisphere. International Journal of Plant Sciences. 174: 445-457.

Takasuka, T.E., Book, A.J,, Lewin, G.R., Currie, C.R. \& Fox, B.G. 2013. Aerobic deconstruction of cellulosic biomass by an insect-associated Streptomyces.Scientific reports 3: 1030. DOI: 10.1038/srep01030.

Taylor, T.N., Taylor, E.L., 2000. The Rhynie chert ecosystem: a model for understanding fungal interactions. In: Bacon, C.W., White Jr., J.F. (Eds.), Microbial Endophytes. Marcel Dekker, Inc., New York, pp. 31-47.

Taylor, T. N. , and E. L. Taylor . 1993. The Biology and Evolution of Fossil Plants. Prentice Hall , Englewood Cliffs, NJ . 982 p.

TAYLOR, T.N. AND KRINGS, M., 2005. Fossil microorganisms and land plants: associations and interactions. Symbiosis 40, 119-135.

Taylor, T.N., Taylor, E.L. y Krings, M. 2009. Paleobotany, The Biology and Evolution of Fossil Plants, Second Edition, Academic Press, Amsterdam, 1230 pp.

Taylor, T.N., Krings, M. and Taylor, E.L. 2015. Fossil Fungi. Academic Press. London, UK.

Torres, T.G. y Lemoigne, Y. 1989. Hallazgos de maderas fósiles de Angiospermas y Gimnospermas del Cretácico Superior en punta Williams, isla Livingston, islas Shetland del Sur, Antártida. Serie Científica Instituto Antártico Chileno 39: 9-29.

Torres, T.G., Valenzuela, E. y González, I. 1982. Paleoxilología de Península Byers, Isla Livington, Antártida, Islas Sheetland del Sur. Antártica. Actas $3^{\circ}$ Congreso Geológico Chileno (Concepción, 1982). 1: 321-341.

Torres, T.G., Marensi, S. y Santillana, S. 1994. Maderas fósiles de la Isla Seymour, Formación La meseta, Antártida. Serie Científica Instituto Antártico chileno 44: 17-38.

Torres, T.G.. Galleguillos, H. y Philippe, M. 2000. Maderas fósiles en el Monte Flora, Bahía Esperanza, Península Antártica. Actas $9^{\circ}$ Congreso Geológico Chileno 2: 386-390.

Tortorelli, L.A. 1956. Maderas y bosques argentino. Buenos Aires: Editorial Acme, 910 pp.

Tscharntke, T. and Hawkins, B.A. 2008. Multitrophic Level Interactions. Cambridge University Press.Cambridge, UK.274 pp.

Ugarte, F. 1966. La cuenca compuesta carbonífero-jurásica de la Patagonia Meridional. Anales de la Universidad Patagonia "San Juan Bosco", 2: 37-68.

Unger, F., 1850. Genera etspecies plantarum fossilium. Braunmuller,Vienna, Austria. 
Ana Julia Sagasti - Estudio paleobotánico, paleoecológico y paleoambiental...

Van Amerom, H. W. J. 1975. Die eusphenopteridischen Pteridophyllen aus der Sammlung des geologischen Bureaus in Heerlen, unter besonderer Berucksichtigung ihrer Stratigraphie bezuglich des Sudlimburger Kohlenreviers. Mededelingen Rijks Geologische Dienst, Serie C 3-1 (7): 1 - 208.

Vega, F.E. 2008. Insect pathology and fungal endophytes. Journal of Invertebrate Pathology 98: 277-279.

Vega, F.E. and Blackwell, M. (Eds). 2005. Insect-fungal Associations: Ecology and Evolution. Oxford University Press, New York. 333pp.

Vera, E. 2010. Tesis Doctoral. Estudios anatómicos en paleofloras del aptiano de Antártida y Patagonia y su comparación. Facultad de Ciencias Exactas y Naturales, Universidad de Buenos Aires. 294 pp.

Vera, E.I. y Passalia, M.G. 2012. Korallipteris, a new genus for Mesozoic Gleichenia-like fern fronds. GEOBIOS 45: 421-428.

Volkheimer, W., Manceñido, M. y Damborenea, S. 1978. La Formación Los Patos (Nov. Form.), Jurásico Inferior de la Alta Cordillera de la Provincia de San Juan (República Argentina), en su localidad tipo (Río de los Patos Sur). Revista de la Asociación Geológica Argentina 32: 300-311.

Waggoner, B.M., 1993, Fossil Actinomycetes and other Bacteria in Eocene amber from Washington State, U.S.A.: Tertiary Research, 14, 4, 155-160.

Waggoner, B.M., 1994a, Fossil micro-organisms from the Upper Cretaceous amber of Mississippi: Review of Palaeobotany and Palynology, 80, 75-84.

Waggoner, B.M., 1994b, Fossil actinomycetes in Eocene-Oligocene Dominican amber: Journal of Paleontology, 68, 398-401.

Walker, M.V. 1938. Evidence of Triassic insects in the Petrified Forest National Monument, Arizona.Proceedings of the United States National Museum, 85: 137-141.

Walker, R.G. 1992. Facies, facies models and modern stratigraphic concepts.En Walker, R.G. y James, N.P. (Eds) Facies models, response to sea level changes.1-14.Geological Association of Canada.

Walter, M.R. 1976. Hot-spring sediments in Yellowstone National Park. En: Walter, W.R. (Ed.) Stromatolites: Developments in Sedimentology, 20. Elsevier, pp. 489-498.

Wan, M.L., Yang, W., Liu, L.J., Wang, J., 2016. Plant-arthropod and plant-fungus interactions in late Permian gymnospermous woods from the Bogda Mountains, Xinjiang, northwestern China. Rev. Palaeobot. Palynol. 235, 120-128.

Watson, J. y Sincock, C.A. 1992.Bennettitales of the English Wealden. Monograph of the Palaeontographical Society 145: 2-228.

WEBSTER, J., and WEBER, R., 2007, Introduction to Fungi: Cambridge University Press, Cambridge, UK, $841 \mathrm{p}$.

Weidlich, M. 1986. Zum rezenten Wirtsplanzenspektrum der Buprestidae unter Berücksichtigung phylogenetischer Aspekte.Deutsche Entomologische Zeitschrift, 33: 83-93.

West, D.R., Bernklau, E.J., Bjostad, L.B., Jacobi, W.R. 2016. Host defense mechanisms against Bark Beetle attack differ between Ponderosa and Lodgepole pines. Forests 7: 248. DOI: $10.3390 / f 7100248$.

Whiffen, A. J., 1941. Cellulose decomposition by the saprophytic chytrids. Journal of the Elisha Mitchell Scientific Society 57: 321-330.

Wichmann. 1922. Observaciones geológicas en el Gran Bajo de San Julián y sus alrededores (Territorio de Santa Cruz). Dirección General de Minas, Boletín 30 (B): 1-34.

Wieland, G.R. 1929. The world's two greatest petrified forest. Science 69: 60-63.

Wieland, G.R. 1935. The Cerro Cuadrado petrified forest. Carnegie Institution of Washington, Washington, D.C., U.S.A.

Willis, K.J. y McElwain, J.C. 2002. The Evolution of Plants. Oxford University Press. Oxford, U.K. 378pp.

Williams, S.T. 1970. Further investigations of Actinomycetes by scanning electron microscopy.Journal of General Microbiology 62: 67-73. 
Ana Julia Sagasti - Estudio paleobotánico, paleoecológico y paleoambiental...

WILKINSON, H.P., 2003, Fossil actinomycete filaments and fungal hyphae in dicotyledonous wood from the Eocene London Clay, Isle-of-Sheppey, Kent, England: Botanical Journal of Linnean Society, v. 142, p. 383-394, doi: 10.1046/j.1095-8339.2003.00179.x.

Windhausen, A. 1931. Geología Argentina. En: Geología Histórica y Regional del Territorio Argentino (Segunda Parte). Editorial Peuser: 1-40. Buenos Aires.

Worsley, T.R., Moore, T.L., Fraticelli, C.M. y Scotese, C.R. 1994. Phanerozoic $\mathrm{CO}_{2}$ levels and global temperatures inferred from changing paleogeography. In: Klein, G.D. (Ed.), Pangea: Paleoclimate, Tectonics, and Sedimentation During Accretion, Zenit and Breakup of a Supercontinent. Geological Society America, Special Paper. 288: 57-73.

Zamuner, A.B. y Falaschi, P. 2005. Agathoxylon matildense n. sp., leño araucariáceo del Bosque Petrificado del Cerro Madre e Hija, Formación La Matilde (Jurásico medio), Provincia de Santa Cruz, Argentina. Ameghiniana 42: 339-346.Zhang, Z., Wang, Y. and Ruan, J. 1998. Reclassification of Thermomonospora and Microtetraspora.International Journal of Systematic Bacteriology 48: 411-422.

Zamuner, A. Channing, A., Sagasti, A.J., Edwards,D., Guido, D. 2011. A new Middle-Late Jurassic compression flora associated with the San Agustín hot-spring deposit, Southern Patagonia, Argentina. Atas XXII Congresso Brasileiro de Paleontologia. Natal, Brasil. P. 53-

Zijlstra, G. and Van Konijnenburg-Van Cittert, H. 2000. Proposal to conserve the name Araucarites C. Presl.(Fossil Gymnospermae, Coniferales, Araucariaceae) against Araucarites Endl. (Fossil, Gymnospermae, Coniferales). Taxon 44: 279-280

Zopf, W. 1887. Ueber einige niedere algenpilze (Phycomyceten) und eine neue methode ihre keime aus dem wasser zu isoliren. doi:10.5962/bhl.title.119626 